\title{
Dopamine mechanisms in learning and memory: evidence from rodent studies
}

Citation for published version (APA):

Dela Cruz, J. A. D. A. (2014). Dopamine mechanisms in learning and memory: evidence from rodent studies. [Doctoral Thesis, Maastricht University]. Maastricht University. https://doi.org/10.26481/dis.20140320jd

Document status and date:

Published: 01/01/2014

DOI:

10.26481/dis.20140320jd

Document Version:

Publisher's PDF, also known as Version of record

\section{Please check the document version of this publication:}

- A submitted manuscript is the version of the article upon submission and before peer-review. There can be important differences between the submitted version and the official published version of record.

People interested in the research are advised to contact the author for the final version of the publication, or visit the DOI to the publisher's website.

- The final author version and the galley proof are versions of the publication after peer review.

- The final published version features the final layout of the paper including the volume, issue and page numbers.

Link to publication

\footnotetext{
General rights rights.

- You may freely distribute the URL identifying the publication in the public portal. please follow below link for the End User Agreement:

www.umlib.nl/taverne-license

Take down policy

If you believe that this document breaches copyright please contact us at:

repository@maastrichtuniversity.nl

providing details and we will investigate your claim.
}

Copyright and moral rights for the publications made accessible in the public portal are retained by the authors and/or other copyright owners and it is a condition of accessing publications that users recognise and abide by the legal requirements associated with these

- Users may download and print one copy of any publication from the public portal for the purpose of private study or research.

- You may not further distribute the material or use it for any profit-making activity or commercial gain

If the publication is distributed under the terms of Article $25 \mathrm{fa}$ of the Dutch Copyright Act, indicated by the "Taverne" license above, 


\section{Dopamine mechanisms in learning and memory: evidence from rodent studies}

Julie Dela Cruz 


\section{Dopamine mechanisms in learning and memory: evidence from rodent studies}

\section{DISSERTATION}

To obtain the degree of Doctor at Maastricht University, on the authority of the Rector Magnificus, Prof. Dr. L.L.G. Soete, in accordance with the decision of the Board of the Deans.

By

\section{Julie Angela Delas Alas Dela Cruz}

Born the $10^{\text {th }}$ of February, 1983 in Roanoke, Virginia the United States of America 


\section{Promoter:}

Prof. Dr. H.W.M. Steinbusch

Co-promoters:

Prof. Dr. R.J. Bodnar

Dr. B.P.F. Rutten 


\section{Contents}

Abbreviations

$\begin{array}{ll}\text { Chapter } 1 & 7\end{array}$

General Introduction

Chapter 2

Roles of dopamine D1 and D2 receptors in the acquisition and expression of fat-conditioned flavor preferences in rat

Chapter 3

Roles of Opioid and NMDA receptors in the acquisition and expression of fat-conditioned flavor preferences in rats

\section{Chapter 4}

c-fos Induction in the Dorsal Striatum and Mesotelencephalic Dopamine Pathway Following Oral Intake of Sugars and Fats in Rats

\section{Chapter 5}

Increased number of TH-immunoreactive cells in the Ventral Tegmental Area after Deep Brain Stimulation of the Anterior Nucleus of the Thalamus

Chapter 6

Expression of hypoxia-inducible factor 1-beta (ARNT or ARNT2) in mouse substantia nigra and ventral tegmental area

Chapter 7

Summary and Conclusion 


\section{Abbreviations}

$\begin{array}{ll}\text { AD } & \text { Alzheimer's Disease } \\ \text { AMPA } & \text { a-Amino-3-hydroxy-5-methyl-4-isoxazolepropionic acid } \\ \text { AMY } & \text { Amygdala } \\ \text { ANOVA } & \text { Analysis of Variance } \\ \text { ANT } & \text { Anterior Nucleus of the Thalamus } \\ \text { ARNT } & \text { Aryl-hydrocarbon Receptor Nuclear Translocator } \\ \text { ARNT2 } & \text { Aryl-hydrocarbon Receptor Nuclear Translocator } 2 \\ \text { ASD } & \text { Autism spectrum disorders } \\ \text { BLA } & \text { Basolateral Amygdala } \\ \text { CeA } & \text { Central Amygdala } \\ \text { CFP } & \text { Conditioned Flavor Preference } \\ \text { CO } & \text { Corn-oil } \\ \text { CP } & \text { Caudate/Putamen (Striatum) } \\ \text { CS- } & \text { Negative Conditioned Stimulus } \\ \text { CS+ } & \text { Positive Conditioned Stimulus } \\ \text { D1 } & \text { Dopamine D1 receptor } \\ \text { D2 } & \text { Dopamine D2 receptor } \\ \text { DA } & \text { Dopamine } \\ \text { DAB } & 3,3^{\prime} \text {-diaminobenzidine tetrahydrochloride } \\ \text { DBS } & \text { Deep Brain Stimulation } \\ \text { EC } & \text { Entorhinal Cortex } \\ \text { F/F } & \text { Flavor-Flavor } \\ \text { F/N } & \text { Flavor-nutirent } \\ \text { FLI } & \text { Fos-Like Immunoreactivity } \\ \text { GABA } & \text { gamma-Aminobutyric acid } \\ \text { GFAP } & \text { glial fibrillary acidic protein } \\ \text { HIF-1 } & \text { hypoxia-inducible factor 1 } \\ \text { HSD } & \text { Honest Significant Difference } \\ \text { IG } & \text { Intragastric } \\ \text { ip } & \text { intraperitoneal } \\ \text { LTP } & \text { Long Term Potentiation } \\ \text { MFB } & \text { Medial Forebrain Bundle } \\ \text { mPFC } & \text { medial Prefrontal Cortex } \\ \text { MTT } & \text { Mammillothlalamic Tract } \\ \text { NAc } & \text { Nucleus Accumbens } \\ \text { NDS } & \text { Normal Donkey Serum } \\ \text { NeuN } & \text { Neuronal Nuclei } \\ \text { NMDA } & \text { N-methyl-D-aspartate } \\ \text { NMDAR } & \text { NMDA Receptor } \\ \text { NST } & \text { Nucleus Tractus Solitarius } \\ & \end{array}$




$\begin{array}{ll}\text { NTX } & \text { Naltrexone } \\ \text { PBN } & \text { Parabrachial Nucleus } \\ \text { PBS } & \text { Phosphate Buffer Solution } \\ \text { RAC } & \text { Raclopride } \\ \text { SC } & \text { Subcutaneous } \\ \text { SCH } & \text { SCH23390 } \\ \text { SCZ } & \text { Schizophrenia } \\ \text { SEM } & \text { Standard Error of the Mean } \\ \text { SN } & \text { Substantia Nigra } \\ \text { SNc } & \text { SN, pars compacta } \\ \text { SNr } & \text { SN, pars reticulata } \\ \text { T1R2 } & \text { Taste Receptor 2 } \\ \text { T1R3 } & \text { Taste Receptor 3 } \\ \text { TBS-T } & \text { Tris-buffered Saline with 0.3\% Triton X-100 } \\ \text { TH } & \text { Tyrosine Hydroxylase } \\ \text { VEH } & \text { Vehicle } \\ \text { VTA } & \text { Ventral Tegmental Area } \\ \text { WT } & \text { Wild Type }\end{array}$




\section{Chapter 1}

\section{General Introduction}




\section{Part I: Roles of dopamine D1 and D2, opioid and glutamate NMDA receptor signaling in the acquisition-expression of fat-conditioned flavor preferences in rats; \\ c-Fos analysis of the mesotelencephalic dopamine reward- nigrostriatal pathways following intake of sugars and fats in rats.}

\section{Background}

The following sections will introduce the problem of overeating, which may eventually lead to obesity. Overconsumption of food is based, in part, on learned preferences for food. These learned preferences are suspected to be influenced by certain neurotransmitters in the brain: opioids, glutamate and DA. DA, in particular, is believed to be involved in conditioned intake because of its connection to learning and reward. Because of this connection, the pathways of the mesotelencaphalic DA pathway and the nigrostriatal DA pathway will be examined through intake and immunohistochemical exploration of c-fos in the DA-associated areas.

\section{Food preference/Obesity}

Food consumption provides the energy necessary for the metabolic activity of the body. When caloric intake exceeds the body's needs, the body stores the excess energy as body fat. Obesity occurs when net energy intake exceeds net energy expenditure over a prolonged period of time (Stunkard, 1996), leading to an overabundance of body fat. Obesity can lead to shortened life expectancy and numerous health complications, including diabetes, heart disease and cancer (Abelson \& Kennedy, 2004). In fact, excess body weight is the $6^{\text {th }}$ greatest contributing factor to diseases worldwide (Haslam \& James, 2005). Furthermore, it is predicted that the current generation of children will grow into the most obese generation of adults in United States history (Birch \& Fisher, 1998). Obesity generally results from a combination of environmental and biological factors, including the previously-mentioned excess food intake, lack of physical activity, and 
genetic susceptibility. In some cases, obesity can be caused by other factors such as endocrine disorders, medications or psychiatric illness (Adams \& Murphy, 2000).

Obesity occurs particularly in the developed countries, where cheap, highly palatable, energy-dense food is readily available (Dragone, 2009), usually in the form of high-fat and or sugar-rich fare. Learning appears to play an important role in the preferences for high-fat and sugar-rich foods (Sclafani, 1999). Palatability is a factor that can exacerbate intake thereby playing an important role in driving caloric consumption in excess of metabolic demand and ultimately promoting obesity (Raynor and Epstein, 2001). Preferences can be based on learned associations between a stimulus (e.g., Kool Aid flavor) and the orosensory flavor characteristics of the nutrient (smell, sight, taste, texture) (flavor-flavor conditioning) or learned associations between a stimulus and the post-ingestive consequences of the nutrient (flavor-nutrient conditioning) (Azzara et al., 2001; Baker et al., 2003, Yu et al. 2000a, 2000b, Dela Cruz, et al., 2012). Most food preferences are learned through experiences of combinations of flavor-flavor and flavor-nutrient learning consequences in ingesting those foods.

\section{Macronutrients}

The two major macronutrients involved in intake overconsumption and development of CFP are sugars and fats. Each will be briefly described in the following section

a. Sugars. While food preference has been examined through a variety of macronutrients, sugar has been largely studied due to its intrinsic rewarding properties (both postingestive and orosensory) from its sweet taste. Foods high in sugars are highly attractive, due to its hedonic taste and nutritional value, which may lead to overeating. In fact, the sweetness in these foodstuffs are connected with carbohydrates as sources of energy with its detection associated with its hedonic appeal (Ventura \& Menella, 2011). This sweet-tasting carbohydrate source of calories is mediated through specific taste receptors as an organism consumes 
sugars, and other sweet sources like artificial sweeteners, sweet amino acids and sweet proteins (Yoshida, et al., 2013).

The molecular mechanisms responsible for the specific sweet taste receptors in the oral cavity have been identified. Two members of the T1R class of tastespecific G protein-coupled receptors have been hypothesized to function in combination as hetereodimeric sweet taste receptors: receptor member 2 (T1R2), and member 3 (T1R3) (Li, et al., 2002). Sweet taste begins with activation of the T1R2/T1R3 receptors in the mouth; the combination of these hetereodimers function as a general sweet taste receptor for a variety of sugars and artificial sweeteners in animals (Sclafani, 2006; Montmayeur, et al., 2001; Nelson, et al., 2010) and the receptors can recognize sweet tastants (Li, et al., 2002).

b. Fats. Fat-rich foods, which are generally observed to be preferred over low-fat foods, are highly attractive and are capable of eliciting CFP's in animal models. Fats are highly palatable and lead to positive effects in the gut, leading to overeating and overconsumption. Greenberg and Smith (1996) demonstrated this overconsumption with sham-fed Zucker obese rats. They found that oils produced significantly more orosensory positive feedback in obese Zucker rats than in control Sprague-Dawley lean rats in experimental tests of preference. Although it is currently unknown if there are specific taste receptors for fats, it has been suggested that in rodents lingual CD36 may be involved in the orosensory identification of fat in foodstuffs. Mizushige and colleagues (2002) proposed that long-chain fatty acid CD36/FAT (a long-chain fatty acid transporter) in the circumvallate papillae of the tongue play an important role in the palatability of dietary fat and reward. In addition, mice with CD36-knockout have shown a deceased preference for the consumption of long-chain fatty acids during a choice feeding session as compared to the controls (Khan \& Besnard, 2002). 


\section{Macronutrients in CFP}

a. Conditioned flavor preferences. Sugar and fat macronutrients have been studied in the two different types of conditioned flavor preferences. Both sucrose (a disaccharide) (Azzara et al., 2001; Yu et al, 2000a, 2000b) one of its monosaccharides (glucose) (Sclafani and Ackroff, 1994; Touzani, Bodnar and Sclafani, 2009a, 2010a), and fat (in form of corn-oil) (Elizade \& Sclafani, 1990; Dela Cruz, et al., 2012) are hypothesized to condition both flavor-flavor and flavornutrient preferences. While there is lack of direct evidence that glucose or corn-oil produced flavor-flavor conditioning (there are no sham-feeding CFP studies with glucose or corn-oil), it is reasonable to hypothesize that glucose would do so. This is based on the ability that saccharin and sham-fed sucrose are able to produce conditioned preferences. In terms of corn-oil F/F CFP, it has been reported of orallyconsumed corn oil and mineral oil conditioned flavor preferences and that the mineral oil effect was due to F/F conditioning (Elizalde \& Sclafani, 1990). More recently, the same lab tested male rats with $3 \%$ Sefose vs. $0.9 \%$ Sefose (a nonmetabolizable oil similar to olestra) and observed conditioned CS+ preferences (Ackroff \& Sclafani, unpublished).

In contrast, the other monosaccharide of sucrose, fructose, conditions only flavor-flavor preferences in short-term tests (Baker et al., 2003; Sclafani, et al., 1993, 1999). It should be noted that whereas IG fructose fails to condition preferences in 30-min/day tests, it does condition strong preferences in food-deprived rats trained 20-h/day and in non-deprived rats trained $24 \mathrm{~h}$ /day with a saccharin-sweetened CS+ flavor and a mild preference in rats trained $24 \mathrm{~h}$ /day with an unsweetened CS+ paired with 7.1\% IG fructose. (Ackroff \& Sclafani, 2004; Ackroff et al., 2001). For the most part, this introduction will refer to flavor-flavor conditioning with fructose using the short-term (30 min/day) training paradigm.

These solutions can also be modified in order to isolate an orosensory element to examine the effects of solely a flavor-flavor consequence or to isolate a post-ingestive element to examine the effects of a flavor-nutrient consequence. For example, in addition to providing fructose solutions in real-feeding intake tests, 
glucose, sucrose or corn-oil solutions can be consumed under sham-feeding conditions which will minimize the post-ingestive consequences of those solutions (Hsaio \& Smith, 1995; Liang, Hajnal, \& Norgren, 2006; Weatherford, et al., 1990; Yu, et al., 2000a; Yu, et al., 2000b). In contrast, IG infusions of glucose, sucrose or cornoil are used to examine the selective effects of flavor-nutrient conditioning (Touzani, Bodnar \& Sclafani, 2008, 2009b, 2010a; Sclafani, et al., 1993; Sclafani, Fanizza \& Azzara, 1999). Flavor-flavor and flavor-nutrient sugar-CFP learning require some form of DA transmission from the NAc, AMY and/or mPFC (Bernal, et al., 2008; 2009; Touzani, Bodnar and Sclfani, 2008; 2009a; 2010a; Malkusz, et al., 2008; 2009; 2010), and these types of conditioning have been tested in isolation in the laboratory. Flavor-flavor and flavor-nutrient conditioning warrant study because they appear to be mediated to some extent by distinct neural mechanisms and exert different effects on preference behavior.

\section{Neurochemical candidates for CFP}

\section{a. Opioids}

1. The rewarding consequences of opioids. Research has shown that the opioid system is important in palatable food intake. Opioids are involved in a broadly distributed neural network that regulates ingestive behavior, particularly intake of foods that are rewarding. (Bodnar, 2004; Levine \& Billinton, 2004). In fact, it is generally believed that the opioid system is related to the intake of rewardassociated and hedonically associated palatable food consumption. Thus, morphine increased both the intake of and the preference for such palatable solutions as saccharin and sugars (Bertino et al., 1988; Calcagnetti and Reid, 1983; Cooper, 1983), presumably by increasing the hedonic value of the solutions (Cooper et al., 1988). Opioid signaling is thought to regulate palatability of food through orosensory context cues such as taste and texture. These orosensory context cues are thought to determine the reward value of a food item (Taha, et al., 2006). 
Naltrexone (NTX) and naloxone are two effective general opioid antagonists that block many types of intake mediated by sugars and fats. Animals treated with these general opioid antagonists display reduced intake under a wide range of spontaneous deprivation, glucoprivic and lipoprivic conditions (Bodnar, 2004). Peripheral NTX decreased the intake of a sweet diet more effectively than a nonsweetened diet (Levine and Billington, 2004; Weldon, et al, 1996). Levine, et al. (1995) found that NTX robustly reduced intake of rats' sweet chow while being relatively ineffective at reducing normal chow with very low doses of NTX reducing sweet chow intake by 50\%. Naloxone reduced sucrose intake without affecting eating latency, suggesting effects upon the maintenance, rather than the initiation of intake (Kirkham \& Blundell, 1984; 1986), and it blocked saccharin intake ostensibly by interfering with preference acquisition (Lynch, 1986). In humans, naltrexone was found to decrease the pleasantness of a sucrose solution (Bertino, Beauchamp \& Engelman, 1991; Fantino, Hosotte \& Apfelbaum, 1986). Naltrexone administration not only reduced overall human food consumption, but also significantly reduced subjective perceived pleasure ratings (Yeomans and Grey, 1997). In addition, Rockwood and Reid (1982) conducted sham feeding studies, which eliminates the effects of postabsorbtional meals, and found that naltrexone reduced intake of a $10 \%$ sucrose solution in both food-deprived and nondeprived rats with open gastric fistulas. Ventricular administration of mu and kappa, but not delta-1 opioid antagonists reduced intake of palatable fat or sucrose diets (Arjune \& Bodnar, 1990; Arjune, et al., 1990, 1991; Becakowska, et al., 1992, 1993; Calcagnetti, et al., 1990). Moreover, central studies have implicated the NAc and VTA in opioid antagonistinduced reductions of sucrose intake (Bodnar et al., 1995; Ragnauth et al., 1997). All the aforementioned research supports the hypothesis that opioid receptors are involved in the rewarding properties of sweet tastants.

Opioids have also been shown to affect the intake of fats. Therefore, both antagonists decreased intake of high-fat diets (Apfelbaum \& Mandenoff, 1981; Cooper et al., 1985; Marks-Kaufman et al., 1984), and opioid agonists stimulate the intake of fat (Marks-Kaufman, 1981; Marks-Kaufman \& Kanarek, 1981; Romsos, et al., 1987). Interestingly, the concept of preferences come into play. Most rats will 
prefer a fat diet relative to a carbohydrate diet, and in these animals, morphine increased the preferred (fat) diet more than the non-preferred diet. However, some rats preferred a carbohydrate diet to a fat diet, and in these animals, morphine was more effective in increasing carbohydrate intake (Gosnell et al., 1990; Koch et al., 1995). Further in studies in which preferred and nonpreferred food items were offered concurrently, naltrexone decreased preferred food intake while slightly increasing nonpreferred food intake (Cooper \& Turkish, 1989; Weldon, et al., 1996; Giraudo, et al., 1993; Sclafani, et al., 1982; Glass, et al., 1996). Mu opioid receptors played a major role in opioid mediation of fat intake (Islam \& Bodnar, 1990). A specific role for opioids in signaling the reinforcing value of palatable food items can be concluded from these findings.

Natural opioid levels in the brain are also affected when palatable food is ingested. Yamamoto and colleagues $(2000 ; 2003)$ examined levels of opioids in the brains after given particular solutions to drink. Water-deprived animals drank sucrose, saccharin, $\mathrm{NaCl}$, quinine or water. Sucrose and saccharin elicited the strongest release of $\beta$-endorphin into the cerebrospinal fluid, which supported the hypothesis that release of a particular opioid, $\beta$-endorphin, is positively correlated with palatability of taste stimuli.

With this knowledge extensive evidence implicating the brain opioid system in the control of food palatability and intake, it was then suggested that opioids may play a role in learning a preference in conditioned flavor preference studies.

2.Systemic studies- Opioid CFP. The role of opioids in learned responses has not been as clear-cut as their role in the ad libitum intake of sweet stimuli. Opioids appear to affect the general rewarding characteristics of a sweet food/solution rather than the ability to discriminate the taste of the sweet food/solution (Fantino, et al., 1986; Arbisi, Billington \& Levine, 1999). However, surprisingly, in flavorflavor and flavor-nutrient CFP studies, NTX failed to alter either the acquisition or expression of sugar-CFP, yet significantly and markedly decreased intake of the sugar solutions. Yu, et al. (1999) conducted sham-feeding studies to minimize the 
post-ingestive effects of sucrose ingestion in a flavor-flavor CFP experiment. Systemic injection of NTX decreased intakes of CS+ (sucrose) and CS- (saccharin) during training, but NTX failed to alter the expression or acquisition of the CFP. Baker, et al. (2004) similarly conducted a flavor-flavor CFP experiment by using real-feeding rats and fructose, which mainly induces flavor-flavor CFP. Correspondingly, NTX dose-dependently reduced fructose (CS+) and saccharin (CS-) intakes when injected during training, yet NTX was unable to reduce flavor-flavor conditioning in either acquisition CFP or expression CFP. Flavor-nutrient conditioning was also examined. Azzara, et al (2000) infused sucrose or water into the stomach through IG infusions and paired this with flavored saccharin solutions. NTX reduced total intake of CS+ and CS- solutions, yet failed to alter either the acquisition or expression of CFP elicited by IG sucrose infusions. It can be concluded that the opioid system modulates the consumption of flavored solutions, but is not critically involved in the acquisition or expression of sugar- CFP.

b. NMDA glutamate. The $N$-methyl-D-aspartate (NMDA) glutamate receptor has a role in the controlling synaptic plasticity and memory function (Li \& Tsien, 2009). More specifically, glutamate receptor activation has been shown to play a role in food-related incentive learning, including in the VTA, NAc, AMY and mPFC, presumably due to the interactions with DA transmission within these key cortical areas (Kelley, 2004; Ranaldi, et al., 2011). Infusions of an NMDA antagonist into the NAc core were shown to affect the acquisition of appetitive instrumental learning of a pellet lever-pressing task (Kelley, Smith-Roe \& Holahan, 1997; Hernandez, et al., 2005). In addition, VTA NMDAR antagonism blocks the acquisition of drug-induced conditioned place preference (Harris \& Aston-Jones, 2003), while levels of extracellular levels of glutamate were found to be significantly higher when exposed to drug-associated cues (You, et al., 2007), suggesting an important role of VTA glutamatergic neurotransmission in modulating goal-directed behavior by conditioned stimuli (Stuber, et al., 2008). Within the VTA, glutamate antagonists impaired sucrose learning and DA release in the NAc elicited by the sucrosepredictive cue (Stuber, et al, 2008; Zellner, Kest \& Ranaldi, 2009; Zweifel, et al., 
2009). AP-5, a competitive NMDA antagonist, was found to affect the operant conditioning of free food in acquisition, but not expression, of reward-related learning when injected directly into the VTA (Zellner, Kest \& Ranaldi, 2009). AP-5 also affects the NAc core, as c-fos expression in the NAc core was reduced as compared to the controls when AP-5 was injected into the VTA. (Ranaldi, et al., 2011). Lastly, NMDA receptor blockade in both the lateral/basolateral AMY and the mPFC was also found to strongly disrupt acquisition of lever-pressing for food (Baldwin, et al., 2000).

The NMDA system produces complex effects upon feeding behavior in general, but been less studied for its effects upon fat intake. Thus, the noncompetitive NMDA antagonist, MK-801, significantly increased sucrose intake in moderately food-deprived animals (Burns \& Ritter, 1997; Covasa et al., 2004; Qian, et al., 2000; Treece, et al., 1998; Zheng, et al., 1999). Moreover, MK-801 significantly enhanced feeding elicited by the anti-metabolic glucose analogue, 2-deoxy-Dglucose (Sugimoto et al., 1999), but produced initial suppression and subsequent enhancements for lipoprivic feeding elicited by mercaptoacetate (Duva, et al., 2005). Feeding responses are observed following AMPA and kainate, but not NMDA receptor antagonists administered into the NAc (Maldonado-Irizarry, et al., 1995; Reynolds \& Berridge, 2003). Moreover, glutamate and NMDA, AMPA and kainate receptor agonists also powerfully stimulate feeding when microinjected into the lateral (Duva, et al., 2001; Hettes, et al., 2007; 2010; Stanley, et al., 1993, 1996) and perifornical/paraventricular (Hettes, et al., 2003; Lee \& Stanley, 2005) hyothalamus as well as the NAC (Echo, et al., 2001).

\section{Conditioned Flavor Preference and glutamate NMDA signals . Glutamate} signaling has also been shown to be involved in sugar conditioned flavor preference. Golden and Houpt (2007) studied the effects of systemic injections of the noncompetitive glutamate NMDA antagonist, MK-801 on the acquisition and expression of fructose-CFP. Whereas vehicle-treated rats acquired a preference for $8 \%$ fructose-associated flavor over the $0.2 \%$ saccharin associated flavor when given a two bottle test, rats injected with MK-801 prior to conditioning were blocked in 
acquisition of the fructose-CFP learning. In addition, MK-801 substantially reduced the intake of the CS+ flavor during training. In contrast, MK-801 failed to affect the expression of a fructose-CFP. Thus, glutamate NMDA receptor antagonists affect acquisition, but not expression of learning suggesting that NMDA receptor activation is required for plasticity only in the early learning process.

\section{C. $D A$}

1. Rewarding consequences of DA. Many of the learned associations to flavor cues are thought to stem from the connection of the palatability of food and the reward of DA released in the brain. Overeating and obesity may have an acquired drive like drug addiction with respect to motivation and incentive; craving, wanting and liking occur from early and repeated exposures to stimuli (Liu, et al., 2010). In this case, the stimuli are the foods ingested and the positive and rewarding consequences are the effects from those foods (i.e., release of DA in the brain). There are many findings linking the brain DA activity with the reward value of sweet taste and the motivation to obtain sweet rewards (Agmo, Galvan \& Talmantes, 1995; ElGhundi, et al., 2003; Genn, Ahn \& Phillips, 2004; Hajnal, Smith \& Norgren, 2004; Imaizumi, Takeda \& Fuksiki, 2000; Liu, et al., 2010; Pecina, et al., 2003; Sawano, et al., 2000; Smith, 2004).

An alternative view postulated that DA systems are not needed to mediate hedonic reinforcers or predictive associations in hedonic reward learning ('liking'), but instead may be necessary for incentive salience attributions (as a direct component of motivation and reward) to the neural representations of rewardrelated stimuli ('wanting') (Berridge \& Robinson, 1998). In fact, Berridge (2012) concluded that DA does not cause pleasure or even cause learning about reward. Instead, the authors of this paper believe a statement made by Wise (2006): DA has several roles in the ability of food to serve as a reward; which is important, but not necessary, for the reinforcement function of rewards and associations. Berridge (2012) failed to cite any evidence supporting the notion that dopamine can induce hedonic feelings for certain actions, for example, drug abuse and self-administration (Gardner, 2005), pleasant tastes to humans (O’Doherty, et al., 2003), food intake in 
rodents (Wise \& Raptis, 1985) and sucrose intake in rodents (Smith, 1995; Meyers \& Sclafani, 2001; Sclafani \& Ackroff, 2006; Touzani, Bodnar \& Sclafani, 2010b; Sclafani, Touzani \& Bodnar, 2011). In addition, Berridge (2012) also fails to cite any studies supporting the idea that DA is involved in reward learning. Many of the studies of the Bodnar and Sclafani labs study DA and learning through conditioned flavor preferences (Yu, et al., 2000a; 2000b; Azzara, et al., 2001; Baker, et al., 2003; Touzani, et al., 2008; 2009a; Bernal, et al., 2008; 2009; Malkusz, et al., 2012), which support the notion that DA is involved in reward learning. Reward function-and food reward in particular-is only one of the many functions in which DA plays an important contributing role.

DA has been found in certain regions of the brain that have been speculated to regulate and control behavior by inducing pleasurable effects, including the hedonic feeling of ingesting food. These neurological reward systems make reinforcement possible. Decreased intake of sweet solutions have been observed under shamfeeding and real-feeding conditions following treatment with DA antagonists (Geary \& Smith, 1985; Muscat \& Willner, 1989; Schneider, et al., 1986a, 1986b, 1989, 1990). Correspondingly, DA mediation of the rewarding effect of fat flavor is suggested by the findings that corn oil sham-feeding promotes NAc DA release (Liang, et al., 2006), and DA D1 and D2 antagonists suppress the sham-feeding response to corn oil and real-feeding of fats in rats (Baker, et al., 2001; Davis, et al., 2006; Rao, et al., 2008; Weatherford, et al., 1988; 1990). In inbred mice, strain differences were observed in the ability of the D1 antagonist, SCH23390 to significantly reduce fat intake whereas the D2 antagonist, raclopride, had minimal effects on fat intake (Dym, et al., 2010). Furthermore, DA D2, but not D1 receptor antagonism suppressed operant responding for corn oil in mice (Yoneda, et al., 2007), whereas D1, but not D2 receptor antagonism attenuated place preference conditioning by corn oil intake (Imaizumi, et al., 2000). Research on pleasant rewards have demonstrated an activation in mesolimbic DA systems, ranging from food, sex, and drugs to social and cognitive rewards (Becker, et al. 2001; Roitman, et al. 2004; Small, et al. 2003; Thut, et al. 1997; Volkow \& Wise 2005; Wise, 1985). Our lab has previously studied the effects of the mesolimbic and the mesotelecephalic reward 
pathway on DA and the hedonic effects of food (Azzara, et al., 2001; Baker, et al., 2003; Yu, et al. 2000a, 2000b; Sclafani \& Ackroff, 1994; Touzani, Bodnar \& Sclafani, 2009a, 2009b, 2010a; Sclafani, et al., 1993; Sclafani, Fanizza \& Azzara, 1999).

2. Systemic DA antagonist studies. A systemic injection of raclopride, a DA D2 antagonist, was found to reduce the preference of a flavored $10 \%$ sucrose solution compared to a second flavor paired with a saline vehicle injection (Hsaio \& Smith, 1995). Systemic injections of a DA D1 antagonist (SCH23390) but not a DA D2 (Raclopride) antagonist blocked the flavor-nutrient conditioning of IG sucrose infusions (Azzara, et al., 1999). In flavor-flavor paradigms, sham-feeding rats showed preference for a sucrose CS+ associated flavor in two bottle testing as opposed to a saccharin CS- associated flavor. When either DA D1 or D2 antagonists were administered with the two-bottle expression testing, the preferences were dose-dependently reduced, indicating that DA D1 and D2 are involved in the expression of conditioned preference (Yu, et al., 2000a; Yu, et al., 2000b). In a subsequent study, a rationed portion of a distinctly-flavored fructose and saccharin solution (CS+) and another flavored saccharin solution (CS-) was employed in realfeeding rats. Systemic injections with SCH23390 and, to a lesser degree, Raclopride, blocked acquisition of fructose-flavor conditioning, whereas both D1 and D2 antagonism significantly reduced the expression of a CS+ fructose-CFP (Baker et al., 2003). Thus, DA has been proven to play a role in conditioned flavor preference, both in expression and acquisition. It would be interesting to know which brain areas, particularly the mesolimbic system and the mesotelecephalic system, are activated after initial exposure to sugars and fats.

\section{Mesotelencephalic DA pathway}

Following the success of the systemic studies, the roles of sites within the mesotelencephalic DA reward pathway were explored in terms of their intrinsic connections. 
a. Anatomy of the mesotelecephalic pathway and the VTA. The mesotelencephalic pathway starts with the Ventral Tegmental Area (VTA). The VTA is a group of neurons located close to the midline on the floor of the mesencephalon and is partially populated (50\%) with melanin-pigmented dopaminergic neurons (Margolis, et al., 2006). The VTA releases DA which continues to the following areas of the mesotelencephalic pathway: Nac, AMY and mPFC.

b. Relationship of the Mesotelencephalic DA pathway and the gustatory system. The nucleus of the solitary tract (NST), the first central relay of the gustatory system (Norgren, 1995) was found to possess neural connections with the VTA (Ito \& Seki, 1998; Kirouac and Gangluly, 1995), providing physical connection of feeding to a DA mesotelencephalic site. The gustatory system also has connections to the NAc through the parabrachial nucleus (PBN), the second central gustatory relay. Some of the PBN projections connects heavily to limbic structures include the central nucleus of the amygdala, the lateral hypothalamus, and the bed nucleus of the stria terminalis (Norgren, 1995), all of which send axons to the NAc shell (Kirouac \& Ciriello, 1997) and are connected also to the VTA (Oades \& Halliday, 1987; Phillippson, 1979).

c. Anatomy of the mesotelecephalic pathway and the NAc. In the mesolimbic reward system (part of the mesotelencephalic system), DA is sent from the VTA to the NAc via the medial forebrain bundle (MFB) (Hernandez, et al., 2006). The NAc is the known as a "reward" center and the activation of the MFB from the VTA to the NAc is sometimes called the "hedonic highway" (Howard, 2006). The NAc can be separated into two areas: the shell and the core. The NAc shell plays a role in regulating motivation, reward, and psychiatric disorders related to improper regulation of these qualities. Particularly important are the effects of drug and food stimuli on the NAc shell because these effects are related to addiction and behavioral inhibition, whereas the NAc core is involved in sensory motor integration, reward, the regulation of goal-directed behavior, and emotional cues (di 
Chiara, 2002). DA levels have been found to increase in both the NAc shell and NAc core, when drugs of abuse like amphetamines and cocaine are introduced into the body, but the effect of these increases are more pronounced in the NAc shell (Pontieri, G. Tanda, \& Di Chiara, 1995).

d. Anatomy of the mesotelecephalic pathway and the AMY. Another DA projection of the mesolimbic and mesotelecephalic reward pathway is from the VTA to the AMY (Bjorklund \& Dunnett, 2007). The VTA also has DA projections to the Bed Nucleus of the Stria Terminalis (BNST), which is considered to be an extended part of the AMY (Kauer \& Malenka, 2007). The AMY receives DA innervation from VTA neurons and contains a moderate to high density of DA D1 receptors (Dawson, et al., 1986; Mansour, et al., 1990; Huang, et al., 1992; Asan, 1997; Leonard, et al., 2003). One of the projections of the second gustatory relay (PBN) is to the limbic structures (including the AMY). The limbic structures from the PBN then project to the NAc shell (Kirouac \& Ciriello, 1997) and these limbic structures are connected also to the VTA (Oades \& Halliday, 1987; Phillippson, 1979). To complete the AMY portion of the mesolimbic system, the central nucleus of the AMY connects back to the VTA (Baxter \& Murray, 2002), providing feedback to its' DA projection site.

e. Anatomy of the mesotelecephalic pathway and the mPFC. The last brain site in the mesotelencephalic DA reward pathway connects the VTA to the medial prefrontal cortex (mPFC) (Swanson, 1982), via the DA projection from the A10 cell group of the VTA (Lindvall, Bjorklund \& Divac, 2010). The mPFC then sends its efferents to the NAc (Brog et al., 1993; Sesack, et al., 1989; Wright and Groenewegen, 1995; Wright et al., 1996), completing the loop of the mesotelencephalic reward pathway. Lastly, there is also a strong reciprocal connectivity between the AMY and the frontal cortices (including mPFC) (Aggleton, et al., 1980; Berendse, et al., 1992; Groenewegen, et al., 1999; McDonald, 1991; McDonald, et al., 1996). 


\section{Mesotelencephalic DA pathway and CFP}

a. NAC and CFP. There are also previous experiments of conditioned flavor preference paradigms that implicate the mesotelencephalic DA reward pathway in food reward. When testing for flavor-flavor learning and orosensory consequences, microinjections of D1 and D2 DA antagonists into the NAc shell attenuated the expression of fructose-CFP. Whereas these antagonists did not block the initial acquisition, they hastened the subsequent extinction of fructose-CFP (Bernal, et al., 2008). IG infusions of sugars and fats enabled testing of flavor nutrient learning and the effects of postingestive consequences through the NAc. Lastly, administration of DA D1receptors antagonism into either the NAc Shell or core eliminated the acquisition of IG glucose-CFP, but had lesser effects upon expression (Touzani, Bodnar and Sclafani, 2008).

b. AMY and CFP. Flavor-nutrient conditioning was examined through IG infusions of glucose and again, the acquisition of CS+ preference was blocked by microinjections of SCH23390, the DA D1 antagonist, into the AMY (Touzani, Bodnar \& Sclafani, 2009a). In addition, expression of the CS+ IG glucose was dose-dependently reduced by SCH23390 and blocked by the highest dose. To examine site-specificity, SCH23390 was separately injected into the Basolateral (BLA) and central (CeA) amygdala; this weakened, but did not eliminate the acquisition of IG glucose-CFP (Touzani, Bodnar \& Sclafani, 2009a), thereby suggesting a role for both amygdalar nuclei. In studies of flavor-flavor conditioning (Bernal, et al., 2009), injections of SCH23390 into the AMY, and to a lesser degree, Raclopride (DA D2 antagonist), significantly reduced the expression of CS+ fructose-CFP. Microinjections of SCH23390 and Raclopride into the AMY did not affect the initial acquisition of CS+ fructose-CFP, but the DA D1 antagonist hastened the extinction of the learned response. The results of the AMY studies were similar to the NAc shell studies, which may suggest that flavor conditioning involves a regionally distributed network, that include the mesolimbic and mesotelecephalic reward pathways. 
c. $m P F C$ and CFP. The mPFC was also studied in both flavor-flavor conditioning and flavor-nutrient conditioning. In flavor-flavor conditioning, DA D2 receptor antagonism in the $\mathrm{MPFC}$ was more effective than DA D1 receptor antagonism in dose-dependently reducing the expression of fructose-CFP (Malkusz, et al., 2008; Malkusz, et al., 2009). Acquisition of fructose-CFP was blocked by DA D1 and D2 antagonists into the mPFC (Malkusz, et al., 2010) and was the only site where both antagonists blocked flavor-flavor conditioning during training. Malkusz, et al., (2012) later found evidence providing the reciprocal connections between mPFC and the AMY using higher DA antagonist doses. Acquisition, but not expression for fructose-CFP is dependent on DA D1 and D2 receptor signaling in the $\mathrm{MPFC}$ and the DA D2 receptor in the AMY, while the NAc does not seem to play a role in flavorflavor acquisition. For flavor-nutrient conditioning, glucose was infused through the stomach. SCH23990, the DA D1 antagonist, was injected into the mPFC and dosedependently reduced the expression of IG glucose-CFP (Touzani, Bodnar \& Sclafani, 2010a). The rats in the acquisition study who were treated with SCH23990 into the mPFC failed to prefer CS+ of IG glucose, in comparison to the control rats (Touzani, Bodnar \& Sclafani, 2010a). The results of this acquisition study that IG glucose flavor-nutrient preferences were blocked by DA D1 antagonism in the MPFC are similar to the results found in the NAc (Touzani, Bodnar \& Sclafani, 2008) and the AMY (Touzani, Bodnar \& Sclafani, 2009) indicating a further existence of a distributed brain network mediating this response (Touzani, Bodnar \& Sclafani, 2010b).

\section{Nigrostriatal DA pathway and feeding}

Another DA pathway associated with feeding is the nigrostriatal pathway, which connects the substantia nigra to the striatum (Swanson, 1982). More specifically, the substantia nigra pars compacta $(\mathrm{SNc})$ is made of up of large DA containing-cells and project to the caudate and putamen in a topographic manner (Haber, et al, 2000). Infusions of the glucose metabolism inhibitor 2-DG into the substantia nigra 
increases GABAergic signaling, possibly influencing DA release in the striatum (During, et al, 1995). 2-DG inhibits GABA release and simultaneously increases striatal DA release, suggesting a disinhibition of nigrostiatal neurons.

The dorsal striatum (the caudate and the putamen:CP) has also been associated with DA release during feeding. Ungerstedt (1971) found that the dorsal striatum was important in feeding by using the neurotoxin 6-OHDA to lesion dopaminergic neurons. Later studies verified this finding of DA depletions by affecting the whole striatum (including the CP) leading to aphagia (Dunnett \& Iversen, 1980; Jicha \& Salamone, 1991; Koob, et al., 1978, Salamone, et al., 1990). In addition, virally mediated restoration of DA production in DA deficient mice reversed aphagia when the caudate-putamen is targeted, and the dorsal striatum has been linked to being a role in obtaining sufficient energy (Szcypka, et al., 2001; Sotak, et al., 2005). Lastly. Ren, et al., (2010) found that like the NAc, the dorsal striatum (CP) can be induced by direct stimulation of the gastrointestinal tract.

In addition to being released during feeding, the amount of DA release in the $\mathrm{CP}$ has been found to correlate with the degree of pleasure the food induces (Small, et al, 2003; Szcypka, et al., 2001). Small, et al. (2003) found evidence of feeding-induced DA release in humans and suggests that food reward is related to DA action in the dorsal striatum. Researchers found that the dorsal striatum is less responsive to food reward in obese, relative to lean individuals. The reason is that obese individuals potentially have reduced DA D2 receptor density and compromised dopamine signaling, which may prompt them to overeat in an effort to compensate for this reward deficit (Stice, et al., 2008, Rothemund, et al. 2007). Ferreira, et al (2012) found that extracellular dorsal striatum dopamine levels increased in proportion to the infusates' caloric density from their studies on microdialysis measurements taken through dry licking behaviors. Extracellular DA levels were more closely associated with the amounts of calories consumed (via IG methods) than with the motor behaviors associated with the IG infusions. 
Due to the fact that DA is released from the SNc to the $\mathrm{CP}$ and this DA release was found to be correlated with the amount of pleasure by intake, the nigrostriatal pathway will also be investigated. Thus, chapter 4 will examine how sugars and fats (through differing levels of orosensory and post-ingestive avenues) affect DA release in the VTA and its major projection areas (Nac, AMY and $\mathrm{mPFC}$ ) as well as the substantia nigra and the dorsal striatum.

\section{8. c-Fos}

a. Reliability of c-Fos as a neuronal marker. c-Fos is used an indirect marker of neuronal activity because this protoonco-gene is often expressed when neurons fire action potentials (VanElakker, et al., 2008; Dragunow \& Faull, 1989). In addition, the upregulation of c-fos mRNA in a neuron indicates recent activity (Day, et al., 2008). c-Fos is a reliable neuronal marker and its' use can be justified from its' advantages. First, activation of the c-Fos gene by a sensory stimulus results in c-Fos protein synthesis within 1h (Morgan \& Curran, 1991), so immediate results can be obtained with perfusion of the rat brain. Several studies have demonstrated a coincidence between Fos-like immunoreactivity and (14C)-2- deoxyglucose uptake thus suggesting a tight correlation between neuronal activity and the expression of c-fos. (Streefland, et al., 1996). In addition, the pattern of c-Fos expression in the brain provides cellular resolution of neural activity that can be quantified by counting the number of labeled cells (Sagar, Sharp, \& Curran, 1988). The degree of c-Fos expression can then be correlated with quantifiable behavioral measures, like conditioned flavor preference tests. Third, c-Fos allows mapping of neuronal populations activated by a stimulus. Because many sections can be processed for cFos, activity in multiple brain regions of the same animal can be visualized for the analysis of a distributed network. Our study will be taking information from four parts of the brain from each rat. This is unlike other methods, including microdialysis, which cannot measure multiple brain areas at the same time. c-Fos also has better spatial resolution than other methods. Lastly, the patterns of c-Fos expression can be interpreted against a large database of c-Fos literature. For 
example, c-Fos has been used extensively to map the sites involved in conditioned taste aversion acquisition and expression (Houpt, Philopena, Joh, \& Smith, 1995, 1996a, 1996b; Houpt, Philopena, Wessel, Joh, \& Smith, 1994; Swank \& Bernstein, 1994; Swank, Ellis, \& Chochran, 1996; Swank, Schafe, \& Bernstein, 1995), or to better understand neural activation of drug addiction (Ranaldi, et al., 2011; Rotllant, et al., 2010; Ferario, et al., 2008).

\section{b. Previous c-Fos studies examining food and the gustatory system. There are many} studies using fos-like immunoractivity (FLI) to study activation patterns examining the rewards of ingestion of sugars and fats. Previous studies used sugar ingestion to study the role of taste information by tracing the pathways that convey taste information. This pathway includes parts of the brainstem of the central gustatory system used to process taste information (NTS, PBN, the Vagus nerve, etc.), which in turn innervates to the pancreas. The pancreas, subsequently, regulates insulin and sugar levels in the body (Streefland, et al., 1996). These studies have rats and mice ingest sugars (sucrose, glucose or a mixture of food which included sucrose) through voluntary oral means (Anseloni, et al., 2005; Streefland, et al., 1996; Washington, et al., 2010; Yamamoto, et al., 2007; Zhao, et al., 2011; Chen, et al., 2011), through IG infusions (Yamamoto, et al., 1997; Yamamoto and Sawa, 2000a, 2000b) or through intraoral infusions (Schwarz, et al., 2010; Harrer, et al., 1996). Increased levels of FLI found in the NTS (Anseloni, et al., 2005; Streefland, et al., 1996; Schwarz, et al., 2010; Yamamoto, et al., 1997, Yamamoto and Sawa, 2000a, 2000b; Washington, et al., 2010, Harrer, et al., 1996; Zhao, et al., 2011; Chen, et al., 2011), in the PBN (Streefland, et al., 1996; Yamamoto, et al., 1997; Yamamoto and Sawa, 2000a, 2000b; Zhao, et al., 2011; Chen, et al., 2011), in the Area Postrema (Yamamoto and Sawa, 2000a, 2000b; Schwarz, et al., 2010; Washington, et al., 2010) and in the connections to the Vagus nerve (Streefland, et al., 1996; Washington, et al., 2010). These studies examined how sugars affect the gustatory pathway, which may affect the mesotelencephalic reward pathway, but they did not directly study dopamine or reward. Other studies examined c-fos activation and satiation of sweet solutions and found increased levels of FLI in both the hypothalamus and supraoptic 
nucleus (Naimi, et al., 1997; Mitra, et al., 2010). In addition, other sugar c-fos studies examined the effects of sugar with hyperalgelsia or analgesia and found FLI activation in the brainstem (Anseloni, et al., 2005) and the spinal cord (Anseloni, et al., 2005; Ren, et al., 1997). Injections of opioid antagonists with sugar consumption found increases only in the central nucleus of the AMY while all other areas were not significantly affected (Park \& Carr, 1998; Pomonis, et al., 2000).

c. C-fos, sugar consumption and the mesotelencephalic areas of reward. In studies that examined both orosensory and post-ingestive consequences of sugars, oral voluntary intake of sugar was found to have greater FLI in the central nucleus of the AMY (Zhao, et al., 2011; Norgren, et al., 2006) and the NAc (shell, not core) (Norgren, et al., 2006) as compared to control brains. In studies that examine the FLI of orosensory consequences of sugar, rats that sham licked sucrose were found to have increased FLI in the central nucleus of the AMY and in the NAc shell, but not the VTA (Mungarndee, Lundy \& Norgren, 2008). Lastly, in a study that examines FLI of solely post-ingestive consequences of sugar, IG infusion of sugar were found to have increased levels of FLI in the NAc, IG infusion of glucose produced increased FLI in only the central nucleus of the AMY (Otsubo, et al., 2011), whereas IG infusion of sucrose produced increased FLI in both the central nucleus and basolateral AMY (Yamamoto, et al., 2007). In chronic sugar exposure studies, Mitra et al., (2011), found that adding sucrose to scheduled chow access increases the FLI in both parts of the NAc (shell and core) as well as the prefrontal cortex (including mPFC), while Pecoraro and Dallman (2005) found after sucrose concentration downshift (rats were expecting sugar intake), there was a greatest increase of FLI in the basolateral AMY and the NAc, whereas the VTA was not activated. In sugar conditioning studies, Hamlin, et al., (2006) found that after extinguished natural reward behaviors of sugars, there were increased FLI in the basolateral AMY and the NAc, while Kerfoot, et al. (2007) conditioned sugar to a tone and found that when testing the CS+ alone (tone) there were increased levels of FLI in the basolateral AMY. Lastly when presented a palatable chow (30\% sucrose), increased levels of FLI were found in the VTA (Park and Carr, 1998). The current study will expand on the aforementioned 
experiments examining FLI in the four mesotelecephalic DA reward sites (mPFC, NAc, AMY and VTA) after initial exposure to oral voluntary ingestion or IG infusions of sugars and fats.

\section{Part II. Dopamine, memory, deep brain stimulation and hypoxia}

DA is involved in many other processes in addition to feeding and food reward. DA has shown to play a role in working memory and long-term memory. Impairment in the DA system is thought to contribute to the memory loss found in some mental disorders. In addition to memory, DA has been linked to mental disorders in general and a contributor to this link may be due to hypoxia in early development.

\section{Dopamine and deep brain stimulation treatment for diseases with memory impairment}

a. Dopamine and memory. Besides playing a role in memory of food preference, DA is also thought to influence other types of memory. Working memory, including spatial working memory, has been associated with DA D1 receptor down regulation, which is believed to have an important role in working memory tasks (Williams \&Castner, 2009; McNab, et al., 2009). Studies have shown that insufficiency and dysfunction of prefrontal DA, which tends to be age-related, and excessive transmission, as in acute stress, leads to impairments with the working memory. These impairments can be reversed through D1 receptor agonist and antagonist treatment, as seen in both animal and human studies (Williams \& Castner, 2006; Collins, et al., 1998; Mizoguchi, et al., 2009; Apitz \& Bunzeck, 2013). Behavioral and physiological research has shown that DA in the prefrontal cortex can be described as an "inverted U" relationship between DA transmission, especially towards D1 receptor, and working memory. Specifically, slightly enhanced DA levels accelerate 
neural/cognitive processes while excessive DA levels impair them (Williams \& Castner, 2006; Collins, et al., 1998; Mizoguchi, et al., 2009; Apitz \& Bunzeck, 2013).

DA does not process memory only in the prefrontal cortex, DA is has also been found to involved in the processes of long-term potentiation, which leads to long-term memory. The hippocampus detects newly arrived information that is not already stored in its long-term memory and is sent to the VTA (via the nucleus accumbens and ventral pallidum), which releases DA into the hippocampus- thus, regulating the entry of information into long-term memory and enhancing long term potentiation (LTP) (Lisman \& Grace, 2005). DA appears to be a key modulator for LTP in the CA1 region of the hippocampus, cholinergic and noradrenergic antagonists did not block novelty-induced enhancement of LTP (Li, Cullen, Anwyl, \& Rowan, 2003).

\section{b. The relation between Deep Brain Stimulation and memory loss: treatment} strategies. Some memory problems are linked to dementia-related disorders like Alzheimer's disease (AD). In the early-stage of AD, cognition and the ability to acquire new memories are impaired. In the later stages, some symptoms include progressive deterioration and long-term memory loss (Hescham, et al., 2013b). The number of cases of reported AD is increasing every year, and is correlated with the growth rate of the elderly population (Pollack, 2005). Currently, no treatment exists and care is mainly palliative (Qaseem, et al., 2008).

In the past few years, the applicability of Deep Brain Stimulation (DBS) has been evaluated for memory-related disorders as a non-drug alternative treatment to reduce or delay the progression of dementia and memory loss (Hamani, et al., 2008; Hescham et al., 2013a, Laxton, et al., 2010). The basic principle of this treatment includes bilateral implantation of electrodes in a desired target region of the brain via stereotactic surgery. These electrodes deliver electrical impulses to specific parts of the brain. DBS has already been shown to have therapeutic effects in many other neurological disorders, including Parkinson's, Tourette's syndrome and nonresponsive forms of epilepsy (Andrade et al., 2006; Houeto et al., 2005; Savica et al., 2012; Temel and Visser-Vandewalle, 2006; Wichmann and DeLong, 2006). 
The application of implementing DBS to treat dementia and memory loss was found incidentally through treating a different disorder. In one case, a 50 year-old man was shown to generate detailed autobiographical memories after bilateral hypothalamic/fornical DBS to treat his morbid obesity. After applying electroencephalographic source localization, enhanced activity in the hippocampus was found (Hamani et al., 2008). A following study was conducted to validate the safety of the DBS procedure on mild AD patients and found that treatment tended to be most effective in early stages of AD. In addition, no major adverse effects have been observed (Laxton et al., 2010). Furthermore, preclinical studies have also been conducted to suggest that DBS can be used as a tool to enhance memory functions (Hamani, Stone, Garten, Lozano, \& Winocur, 2011; Hescham et al., 2013a; Stone et al., 2011). Despite the fact that these results seem very promising, further research is required to understand the underlying mechanisms of memory improvement with this treatment, including the neurotransmitters that may play a role in DBS in learning and memory. Because of the connection to memory, we suspect that DA may also play a role in the DBS treatment in memory-related disorders.

\section{Dopamine, hypoxia and mental disorders}

a. DA and hypoxia. In addition to reward-motivated behavior and memory, DA has many other roles as one of the neurotransmitters released in the brain. Several of which include motor control, cognition, and release of several important hormones. One recent speculation states that DA may also benefit from low oxygen conditions (Mannello, Medda \& Atonti, 2011). During a state of hypoxia, at lower oxygen levels, hypoxia-inducible factor $1 \alpha(\mathrm{HIF} 1 \alpha)$ facilitates signal transduction pathways that promote self-renewal, cell survival and inhibit cell apoptosis (Panchision, 2009). In addition to the previously aforementioned actions, researchers have also found that lowered oxygen states also triggers a cascade of gene expressions for tyrosine hydroxylase and DA D1 and D2 receptors (Gross, et al., 2000). The amount of DA cells found depends on the severity of hypoxia. Moderate hypoxia showed a small increase in DA levels, while severe hypoxia showed a significantly greater number of 
DA cells (Gross, et al., 1999). This increase in DA may be due to increased phenotypic dopaminergic proliferation during development (Studer, et al., 2000, Mannello, Meddia \& Atonti, 2009). In fact, HIF1 $\alpha$ in some way regulates the differentiation and production of dopaminergic neurons (Kim, et al., 2008). DA has long been linked to mental disorders, but there may also be a link between hypoxia and mental disorders, which may be explained through the connection of hypoxia, HIF1 $\alpha$ and DA.

b. Hypoxia and mental disorders. Recent findings indicate a role for hypoxia and HIF1 $\alpha$ in the context of psychiatric disorders. Studies have shown that hypoxia plays an important role in almost any risk factor related to brain development in early life, before birth and during birth. This is especially important in the neurodevelopmental model of mental disorders because abnormalities brain development have a greater chance of leading to a psychotic manifestation later in life (Basovich, 2010). A 19-year longitudinal study of hypoxic-ischemia-related complications during development found that these complications lead to doubling the risk of developing a mental disorder (Zornberg, Buka \& Tsuang, 2000). In fact, hypoxia is a known factor in the gene $\mathrm{x}$ environment interactions in schizophrenia under the neurodevelopmental models (Schmidt-Kastner, et al., 2012). In a recent literature review, it was found that $55 \%$ of the schizophrenia candidate genes had the same criteria link to ischemia-hypoxia and/or vascular factors (SchmidtKastner, et al., 2012). Even in research methods this phenomenon was known sometimes albeit indirectly: hypoxia is used as a condition in animal models to mimic preterm birth and other events resulting in neurodevelopmental disability including schizophrenia and depression (Yang \& Levison, 2006; Yang, et al., 2007; Ong, et al., 2005; Morales, et al., 2007; Miles \& Kernie, 2008; Scheepens, et al., 2003). More research needs to be conducted to link the transcription factors that lead to hypoxia with DA and even hypoxia and DA dysfunction in animal models of mental disorders. 


\section{AIMS AND OUTLINE OF THE THESIS}

This thesis is divided over two main aims. The first aim is to investigate the processes of how learning involved in DA and feeding behavior. The second aim is exploring the relation between DA, hypoxia and memory functioning.

In chapter 2, we investigated the role of DA D1 and D2 receptors in fat intake through corn-oil conditioned flavor-preference. We examined learning through both acquisition and expression of a preference. We expanded fat intake in chapter 3, where we investigated the role of opioid and glutamate NDMA receptors in the acquisition and expression of a corn-oil conditioned flavor preference. In chapter 4, we examined DA activation in the mesotelencephalic pathway and the nigrostriatal pathway through novel intake of fats and sugars. We explored a different topic in the next chapter. In chapter 5, we looked at the role of deep brain stimulation in scopolamine-induced memory loss through activation of DA cells in the substantia nigra and the ventral tegmental area. In chapter 6, we explored DA and how it was co-expressed with ARNT and ARNT2, hetereodimers of hypoxiainducible factor $1 \beta$ (HIF1 $\beta$ ) in the midbrain. Lastly, in chapter 7 , we provide an overall conclusion from our findings. 


\section{References}

Abelson, P. \& Kennedy, D. (2004). The Obesity Epidemic. Science, 304:5676, 1413.

Ackerman, S.H., Albert, M., Shindledecker, R.D., Gayle, C., \& Smith, G.P. (1992). Intake of different concentrations of sucrose and corn oil in preweanling rats. American Journal of Physiology, 262: R624-R627.

Adams, J.P \& Murphy, P.G. (2000). Obesity in anaesthesia and intensive care. British Journal of Anaesthesia, 85(1): 91-108.

Aggleton, J. P., Burton, M. J., \& Passingham, R. E. (1980). Cortical and subcortical afferents to the amygdala of the rhesus monkey (Macaca mulatta). Brain Research, 190, 347-368.

Ågmo, A., Galvan, A., \& Talamantes, B. (1995). Reward and reinforcement produced by drinking sucrose: Two processes that may depend on different neurotransmitters. Pharmacology Biochemistry and Behavior, 52: 403-414.

Andrade, D.M., Zumsteg, D., Hamani, C., Hodaie, M., Sarkissian, S., Lozano, A.M., Wennberg, R.A. (2006). Long-term follow-up of patients with thalamic deep brain stimulation for epilepsy. Neurology 66, 1571-1573.

Andrzejewski, M.E., Spencer, R.C. \& Kelley, A.E. (2005) Instrumental learning, but not performance, requires dopamine D1-receptor activation in the amygdala. Neuroscience, 135, 335-345.

Anseloni, V. C. Z., Ren, K., Dubner, R. \& Ennis, M. (2005). A brainstem substrate for analgesia elicited by intraoral sucrose. Neuroscience, 133, 231-243.

Apitz, T., \& Bunzeck, N. (2013). Dopamine controls the neural dynamics of memory signals and retrieval accuracy. Neuropsychopharmacology.

Asan, E. (1997) Ultrastructural features of tyrosine hydroxylase-immunoreac- tive afferents and their targets in the rat amygdala. Cell Tissue Res., 288, 449-469.

Arbisi, P.A., Billington, C.J. \& Levine, A.S. (1999). The effect of naltrexone on taste detection and recognition threshold. Apetite, 32: 241-249.

Azzara A.V., Bodnar R.J., Delamater A.R., Sclafani, A. (2000). Naltrexone fails to block the acquisition or expression of a flavor preference conditioned by 
intragastric carbohydrate infusions. Pharmacology Biochemistry and Behavior, 67: 545-557.

Azzara, A.V., Bodnar, R.J., Delamater, A.R. \& Sclafani, A. (2001). $\mathrm{D}_{1}$ but not $\mathrm{D}_{2}$ dopamine receptor antagonism blocks the acquisition of a flavor preference conditioned by intragastric carbohydrate infusions. Pharmacol Biochem Behav 68: 709-720.

Baker, R. M., Shah, M.J., Sclafani, A. \& Bodnar, R.J. (2003). Dopamine D1 and D2 antagonists reduce the acquisition and expression of flavor-preferences conditioned by fructose in rats. Pharmacol Biochem Behav 75: 55-65.

Baker R.W., Li Y., Lee M.G., Sclafani A., Bodnar, R.J. (2004). Naltrexone does not prevent acquisition or expression of flavor preferences conditioned by fructose in rats. Pharmacology Biochemistry and Behavior, 78: 239-246.

Baldwin, A.E., Holahan, M.R., Sadeghian, K. \& Kelley, A. E. (2000). N-methyl-Daspartate receptor-dependent plasticity within a distributed corticostriatal network mediates appetitive instrumental learning. Behavioral Neuroscience, 114: 1-15.

Bassareo, V. \& Di Chiara, G. (1997). Differential influence of associative and nonassociative learning mechanisms on the responsiveness of prefrontal and accumbal dopamine transmission to food stimuli in rats fed ad libitum. $J$ Neurosci 17: 851-861.

Bassareo, V., De Luca, M.A. \& Di Chiara, G. (2002). Differential expression of motivational stimulus properties by dopamine in nucleus accumbens shell versus core and prefrontal cortex.Journal of Neuroscience. 22:4709-4719

Baxter, M.G. \& Murray, E.A. (2002) The amygdala and reward. Nat. Rev. Neurosci., 3, 563-573.

Becker, J.B., Rudick, C.N. \& Jenkins, W.J. (2001) The role of dopamine in the nucleus accumbens and striatum during sexual behavior in the female rat. Journal of Neuroscience, 21:3236-3241.

Berendse, H.W., Galis-de-Graaf, Y. \& Groenewegen, H.J. (1992). Topographical organization and relationship with ventral striatal compartments of prefrontal corticostriatal projections in the rat. J Comp Neurol, 316:314-347. 
Bernal, S.Y., Dostova, I., Kest, A., Abayev, Y., Kandova, E., Touzani, K., Sclafani, A. \& Bodnar, R. (2008). Role of dopamine D1 and D2 receptors in the nucleus accumbens shell on the acquisition and expression of fructose-conditioned flavor-flavor preferences in rats. Behav Brain Res, 190: 59-66.

Bernal, S., Miner, P., Abayev, Y., Kandova, E., Gerges, M., Touzani, K., Sclafani, A., \& Bodnar, R.J. (2009). Role of amygdala dopamine D1 and D2 receptors in the acquisition and expression of fructoseconditioned flavor preferences in rats. Behav Brain Res 2009: 183-190.

Berridge, K.C. (2007). The debate over dopamine's role in reward: the case for incentive salience. Psychopharmacology, 191:391-431.

Berrige, K.C. \& Robinson, T.E. (1998). What is the role of dopamine in reward: hedonic impact, reward learning of incentive salience? Brain Research Reviews, 28: 309-369.

Bertino, M., Beauchamp, G.K.. \& Engelman, K. (1991). Naltrexone, an opioid blocker, alters taste perception and nutrient intake in humans. Am J. Physiol., 261: R59-R63.

Birch, L.L. \& Fisher, J.O. (1998). Development of Eating Behaviors Among Children and Adolescents. Pediatrics, 101(3): 539-549.

Bjorklund, A. \& Dunnett, S.B. (2007). Dopamine neuron systems in the brain: an update. Trends in Neurosciences, 30(5): 194-202.

Bodnar R.J. (2004). Endogenous opioids and feeding behavior: a 30-year historical perspective. Peptides, 25: 697-725.

Brog, J.S., Salyapongse, A., Deutch, A.Y. \& Zahm, D.S. (1993). The patterns of afferent innervation of the core and shell in the "accumbens" part of rat ventral striatum: immunohistochemical detection of retrogradely transported fluoro-gold. J Comp Neurol, 338:255-278.

Bures J, Bermúdez-Rattoni F, Yamamoto T. Conditioned Taste Aversion: Memory of a Special Kind. Oxford University Press; Oxford: 1998.

Capaldi, E.D. (1996) Conditioned food preferences. In: Capaldi ED, editor. Why We Eat What We Eat: The Psychology of Eating. Washington, DC: American Psychological Association; 53-80. 
Cardinal, R.N., Parkinson, J.A., Hall, J. \& Everitt, B.J. (2002) Emotion and motivation: the role of the amygdala, ventral striatum, and prefrontal cortex. Neurosci. Biobehav. Rev., 26, 321-352.

Chen, K., Yan, J., Li, J., Lv, B. \& Zhao, X. (2011). c-Fos expression in rat brainstem following intake of sucrose or saccharin. Frontiers in Medicine, 5, 294301.

Collins, P., Roberts, A. C., Dias, R., Everitt, B. J., \& Robbins, T. W. (1998).

Perseveration and strategy in a novel spatial self-ordered sequencing task for nonhuman primates: effects of excitotoxic lesions and dopamine depletions of the prefrontal cortex. Journal of Cognitive Neuroscience, 10(3), 332-354

Cooper, S. J. \& Turkish, S. (1989). Effects of naltrexone on food preference and concurrent behavioral responses in food-deprived rats. Pharmacol. Biochem. Behav., 33, 17-20.

di Chiara, G. (2002). Nucleus Accumbens Shell and Core Dopamine: Differential Role in Behavior and Addiction." Behav Brain Res. 137: 75-114.

Dawson, T.M., Gehlert, D.R., McCabe, R.T., Barnett, A. \& Wamsley, J.K. (1986) D-1 dopamine receptors in the rat brain: a quantitative autoradio- graphic analysis. J. Neurosci., 6, 2352-2365.

Day, H.E., Kryskow, E.M., Nyhuis, T.J., Herlihy, L. \& Campeau, S. (2008). "Conditioned Fear Inhibits c-fos mRNA Expression in the Central Extended Amygdala". Brain Res. 1229: 137-46.s

Dela Cruz, J.A.D., Icaza-Cukali, D., Tayabali, H., Sampson, C., Galanoupolos, V., Bamshad, D., Touzani, K., Sclafani, A.\& Bodnar, R. (2012). Roles of Dopamine D1 and D2 receptors in the acquisition and expression of fat-conditioned flavor preferences in rats. Neurobio of Learning and Memory.

Dragone, D. (2009). A rational eating model of binges, diets and obesity. The Journal of Health Economics, 28(4), 799-804.

Dragunow, M. \& Faull, R. (1989). The use of c-fos as a metabolic marker in neuronal pathway tracing. Journal of Neuroscience Methods 29 (3): 261-265. 
Dunnett, S. B., \& Iversen, S. D. (1980). Regulatory impairments following selective kainic acid lesions of the neostriatum. Behavioural Brain Research, 1(6), 497506.

During, M.J., Leone, P., Davis, K.E., Kerr, D. \& Sherwin, R.S. (1995). Glucose modulates rat substantia nigra GABA release in vivo via ATP-sensitive potassium channels. J clin. Invest, 95: 2403-2408.

El-Ghundi, M., O'Dowd, B.F., Erclik, M.\& George, S.R. (2003). Attenuation of sucrose reinforcement in dopamine D1 receptor deficient mice. European Journal of Neuroscience 17: 851-862.

Fantino, M., Hosotte, J. \& Apfelnaum, M. (1986). An opioid antagonist naltrexone, reduces the preference for sucrose in humans. American Journal of Physiology, 251: R91-6.

Ferrario, C.R., Shou, M., Samaha, A.N., Kennedy, R.T. \& Robinson, T.E. (2008). The rate of intravenous cocaine administration alters c-fos mRNA expression and the temporal dynamics of dopamine, but not glutamate, overflow in the striatum. Brain Res., 1209:151-156.

Ferreira, J. G., Tellez, L. A., Ren, X., Yeckel, C. W., \& de Araujo, I. E. (2012). Regulation of fat intake in the absence of flavour signalling. The Journal of Physiology, 590(4), 953-972.

Genn, R.F., Ahn, S. \& Phillips, A.G. (2004). Attenuated dopamine efflux in the rat nucleus accumbens during successive negative contrast. Behavioral Neuroscience, 118: 869-873.

Gilbert, P.E., Campbell, A. \& Kesner, R.P. (2003) The role of the amygdala in conditioned flavor preference. Neurobiol. Learn. Mem., 79, 118-121.

Giraudo, S.Q., Grace, M.K., Welch, C.C., Billington, C.J. \& Levine, A.S. (1993). Naloxone's anorectic effect is dependent upon the relative palatability of food. Pharmacol Biochem Behav, 46: 917-921.

Glass, M.J., Grace, M., Cleary, J.P., Billington, C.J. \& Levine, A.S. (1996). Potency of naltrexone's anorectic effect in rats is dependent on diet preference. American Journal of Physiology-Regulatory, Integrative and Comparative Physiology, 271: R217-R221. 
Greenberg, D., \& Smith, G. P. (1996). The controls of fat intake. Psychosomatic medicine, 58(6), 559-569.

Groenewegen, H.J., Wright, C.I., Beijer, A.V. \&Voorn, P. (1999). Convergence and segregation of ventral striatal inputs and outputs. Ann NY Acad Sci, 877:4963.

Gross, J., Ungethüm, U., Andreeva, N., Heldt, J., Gao, J., Marschhausen, G. \& Andersson, K. (1999). Hypoxia during early developmental period induces long-term changes in the dopamine content and release in a mesencephalic cell culture. Neuroscience, 92(2), 699-704.

Gross, J., Müller, I., Chen, Y., Elizalde, M., Leclere, N., Herrera-Marschitz, M., \& Andersson, K. (2000). Perinatal asphyxia induces region-specific long-term changes in mRNA levels of tyrosine hydroxylase and dopamine D1and D2 receptors in rat brain. Molecular brain research, 79(1), 110-117.

Haber, S. N., Fudge, J. L., \& McFarland, N. R. (2000). Striatonigrostriatal pathways in primates form an ascending spiral from the shell to the dorsolateral striatum. The Journal of neuroscience, 20(6), 2369-2382.

Hajnal, A. \& Lenard, L. (1997) Feeding-related dopamine in the amygdala of freely moving rats. Neuroreport, 8, 2817-2820.

Hajnal, A., Smith, G.P. \& Norgren, R. (2004). Oral sucrose stimulation increases accumbens dopamine in the rat. American Journal of Physiology, 286(1): R31R37.

Hamani, C., McAndrews, M. P., Cohn, M., Oh, M., Zumsteg, D., Shapiro, C. M., Lozano, A. M. (2008). Memory enhancement induced by hypothalamic/fornix deep brain stimulation. Ann Neurol, 63(1), 119-123.

Hamani, C., Stone, S. S., Garten, A., Lozano, A. M., \& Winocur, G. (2011). Memory rescue and enhanced neurogenesis following electrical stimulation of the anterior thalamus in rats treated with corticosterone. Exp Neurol, 232(1), 100-104.

Hamlin, A. S., Blatchford, K. E. \& McNally, G. P. (2006). Renewal of an extinguished instrumental response: Neural correlates and the role of D1 dopamine receptors. Neuroscience, 143, 25-38. 
Harrer, M. I. \& Travers, S. P. (1996). Topographic organization of Fos-like immunoreactivity in the rostral nucleus of the solitary tract evoked by gustatory stimulation with sucrose and quinine. Brain Research, 711, 125137.

Harris, G.C. \& Aston-Jones, G. (2003). Neuropsychopharmacology, 28: 73.

Haslam, D. \& James, P. (2005). Obesity. The Lancet, 366:9492, 1197-1209.

Heffner, T.G., Hartman, J.A. \& Seiden, L.S. (1980) Feeding increases dopamine metabolism in the rat brain. Science, 208, 1168-1170.

Hernandez, G., Hamdani, S., Rajabi, H., Conover, K., Stewart, J., Arvanitogiannis, A. \& Shizgal, P. (2006). Prolonged rewarding stimulation of the rat medial forebrain bundle: neurochemical and behavioral consequences. Behavioral Neuroscience, 120(4): 888-904.

Hernandez, L. \& Hoebel, B.G. (1988). Feeding and hypothalamic stimulation increase dopamine turnover in the accumbens. Physiol Behav, 44:599-606.

Hernandez, L. \& Hoebel, B.G. (1990). Feeding can enhance dopamine turnover in the prefrontal cortex.Brain Research Bulletin. 25:975-979.

Hernandez, P., Andrezewjewski, J.J., Sadeghian, M.E., Panlsepp, J.B. \& Kelly, A.E. (2005). AMPA/kainite, NMDA, and dopamine D1 receptor function in the nucleus accumbens core: A context-limited role in the encoding and consolidation of instrumental memory. Learning and Memory, 12: 285-295.

Hescham, S., Lim, L. W., Jahanshahi, A., Steinbusch, H. W., Prickaerts, J., Blokland, A., \& Temel, Y. (2013a). Deep brain stimulation of the forniceal area enhances memory functions in experimental dementia: the role of stimulation parameters. Brain Stimul, 6(1), 72-77.

Hescham, S., Lim, L., Jahanshahi, A., Blokland, A., \& Temel, Y. (2013b). Deep brain stimulation in dementia-related disorders. Neuroscience \& Biobehavioral Reviews.

Houpt, T.A., Philopena, J.M., Wessel, T.C., Joh, T.H. \& Smith, G.P. (1994). Increased cFos expression in the rat nucleus of the solitary tract after conditioned taste aversion formation. Neurosci. Lett. 172: 1-5. 
Houeto, J.L., Karachi, C., Mallet, L., Pillon, B., Yelnik, J., Mesnage, V., Welter, M.L., Navarro, S., Pelissolo, A., Damier, P., Pidoux, B., Dormont, D., Cornu, P., Agid, Y., 2005. Tourette's syndrome and deep brain stimulation. Journal of Neurology, Neurosurgery \& Psychiatry 76, 992-995.

Howard, P.J. (2006). The Owner's Manual for the Brain: Everyday Applications from Mind-Brain Research, 3rd ed. 2006. Austin: Bard Press.

Hsiao, S., Smith, G.P. (1995). Raclopride reduces sucrose preference in rats. Pharmacol Biochem Behav, 50, 121-125.

Huang, Q., Zhou, D., Chase, K., Gusella, J.F., Aronin, N. \& DiFiglia, M. (1992) Immunohistochemical localization of the D1 dopamine receptor in rat brain reveals its axonal transport, pre- and postsynaptic localization, and prevalence in the basal ganglia, limbic system, and thalamic reticular nucleus. Proc. Natl Acad. Sci. USA, 89, 11988-11992.

Imaizumi M., Takeda, M. \& Fushiki, T. (2000). Effects of oil intake in the conditioned place preference test in mice. Brain Research, 870: 150-156.

Ito, H. \& Seki, M. (1998). Ascending projections from the area postrema and the nucleus of the solitary tract of Suncus murinus: anterograde tracing study using Phaseolus vulgaris leucoagglutinin. Okajimas Folia Anat Jpn 75: 9-31.

Izaki, Y., Hori, K. \& Nomura, M. (1999). Dopamine and acetylcholine elevation on lever-press acquisition in rat prefrontal cortex. Neuroscience Letters. 258:3336.

Jicha, G. A., \& Salamone, J. D. (1991). Vacuous jaw movements and feeding deficits in rats with ventrolateral striatal dopamine depletion: possible relation to parkinsonian symptoms. The Journal of neuroscience, 11(12), 3822-3829.

Kauer, J.A. \& Malenka, R. C (2007). Synaptic plasticity and addiction. Nature Reviews Neuroscience, 8: 844-858.

Kelley AE. (2004). Ventral striatal control of appetitive motivation: role in ingestive behavior and reward-related learning. Neuroscience \& Biobehavioral Reviews, 27(8), 765-776.

Kelley, A.E., Smith-Roe, S.L. \& Holahan, M.R. (1997). Response-reinforcement learning is dependent on N-methyl-D-aspartate receptor activation in the 
nucleus accumbens core. Proceedings National Academy of Sciences (USA) 94: 12174-12179.

Kerfoot, E. C., Agarwal, I., Lee, H. J. \& Holland, P. C. (2007). Control of appetitive and aversive taste-reactivity responses by an auditory conditioned stimulus in a devaluation task: A FOS and behavioral analysis. Learning \& Memory, 14, 581-589.

Kirouac, G.J. \& Ciriello, J. (1997) Cardiovascular afferent inputs to ventral tegmental area. Am J Physiol Regul Integr Comp Physiol 272: R1998- R2003.

Khan NA., \& Besnard. (2009). Review: Oro-sensory perception of dietary lipids: New insights into the fat taste transduction. Biochimica et Biophysica Acta, 1791, 149-155.

Kim, T. S., Misumi, S., Jung, C. G., Masuda, T., Isobe, Y., Furuyama, F., ... \& Hida, H. (2008). Increase in dopaminergic neurons from mouse embryonic stem cellderived neural progenitor/stem cells is mediated by hypoxia inducible factor-1 $\alpha$. Journal of neuroscience research, 86(11), 2353-2362.

Kirouac, G.J. \& Ganguly, P.K. (1995) Topographical organization in the nucleus accumbens of afferents from the basolateral amygdala and efferents to the lateral hypothalamus. Neuroscience 67: 625-630.

Koh, M.T. \& Bernstein, I.L. (2005). Mapping conditioned taste aversion associations using c-Fos reveals a dynamic role for insular cortex. Behav Neurosci, 119(2):388-98.

Koob, G. F., Riley, S. J., Smith, S. C., \& Robbins, T. W. (1978). Effects of 6hydroxydopamine lesions of the nucleus accumbens septi and olfactory tubercle on feeding, locomotor activity, and amphetamine anorexia in the rat. Journal of Comparative and Physiological Psychology, 92(5), 917.

Laxton, A. W., Tang-Wai, D. F., McAndrews, M. P., Zumsteg, D., Wennberg, R., Keren, R., Lozano, A. M. (2010). A phase I trial of deep brain stimulation of memory circuits in Alzheimer's disease. Ann Neurol, 68(4), 521-534

Leonard, S.K., Petitto, J.M., Anderson, C.M., Mooney, D.H., Lachowicz, J.E., Schulz, D.W., Kilts, C.D. \& Mailman, R.B. (2003) D1 dopamine receptors in the amygdala exhibit unique properties. Ann. NY Acad. Sci., 985, 536-539. 
Levine, A.S. \& Billington, C.J. (2004). Opioids as agents of reward-related feeding, a consideration of evidence. Physiology and Behavior, 82: 57-61.

Levine, A.S., Weldon, D.T., Grace, M., Cleary, J.P., Billington, C.J. (1995). Naltrexone blocks that portion of feeding driven by sweet taste in food-restricted rats. American Journal of Physiology, 268: R248-252.

Li, F. \& Tsien, J.Z. (2009). Clinical Implications of Basic Research:Memory and the NMDA receptors. New England Journal of Medicine, 361: 302.

Li, S., Cullen, W. K., Anwyl, R., \& Rowan, M. J. (2003). Dopamine-dependent facilitation of LTP induction in hippocampal CA1 by exposure to spatial novelty. Nat Neurosci, 6(5), 526-531.

Liang, N.C., Hajnal, A., \& Norgren, R. (2006). Sham feeding corn oil increases accumbens dopamine in the rat. American Journal of Physiology, 291: R1236R1239.

Lindvall, O., Björklund, A. \& Divac, I. (2010). Organization of catecholamine neurons projecting to the frontal cortex in the rat. Brain Research. 142:1-24.

Lisman, J. E., \& Grace, A. A. (2005). The hippocampal-VTA loop: controlling the entry of information into long-term memory. Neuron, 46(5), 703-713.

Liu, Y., von Deneen, K.M., Kobeissy, F.H. \& Gold, M.S. (2010). Food addiction and obesity: evidnece from bench to bedside. Journal of Psychoactive Drugs, 42: 133-145.

Ljungberg, T., Apicella, P. \& Schultz, W. (1992). Responses of monkey dopamine neurons during learning of behavioral reactions. J. Neurophysiol, 67:145-163.

Lucas, F. \& Sclafani, A. (1989). Flavor preferences conditioned by intragastric fat infusions in rats. Physiology and Behavior 46(3): 403-412.

Malkusz, D.C., Touzani, K., Sclafani, A. \& Bodnar, R.J. (2008) Expression of fructoseconditioned flavor preferences in rats: role of D1 and D2 dopamine receptors in the medial prefrontal cortex. Soc Neurosci Abstr 2008 (Abstract).

Malkusz, D.C., Banakos, T., Bohn, T., Aviel, M., Malkusz, G., Touzani, K., Sclafani, A. \& Bodnar, R.J. (2009) Differential dopamine D1 and D2 receptor modulation in the medial prefrontal perilimbic and orbitofrontal cortex of expression of 
fructose-conditioned flavor preferences in rats. Soc Neurosci Abstr 2009. (Abstract).

Malkusz, D.C., Banakos, T., Vongwattanakit, T., Mohammed, A., Bohn, T., Mahmud, F., Martinez, S., Saeed, S., Orr, J., Touzani, K., Sclafani, A. \& Bodnar, R.J. (2010). Acquisition of fructose-conditioned flavor preference is blocked by dopamine D1 and D2 receptor antagonists in the medial prefrontal cortex of rats. Soc Neurosci Abstr 2010. (Abstract)

Malkusz, D.C., Banakos, T., Mohammed, A., Malkusz, G., Vongwattanakit, T., Bohn, T., Mahmud, F., Saeed, S., Touzani, K., Sclafani, A. \& Bodnar, R.J. (2012). Activation of dopamine D1 and D2 receptors in the medial prefrontal cortex and of D2 receptors in the amygdala is required for acquisition of fructoseconditioned flavor preferences in rats. Behavioural brain research, 233(2), 500-507.

Mannello, F., Medda, V., \& Tonti, G. A. (2011). Hypoxia and neural stem cells: from invertebrates to brain cancer stem cells. Int. J. Dev. Biol, 55, 569-581.

Mansour, A., Meador-Wooruff, J.H., Bunzow, J.R., Civelli, O., Akil, H. \& Watson, S.J. (1990) Localization of dopamine D2 receptor mRNA and D1 and D2 receptor binding in the rat brain and pituitary: an in situ hybridization-receptor autoradiographic analysis. J. Neurosci., 10, 2587- 2600.

Margolis, E.B., Lock, H., Hjelmstad, G.O. \& Fields, H.L. (2006). The ventral tegmental area revisited: Is there an electrophysiological marker for dopaminergic neurons? J. Physiol. 577(Pt. 3):907-24.

Marks, R. \& Kanarek, R.B. (1981). Modifications of nutrient selection induced by naltrexone in rats. Psychopharmacolo. Ser. Berl. 74: 321-324.

Marks, G.P., Blander, D.S. \& Hoebel, B.G. (1991). A conditioned stimulus decreases extracellular dopamine in the nucleus accumbens after the development of a learned taste aversion. Brain Res, 551: 308-310.

Marks, G.P., Smith, S.E., Rada, P.V., \& Hoebel, B.G. (1994). An appetitively conditioned taste elicits a preferential increase in mesolimbic dopamine release. Pharmacol Biochem Behav, 48: 651-660. 
Martel, P. \& Fantino, M. (1996). Mesolimbic dopaminergic system activity as a function of food reward: a microdialysis study. Pharmacol Biochem Behav, 53(1): 221-226.

McDonald, A.J. (1991). Organization of amygdaloid projections to the prefrontal cortex and associated stritum in the rat. Neurosci, 44:1-14.

McDonald, A. J., Mascagni, F., \& Guo, L. (1996). Projections of the medial and lateral prefrontal cortices to the amygdala: A Phaseolus vulgaris leucoagglutinin study in the rat. Neuroscience, 71, 55-75.

McNab, F., Varrone, A., Farde, L., Jucaite, A., Bystritsky, P., Forssberg, H., \& Klingberg, T. (2009). Changes in cortical dopamine D1 receptor binding associated with cognitive training. Science, 323(5915), 800-802.

Mendoza, J., Angeles-Castellanos, M. \& Escobar, C. (2005). Entrainment by a palatable meal induces food-anticipatory activity and c-Fos expression in reward-related areas of the brain. Neuroscience, 133:293-303.

Miles, D. K., \& Kernie, S. G. (2008). Hypoxic-ischemic brain injury activates early hippocampal stem/progenitor cells to replace vulnerable neuroblasts. Hippocampus, 18(8), 793-806.

Mitra, A., Gosnell, B. A., Schiöth, H. B., Grace, M. K., Klockars, A., Olszewski, P. K. \& Levine, A. S. (2010). Chronic sugar intake dampens feeding-related activity of neurons synthesizing a satiety mediator, oxytocin. Peptides, 31, 1346-1352.

Mitra, A., Lenglos, C., Martin, J., Mbende, N, Gagne, A., Timofeeva, E. (2011). Sucrose modifies c-fos mRNA expression in the brain of rats maintained on feeding schedules. Neurosci, 192: 459-474.

Mizoguchi, K., Shoji, H., Tanaka, Y., Maruyama, W., \& Tabira, T. (2009). Age-related spatial working memory impairment is caused by prefrontal cortical dopaminergic dysfunction in rats. Neuroscience, 162(4), 1192-1201.

Mizushige, T., Inoue, K., \& Fushiki, T. (2007). Why is fat so tasty? Chemical reception of fatty acid on the tongue. Journal of nutritional science and vitaminology, 53(1), 1-4.

Montmayeur JP, Liberles SD, Matsunami H, \& Buck LB. (2001). A candidate taste receptor gene near a sweet taste locus. Nat Neurosci, 4(5), 492-8. 
Morales, P., Huaiquin, P., Bustamante, D., Fiedler, J., \& Herrera-Marschitz, M. (2007). Perinatal asphyxia induces neurogenesis in hippocampus: an organotypic culture study. Neurotoxicity research, 12(1), 81-84.

Morgan, J. I. \& Curran, T. (1991). Stimulus-transcription coupling in the nervous system: Involvement of the inducible proto-oncogenes fos and jun. Ann. Rev. Neurosci. 14: 421-451.

Mungarndee, S.S., Lundy, R.F. \& Norgren, R. (2008). Expression of fos during sham sucrose intake in rats with central gustatory lesions. Am J Physiol Regul Integr Comp Physiol, 295: R751-R763.

Naimi, N., Rivest, S., Racotta, I. \& Richard, D. (1997). Neuronal activation of the hypothalamic magnocellular system in response to oropharyngeal stimuli in the rat. Journal of Neuroendocrinology, 9, 329-340.

Navarro, M., Spray, K.J., Cubero, I., Thiele, T.E. \& Bernstein I.L. (2000). cFos induction during conditioned taste aversion expression varies with aversion strength. Brain Res. 887(2):450-3.

Nelson G., Hoon MA., Chandrashekar J., Zhang Y., Ryba NJP., Zuker CS. (2010). Mammalian Sweet Taste Receptors. Cell, 106, 381-390.

Norgren R. (1995) Gustatory system. In: The Rat Nervous System, edited by Paxinos G. New York: Academic, 751-771.

Norgen, R., Hajnal, A. \& Mungarndee, S.S. (2006). Gustatory reward and the nucleus accumbens. Physiol Behav, 89:531-535.

Oades, R.D. \& Halliday, G.M.(1987). Ventral tegmental (A10) system: neurobiology: Anatomy and connectivity. Brain Res 434: 117-165.

Ong, J., Plane, J. M., Parent, J. M., \& Silverstein, F. S. (2005). Hypoxic-ischemic injury stimulates subventricular zone proliferation and neurogenesis in the neonatal rat. Pediatric research, 58(3), 600-606.

Otsubo, H., Kondoh, T., Shibata, M., Torii, K. \& Ueta, Y. (2011). Induction of Fos expression in the rat forebrain after intragastric administration of monosodium L-glutamate, glucose and $\mathrm{NaCl}$. Neuroscience, 196: 97-103.

Panchision, D. M. (2009). The role of oxygen in regulating neural stem cells in development and disease. Journal of cellular physiology, 220(3), 562-568. 
Park, T.H. \& Carr, K.D. (1998) Neuroanatomical patterns of fos-like immunoreactivity induced by a palatable meal and meal-paired environment in saline- and naltrexone-treated rats. Brain Res 805: 169-180.

Peciña, S., Cagniard, B., Berridge, K.C., Aldridge, J.W. \& Zhuang, X. (2003). Hyperdopaminergic mutant mice have higher "wanting" but not "liking" for sweet rewards. J Neurosci 23: 9395-9402.

Pecoraro, N. \& Dallman, M. F. (2005). c-Fos after incentive shifts: expectancy, incredulity, and recovery. Behavioral Neuroscience, 119, 366-387.

Phillipson, O.T. (1979). Afferent projections to the ventral tegmental area of Tsai and interfascicular nucleus: a horseradish peroxidase study in the rat. J Comp Neurol 187: 117-143.

Pollack, M.E. (2005). Intelligent technology for an aging population: The use of AI to assist elders with cognitive impairment. AI magazine, 26(2): 9.

Pomonis, J. D., Jewett, D. C., Kotz, C. M., Briggs, J. E., Billington, C. J. \& Levine, A. S. (2000). Sucrose consumption increases naloxone-induced c-Fos immunoreactivity in limbic forebrain. American Journal of Physiology.Regulatory, Integrative and Comparative Physiology, 278, R712R719.

Pontieri, F. E., Tanda, G. \& Di Chiara., G. (1995). Intravenous Cocaine, Morphine, and Amphetamine Preferentially Increase Extracellular Dopamine in the "shell" as Compared with the "core" of the Rat Nucleus Accumbens. Proc. Natl. Acad. Sci. USA, 92: 12304-12308.

Qaseem, A., Snow, V., Cross, J.T., Forciea, M.A., Hopkins, R., Shelelle, P., et al., (2008). Current pharmacologic treatment of dementia: clinical practice guidline from the American College of Physicians and the American Academy of Family Physicians. Annals of Internal Medicine, 148(5): 370-378.

Ranaldi, R., Kest, L., Zellner, M.R., Lubelski, D., Muller, J., Cruz, Y. \& Saliba, M. (2011). The effects of VTA NMDA receptor antagonism on reward-related learning and associated c-fos expression in the forebrain. Behav Brain Res, 216(1): 424-432. 
Raynor, H.A. \& Epstein, L.H. (2001). Dietary variety, energy regulation, and obesity. Psychology Bulletin, 127, 325-341.

Ren, K., Blass, E. M., Zhou, Q.-Q. \& Dubner, R. (1997). Sucking and sucose ingestion suppress persistent hyperalgesia and spinal Fos expresssion after forepaw inflammation in infants rats. Proceedings of the National Academy of Sciences of the United States of America, 94, 1471-1475.

Ren, X., Ferreria, J.G., Zhou, L., Asma-Lagnado, S.J., Yeckel, C.W. \& de Araujo, I. E. (2010). Nutrient selection in the absence of taste receptor signaling. Journal of Neuroscience, 30(23): 8012- 8023.

Rockwood, G.A. \& Reid, L.D. (1982). Naloxone modifies sugar-water intake in rats drinking with open gastric fistulas. Physiol Behav, 29: 1175-1178.

Roitman, M.F., Stuber, G.D., Phillips, P.E.M., Wightman, R.M. \& Carelli, R.M. (2004). Dopamine operates as a subsecond modulator of food seeking. Journal of Neuroscience, 24:1265-1271.

Rothemund, Y., Preuschhof, C., Bohner, G., Bauknecht, H. C., Klingebiel, R., Flor, H., \& Klapp, B. F. (2007). Differential activation of the dorsal striatum by highcalorie visual food stimuli in obese individuals. Neuroimage, 37(2), 410.

Romo, R. \& Schultz, W. (1990). Dopamine neurons of the monkey midbrain: contingencies of responses to active touch during self-initiated arm movements. J. Neurophysiol, 63:592-606.

Romsos, D.R., Gosnell, B.A., Morely, J.E. \& Levine, A.S. (1987). Effects of kappa opiate agonists, cholecystokinin and bombesin, on intake of diets varying in carbohydrate-to-fat ratio in rats. J.Nutr. 117: 976-985.

Rotllant, D., Marquez, C., Nadal, R. \& Armario, A. (2010). The brain pattern of c-fos induction by two doses of amphetamine suggests different brain processing pathways and minor contribution of behavioural traits. Neuroscience, 168(3): 691-705.

Sagar, S. M., Sharp, F.R. \& Curran, T. (1988). Expression of c-fos protein in brain: metabolic mapping at the cellular level. Science, 240: 1328-1331. 
Salamone, J. D., Zigmond, M. J., \& Stricker, E. M. (1990). Characterization of the impaired feeding behavior in rats given haloperidol or dopamine-depleting brain lesions. Neuroscience, 39(1), 17-24.

Savica, R., Stead, M., Mack, K.J., Lee, K.H., Klassen, B.T., 2012. Deep Brain Stimulation in Tourette Syndrome: A Description of 3 Patients With Excellent Outcome. Mayo Clinic Proceedings 87, 59-62.

Sawano, S., Takeda, M., Imaizumi, M., Manabe, Y., Kuroda, K. \& Fushiki, T. (2000). Biochemical studies of dopaminergic activation by stimuli of corn oil in the oral cavity in mice. Methods Find Exp Clin Pharmacol 22: 223-227. American Journal of Physiology, 265: R320-R325.

Scheepens, A., Wassink, G., Piersma, M. J., Van de Berg, W. D., \& Blanco, C. E. (2003). A delayed increase in hippocampal proliferation following global asphyxia in the neonatal rat. Developmental brain research, 142(1), 67-76.

Schwarz, J., Burguet, J., Rampin, O., Fromentin, G., Andrey, P., Tome, D., Maurin, Y. \& Darcel, N. (2010). Three-dimensional macronutrient-associated Fos expression patterns in the mouse brainstem. PLoS ONE, 5, e8974.

Sclafani, A. (1995). How food preferences are learned: laboratory animal models. Proc. Nutr. Soc., 54: 419-427.

Sclafani, A. (1999). Macronutrient-conditioned flavor preferences. In: Berthoud H-R, Seeley R, editors. Neural and metabolic control of macronutrient intake. Boca Raton, FL: CRC; 93-107.

Sclafani, A. (2006). Oral, Post-Oral and Genetic Interactions in Sweet Appetite. Physiol Behav. 89(4): 525-530.

Sclafani, A. (2007). Taste Signaling in the Gut. Proceedings Nationall Academy of Science U S A. 104(38): 14887-14888.

Sclafani, A., Aravich, P.F. \& Xenakis, S. (1982). Dopaminergic and endorphinergic mediation of sweet reward. In: Hoebel, B., Novin, D., editors. The Neural basis of feeding and reward. Brunswick, Manine: Haier Institute. 507-515.

Sclafani, A., \& Ackroff, K. (1994). Glucose- and fructose-conditioned flavor preferences in rats: Taste versus postingestive conditioning. Physiology and Behavior, 56: 399-405. 
Sclafani, A., Cardieri, C., Tucker, K., Blusk, D., \& Ackroff, K. (1993). Intragastric glucose but not fructose conditions robust flavor preferences in rats.

Sclafani, A., Fanizza, L.J., \& Azzara, A.V. (1999). Conditioned flavor avoidance, preference and indifference produced by intragastric infusions of galactose, glucose and fructose in rats. Physiology and Behavior, 67: 227-234.

Sesack, S.R., Deutch, A.Y., Roth, R.H. \& Bunney, B.S. (1989) Topographical organization of the efferent projections of the medial prefrontal cortex in the rat: an anterograde tract-tracing study with Phaseolus vulgaris leucoagglutinin. J Comp Neurol 290:213-242.

Shimura, T., Kamada, Y., \& Yamamoto, T. (2002). Ventral tegmental lesions reduce overconsumption of normally preferred taste fluid in rats. Behav Brain Res 134: 123-130.

Small, D.M., Jones-Gotman, M. \& Dagher, A. (2003). Feeding-induced dopamine release in dorsal striatum correlates with meal pleasantness ratings in healthy human volunteers. Neuroimage, 19:1709-1715.

Smith, G.P. (1995). Dopamine and food reward. Progress in psychobiology and physiological psychology, 16: 83.

Smith, G.P. (2004). Accumbens dopamine mediates the rewarding effect of orosensory stimulation by sucrose. Appetite 43: 11-13.

Sotak, B. N., Hnasko, T. S., Robinson, S., Kremer, E. J., \& Palmiter, R. D. (2005). Dysregulation of dopamine signaling in the dorsal striatum inhibits feeding. Brain research, 1061(2), 88-96.

Stice, E., Spoor, S., Bohon, C., \& Small, D. M. (2008). Relation between obesity and blunted striatal response to food is moderated by TaqIA A1 allele. Science, 322(5900), 449-452.

Stone, S. S., Teixeira, C. M., Devito, L. M., Zaslavsky, K., Josselyn, S. A., Lozano, A. M., \& Frankland, P. W. (2011). Stimulation of entorhinal cortex promotes adult neurogenesis and facilitates spatial memory.J Neurosci, 31(38), 1346913484. 
Streefland, C., Farkas, E., Maes, F. W. \& Bohus, B. (1996). C-fos expression in the brainstem after voluntary ingestion of sucrose in the rat. Neurobiology, 4, 85102.

Stuber, G.D., Klanker, M., de Ridder, B., Bowers, M.S., Joosten, R.N., Feenstra, M.G. \& Bonci, A. (2008). Reward-Predictive Cues Enhance Excitatory Synaptic Strength onto Midbrain Dopamine Neurons. Science, 321: 1690-1692.

Studer, L., Csete, M., Lee, S. H., Kabbani, N., Walikonis, J., Wold, B., \& McKay, R. (2000). Enhanced proliferation, survival, and dopaminergic differentiation of CNS precursors in lowered oxygen. The Journal of Neuroscience, 20(19), 7377-7383.

Stunkard, A.J. (1996). Current views on obesity. American Medical Journal, 100: 230235.

Swank, M. W., G. E. Schafe, \& Bernstein, I.L. (1995). c-Fos induction in response to taste stimuli previously paired with amphetamine or $\mathrm{LiCl}$ during taste aversion learning. Brain Res. 673: 251-261.

Swanson, L.W. (1982). The projections of the ventral tegmental area and adjacent regions: A combined fluorescent retrograde tracer and immunofluorescence study in the rat. Brain Research Bulletin. 9:321-353.

Szczypka, M. S., Kwok, K., Brot, M. D., Marck, B. T., Matsumoto, A. M., Donahue, B. A., \& Palmiter, R. D. (2001). Dopamine production in the caudate putamen restores feeding in dopamine-deficient mice. Neuron, 30(3), 819-828.

Taha, S.A., Norsted, E., Lee, L.S., Lang, P. D., Lee, B.S., Woolley, J.D. \& Fields, H.L. (2006). Endogenous opioids encode relative taste preference. European Journal of Neuroscience, 24: 1120-1226.

Temel, Y., Visser-Vandewalle, V., 2006. Targets for deep brain stimulation in Parkinson's disease. Expert Opinion on Therapeutic Targets 10, 355-362.

Thut, G., Schultz, W., Roelcke, U., Nienhusmeier, M., Missimer, J., Maguire, R.P. \& Leenders, K.L. (1997). Activation of the human brain by monetary reward. Neuroreport, 8:1225-1228.

Touzani, K. \& Sclafani, A. (2005) Critical role of amygdala in flavor but not taste preference learning in rats. Eur. J. Neurosci., 22, 1767-1774. 
Touzani, K., Bodnar, RJ, \& Sclafani, A. (2008). Activation of dopamine D1 receptors in the nucleus is critical for the acquisition, but not the expression, of flavor preference conditioned by instragastric glucose in rats. Eur J Neurosci, 27: 1525-1533.

Touzani, K., Bodnar, R.J., \& Sclafani, A. (2009a). Dopamine D1-like receptor antagonism in amygdala impairs the acquisition of glucose-conditioned flavor preferences in rats. European Journal of Neuroscience, 30: 289-298.

Touzani, K., Bodnar, R.J., \& Sclafani, A. (2009b). Lateral hypothalamus dopamine D1like receptors and glucose-conditioned flavored preference in rats. Neurobiology of Learning and Memory, 92: 464-467.

Touzani, K., Bodnar, R.J., \& Sclafani, A. (2010a). Acquisition of glucose-conditioned flavor preference requires the activation of dopamine D1-like receptors within the medial prefrontal cortex in rats. Neurobiology of Learning and Memory, 94: 214-219.

Touzani, K., Bodnar, R.J., \& Sclafani, A. (2010b). Pharmacology of food learning preferences. Pharmacology Biochemistry and Behavior, 97, 55-62.

Ungerstedt, U. (1971). Adipsia and aphagia after 6-hydroxydopamine induced degeneration of the nigro-striatal dopamine system. Acta Physiologica Scandinavica. Supplementum, 367, 95.

VanElzakker, M., Fevurly, R.D., Breindel, T. \& Spencer, R.L. (2008). Environmental novelty is associated with a selective increase in Fos expression in the output elements of the hippocampal formation and the perirhinal cortex. Learn. Mem. 15 (12): 899-908.

Ventura, A.K. \& Menella, J.A. (2011). Innate and learned preferences for sweet taste during childhood. Current Opinion in Nutrition and Metabolic Care, 14(4), 379-384.

Volkow, N.D. \& Wise, R.A. (2005). How can drug addiction help us understand obesity? Nat Neurosci, 8:555-560.

Washington, M. C., Raboin, S. J., Thompson, W., Larsen, C. J. \& Sayegh, A. I. (2010). Exenatide reduces food intake and activates the enteric nervous system of 
the gastrointestinal tract and the dorsal vagal complex of the hindbrain in the rat by a GLP-1 receptor. Brain Research,1344:124-33.

Weatherford, S.C., Greenberg, D., Gibbs, J., \& Smith, G.P. (1990). The potency of D-1 and D-2 receptor antagonists is inversely related to the reward value of sham-fed corn oil and sucrose in rats. Pharmacology Biochemistry and Behavior, 37: 317-323.

Weldon, D.T., O’Hare, E., Cleary, J., Billington, C.J. \& Levine, A. S. (1996). Effect of naloxone on intake of cornstarch, sucrose and polycose diets in restricted and nonrestricted rats. Am J Physiol, 270: R1183-1188.

Wichmann, T., DeLong, M.R., 2006. Deep Brain Stimulation for Neurologic and Neuropsychiatric Disorders. Neuron 52, 197-204.

Williams, G.V. \& Castner, S. A. (2006). Under the curve: critical issues for elucidating D1 receptor function in working memory. Neuroscience, 129: 263-276.

Wise, R.A. (1985). The anhedonia hypothesis: Mark III. Behav Brain Sci, 8:178-186. Wright, C.I., Beijer, A.V. \& Groenewegen, H.J. (1997). Basal amygdaloid complex afferents to the rat nucleus accumbens are compartmentally organized. $J$ Neurosci, 16:1877-1893.

Wright, C.I. \& Groenewegen, H.J. (1997). Patterns of convergence and segregation in the medial nucleus accumbens of the rat: relationships of prefrontal cortical, midline thalamic and basal amygdaloid afferents. J Comp Neurol, 361:383403.

Yamamoto, T. (2003). Brain Mechanisms of Sweetness and Palatability of Sugars. Nutrition Review, 61(5): S5-S9.

Yamamoto, T., Sako, N., Sakai, N. \& Iwafune, A. (1997). Gustatory and visceral inputs to the amygdala of the rat: Conditioned taste aversion and induction of c-fos-like immunoreactivity. Neuroscience Letters, 226, 127-130.

Yamamoto, T., Sake, N. \& Maeda, S. (2000). Effects of taste stimulation on betaendorphin levels on rat cerebrospinal fluid and plasma. Physiol Behav, 69: 345-350. 
Yamamoto, T. \& Sawa, K. (2000a) Comparison of c-fos-like immunoreactivity in the brainstem following intraoral and intragastric infusions of chemical solutions in rats. Brain Research, 866(1-2): 144-151.

Yamamoto, T. \& Sawa. K. (2000b). c-Fos-like immunoreactivity in the brainstem following gastric loads of various chemical solutions in rats. Brain Research, $866,135-143$.

Yang, Z., Covey, M. V., Bitel, C. L., Ni, L., Jonakait, G. M., \& Levison, S. W. (2007). Sustained neocortical neurogenesis after neonatal hypoxic/ischemic injury. Annals of neurology, 61(3), 199-208.

Yang, Z., \& Levison, S. W. (2006). Hypoxia/ischemia expands the regenerative capacity of progenitors in the perinatal subventricular zone. Neuroscience, 139(2), 555-564.

Yoshida, M., Yokoo, H., Mizoguchi, K., Kawahara, H., Tsuda, A., Nishikawa, T., \& Tanaka, M. (1992). Eating and drinking cause increased dopamine release in the nucleus accumbens and ventral tegmental area in the rat: Measurement by in vivo microdialysis, Neuroscience Letters, 139(1): 73-76.

Yoshida R., Niki M., Jyotaki M., Sanematsu K., Shigemura N., Ninomiya Y. (2013). Modulation of sweet responses of taste receptor cells. Seminars in Cell \& Developmental Biology, 24(13), 226-231.

You, Z.B., Wang, B., Zitzman, D., Azari, S., \& Wise, R.A. (2007). Journal of Neuroscience, 27: 10546.

Yu, W.Z., Sclafani, A., Delamater, A.R. \& Bodnar, R.J. (1999). Pharmacology of Flavor Preference Conditioning in Sham-Feeding Rats: Effects of Naltrexone. Pharmacology, Biochemistry, and Behavior, 64(3):_573-584.

Yu, W.Z., Silva, R.M., Sclafani, A., Delamater, A.R., \& Bodnar, R.J. (2000a).Pharmacology of flavor preference conditioning in sham-feeding rats: effects of dopamine receptor antagonists. Pharmacology Biochemistry and Behavior, 65, 635-647.

Yu, W.Z., Silva, R.M., Sclafani, A., Delamater, A.R., \& Bodnar, R.J. (2000b). Role of D1 and D2 dopamine receptors in the acquisition and expression of flavor 
preference conditioning in sham-feeding rats. Pharmacology Biochemistry and Behavior, 67, 537-544.

Zellner MR., Kest K., Ranaldi R. (2009). NMDA receptor antagonism in the ventral tegmental area impairs acquisition of reward-related learning. Behavioural Brain Research, 197, 442-449.

Zhao, X. L., Yan, J. Q., Chen, K., Yang, X. J., Li, J. R. \& Zhang, Y. (2011). [Glutaminergic neurons expressing c-Fos in the brainstem and amygdala participate in signal transmission and integration of sweet taste]. Nan.Fang Yi.Ke.Da.Xue.Xue.Bao., 31, 1138-1142.

Zornberg, G. L., Buka, S. L., \& Tsuang, M. T. (2000). Hypoxic-ischemia-related fetal/neonatal complications and risk of schizophrenia and other nonaffective psychoses: a 19-year longitudinal study. American Journal of Psychiatry, 157(2), 196-202.

Zweifel, L.S., Parker, J.G., Lobb, C.J., Rainwater, A., Wall, V.Z., Fadok, J.P., Darvas, M., Kim, M.J., Mizumori, S.J.Y., Paladini, C.A., Phillips, P.E.M., \& Palmiter, R.D. (2009). Disruption of NMDAR-dependent burst firing by dopamine neurons provides selective assessment of phasic dopamine-dependent behavior. Proceedings of National Academy of Sciences (USA), 106: 7281-7288. 


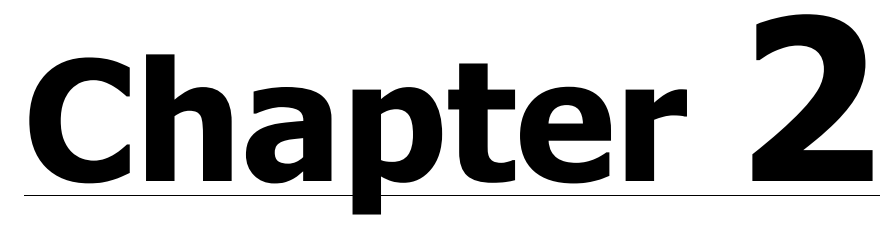

\section{Roles of dopamine D1 and D2}

\section{receptors in the acquisition and}

\section{expression of fat-conditioned flavor}

\section{preferences in rats}

J.A.D. Dela Cruz ${ }^{1,5}$, D. Icaza-Cukali ${ }^{3}$, H. Taybali ${ }^{3}$, C. Sampson ${ }^{3}$, V. Galanopoulos ${ }^{3}$, D. Bamshad ${ }^{3}$, K. Touzani ${ }^{4}$, A. Sclafani ${ }^{1,2,4}$ and R.J. Bodnar ${ }^{1,3}$

${ }^{1}$ Neuropsychology and ${ }^{2}$ Cognition, Brain and Behavior Psychology Doctoral Sub-Programs, The Graduate Center, and Departments of Psychology, ${ }^{3}$ Queens and ${ }^{4}$ Brooklyn Colleges, City University of New York, ${ }^{5}$ School of Mental Health and Neuroscience, Maastricht University 


\begin{abstract}
Sugars and fats elicit innate and learned flavor preferences with the latter mediated by flavor-flavor (orosensory) and flavor-nutrient (post-ingestive) processes. Systemic dopamine (DA) D1 (SCH23390: SCH) and D2 (raclopride: RAC), but not opioid antagonists blocked the acquisition and expression of flavor-flavor preferences conditioned by sugars. In addition, systemic D1, but not D2 or opioid antagonists blocked the acquisition of flavor-nutrient preferences conditioned by intragastric (IG) sugar infusions. Given that DA antagonists reduce fat intake, the present study examined whether systemic D1 or D2 antagonists altered the acquisition and/or expression of conditioned flavor preferences (CFP) produced by pairing one novel flavor (CS+, e.g., cherry) with a 3.5\% corn oil (CO: fat) solution relative to another flavor (CS-, e.g., grape) paired with a $0.9 \%$ CO solution. In an expression study, food-restricted rats were trained to drink either flavored $3.5 \%$ or $0.9 \%$ CO solutions on alternate days. Subsequent two-bottle tests with the CS+ and CS- flavors mixed in $0.9 \%$ CO solutions occurred $0.5 \mathrm{~h}$ after systemic administration of vehicle (VEH), SCH (50-800 nmol/kg) or RAC (50-800 nmol/kg). The rats displayed a robust CS+ preference following VEH treatment (87-88\%) the expression of which was attenuated by treatment with moderate doses of RAC, and to a lesser degree, SCH. In an acquisition study, six groups of rats received VEH, SCH $(25,50,200 \mathrm{nmol} / \mathrm{kg})$ or $\operatorname{RAC}(50,200 \mathrm{nmol} / \mathrm{kg}) 0.5 \mathrm{~h}$ prior to one-bottle training trials with CS+ flavored 3.5\% and CS- flavored 0.9\% (CS-) CO solutions. A seventh Limited VEH group was trained with its training intakes limited to that of the SCH and RAC groups. Subsequent two-bottle tests were conducted with the CS+ and CSflavors presented in $0.9 \%$ CO without injections. Significant and persistent CS+ preferences were observed in VEH (75-82\%), Limited (70-88\%), SCH25 (75-84\%), SCH50 (64-87\%), SCH200 (78-91\%) and RAC200 (74-91\%) groups. In contrast, the group trained with RAC50 displayed significant an initial CS+ preference (76\%) which declined over testing to 61\%. These data indicate limited DA D1 and D2 receptor signaling involvement in the expression and acquisition of a fat-CFP relative to previous robust effects for sugar-CFP.
\end{abstract}




\section{Introduction}

Fats and sugars are both recognized as contributing to the palatability of foods, overeating, and diet-induced obesity. In addition to the inherent hedonic properties associated with these nutrients, learning plays an important role in the preferences for fat- and sugar-rich foods (Sclafani, 1999). Preferences are based in part on learned associations between the various flavor elements in foods, flavorflavor conditioning, and between flavor cues and postingestive consequences, flavor-nutrient conditioning. Animal research on conditioned flavor preferences (CFP) has focused almost exclusively on sugar and sweet taste, and the putative underlying roles of DA and opioid systems mediating its effects (Azzara et al., 2000, 2001; Baker et al., 2003, 2004; Holman, 1975; Hsiao and Smith, 1995; Yu et al., 1999, 2000a, 2000b). In this regard, flavor-flavor conditioning studies using either sucrose in sham-feeding rats (Yu et al., 1999, 2000a, 2000b) or fructose in real-feeding rats (Baker et al., 2003, 2004), identified a critical role for DA D1 and D2, but not opioid, receptor signaling in the acquisition and expression of these preferences. In contrast, flavor-nutrient conditioning studies using intragastric (IG) sucrose infusions (Azzara et al., 2000, 2001), identified a critical role for DA D1, but not D2 or opioid receptor signaling in the acquisition, and to a lesser degree, the expression of this preference. In addition, the acquisition of IG glucose flavor-nutrient preferences was blocked by DA D1 antagonism into the nucleus accumbens (NAc: Touzani et al., 2008), amygdala (AMY: Touzani et al., 2009) and medial prefrontal cortex (mPFC: Touzani et al., 2010a), indicating the existence of a distributed brain network mediating this response (see review: Touzani et al., 2010b). DA D1 and D2 antagonism in the NAc and AMY reduced, but did not eliminate the expression of fructose-conditioned flavor-flavor CFP. The acquisition of a fructose-CFP was completely blocked by DA D1 and D2 antagonism into the mPFC (Malkusz et al., 2010), but DA D1 and D2 antagonism in the NAc or AMY only hastened the extinction of these preferences (Bernal et al., 2008, 2009). In contrast, naltrexone administered into either the shell or core regions of the NAc failed to alter the 
expression of either fructose-conditioned flavor-flavor or IG glucose-conditioned flavor-nutrient CFP (Bernal et al., 2010).

Rodents are attracted to the flavor of fat (e.g., corn oil) and nonnutritive fat substitutes (e.g., mineral oil, sefose) from an early age which may be mediated by taste receptors for fatty acids (Ackroff \& Sclafani, 2009; Passilly-Degrace et al., 2009). In addition, both the postingestive actions and orosensory properties of fat are rewarding and condition a CS+ flavor preference (Sclafani, 1999; Ackroff \& Sclafani, 2009). DA mediation of the rewarding effect of fat flavor is suggested by the findings that corn oil sham-feeding promotes NAc DA release (Liang et al., 2006), and DA D1 and D2 antagonists suppress the sham-feeding response to corn oil and real-feeding of fats in rats (Baker et al., 2001; Davis et al., 2006; Rao et al., 2008; Weatherford et al., 1988; 1990). In inbred mice, strain differences were observed in the ability of the D1 antagonist, SCH23390 to significantly reduce fat intake whereas the D2 antagonist, raclopride, had minimal effects on fat intake (Dym et al., 2010). Furthermore, DA D2, but not D1 receptor antagonism suppressed operant responding for corn oil in mice (Yoneda et al., 2007), whereas D1, but not D2 receptor antagonism attenuated place preference conditioning by corn oil intake (Imaizumi et al., 2000).

The present study examined whether systemic administration of DA D1 and D2 receptor antagonists (SCH23390 and raclopride, respectively) would attenuate flavor preference conditioning by corn oil ingestion. The first experiment revealed that a flavor (e.g., cherry) paired with a higher (3.5\%) concentration of a corn oil (CO: fat) solution conditioned a flavor preference relative to a flavor (e.g., grape) paired with a lower ( $0.9 \%$ ) concentration of a $\mathrm{CO}$ solution. Consequently we used this paradigm to investigate the effects of DA receptor antagonism on corn oil-CFP. To this end, SCH22390 or raclopride, at different doses, was injected systemically either prior to testing (expression) or training (acquisition) sessions. Based on the observed reductions in corn oil sham-feeding produced by both SCH23390 and raclopride (Weatherford et al., 1988; 1990), we expected that both DA D1 and D1 
receptors antagonists would impair both the acquisition and expression of corn oilCFP.

\section{Materials and Methods}

\section{Subjects:}

Male Sprague-Dawley rats (260-300 g, Charles River Laboratories, Wilmington, MA) were housed individually in wire mesh cages and maintained on a 12:12 h light/dark cycle with chow (5001, PMI Nutrition International, Brentwood, MO) and water available ad libitum, except as noted below. The experimental protocols were approved by the Queens College Institutional Animal Care and Use Committee (Protocol 69) certifying that all subjects and procedures are in compliance with the National Institutes of Health Guide for Care and Use of Laboratory Animals.

\section{Test Solutions:}

The training fluids consisted of 3.5\% and 0.9\% corn oil (CO: Sigma Chemical Co., St. Louis, MO) flavored with $0.05 \%$ unsweetened grape or cherry Kool-Aid (General Foods, White Plains, NY) and prepared as suspensions using 0.3\% xanthan gum (Sigma). These concentrations are isocaloric to $8 \%$ and $2 \%$ sugar solutions used in another flavor conditioning study (Sclafani and Ackroff, unpublished). Half of the rats in each group had the cherry flavor added to the 3.5\% CO and the grape flavor added to the $0.9 \% \mathrm{CO}$; the flavors were reversed for the remaining rats. In the two-bottle preference tests, the cherry and grape flavors were each presented in 0.9\% CO. The CO + Kool-Aid + gum mixtures are hereafter referred to as solutions. The flavored training solutions are referred to as the CS+/3.5\% CO and CS- $/ 0.9 \%$ CO. The flavored $0.9 \%$ solutions used in the two bottle tests are referred to as CS+ and CS-. All testing took place in the rat's home cage during the mid-light phase of the light:dark cycle. Two weeks before testing began, the rats were placed on a food restriction schedule that maintained their body weights at $85-90 \%$ of their ad 
libitum level. The rats were initially trained to drink an unflavored $0.2 \%$ saccharin solution from sipper tubes during daily 2-h sessions. The sipper tube was mounted on the front of the cage held by a taut steel spring, and was positioned $3-6 \mathrm{~cm}$ above the cage floor. This training procedure was repeated daily until all rats approached the sipper tubes with short ( $<1 \mathrm{~min}$ ) latency, typically within three days. The limited food rations were given $30 \mathrm{~min}$ after each training session.

\section{Experiment 1:}

Eight naïve male rats were given ten 1-bottle training sessions ( $2 \mathrm{~h} /$ day) with $24 \mathrm{ml}$ of the CS+/3.5\% CO solution presented on odd-numbered days, and 24 $\mathrm{ml}$ of the CS-/0.9\% CO solution presented on even-numbered days. On days 9 and 10 , the rats had access to a second sipper tube containing water. This familiarized the rats to the presence of two sipper tubes used during the choice tests; water intake was negligible in these training trials. Training intakes were limited to 24 $\mathrm{ml} /$ session to minimize the difference between $\mathrm{CS}+/ 3.5 \% \mathrm{CO}$ and $\mathrm{CS}-/ 0.9 \% \mathrm{CO}$ intakes. The left-right position of the CS and water sipper tubes was counterbalanced over the two days. Following training, the rats were given eight two-bottle choice test sessions ( $2 \mathrm{~h} /$ day) with unlimited access to the CS+ vs. CSsolutions. Intakes during training and testing in this and all subsequent experiments were measured by weighing $(0.1 \mathrm{~g})$ the bottles before and after the $2 \mathrm{~h}$ sessions. Because some of the effects could be potentially small, care was also taken to minimize spillage. After initially weighing each bottle, it was gently shaken to insure appropriate flow of the viscous corn oil solutions. Any effluent from the bottle $(\sim$ 0.5-1.0 g) was collected and appropriate spillage adjustments were made to obtain an accurate pre-weight measurement. The sipper tube was occluded when the bottles were placed onto the cage and subsequently removed. The taut steel spring prevented movement of the bottles during the sessions. Visual inspection of the bottles during the study revealed minimal if any spillage because of the viscosity of the solutions. The session length of $2 \mathrm{~h}$ was identical to that previously used in assessing fructose-CFP (Baker et al., 2003, 2004). 


\section{Experiment 2: Expression Procedure:}

Twenty-two naïve male rats received the identical training procedure described above with the following modifications. Following training, all rats were given ten daily two-bottle choice test sessions (2h/day) with the CS+ and CSsolutions. Thirty min prior to the two-bottle test sessions, all rats were given vehicle ( $1 \mathrm{ml} 0.9 \%$ saline/kg body weight, sc) injections for the first two sessions. Two subgroups of 11 rats matched for their CS+ preference under vehicle injections received sc treatment with four doses (50, 200, 400 and $800 \mathrm{nmol} / \mathrm{kg}$ ) of SCH23390 or raclopride prior to two-bottle test sessions; half of the rats were tested with an ascending dose order, and the remaining rats were tested with a descending dose order. The rats were tested in two consecutive daily sessions at each drug dose with the left-right position of the CS+ and CS- solutions counterbalanced across sessions to control for position effects. A second group of eleven rats was treated identically, except that they received sc administration of the D2-like antagonist, raclopride (Sigma) at doses of 50, 200, 400 and $800 \mathrm{nmol} / \mathrm{kg}$. The antagonist dose range was identical to that used in our prior conditioning studies (Azzara et al., 2001; Baker et al., 2003; Yu et al., 2000a, 2000b).

\section{Experiment 3: Acquisition Procedure:}

Seven groups of naïve male rats were matched for their intakes of an unflavored $0.2 \%$ saccharin solution prior to training. The rats were given ten 1 bottle training sessions ( $2 \mathrm{~h} /$ day, $24 \mathrm{ml}$ ) with the $\mathrm{CS}+/ 3.5 \%$ CO solution presented on odd-numbered sessions, and the CS- $/ 0.9 \%$ CO solution presented on evennumbered sessions. The first group ( $\mathrm{n}=8)$ received vehicle ( $1 \mathrm{ml} 0.9 \%$ saline $/ \mathrm{kg}$ body weight, sc) injections 30 min prior to each training session. The second $(n=9)$, third $(n=8)$ and fourth (n=11) groups received daily sc injections of SCH23390 at respective doses of 25,50 and $200 \mathrm{nmol} / \mathrm{kg} 30$ min prior to each training session. The fifth $(n=9)$ and sixth $(n=7)$ groups received daily sc injections of raclopride at respective doses of 50 and $200 \mathrm{nmol} / \mathrm{kg} 30 \mathrm{~min}$ prior to each training session. Because SCH23390 and raclopride reduce corn oil intake, the seventh group (Limited Control) of ten rats received daily sc injections of vehicle 30 min prior to 
each training session, and their intakes were limited to approximate the reduced intakes observed in the drug groups. These doses were similar to those employed in acquisition studies with sucrose in sham-feeding rats and fructose in real-feeding rats (Baker et al., 2003; Yu et al., 2000a, 2000b). Following training, all seven groups were given six daily two-bottle choice sessions ( $2 \mathrm{~h} /$ day) with unlimited access to the CS+ and CS- solutions; no drugs were administered prior to these sessions. The positions of the CS+ and CS- solutions were counterbalanced across sessions. Data analysis:

In the expression study, training intakes were averaged over the five $\mathrm{CS}+/ 3.5 \% \mathrm{CO}$ and five CS-/0.9\% CO sessions and evaluated by t-tests. Intakes during the preference tests were averaged over the two sessions at each dose and evaluated with two-way repeated-measures analyses of variance (ANOVA, CS condition vs. Dose) for the D1 and D2 groups, respectively. Separate ANOVAs evaluated percent CS+ intakes as a function of dose for the two groups.

In the acquisition studies, training intakes were averaged over the five $\mathrm{CS}+/ 3.5 \% \mathrm{CO}$ and CS- $/ 0.9 \% \mathrm{CO}$ sessions and were analyzed with a two-way randomized-blocks ANOVA (CS conditions x Groups). Intakes during the preference tests were averaged over sessions 1-2, 3-4, and 5-6 (referred to as Tests 1, 2, and 3) to control for side position effects. A three-way randomized-blocks ANOVA compared the CS intakes of D1, D2 and control groups (Group x CS x Test). A separate two-way ANOVA evaluated percent CS+ intakes of the groups. When main or interaction effects were found, Bonferroni corrected comparisons $(p<0.05)$ detected significant effects.

\section{$\underline{\text { Results }}$}

Experiment 1. CO-CFP baseline study:

The mean 1-bottle training intake of the CS+/3 .5\% CO solution $(20.4( \pm 1.2) \mathrm{g})$ was significantly $(\mathrm{t}(1,7)=7.77, \mathrm{p}=0.027)$ higher than intake of the CS- $0.9 \%$ CO solution (15.7 ( +1.9$) \mathrm{g})$. In the two-bottle preference tests, overall, rats consumed significantly more CS+ than CS- $(F(1,7)=36.97, \mathrm{p}<0.0001)$, but neither total intake or test pairs $(F(3,21)=1.70, n s)$ nor the pair by condition interaction $(F(3,21)=0.44$, 
ns) achieved significance. CS+ intakes significantly exceeded CS- intakes during all four test pairs, indicating a CO-CFP (Figure 1). CS+ or CS- intake failed to vary across the four test pairs; total intake also failed to vary across pairs. Significant differences in the percent $\mathrm{CS}+/ \mathrm{s}$ intakes failed to be observed $(\mathrm{F}(3,21)=0.71, \mathrm{~ns})$ across the first $(83 \%)$, second (75\%), third (77\%) and fourth (75\%) test pairs, indicating stability of the CO-CFP preferences.

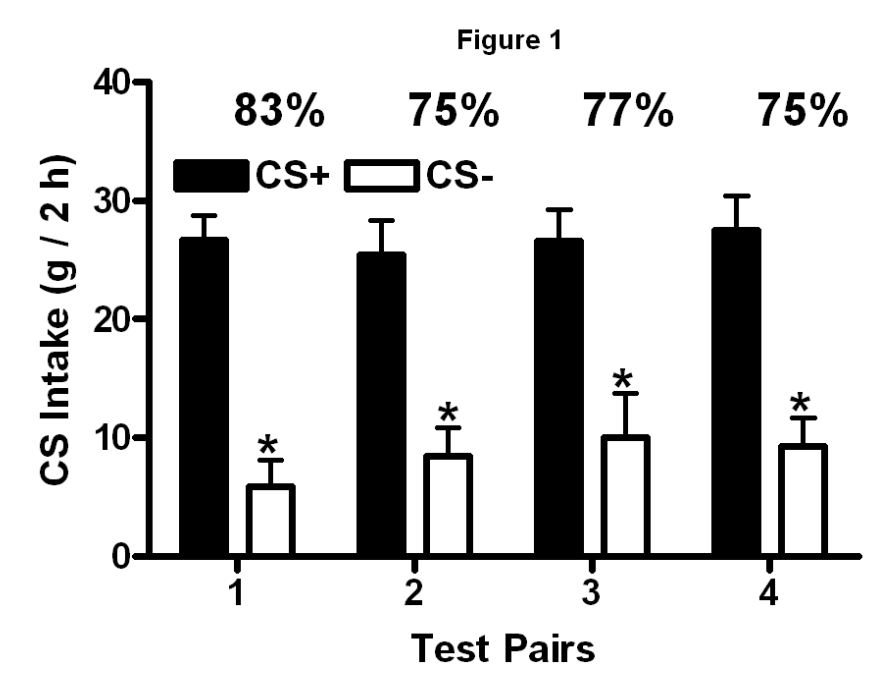

Figure 1. (Baseline Study): Intakes (mean in g, +SEM, 2 h) of CS+/corn oil (co) and CS-/co solutions in four pairs of two-bottle preference tests in untreated animals. Significant differences are denoted between CS+ and CS-/co intake within pairs of tests. The percentages of CS+ intake over total intake are denoted above each pair of values.

Experiment 2A. DA D1 receptor antagonism and expression of CO-CFP.

The mean 1-bottle training intakes of the $\mathrm{CS}+/ 3.5 \% \mathrm{CO}(22.5( \pm 0.7) \mathrm{g})$ and CS-/0.9\% CO (20.1 $( \pm 0.8)$ g) solutions failed to significantly $(\mathrm{t}(1,10)=2.05, \mathrm{p}=0.068)$ differ from each other. In the two-bottle choice tests, overall, rats consumed significantly more CS+ than CS- $(\mathrm{F}(1,10)=162.95, \mathrm{p}<0.0001)$; total intake significantly varied as a function of drug dose $(F(4,40)=67.78, p<0.0001)$, and there was a significant CS $x$ Dose interaction $(F(4,40)=33.96, p<0.0001)$. CS+ intakes significantly exceeded CS- intakes at the 0 (vehicle), 50 and $800 \mathrm{nmol} / \mathrm{kg}$ doses of SCH23390, but not at the 200 or $400 \mathrm{nmol} / \mathrm{kg}$ doses (Figure 2A). Rats consumed significantly less CS+ at all SCH23390 doses as compared to vehicle, whereas CSintakes were significantly reduced following the two highest SCH23390 doses 
(Figure 2A). Correspondingly, total intake significantly declined following the 50 (14.8 (ㅃ1.9) g), $200(5.3( \pm 1.3) \mathrm{g}), 400(3.4( \pm 1.0) \mathrm{g})$ and $800(5.4( \pm 1.6) \mathrm{g}) \mathrm{nmol} / \mathrm{kg}$ SCH23390 doses relative to vehicle $(34.7( \pm 2.0) \mathrm{g})$. Significant differences in the percent $C S+$ intakes were observed $(F(4,40)=3.13, p<0.025)$, and the preference (56\%) at the $200 \mathrm{nmol} / \mathrm{kg} \mathrm{SCH} 23390$ dose was significantly lower than the preference (88\%) following vehicle (Figure 2A). Preferences at the 50 (68\%), 400 (67\%) and $800(72 \%) \mathrm{nmol} / \mathrm{kg} \mathrm{SCH} 23390$ doses were intermediate, but failed to significantly differ from the vehicle test. For these DA D1 receptor antagonist effects, issues related to low intakes might explain the failure to detect a meaningful preference. Thus, the observed 56\% preference following the $200 \mathrm{nmol} / \mathrm{kg}$ SCH23390 dose reflected a difference of $1.2 \mathrm{~g}$ between the CS+ and CS- intakes.

Experiment 2B. DA D2 receptor antagonism and expression of CO-CFP:

The mean 1-bottle training intake of the $\mathrm{CS}+/ 3.5 \% \mathrm{CO}$ solution $(22.7( \pm 0.6)$ g) was significantly $(\mathrm{t}(1,10)=36.23, \mathrm{p}<0.0001)$ higher than intake of the CS- $/ 0.9 \%$ CO solution (18.0 (+0.6) g). In the two-bottle preference tests, overall, rats consumed significantly more CS+ than CS- $(F(1,10)=51.87, \mathrm{p}<0.0001)$, and significant effects were observed for the CS x Dose interaction $(F(4,40)=3.35$, $\mathrm{p}<0.019)$, but not across drug doses $(\mathrm{F}(4,40)=0.51, \mathrm{~ns}) . \mathrm{CS}+$ intakes significantly exceeded CS- intakes at the 0 (vehicle), 50, 400 and $800 \mathrm{nmol} / \mathrm{kg}$ doses of raclopride, but not at the $200 \mathrm{nmol} / \mathrm{kg}$ dose (Figure 2B). Rats consumed significantly less CS+ at the $200 \mathrm{nmol} / \mathrm{kg}$ raclopride dose as compared to vehicle, whereas CS- intakes were significantly increased following the 50, 200 and 400 $\mathrm{nmol} / \mathrm{kg}$ raclopride doses (Figure $2 \mathrm{~B},+$ ). Total intake failed to differ across the 0

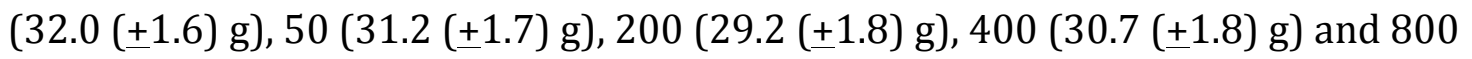
$(29.5( \pm 1.9) \mathrm{g}) \mathrm{nmol} / \mathrm{kg}$ raclopride dose range. Significant differences in the percent $\mathrm{CS}+$ intakes were observed $(\mathrm{F}(4,40)=3.31, \mathrm{p}<0.02)$, and the preference $(61 \%)$ at the $200 \mathrm{nmol} / \mathrm{kg}$ raclopride dose was significantly lower than the preference (87\%) following vehicle (Figure 2B). Preferences at the 50 (70\%), 400 (71\%) and 800 $(85 \%) \mathrm{nmol} / \mathrm{kg}$ raclopride doses were intermediate, but failed to significantly differ from the vehicle test. 
Figure 2
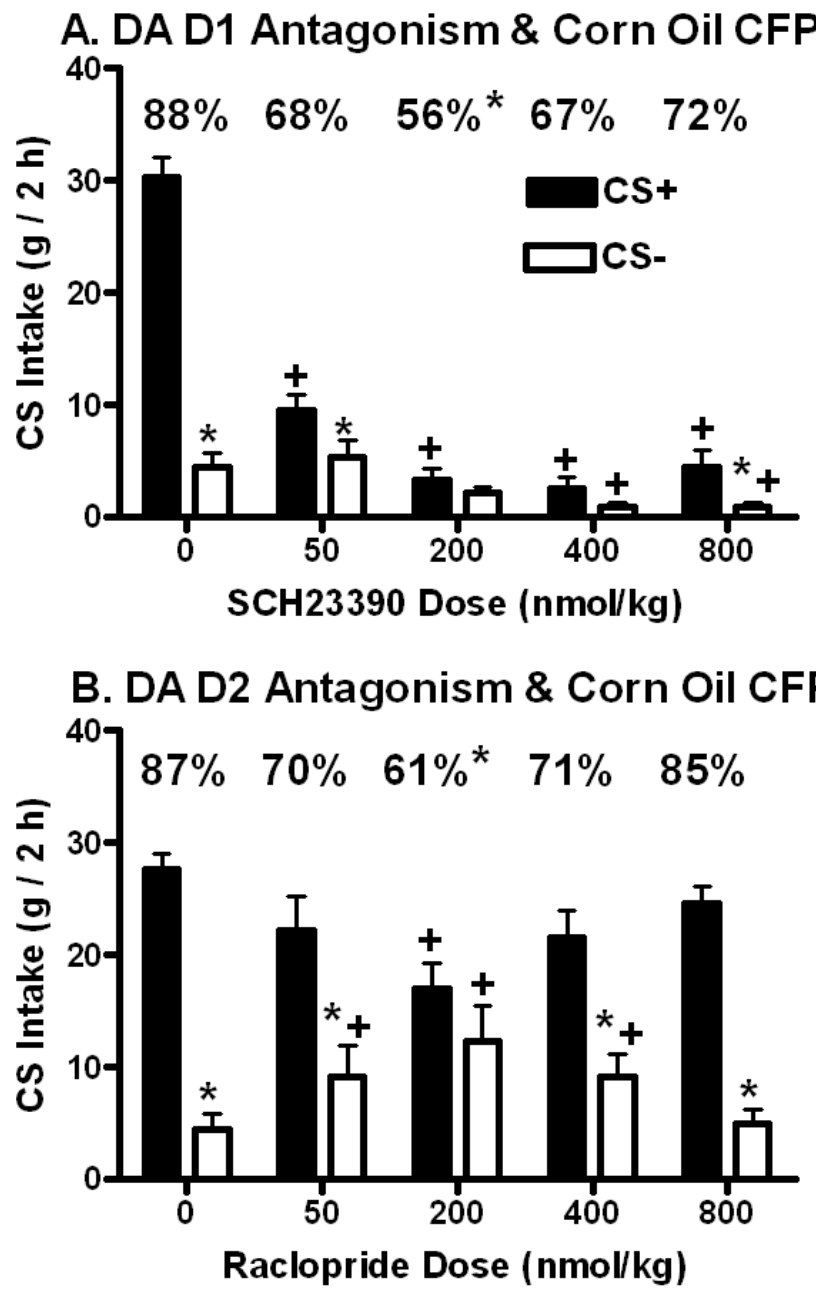

Figure 2. (Expression Study): Intakes (mean in g, +SEM, 2 h) of CS+/corn oil (co) and CS-/co solutions in two-bottle preference tests in animals receiving systemic injections of the DA D1 antagonist, SCH23390 (Panel A) or the DA D2 antagonist, raclopride (Panel B) 30 min prior to testing. Significant differences are denoted between CS+ and CS-/co intake within an injection condition $(*)$ and between CS+ or CS- intake following a drug dose relative to the corresponding vehicle treatment $(+)$. The percentages of CS+ intake over total intake are denoted above each pair of values with significant differences relative to vehicle treatment $\left(^{*}\right)$ noted.

Experiment 3. DA D1 and D2 receptor antagonism and acquisition of CO-CFP:

In the 1-bottle training intakes, overall $\mathrm{CS}+/ 3.5 \% \mathrm{CO}$ intake $(31.4( \pm 2.0) \mathrm{g})$ significantly $(\mathrm{F}(1,55)=86.80, \mathrm{p}<0.0001)$ exceeded CS- $/ 0.9 \%$ CO intake $(19.2( \pm 2.2)$ $\mathrm{gl})$, and significant differences were observed among the seven groups $(F(6,55)=$ $12.50, \mathrm{p}<0.0001)$ and for the group by CS interaction $(F(6,55)=4.20, p<0.002)$.

Total training intakes significantly differed from vehicle-treated animals (36.2 
$( \pm 1.9) \mathrm{g})$ in groups trained in the limited condition $(19.0( \pm 0.5) \mathrm{g}), \mathrm{SCH} 23390$ at 50 $(25.3( \pm 3.3) \mathrm{g})$ and $200(18.1( \pm 1.9) \mathrm{g}) \mathrm{nmol} / \mathrm{kg}$ and raclopride at $200 \mathrm{nmol} / \mathrm{kg}$ $(16.4( \pm 1.0) \mathrm{g})$ conditions. However in turn, these three drug groups failed to differ from the limited group in total training intakes. CS+/3.5\% CO training intake was significantly greater than CS- $/ 0.9 \%$ CO intake in animals receiving vehicle, $\mathrm{SCH} 23390$ at 25, 50 and $200 \mathrm{nmol} / \mathrm{kg}$, and raclopride at $200 \mathrm{nmol} / \mathrm{kg}$, but not in animals receiving raclopride at $50 \mathrm{nmol} / \mathrm{kg}$ or in the limited control group (Figure $3)$. The SCH23390 trained animals did not differ significantly from the vehicle group in their $\mathrm{CS}+/ 3.5 \% \mathrm{CO}$ intakes. Animals trained with a raclopride dose of 200 $\mathrm{nmol} / \mathrm{kg}$ consumed significantly less $\mathrm{CS}+/ 3.5 \% \mathrm{CO}$ relative to vehicle-trained animals, but were similar to the limited control group (Figure 3). Whereas animals trained with SCH23390 at 50 or $200 \mathrm{nmol} / \mathrm{kg}$ or raclopride at $200 \mathrm{nmol} / \mathrm{kg}$ consumed significantly less CS-/0.9\% CO than vehicle-treated animals, they failed to differ from the limited control group (Figure 3).

Figure 3

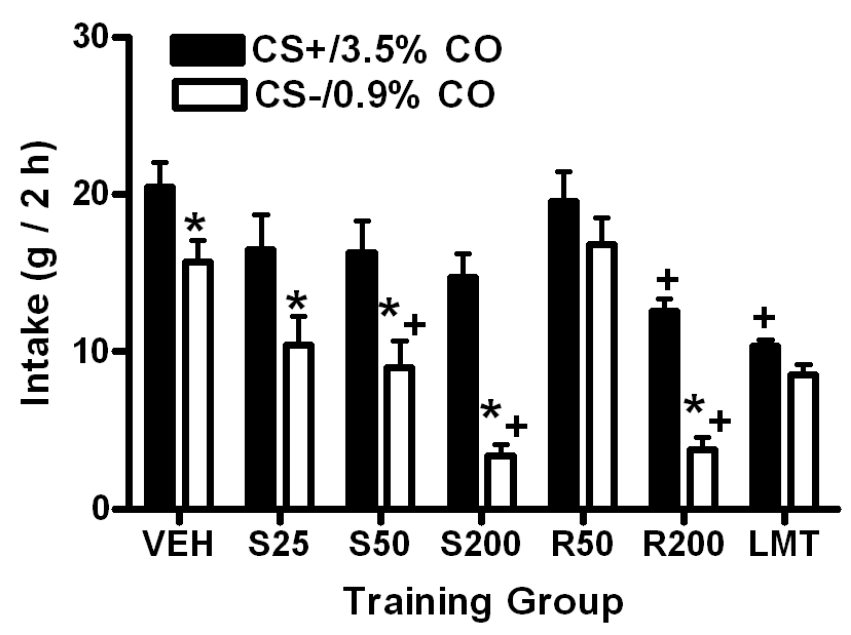

Figure 3. (Acquisition Training Paradigm): Training intakes (mean in g, $+\mathrm{SEM}, 2 \mathrm{~h}$ ) of rats exposed to ten 1-bottle sessions of flavored corn oil solutions of 3.5\% (CS+/3.5\% CO, Days 1, 3, 5, 7, 9) or 0.9\% (CS-/0.9\% CO, Days 2, 4, 6, 8, 10) 30 min following systemic injections of vehicle (VEH), the DA D1 antagonist, SCH23390 at doses of 25 (S25), 50 (S50) or 200 (S200) nmol/kg or the DA D2 antagonist, raclopride at doses of 50 (R50) or 200 (R200) nmol/kg). A seventh group (LMT) received vehicle injections and had CS+/3.5\% CO and CS- $/ 0.9 \%$ CO intakes limited to approximate the intakes of the drug groups. Significant differences are denoted between $\mathrm{CS}+/ 3.5 \% \mathrm{CO}$ and $\mathrm{CS}-/ 0.9 \% \mathrm{CO}$ intake within an injection condition $\left({ }^{*}\right)$ and between $\mathrm{CS}+/ 3.5 \% \mathrm{CO}$ or $\mathrm{CS}-/ 0.9 \% \mathrm{CO}$ intake following a drug dose relative to VEH treatment (+). 
In the two-bottle preference tests, overall, rats consumed significantly more $(F(1,55)=239.18, \mathrm{p}<0.0001) \mathrm{CS}+(26.5 \mathrm{~g})$ than $\mathrm{CS}-(8.3 \mathrm{~g})$ solution, and significant differences were observed among the seven groups $(F(6,55)=5.15, p<0.0003)$ and for the interaction between tests and $\operatorname{CS}(F(2,110)=5.06, p<0.008)$, but not among tests $(F(2,110)=0.52$, ns $)$ or for the interactions between groups and tests $(F(12,110)=0.98, n s)$, groups and $\operatorname{CS}(F(6,55)=0.94, n s)$ or among groups, tests and $\mathrm{CS}(\mathrm{F}(12,110)=1.05, \mathrm{~ns})$. Total CS intake was significantly lower in the group receiving raclopride at a $200 \mathrm{nmol} / \mathrm{kg}$ dose $(23.0( \pm 2.9) \mathrm{g})$ relative to vehicle $(38.6$ $( \pm 2.5) \mathrm{g})$ or limited control $(32.8( \pm 1.5)$ g) groups during testing; all other groups were similar to the control treatments. CS+ intakes significantly exceeded CSintakes across all three test pairs in groups receiving vehicle, SCH23390 at doses of 25, 50 and $200 \mathrm{nmol} / \mathrm{kg}$, raclopride at the $200 \mathrm{nmol} / \mathrm{kg}$ dose, and the limited control condition during training (Figure 4). CS+ intakes significantly exceeded CS- intakes for the first and second, but not third tests in the group receiving raclopride at the $50 \mathrm{nmol} / \mathrm{kg}$ dose during training (Figure 4). Finally, CS+ intake in the group receiving raclopride at the $50 \mathrm{nmol} / \mathrm{kg}$ dose was significantly lower in the first test pair than corresponding vehicle or limited control intake (Figure 4).

Significant differences in the percent CS+ intakes were observed among tests $(F(2,110)=6.37, p<0.002)$, but not among groups $(F(6,55)=0.81, n s)$, or for the interaction between groups and tests $(F(12,110)=1.23$, ns). Thus, none of the groups significantly differed from each other in the magnitude of their corn oil-CFP across the three tests (Figure 4). 


\section{Figure 4}
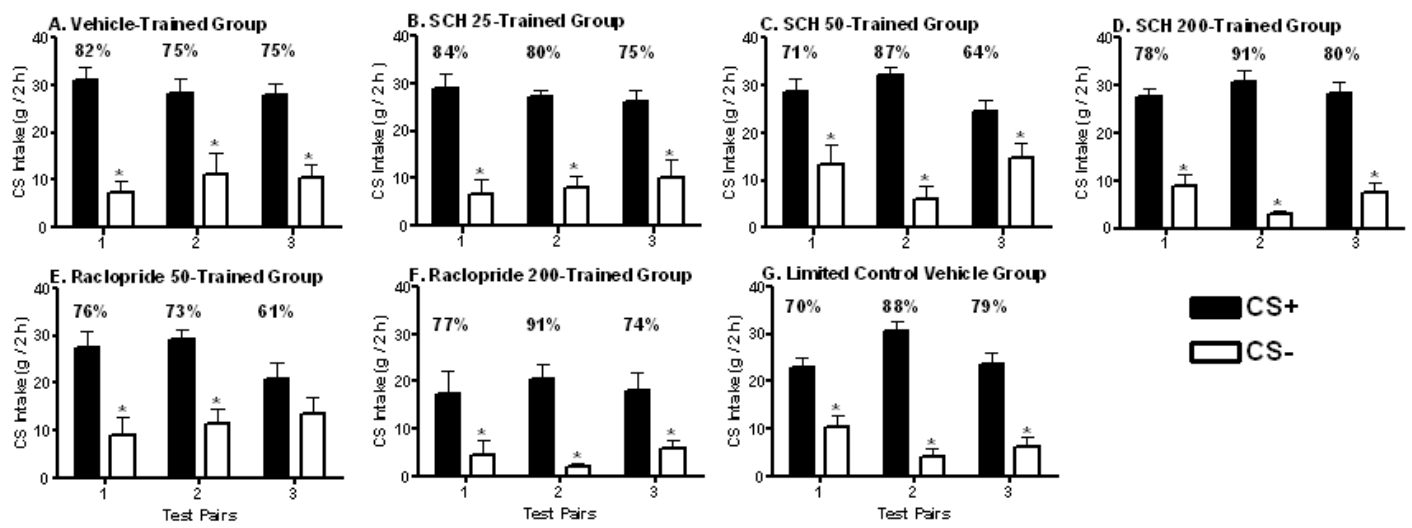

$\mathrm{CS}+$

$\square$ CS-

Figure 4. (Acquisition Study): Intakes (mean in g, +SEM, 2 h) of three pairs of CS+ and CS-/co solutions of two-bottle preference tests. During training, separate groups received vehicle (Panel A), the DA D1 antagonist SCH23390 at doses of 25 (Panel B), 50 (Panel C) or 200 (Panel D) nmol/kg or the DA D2 antagonist, raclopride at doses of 50 (Panel E) or 200 (Panel F) $\mathrm{nmol} / \mathrm{kg}$. An additional group (Limited Control, Panel G) received vehicle injections with CO intake limited to approximate the intakes of the drug groups. Significant differences $\left({ }^{*}\right)$ are denoted between CS+ and CS-/co intake within each test and each group.

\section{Discussion}

The present study was designed to investigate the role of DA signaling in fatCFP. Experiment 1 demonstrated that a CFP could be conditioned in male rats by mixing one novel flavor (CS+) in a higher concentration of corn oil (3.5\%) and a second novel flavor (CS-) in a lower concentration (0.9\%) of corn oil. In subsequent two-bottle tests with each flavor mixed in $0.9 \%$ corn oil solutions, rats displayed significant preferences (75-83\%) for the CS+ flavor that persisted over 8 two-bottle test sessions. These findings extend earlier flavor preference results obtained with rats trained with CS+ flavored corn oil solutions (3.5 or 7.1\%) (Elizalde et al., 1990; Mehiel \& Bolles, 1988). The preferences reported in these earlier studies were measured in only one or two test sessions whereas Experiment 1 revealed a CS+ preference that persisted over at least 8 test sessions. The consistent robustness of the preference over time therefore made this CFP protocol amenable to the investigation of the effects of DA D1 and D2 receptor antagonists on the expression (Experiment 2) and acquisition (Experiment 3) of fat-CFP. This was of interest in view of published studies showing that DA receptor antagonism suppresses the intake of fat emulsions and high-fat diets (Baker et al., 2001; Davis et al., 2006; Rao 
et al., 2008; Weatherford et al., 1988; 1990), and attenuates flavor conditioning by sugar solutions (Azzara et al., 2001; Baker et al., 2003; Yu et al., 2000a, 2000b).

DA D1/D2 Antagonism and Expression of CO-CFP: In the two-bottle tests of Experiment 2, the rats consumed significantly more CS+ than CS- following vehicle treatment but not following SCH23390 at the 200 and $400 \mathrm{nmol} / \mathrm{kg}$ doses. All drug doses significantly reduced CS+ intake compared to vehicle, but at $50 \mathrm{nmol} / \mathrm{kg}$ and, unexpectedly at the $800 \mathrm{nmol} / \mathrm{kg}$ dose, CS+ intake exceeded CS- intake. With respect to the percent CS+ measure, there was a significant reduction at the $200 \mathrm{nmol} / \mathrm{kg}$ dose (to 56\%) but only intermediate reductions at the other SCH23390 doses relative to vehicle (88\%). This dose-limited reduction in expression of corn oil-CFP stands in contrast to SCH23390-induced eliminations of the expression of sucroseCFP in sham-feeding rats (Yu et al., 2000a, 2000b) and fructose-CFP in real-feeding rats (Baker et al., 2003). Moreover, total CS intakes were greatly suppressed by the three highest doses, which makes the interpretation difficult. Thus, it appears that DA D1 receptor antagonism resulted in at best a modest attenuation of the expression of previously learned corn oil-CFP that was accompanied by overall fat intake suppression. Such DA D1 antagonist effects upon the expression of fat-CFP is not unique given that systemic DA D1 antagonism suppressed the expression of a preference conditioned by intragastric sucrose only at doses that were accompanied by strong sugar intake suppression (Azzara et al., 2001). A similar pattern of effects were also observed for the expression of preferences conditioned by intragastric glucose following administration of SCH23390 directly into the nucleus accumbens, amygdala or medial prefrontal cortex (see review: Touzani et al., 2010b).

Treatment with the DA D2 antagonsit raclopride blocked the CS+ preference only at the $200 \mathrm{nmol} / \mathrm{kg}$ dose which also significantly reduced the percent CS+ intake relative to the vehicle (61\% vs. 87\%). In contrast to SCH23390, raclopride did not reduce total CS intakes during the two-bottle tests. Why D2 receptor antagonism decreased CS+ preferences at intermediate doses is not clear. With the ascending/descending dose sequences used here, the tests with the intermediate doses occurred after other drug doses in the non-reinforced sequence. This Ushaped dose-response curve was also observed with the raclopride effect on the 
expression of fructose-CFP (Baker et al., 2003). Further study is needed to evaluate the independent effects of these raclopride doses in separate groups of animals on the expression of fat-CFP.

DA D1/D2 Antagonism and Acquisition of CO-CFP: Our previous studies (Azzara et al., 2001; Baker et al., 2003; Yu et al., 2000a, 2000b) demonstrated that DA D1 and D2 receptor signaling was essential for the acquisition of flavor-flavor conditioning produced by the sweet taste of sugars, whereas only D1 receptor signaling was essential for the acquisition of flavor-nutrient conditioning by IG sugar. In these studies, the $75-90 \%$ preference observed in rats receiving vehicle during training was reduced to $\sim 50 \%$ (i.e., indifference) by the effective antagonist treatments. In the present study, SCH23390 treatment at 25, 50 or $200 \mathrm{nmol} / \mathrm{kg}$ doses during training failed to significantly reduce the $\mathrm{CS}+$ preference during twobottle testing. The drug significantly reduced total CS intake during training, but not the intake of the $\mathrm{CS}+/ 3.5 \% \mathrm{CO}$ solution. This is of particular interest because the $200 \mathrm{nmol} / \mathrm{kg}$ dose used in the prior sugar conditioning studies reduced the intake of the CS+ as well as CS- solutions during training (Baker et al., 2003, Yu et al., 2000b). Hence, it is possible that the failure of SCH23390 to attenuate fat-CFP is due to the failure of the antagonist to reduce CS+ training intakes. Why SCH23390 was effective in reducing $\mathrm{CS}+$ /sugar but not $\mathrm{CS}+$ /fat is not clear. It is possible that the $3.5 \%$ corn oil solution (which has both orosensory and post-oral positive consequences) induces more DA release in the reward areas involved in flavor preference learning than does a $8 \%$ fructose solution in real-fed rats or a $16 \%$ sucrose solution in sham-fed rats. Further experiments are needed to address this issue. With raclopride, the only significant drug acquisition effect was that the 50 $\mathrm{nmol} / \mathrm{kg}$ dose resulted in a hastening of extinction of the CS+ preference. Corn oilCFP has both orosensory and viscerosensory positive reinforcing signals and the failure of raclopride to affect the acquisition of this preference was probably due to the postingestive consequences of corn oil. We previously reported that raclopride has no effect on flavor preference learning induced by IG sugar infusions (Azzara et al., 2001). Thus, compared to DA antagonist effects observed in sugar-conditioned animals (Azzara et al., 2001; Baker et al., 2003; Yu et al., 2000a, 2000b), DA D1 and 
D2 antagonism is much less effective in attenuating the acquisition of fatconditioned flavor preferences. In contrast to these findings, other studies suggest that DA receptor antagonism is more effective in blocking the conditioning of place preferences by fat than sugar, but procedural and species (rat vs. mouse) differences may account for the discrepant results (Ågmo et al ., 1995; Imaizumi et al., 2000). Additional studies are needed to clarify the effects of DA receptor antagonism on fat vs. sucrose conditioned preferences and to differentiate between the flavor vs. postingestive reinforcing actions of these nutrients. This can be accomplished by comparing DA drug effects on flavor conditioning by IG nutrient infusions as compared to sham-fed nutrient intakes.

Fat and sugar intakes and preferences may employ dfferent central processes: Sugars (e.g., sucrose) and fats (e.g., corn oil) are potent stimulators of intake under conditions of brief access (e.g., Ackerman et al., 1992). Intakes of sugars and fats are correspondingly dependent upon DA processes such that DA antagonists suppress the intake of sweet (Geary and Smith, 1985; Muscat and Willner, 1989; Xenakis and Sclafani, 1981) and fat (Baker et al., 2001; Davis et al., 2006; Rao et al., 2008; Weatherford et al., 1988; 1990) solutions. Similarly, both sucrose (and other sugars) and corn oil each elicit potent and persistent conditioned flavor preferences. The present data indicate that one aspect of the underlying pharmacology, DA signaling, mediating the two preferences differ. Liang and coworkers (Liang et al., 2012a, 2012b, 2012c) recently investigated the premise that sucrose intake and corn oil intake are processed through different central pathways. Their initial study (Liang et al., 2012a) demonstrated that rats sustaining parabrachial nucleus lesions licked significantly less sucrose than controls under free access conditions, but that lesion and control groups consumed comparable volumes of corn oil. In operant tests, rats with parabrachial lesions failed to respond at all for sucrose, but only responded modestly for corn oil. They concluded that parabrachial lesions dramatically reduce the apparent hedonic value of sucrose regardless of condition, but that any parabrachial influence on oil reward only occurred by increasing contingent motivation. A second study (Liang et al., 2012b) demonstrated that whereas parabrachial nucleus lesions blocked the acquisition of 
a learned aversion to sweet and corn oil tastes in sham-feeding rats, the same lesions disrupted sucrose-conditioned taste aversions, but not corn oil-conditioned taste aversions in real-feeding rats. A third study (Liang et al., 2012c) used an anticipatory contrast effect (ACE) in which an animal responds less than normally to a first stimulus when it is followed shortly by a second, more preferred solution for both sucrose and corn oil solutions. Parabrachial lesions were capable of blocking ACE development to either sucrose or corn oil. Thus, collectively, it appears that intake of corn oil and sucrose are differentially dependent upon parabrachial processes. Hence the present results lend further support for this emerging premise that sweet and fat intake are processed through different central pathways, and extend this difference to preferences conditioned by fat and sugar.

\section{Acknowledgements}

This research was supported by National Institute of Diabetes and Digestive and Kidney Diseases Grant DK071761. We thank Heather Henry, Matthew Yagudayev, Salomon Kandov, Ester Illyayeva and Gregory Fitzgerald for technical support. 


\section{References}

Ackerman, S.H., Albert, M., Shindledecker, R.D., Gayle, C., \& Smith, G.P. (1992). Intake of different concentrations of sucrose and corn oil in preweanling rats. American Journal of Physiology, 262, R624-R627.

Ackroff, K., \& Sclafani, A. (2009). Oral and post-oral determinants of dietary fat appetite. In Montmayeur,J.-P. \& le Coutre,J. (eds), Fat Detection: Taste, Texture, and Post Ingestive Effects. Taylor \& Francis, Boca Raton, pp. 295-321.

Ågmo, A., Galvan, A., \& Talamantes, B. (1995). Reward and reinforcement produced by drinking sucrose: Two processes that may depend on different neurotransmitters. Pharmacology Biochemistry and Behavior, 52, 403-414.

Azzara, A.V., Bodnar, R.J., Delamater, A.R., \& Sclafani, A. (2000). Naltrexone fails to block the acquisition or expression of a flavor preference conditioned by intragastric carbohydrate infusions. Pharmacology Biochemistry and Behavior, 67, 545-557.

Azzara, A.V., Bodnar, R.J., Delamater, A.R., \& Sclafani, A. (2001). D-1 but not D-2 dopamine receptor antagonism blocks the acquisition of a flavor preference conditioned by intragastric carbohydrate infusions. Pharmacology Biochemistry and Behavior, 68, 709-720.

Baker, R.W., Osman, J., \& Bodnar, R.J. (2001). Differential actions of dopamine receptor antagonism in rats upon food intake elicited by mercaptoacetate or exposure to a palatable high-fat diet. Pharmacology Biochemistry and Behavior, 69, 201-208.

Baker, R.W., Shah, M.J., Sclafani, A., \& Bodnar, R.J. (2003). Dopamine D1 and D2 antagonists reduce the acquisition and expression of flavor-preferences conditioned by fructose in rats. Pharmacology Biochemistry and Behavior, $75,55-65$.

Baker, R.W., Li, Y., Lee, M.G., Sclafani, A., \& Bodnar, R.J. (2004). Naltrexone does not prevent acquisition or expression of flavor preferences conditioned by fructose in rats. Pharmacology Biochemistry and Behavior, 78, 239-246. 
Bernal, S., Dostova, I., Kest, A., Abayev, Y., Kandova, E., Touzani, K., Sclafani, A., \& Bodnar, R.J. (2008). Role of dopamine D1 and D2 receptors in the nucleus accumbens shell on the acquisition and expression of fructose-conditioned flavor-flavor preferences in rats. Behavioural Brain Research, 190, 59-66. Bernal, S., Miner, P., Abayev, Y., Kandova, E., Gerges, M., Touzani, K., Sclafani, A., \& Bodnar, R.J. (2009). Role of amygdala dopamine D1 and D2 receptors in the acquisition and expression of fructose-conditioned flavor preferences in rats. Behavioural Brain Research, 205, 183-190.

Bernal, S., Touzani, K., Gerges, M., Abayev, Y., Sclafani, A., \& Bodnar, R.J. (2010). Opioid receptor antagonism in the nucleus accumberns fails to block the expression of sugar-conditioned flavor preferences in rats. Pharmacology Biochemistry and Behavior, 95, 56-62.

Birch, L.L., \& Fisher, J.O. (1998). Development of eating behaviors among children and adolescents. Pediatrics, 101, 539-549.

Davis, J.F., McQuade, J.A., Drazen, D.L., Woods, S.C., Seeley, R.J., \& Benoit, S.C. (2006). Role for dopamine-3 receptor in the hyperphagia of an unanticipated high-fat meal in rats. Pharmacology Biochemistry and Behavior, 85, 190-197.

Dym, C.T., Bae, V., Kraft, T., Yakubov, Y., Winn, A., Sclafani, A., \& Bodnar, R.J. (2010). Genetic variance contributes to dopamine and opioid receptor antagonistinduced inhibition of Intralipid (Fat) intake in inbred and outbred mouse strains. Brain Research, 1316, 51-61.

Elizalde, G., \& Sclafani, A. (1990). Fat appetite in rats: Flavor preferences conditioned by nutritive and non-nutritive oil emulsions. Appetite, 15, 189197.

Geary, N., \& Smith, G.P. (1985). Pimozide decreases the positive reinforcing effect of sham fed sucrose in the rat. Pharmacology Biochemistry and Behavior, 22, 787-790.

Imaizumi, M., Takeda, M., \& Fushiki, T. (2000). Effects of oil intake in the conditioned place preference test in mice. Brain Research, 870, 150-156. 
Kelley, A.E., Baskshi, V.P., Haber, S.N., Steiniger, T.L., Will, M.J., \& Zhang, M. (2002). Opioid modulation of taste hedonics within the ventral striatum. Physiology and Behavior, 73, 389-395.

Levine, A.S, Kotz, C,M., \& Gosnell, B.A. (2003). Sugars and fats: the neurobiology of preference. American Society of Nutritional Science, 133, 831S-834S.

Liang, N.C., Freet, C.S., Grigson, P.S., \& Norgren R. (2012a). Pontine and thalamic influences on fluid rewards: I. Operant responding for sucrose and corn oil. Physiology and Behavior 105, 576-588.

Liang, N.C., Grigson, P.S., \& Norgren R. (2012b). Pontine and thalamic influences on fluid rewards: II. Sucrose and corn oil conditioned aversions. Physiology and Behavior 105, 589-594.

Liang, N.C., Hajnal, A., \& Norgren, R. (2006). Sham feeding corn oil increases accumbens dopamine in the rat. American Journal of Physiology, 291, R1236R1239.

Liang, N.C., Norgren R., \& Grigson, P.S. (2012c). Pontine and thalamic influences on fluid rewards: III. Anticipatory contrast for sucrose and corn oil. Physiology and Behavior 105, 595-606.

Mehiel, R., \& Bolles, R.C. (1988). Learned flavor preferences based on calories are independent of initial hedonic value. Animal Learning and Behavior, 16, 383387.

Malkusz, D.C., Banakos, T., Vongwattanakit, T., Mohammed, A., Bohn, T., Mahmud, F., Martinez, S., Saeed, S., Orr, J., Touzani, K., Sclafani, A., \& Bodnar, R.J. (2010). Acquisition of fructose-conditioned flavor preference is blocked by dopamine D1 and D2 receptor antagonists in the medial prefrontal cortex in rats. Society for Neuroscience Abstracts, 36.

Muscat, R., \& Willner, P. (1989). Effects of selective dopamine receptor antagonists on sucrose consumption and preference. Psychopharmacology 99, 98-102. Passilly-Degrace, P., Gaillard, D., \& Besnard, P. (2009). Orosensory perception of dietary lipids in mammals. Results Problems in Cell Differentiation, 47, 221238. 
Rao, R.E., Wojnicki, F.H., Coupland, J., Ghosh, S., \& Corwin, R.L. (2008). Baclofen, raclopride and naltrexone differentially reduce solid fat emulsion intake under limited access conditions. Pharmacology Biochemistry and Behavior, 89, 581-590.

Sclafani, A. (1999). Macronutrient-conditioned flavor preferences. In Berthoud, H.-R. \& Seeley,R. (eds), Neural and metabolic control of macronutrient intake. CRC Press, Boca Raton, FL, pp. 93-107.

Sclafani, A., \& Ackroff, K. (1994). Glucose- and fructose-conditioned flavor preferences in rats: Taste versus postingestive conditioning. Physiology and Behavior, 56, 399-405.

Sclafani, A., Cardieri, C., Tucker, K., Blusk, D., \& Ackroff, K. (1993). Intragastric glucose but not fructose conditions robust flavor preferences in rats. American Journal of Physiology, 265, R320-R325.

Sclafani, A., Fanizza, L.J., \& Azzara, A.V. (1999). Conditioned flavor avoidance, preference and indifference produced by intragastric infusions of galactose, glucose and fructose in rats. Physiology and Behavior, 67, 227-234.

Touzani, K., Bodnar, R.J., \& Sclafani, A. (2008). Activation of dopamine D1 receptors in nucleus accumbens is critical for the acquisition, but not the expression, of glucose-conditioned flavor preference in rats. European Journal of Neuroscience, 27, 1525-1533.

Touzani, K., Bodnar, R.J., \& Sclafani, A. (2009a). Dopamine D1-like receptor antagonism in amygdala impairs the acquisition of glucose-conditioned flavor preferences in rats. European Journal of Neuroscience, 30, 289-298.

Touzani, K., Bodnar, R.J., \& Sclafani, A. (2009b). A role of the lateral hypothalamic dopamine D1 receptors in intragastric glucose-conditioned flavor preferences in rats. Neurobiology of Learning and Memory, 92, 464-467.

Touzani, K., Bodnar, R.J., \& Sclafani, A. (2010a). Acquisition of glucose-conditioned flavor preference requires the activation of dopamine D1-like receptors within the medial prefrontal cortex in rats. Neurobiology of Learning and Memory, 94, 214-219. 
Touzani, K., Bodnar, R.J., \& Sclafani, A. (2010b). Pharmacology of food learning preferences. Pharmacology Biochemistry and Behavior, 97, 55-62.

Wang, D.J., Volkow, V.D., Logan, J., Pappas, N.R., Wong, C.T., Zhu, W., Netusil, N., \& Fowler, J.S. (2001). Brain dopamine and obesity. The Lancet, 357, 354-357.

Weatherford, S.C., Greenberg, D., Gibbs, J., \& Smith, G.P. (1990). The potency of D-1 and D-2 receptor antagonists is inversely related to the reward value of sham-fed corn oil and sucrose in rats. Pharmacology Biochemistry and Behavior, 37, 317-323.

Weatherford, S.C., Smith, G.P., \& Melville, L.D. (1988). D-1 and D-2 receptor antagonists decrease corn oil sham feeding in rats. Physiology and Behavior, 44, 569-572.

Xenakis, S., \& Sclafani, A. (1981). The effects of pimozide on the consumption of a palatable saccharin - glucose solution in the rat. Pharmacology Biochemistry and Behavior, 15, 435-442.

Yoneda, T., Taka, Y., Okamura, M., Mizushige, T., Matsumura, S., Manabe, Y., Tsuzuki, S., Inoue, K., \& Fushiki, T. (2007). Reinforcing effect for corn oil stimulus was concentration dependent in an operant task in mice. Life Sciences, 81, 15851592.

Yu, W.-Z., Sclafani, A., Delamater, A.R., \& Bodnar, R.J. (1999). Pharmacology of flavor preference conditioning in sham-feeding rats: effects of naltrexone. Pharmacology Biochemistry and Behavior, 64, 573-584.

Yu, W.-Z., Silva, R.M., Sclafani, A., Delamater, A.R., \& Bodnar, R.J. (2000a). Pharmacology of flavor preference conditioning in sham-feeding rats: effects of dopamine receptor antagonists. Pharmacology Biochemistry and Behavior, 65, 635-647.

Yu, W.-Z., Silva, R.M., Sclafani, A., Delamater, A.R., \& Bodnar, R.J. (2000b). Role of D1 and D2 dopamine receptors in the acquisition and expression of flavor preference conditioning in sham-feeding rats. Pharmacology Biochemistry and Behavior, 67, 537-544. 


\section{Chapter 3}

\section{Roles of Opioid and NMDA receptors}

\section{in the acquisition and expression of fat-conditioned flavor preferences}

\section{in rats}

J.A.D. Dela Cruz ${ }^{1,5}$, V.S. Bae ${ }^{3}$, D. Icaza-Cukali³, C. Sampson ${ }^{3}$, D. Bamshad ${ }^{3}$, A. Samra $^{3}$, S. Singh ${ }^{3}$, N. Khalifa ${ }^{3}$, K. Touzani ${ }^{4}$, A. Sclafani ${ }^{1,2,4}$ and R.J. Bodnar ${ }^{1,3}$

${ }^{1}$ Neuropsychology and ${ }^{2}$ Cognition, Brain and Behavior Psychology Doctoral Sub-Programs, The Graduate Center, and Departments of Psychology, ${ }^{3}$ Queens and ${ }^{4}$ Brooklyn Colleges, City University of New York, ${ }^{5}$ School of Mental Health and Neuroscience, Maastricht University 


\begin{abstract}
Animals learn to prefer flavors associated with the intake of dietary fats such as corn oil (CO) solutions. We previously reported that fat-conditioned flavor preferences was relatively unaffected by systemic treatment with dopamine D1 and D2 antagonists. The present study examined whether systemic opioid (naltrexone, NTX) or NMDA (MK801) receptor antagonists altered the acquisition and/or expression of CO-CFP. The CFP was produced by training rats to drink one novel flavor (CS+, e.g., cherry) mixed in a $3.5 \% \mathrm{CO}$ solution and another flavor (CS-, e.g., grape) in a $0.9 \% \mathrm{CO}$ solution. In expression studies, food-restricted rats drank these solutions in one-bottle sessions ( $2 \mathrm{~h}$ ) over 10 days. Subsequent two-bottle tests with the CS+ and CS- flavors mixed in $0.9 \%$ CO solutions occurred $0.5 \mathrm{~h}$ after systemic administration of vehicle (VEH), NTX (0.1-5 $\mathrm{mg} / \mathrm{kg}$ ) or MK-801 (50-200 ug/kg). Rats displayed a robust CS+ preference following VEH treatment (85-88\%), which was significantly though moderately attenuated by NTX (6970\%). The lower doses of MK-801 slightly reduced the CS+ preference; the high dose blocked the CS+ preference (49\%) but also markedly reduced overall CS intake. In separate acquisition studies, rats received VEH or NTX $(0.1,0.5,1 \mathrm{mg} / \mathrm{kg})$ or MK-801 (100 ug/kg) $0.5 \mathrm{~h}$ prior to 1-bottle training trials with $\mathrm{CS}+/ 3.5 \% \mathrm{CO}$ and $\mathrm{CS}-/ \mathrm{0.9 \%} \mathrm{CO}$ training solutions. Additional Limited VEH groups were trained with intakes limited to that of the NTX and MK-801 groups. Subsequent two-bottle CS+ vs. CS- tests were conducted without injections. Significant and persistent CS+ preferences were observed in VEH (77-84\%) and Limited VEH (88\%) groups. NTX treatment during training failed to block the acquisition of CO-CFP although the magnitude of the CS+ preference was reduced by $0.5(70 \%)$ and $1.0(72 \%) \mathrm{mg} / \mathrm{kg}$ doses relative to the Limited VEH treatment (88\%). In contrast, MK-801 (100 ug/kg) treatment during training blocked the acquisition of the CO-CFP. These data suggest a critical role for NMDA, but not opioid receptor signaling in the acquisition of a fat conditioned flavor preferences, and at best limited involvement of NMDA and opioid receptors in the expression of a previously learned preference.
\end{abstract}




\section{Introduction}

The overconsumption of sugars and fats appear to be triggered by both their inherent hedonic properties as well as their respective abilities to trigger learned preferences (Dela Cruz et al., 2012; Sclafani, 1999; Sclafani \& Ackroff, 2012).

Preferences can be elicited on the basis of learned associations either between flavor cues and the orosensory aspects of sugars or fats (flavor-flavor conditioning), or between flavor cues and their postingestive consequences (flavor-nutrient conditioning). The brain dopamine (DA) system has been identified as a neurochemical substrate of conditioned flavor preferences (CFP) elicited by sugars (Azzara et al.,2001; Baker et al., 2003; Hsiao and Smith, 1995; Yu et al., 2000a, 2000b). Flavor-flavor conditioning studies used rats that were either sham-fed sucrose (Yu et al., 2000a, 2000b) or real-fed fructose (Baker et al., 2003), and identified a critical role for DA D1 and D2 receptor signaling in the acquisition and expression of sweet-taste CFP. In contrast, flavor-nutrient conditioning studies involving intragastric (IG) sucrose infusions (Azzara et al., 2000), identified a critical role for DA D1, but not D2 receptor signaling in the acquisition, and to a lesser degree, the expression of post-oral sugarCFP. Brain sites involved in DA modulation of sugar-CFP included the nucleus accumbens NAc: Bernal et al., 2008; Touzani et al., 2008), amygdala (AMY: Bernal et al., 2009; Touzani et al., 2009) and medial prefrontal cortex (mPFC: Malkusz et al., 2012; Touzani et al., 2010). NMDA receptor signaling was also implicated in the acquisition, but not the expression of fructose-CFP given the ability of the non-competitive NMDA antagonist, MK-801 to block this response (Golden and Houpt, 2007). In contrast, systemic or central administration of the general opioid antagonist, naltrexone (NTX) had little or no effect in the flavor preferences conditioned by the sweet taste or post-oral actions of sugar (Azzara et al., 2000; Baker et al., 2004; Bernal et al., 2010; Yu et al., 1999).

Rodents are also attracted to the flavor of fat (e.g., corn oil, $\mathrm{CO}$ ) from an early age, which may be mediated in part by taste receptors for fatty acids and trigeminal "mouth feel" receptors (Ackroff \& Sclafani, 2009). In addition, both the postingestive actions and orosensory properties of fat are rewarding and condition a CS+ flavor 
preference (Sclafani, 1999; Ackroff \& Sclafani, 2009). However, limited DA D1 and D2 antagonist involvement was observed for the acquisition and expression of CO-CFP (Dela Cruz et al., 2012). The present study expanded the study of potential neurochemical substrates mediating CO-CFP by examining the opioid and NMDA signaling systems.

The opioid system has been implicated in the mediation of fat appetite and intake. In particular, there are many reports of opioid receptor antagonists suppressing fat intake in rats and mice (Cole et al., 1995; Dym et al., 2010; Glass et al., 2000; Higgs and Cooper, 1998; Islam and Bodnar, 1990; Marks-Kaufman et al., 1985; Naleid et al., 2007; Sahr et al., 2008). In addition, administration of the mu-selective opioid agonist, DAMGO into the NAC stimulated high-fat intake in rats (Zhang et al., 1998). Place preferences conditioned by oral intake of corn oil or a high-fat snack food are also attenuated by naltrexone administration (Jarosz et al., 2006; Shide and Blass, 1991). However, the role of opioid receptors in fat-conditioned flavor preferences has not been investigated.

The involvement of the NMDA receptor in fat conditioning is also unkown. As noted above, MK-801 blocks fructose-CFP (Golden \& Houpt, 2007). A role for glutamate and its receptors in learning has been well-characterized, and has been specifically linked to reward components of food-related learning. Thus, glutamate antagonism within the AMY and NAc impaired appetitive instrumental learning (Kelley et al., 1997; Hernandez et al., 2005). Glutamate antagonism within the AMY also impaired both the acquisition and expression of conditioned taste avoidance (Yasoshima et al., 2000). Within the VTA, glutamate antagonists impaired cue-sucrose learning and DA release in the NAc elicited by the sucrose-predictive cue (Stuber et al., 2008; Zellner et al., 2009; Zweifel et al., 2009). Finally, glutamate also interacted with DA within the NAc, AMY and mPFC to modulate reward-related appetitive learning (Smith-Roe \& Kelley, 2000; Baldwin et al., 2002; Andrzejewski et al., 2004).

Therefore, the present study examined whether systemic administration of opioid (NTX) and NMDA (MK-801) receptor antagonists would attenuate flavor 
preference conditioning by CO ingestion. To this end, different doses of NTX or MK-801 were injected systemically either prior to testing (expression experiments) or training (acquisition experiments) sessions. Based on the observed reductions in fat intake produced by NTX (Cole et al., 2005; Dym et al., 2010; Glass et al., 2000; Higgs and Cooper, 1998; Islam and Bodnar, 1990; Jarosz et al., 2006; Marks-Kaufman et al., 1985; Naleid et al., 2007; Sahr et al., 2008; Zhang et al., 1998), we expected that opioid receptor antagonism would impair both the acquisition and expression of CO-CFP. Based upon the ability of MK-801 to block the acquisition, but not the expression of fructose-CFP (Golden and Houpt, 2007) and its other effects on food learning (Hernandez et al., 2005; Kelley et al., 1997; Stuber et al., 2008; Yasoshima et al., 2000; Zellner et al., 2009; Zweifel et al., 2009), we expected that NMDA receptor antagonism would impair the acquisition, but not the expression of CO-CFP.

\section{Materials and Methods}

Subjects:

Male Sprague-Dawley rats (260-300 g, Charles River Laboratories, Wilmington, MA) were housed individually in wire mesh cages and maintained on a 12:12 $\mathrm{h}$ light/dark cycle with chow (5001, PMI Nutrition International, Brentwood, MO) and water available ad libitum, except as noted below. The experimental protocols were approved by the Queens College Institutional Animal Care and Use Committee certifying that all subjects and procedures are in compliance with the National Institutes of Health Guide for Care and Use of Laboratory Animals.

\section{Test Solutions:}

The training fluids consisted of $3.5 \%$ and $0.9 \%$ corn oil (CO: Sigma Chemical Co., St. Louis, MO) flavored with $0.05 \%$ unsweetened grape or cherry Kool-Aid (General Foods, White Plains, NY) and prepared as suspensions using $0.3 \%$ xanthan gum (Sigma) as used in our prior study (Dela Cruz et al., 2012). Half of the rats in each group had the cherry flavor added to the $3.5 \% \mathrm{CO}$ and the grape flavor added to the $0.9 \% \mathrm{CO}$; the 
flavors were reversed for the remaining rats. In the two-bottle preference tests, the cherry and grape flavors were each presented in $0.9 \% \mathrm{CO}$. The $\mathrm{CO}+\mathrm{Kool}-\mathrm{Aid}+$ gum mixtures are hereafter referred to as solutions. The flavored training solutions are referred to as the $\mathrm{CS}+/ 3.5 \% \mathrm{CO}$ and $\mathrm{CS}-/ 0.9 \% \mathrm{CO}$. The flavored $0.9 \%$ solutions used in the two bottle tests are referred to as CS+ and CS-. All testing took place in the rat's home cage during the mid-light phase of the light:dark cycle. In the two weeks prior to testing, the rats were placed on a food restriction schedule that maintained their body weights at $85-90 \%$ of their ad libitum level. The rats were initially adapted to drink an unflavored $0.2 \%$ saccharin solution from sipper tubes during daily $2-\mathrm{h}$ sessions. The sipper tube was mounted on the front of the cage held by a taut steel spring, and was positioned 3-6 $\mathrm{cm}$ above the cage floor. This training procedure was repeated daily until all rats approached the sipper tubes with short ( $<1 \mathrm{~min}$ ) latency, typically within three days. The limited food rations were given 30 min after each training session.

\section{Experiment 1: NTX and CO-CFP:Expression Study:}

Eleven male rats were given ten 1-bottle training sessions ( $2 \mathrm{~h} /$ day) with $24 \mathrm{ml}$ of the $\mathrm{CS}+/ 3.5 \% \mathrm{CO}$ solution presented on odd-numbered days, and $24 \mathrm{ml}$ of the $\mathrm{CS}-/ 0.9 \%$ CO solution presented on even-numbered days. On days 9 and 10, the rats had access to a second sipper tube containing water. This familiarized the rats to the presence of two sipper tubes used during the choice tests; water intake was negligible in these training trials. The left-right position of the CS and water sipper tubes was counterbalanced over the two days. Following training, all rats were given ten daily two-bottle choice test sessions ( $2 \mathrm{~h} /$ day) with the CS+ and CS- solutions. Thirty min prior to the first two sessions, all rats were given vehicle injections ( $1 \mathrm{ml} 0.9 \%$ saline $/ \mathrm{kg}$ body weight, $\mathrm{sc}$ ). Then the rats received sc treatment with four doses $(0.1,0.5,1$ and $5 \mathrm{mg} / \mathrm{kg})$ of NTX (Sigma Chemical Co., St. Louis, MO) prior to the remaining sessions; half of the rats were tested with an ascending dose order, and the remaining rats were tested with a descending dose order. The rats were tested in two consecutive daily sessions at each drug dose with the left-right position of the CS+ and CS- solutions counterbalanced 
across sessions to control for side effects. The antagonist dose range was identical to that used in our prior conditioning studies with sugars (Azzara et al., 2000; Baker et al., 2004; Yu et al., 1999). Care was taken to minimize spillage due to the fact that some of the effects could be potentially small. After initially weighing each bottle, it was gently shaken to insure appropriate flow of the viscous corn oil solutions. Any effluent from the bottle ( 0.5-1.0 g) was collected and appropriate spillage adjustments were made to obtain an accurate pre-weight measurement. The sipper tube was occluded when the bottles were placed onto the cage and subsequently removed. The taut steel spring prevented movement of the bottles during the sessions. Visual inspection of the bottles during the study revealed minimal if any spillage because of the viscosity of the solutions. The session length of $2 \mathrm{~h}$ was identical to that previously used in assessing fructose-CFP (Baker et al., 2003, 2004), and CO-CFP (Dela Cruz et al., 2012).

\section{Experiment 2: NTX and CO-CFP: Acquisition Study:}

Five groups of naïve male rats were matched for their intakes of an unflavored $0.2 \%$ saccharin solution prior to training. The rats were given ten 1-bottle training sessions ( $2 \mathrm{~h} /$ day, $24 \mathrm{ml}$ ) with the $\mathrm{CS}+/ 3.5 \% \mathrm{CO}$ solution presented on odd-numbered sessions, and the CS-/0.9\% CO solution presented on even-numbered sessions. The first group (VEH, $\mathrm{n}=8$ ) received vehicle ( $1 \mathrm{ml} 0.9 \%$ saline/ $\mathrm{kg}$ body weight, $\mathrm{sc}$ ) injections 30 min prior to each training session. The second (NTX0.1, n=8), third (NTX0.5, n=10) and fourth (NTX1.0, $n=10$ ) groups received daily sc injections of NTX at respective doses of $0.1,0.5$ and $1 \mathrm{mg} / \mathrm{kg} 30 \mathrm{~min}$ prior to each training session. Because NTX reduced overall CS intakes, the fifth group (Limited VEH) of 17 rats received daily sc injections of vehicle 30 min prior to each training session, and their intakes were limited to approximate the reduced intakes observed in the different drug dose groups. These doses were similar to those employed in acquisition studies with sugars (Baker et al., 2004; Yu et al., 1999). Following training, all five groups were given six daily two-bottle choice sessions (2 h/day) with unlimited access to the CS+ and CS- solutions; no drugs were administered 
prior to these sessions. The positions of the CS+ and CS- solutions were counterbalanced across sessions.

Experiment 3: MK-801 and CO-CFP: Expression Study:

Fourteen naïve male rats received identical expression training and testing procedures described above except that vehicle (i.p. injections) and three doses (50, 100, $200 \mathrm{ug} / \mathrm{kg}$, i.p.) of MK-801 (Sigma) was administered prior to two-bottle test sessions. This dose range bracketed the $100 \mathrm{ug} / \mathrm{kg}$ MK-801 dose used in a previous study evaluating expression of fructose-CFP (Golden and Houpt, 2007).

Experiment 4: MK-801 and CO-CFP: Acquisition Study:

Three groups of naïve male rats received identical acquisition training and testing procedures described above except that vehicle (VEH, n=8, i.p.), MK-801 (MK100, n=12, $100 \mathrm{ug} / \mathrm{kg}$, i.p.) and a Limited VEH ( $n=10)$ condition were administered during the ten one-bottle training sessions. Because MK-801 reduced overall CS intakes, this last group was necessary to approximate the reduced intake. The MK-801 dose was identical to that employed in an acquisition study with fructose (Golden and Houpt, 2007).

Data analysis:

In the expression studies, training intakes were averaged over the five $\mathrm{CS}+/ 3.5 \%$ $\mathrm{CO}$ and five $\mathrm{CS}-/ 0.9 \% \mathrm{CO}$ sessions and evaluated by t-tests. Intakes during the preference tests were averaged over the two sessions at each dose and evaluated with two-way repeated-measures analyses of variance (ANOVA, CS condition vs. Dose) for the NTX and MK-801 groups, respectively. Separate ANOVAs evaluated percent CS+ intakes and total intakes as a function of dose for the two groups.

In the two acquisition studies, training intakes were averaged over the five $\mathrm{CS}+/ 3.5 \% \mathrm{CO}$ and CS-/0.9\% CO sessions and were analyzed separately in a two-way randomized-blocks ANOVA (CS x Groups). Intakes during the preference tests were averaged over sessions 1-2, 3-4, and 5-6 (referred to as Tests 1, 2, and 3) to control for side position effects. A three-way randomized-blocks ANOVA compared the CS intakes 
of the NTX and control groups and of the MK-801 and control groups (Group $x$ CS $x$ Test). Separate two-way ANOVAs evaluated percent CS+ intakes and total intakes of the groups. When main or interaction effects were found, Bonferroni corrected comparisons $(p<0.05)$ detected significant effects.

\section{Results}

Experiment 1. Opioid receptor antagonism and expression of CO-CFP:

The mean 1-bottle training intakes of the CS+/3.5\% CO $(22.0+0.4 \mathrm{~g} / 2 \mathrm{~h})$ was significantly greater $(t(10)=6.12, p<0.0001)$ than the CS-/0.9\% CO $(16.0+1.2 \mathrm{~g} / 2 \mathrm{~h})$. In the two-bottle choice tests, overall, rats consumed significantly more CS+ than CS$(F(1,50)=120.98, p<0.0001)$; total intake significantly varied as a function of drug dose $(F(4,50)=4.68, p<0.028)$, and there was a significant CS $\times$ Dose interaction $(F(4,50)=4.03$, $\mathrm{p}<0.0065)$. CS+ intakes significantly exceeded CS- intakes following vehicle and all NTX doses (Figure 1). Rats consumed significantly less CS+ at all NTX doses compared to vehicle, whereas CS- intakes failed to be significantly affected (Figure 1). Total intake $(\mathrm{g} / 2 \mathrm{~h})$ significantly declined following the $0.1(28.7+2.4 \mathrm{~g}), 0.5(24.7 \pm 1.5 \mathrm{~g}), 1(24.0$ $\pm 2.4 \mathrm{~g})$ and $5(26.0+1.9 \mathrm{~g}) \mathrm{mg} / \mathrm{kg}$ NTX doses relative to vehicle $(33.6+1.3 \mathrm{~g})$. Significant differences in the percent CS+ intakes were observed $(F(4,40)=3.35, p<0.019)$, and the preferences at the $0.1(69 \%)$ and $1(71 \%) \mathrm{mg} / \mathrm{kg}$ NTX doses were significantly lower than the preference (88\%) following vehicle (Figure 1). Preferences at the $0.5(77 \%)$ and 5 (74\%) $\mathrm{mg} / \mathrm{kg}$ NTX doses were intermediate, but failed to significantly differ from the vehicle test. 


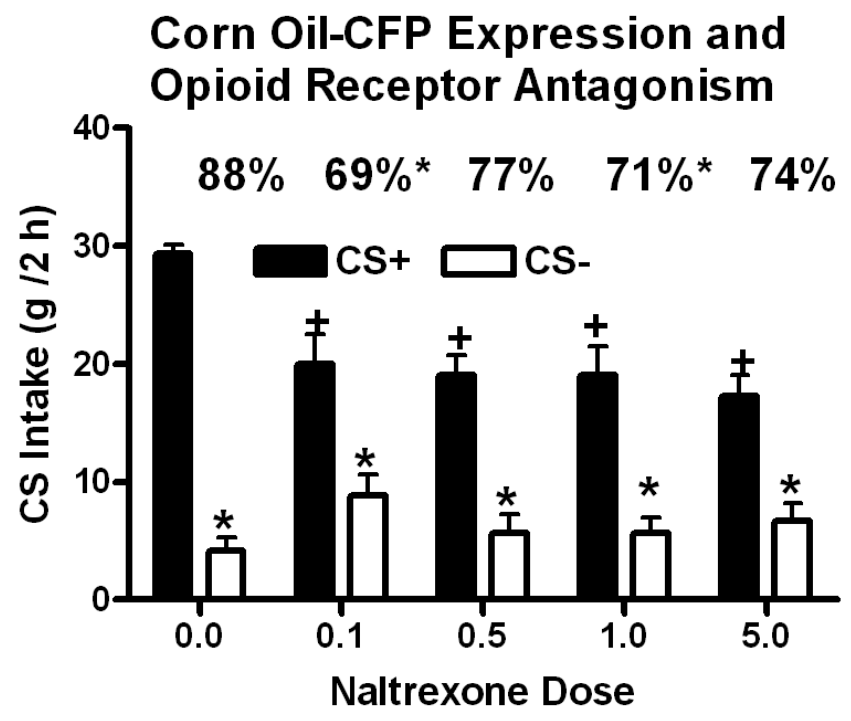

Figure 1. (Expression Study): Intakes (mean in $\mathrm{g} / 2 \mathrm{~h}+\mathrm{SEM}, 2 \mathrm{~h}$ ) of CS+ and CS- solutions in two-bottle preference tests in animals receiving systemic injections of the opioid antagonist, naltrexone $30 \mathrm{~min}$ prior to testing. Significant differences are denoted between CS+ and CS- intake within an injection condition $\left(^{*}\right)$ and between CS+ intake following a drug dose relative to vehicle treatment $(+)$. The percentages of CS+ intake over total intake are denoted above each pair of values with significant differences relative to vehicle treatment $\left({ }^{*}\right)$ noted.

Experiment 2. Opioid receptor antagonism and acquisition of CO-CFP:

During 1-bottle training, overall $\mathrm{CS}+3.5 \% \mathrm{CO}$ intake $(14.8 \mathrm{~g} / 2 \mathrm{~h})$ significantly $(F(1,64)=113.11, p<0.0001)$ exceeded CS-/0.9\% CO intake $(8.8 \mathrm{~g} / 2 \mathrm{~h})$, and significant differences were observed among the five groups $(F(4,64)=30.11, p<0.0001)$ but not for the Group x CS interaction $(F(4,64)=0.97)$. Total training intakes $(2 \mathrm{~h} / \mathrm{g})$ were significantly greater in the VEH group (18.1 g) than the Limited VEH (10.3 g), NTX0.5 (10.3 g) and NTX1.0 (5.7 g) groups; intakes of the later three groups did not differ. $\mathrm{CS}+/ 3.5 \% \mathrm{CO}$ training intake was significantly greater than $\mathrm{CS}-/ 0.9 \%$ CO intake in all groups (Figure $2 \mathrm{~A}$ ). CS+/3.5\% CO and CS-/0.9\% intakes of the NTX0.5, NTX1.0 and Limited VEH groups were significantly lower than the corresponding VEH animals. However, $\mathrm{CS}+/ 3.5 \% \mathrm{CO}$ and CS-/0.9\% CO intakes of the NTX0.5 and NTX1.0 groups failed to differ from those of the Limited VEH group except for lower intake in the CS- $0.9 \%$ CO NTX1.0 group (Figure 2A).

In the two-bottle preference tests, overall, rats consumed significantly more $(F(1,128)=752.95, p<0.0001) C S+(25.0 \mathrm{~g} / 2 \mathrm{~h})$ than $C S-(6.6 \mathrm{~g} / 2 \mathrm{~h})$ solution, and significant differences were observed among the five groups $(F(4,64)=17.69, p<0.0001)$, 
among tests $(F(2,32)=23.95, p<0.0001)$ and for the interactions between Groups $x$ Tests $(F(8,128)=16.15, p<0.001)$, Groups $x \operatorname{CS}(F(4,64)=11.49, p<0.0001)$, and among Groups, Tests and $C S(F(8,128)=4.31, p<0.0001)$. Total CS intake was significantly lower in the NTX1.0 group (18.0 g) relative to VEH (38.6 g) or Limited VEH (32.0 g) groups during testing; the NTX0.1 and NTX0.5 groups were similar to the control groups. CS+ intakes significantly exceeded CS- intakes across all three tests in VEH (Figure 2B), Limited VEH (Figure 2F), NTX0.1 (Figure 2C) and NTX0.5 groups (Figure 2D). In the NTX1.0 group, CS+ intakes significantly exceeded CS- intakes in Tests 2 and 3, but not in Test 1 (Figure 2E). The NTX1.0 group displayed significantly less CS+ intake in all three tests relative to the VEH and Limited VEH groups. The NTXO.5 group displayed significantly less CS+ intake in Test 1 than the VEH and Limited VEH groups, and significantly more CS- intake in Tests 2 and 3 than the Limited VEH group (Figure 2).

Significant differences in the percent $\mathrm{CS}+$ intakes were observed among groups $(F(4,64)=$ $8.49, \mathrm{p}<0.0001)$, but not among tests $(\mathrm{F}(2,32)=1.30)$, or for the interaction between Groups $x$ Tests $(F(8,128)=1.76)$. An analysis of the percent $C S+$ intakes averaged over the three tests revealed that the percent CS+ intakes of the NTX0.5 $(70 \%$,$) and NTX1.0$ (72\%) groups were significantly lower that of the Limited VEH group (88\%) but not the VEH (77\%) group. The NTX0.1 (89\%), VEH and Limited VEH groups did not significantly differ in their CS+ preferences. 


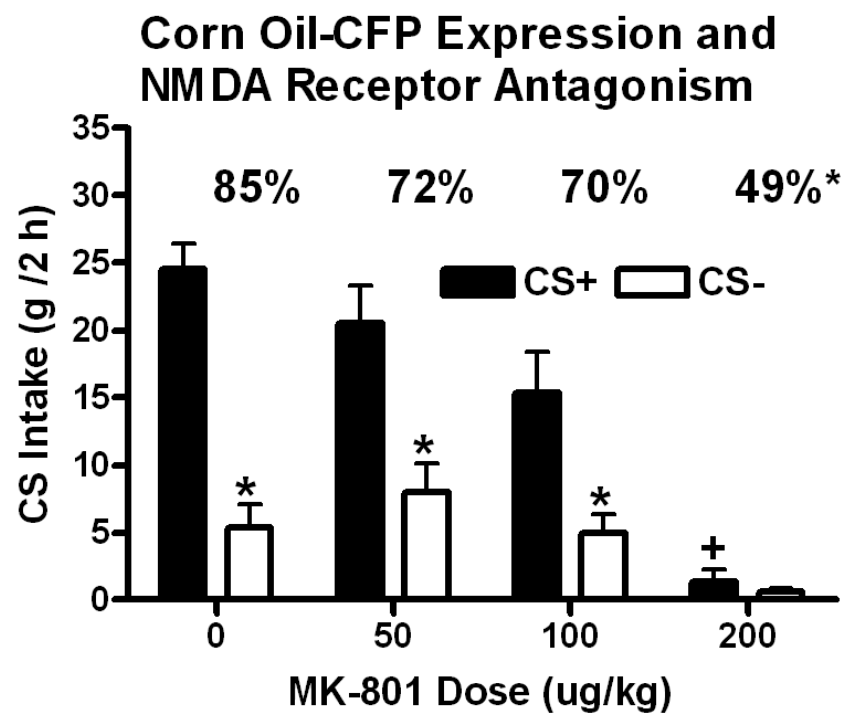

Figure 2. (Acquisition Study): Training intakes (mean in $\mathrm{g} / 2 \mathrm{~h}+\mathrm{SEM}$ ) of rats exposed to ten 1-bottle sessions of flavored $3.5 \%$ corn oil solutions (CS+/3.5\% CO, Days 1, 3, 5, 7, 9) or $0.9 \%$ corn oil solutions (CS-/0.9\% CO, Days 2, 4, 6, 8, 10) 30 min following systemic injections of vehicle (Veh), the opioid antagonist, naltrexone at doses of 0.1 (N0.1), 0.5 (N0.5) or 1 (N1) mg/kg. A fifth group (Limited) received vehicle injections and had $\mathrm{CS}+/ 3.5 \% \mathrm{CO}$ and $\mathrm{CS}-/ 0.9 \% \mathrm{CO}$ intakes limited to approximate the intakes of the drug groups. Significant differences are denoted between $\mathrm{CS}+/ 3.5 \% \mathrm{CO}$ or CS-/0.9\% CO intake following a drug dose relative to VEH (+) or LTD (\#) treatment (Panel A). Intakes (mean in g/2 h +SEM) of CS+ and CS- in three two-bottle preference tests in the VEH (Panel B), NTXO.1 (Panel C), NTX0.5 (Panel D), NTX1 (Panel E) and Limited VEH (Panel F) groups. Significant differences $\left({ }^{*}\right)$ are denoted between CS+ and CS-intake within each test and each group, and between CS+ or CS- intakes following a particular drug group relative to VEH (+) or Limited VEH (\#) conditions.

Experiment 3. NMDA receptor antagonism and expression of CO-CFP:

The mean 1-bottle training intake of the $\mathrm{CS}+/ 3.5 \% \mathrm{CO}(20.1+0.8 \mathrm{~g} / 2 \mathrm{~h})$ failed to differ significantly from intake of the CS-/0.9\% CO $(18.4+0.7 \mathrm{~g} / 2 \mathrm{~h})$. In the two-bottle preference tests, overall, the rats consumed significantly more CS+ than CS- $(F(1,52)=$ $53.81, p<0.0001)$; total intake significantly varied as a function of drug dose $(F(3,52)=$ $25.08, p<0.001)$, and there was a significant CS $\times$ Dose interaction $(F(3,52)=6.71$, $p<0.0007) . C S+$ intakes significantly exceeded CS- intakes at the 0 (vehicle), 50 and 100, but not at the $200 \mathrm{ug} / \mathrm{kg}$ doses of MK-801 (Figure 3). Rats consumed significantly less CS+ at the $200 \mathrm{ug} / \mathrm{kg}$ MK-801 dose as compared to vehicle, whereas CS- intakes failed to be significantly affected (Figure 3). Total intake $(\mathrm{g} / 2 \mathrm{~h}$ ) failed to differ among the 0 (30.0 $+2.8 \mathrm{~g}), 50(28.5+2.8 \mathrm{~g})$ and $100(20.4+3.2 \mathrm{~g}) \mathrm{ug} / \mathrm{kg}$ MK-801 doses, but was significantly lower at the $200(2.0+1.1 \mathrm{~g}) \mathrm{ug} / \mathrm{kg}$ MK-801 dose. Significant differences in the percent $C S+$ intakes were observed $(F(3,39)=4.71, p<0.007)$, and the preference $(49 \%)$ at the 
$200 \mathrm{ug} / \mathrm{kg}$ MK-801 dose was significantly lower than the preference (85\%) following vehicle (Figure 2). Preferences at the 50 (72\%) and 100 (70\%) ug/kg MK-801 doses were intermediate, but failed to significantly differ from the vehicle test.

\section{Corn Oil-CFP Acquisition: Opioid Receptor Antagonism}
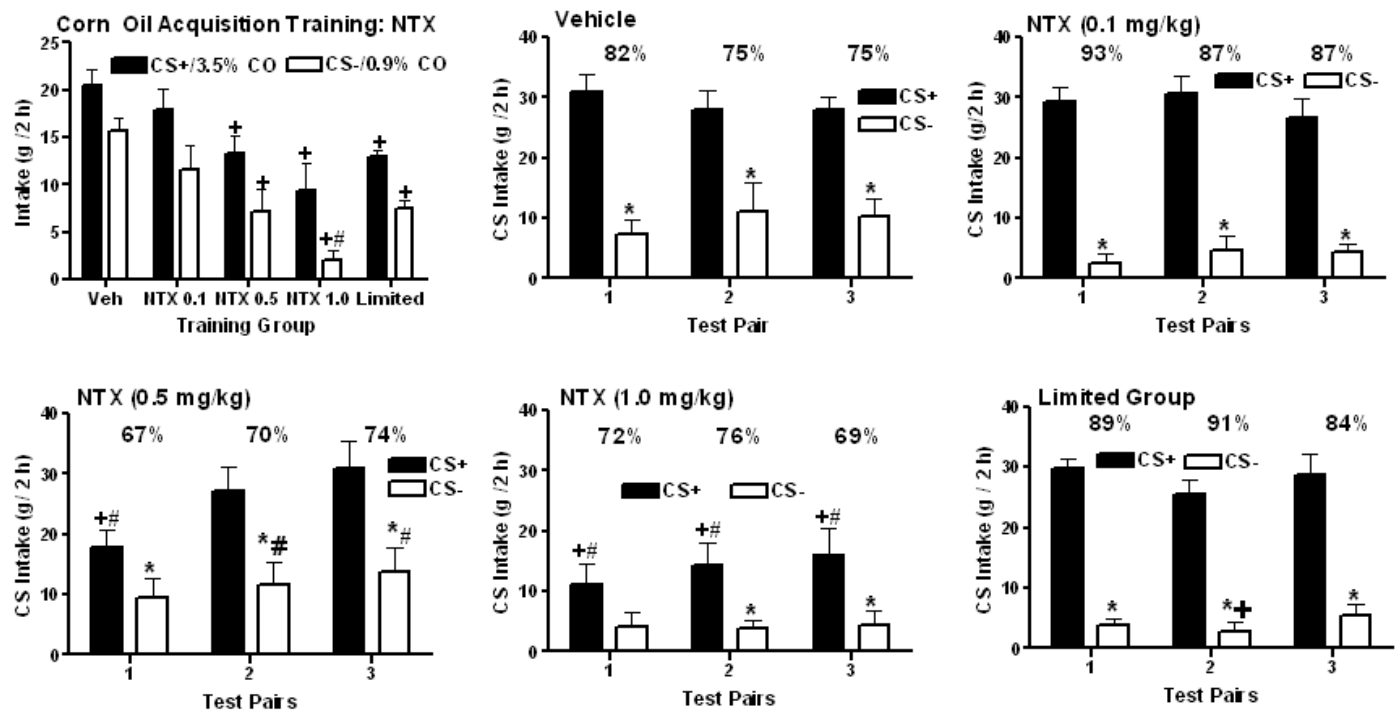

Figure 3. (Expression Study): Intakes (mean in $g / 2 \mathrm{~h}+\mathrm{SEM}$ ) of CS+ and CS- solutions in two-bottle preference tests in animals receiving systemic injections of the NMDA antagonist, MK-801 $30 \mathrm{~min}$ prior to testing. Significant differences are denoted between $\mathrm{CS}+$ and CS- intake within an injection condition $\left({ }^{*}\right)$ and between $\mathrm{CS}+$ intake following a drug dose relative to vehicle treatment $(+)$. The percentages of $\mathrm{CS}+$ intake over total intake are denoted above each pair of values with significant differences relative to vehicle treatment $(*)$ noted.

Experiment 4. NMDA receptor antagonism and acquisition of CO-CFP:

During 1-bottle training, overall CS+/3.5\% CO intake $(14.8 \mathrm{~g} / 2 \mathrm{~h})$ significantly $(F(1,22)=101.17, p<0.0001)$ exceeded CS- $/ 0.9 \%$ CO intake $(8.6 \mathrm{~g} / 2 \mathrm{~h})$, and significant differences were observed among the three groups $(F(2,22)=15.79, p<0.0001)$ but not for the Group x CS interaction $(F(2,22)=0.22)$. Total training intake of the VEH group (33.0 g) was significantly greater than that of the Limited VEH (19.6 g) and MK100 (17.8 g) groups. $\mathrm{CS}+/ 3.5 \% \mathrm{CO}$ training intake was significantly greater than $\mathrm{CS}-/ 0.9 \% \mathrm{CO}$ intake in all groups (Figure $4 \mathrm{~A})$.

In the two-bottle preference tests, overall the rats consumed significantly more $(F(1,44)=108.97, p<0.0001) C S+(20.8 \mathrm{~g})$ than CS- $(5.7 \mathrm{~g})$ solution, and significant 
differences were observed among the three groups $(F(2,22)=6.29, p<0.007)$ and for the interactions between Groups $x$ Tests $(F(4,44)=9.55, p<0.01)$ and Groups $\times$ CS $(F(2,22)=$ 26.36, $p<0.0001)$, but not among tests or the other interactions. Total CS intake was significantly lower in the MK100 group $(19.7 \mathrm{~g} / 2 \mathrm{~h})$ relative to VEH $(28.2 \mathrm{~g} / 2 \mathrm{~h})$ or Limited VEH (31.6 g/2 h) groups. CS+ intakes significantly exceeded CS- intakes across all three tests in the VEH (Figure 4B) and Limited VEH (Figure 4D) groups. In contrast, CS+ and CS- intakes failed to differ in all three tests in the MK100 group (Figure 4C). The MK100 group displayed significantly less CS+ intake in the first two tests relative to the VEH group, and in all three tests relative to the Limited VEH group (Figure 4C).

Significant differences in the percent CS+ intakes were observed among groups $(F(2,22)=13.18, p<0.0002)$, but not among tests $(F(2,22)=1.60)$, or for Group $x$ Test interaction $(F(4,44)=1.62)$. An analysis of the percent $C S+$ intakes averaged over the three tests revealed that the MK100 group (63\%) displayed significantly lower CS+ preferences than did the VEH (84\%) and Limited VEH (88\%) groups. 

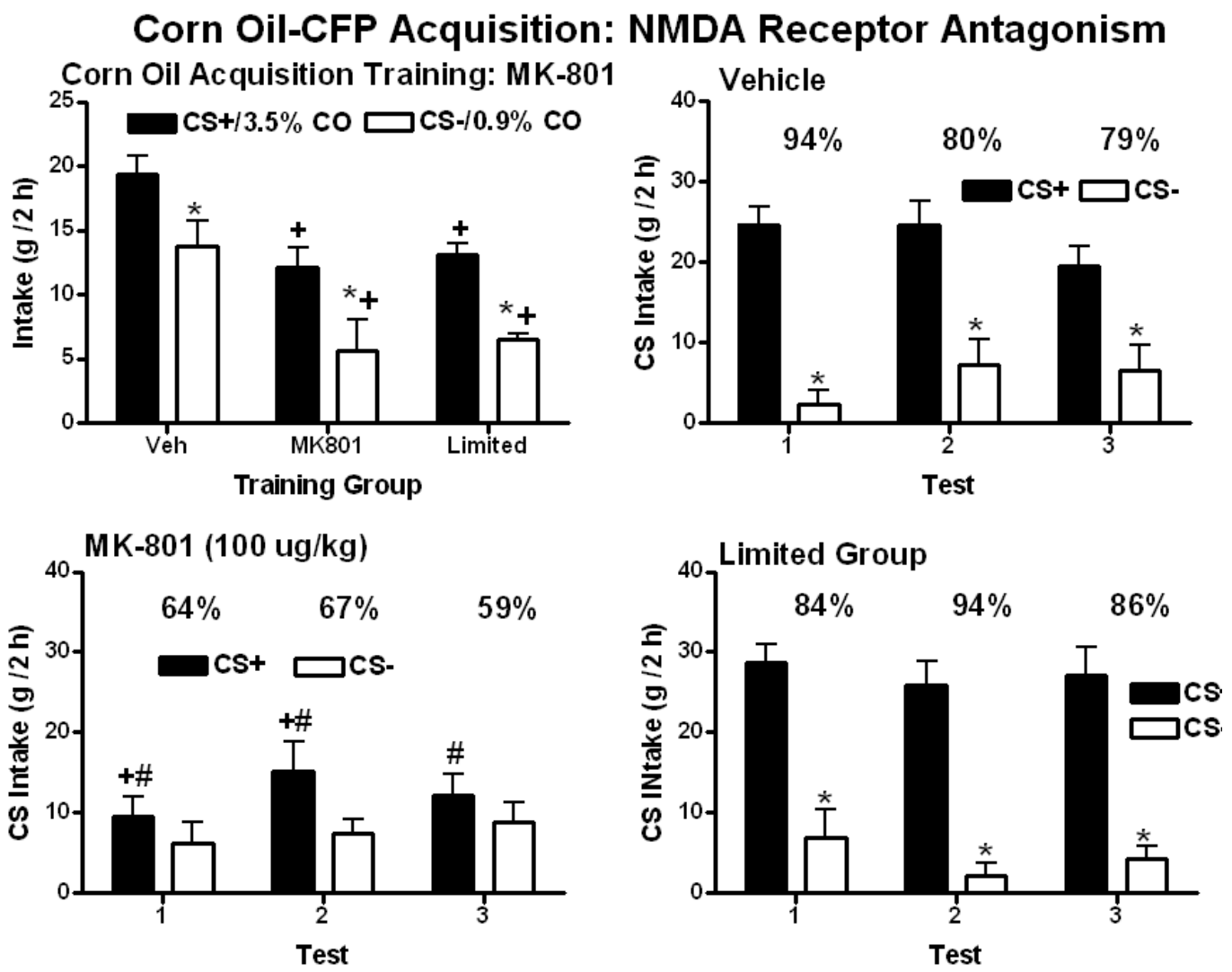

Figure 4. (Acquisition Study): Training intakes (mean in $\mathrm{g} / 2 \mathrm{~h}+\mathrm{SEM}$ ) of rats exposed to ten 1-bottle sessions of flavored $3.5 \%$ corn oil solutions ( $\mathrm{CS}+/ 3.5 \% \mathrm{CO}$ ) or $0.9 \%$ corn oil solutions(CS-/0.9\% CO) $30 \mathrm{~min}$ following systemic injections of vehicle (VEH) or the NMDA antagonist, MK-801 (100 ug/kg). A third group (Limited) received vehicle injections and had CS+/3.5\% CO and CS-/0.9\% CO intakes limited to approximate the intakes of the drug groups. Significant differences are denoted between CS+/3.5\% CO or CS-/0.9\% CO intake following a drug dose relative to VEH (+) or Limited (\#) treatment (Panel A). Intakes (mean in g/2 h+SEM, $2 \mathrm{~h}$ ) of CS+ and CS- in three two-bottle preference tests in the VEH (Panel B), MK-801 (Panel C) and Limited Vehicle (Panel D) groups. Significant differences $(*)$ are denoted between CS+ and CS-intake within each test and each group, and between CS+ or CS- intakes following a particular drug group relative to VEH (+) or Limited VEH (\#) conditions.

\section{Discussion}

The present study extended our previous findings (Dela Cruz et al., 2012) of a robust fat-CFP produced by mixing one novel flavor (CS+) in 3.5\% CO and a second novel flavor (CS-) in 0.9\% CO. DA D1 receptor antagonism during training with $\mathrm{SCH} 23390$ (200$400 \mathrm{nmol} / \mathrm{kg}$ ) failed to significantly reduce the acquisition of CO-CFP, and raclopride treatment (25-200 nmol/kg) had a limited effect on CO-CFP acquisition. SCH23390 and raclopride also had limited effects on the expression of a previously learned CO-CFP and in the case of D1 antagonist, this was associated with substantial reductions in overall CS intakes. These data suggested that other neurochemical receptor systems are 
involved in mediating the acquisition and expression of fat-CFP, and thus the present study examined the roles of opioid and NMDA receptor systems in these responses.

Opioid Receptor Antagonism and Fat-CFP:

Given the observed reductions in fat intake following general opioid antagonism (Cole et al., 2005; Dym et al., 2010; Glass et al., 2000; Higgs and Cooper, 1998; Islam and Bodnar, 1990; Jarosz et al., 2006; Marks-Kaufman et al., 1985; Naleid et al., 2007; Sahr et al., 2008; Zhang et al., 1998), we hypothesized that systemic NTX treatment would impair both the acquisition and expression of CO-CFP. In the expression study, although all doses of NTX significantly reduced CS+, but not CS- intakes, significant preferences (defined by significantly greater CS+ over CS- intake) were observed following VEH and all NTX doses. However, the magnitude of the CO-CFP was significantly, but marginally reduced at $0.1(69 \%)$ and $1 \mathrm{mg} / \mathrm{kg}(71 \%)$ doses, but not at the $0.5(77 \%)$ and $5(74 \%)$ $\mathrm{mg} / \mathrm{kg}$ doses relative to VEH treatment (88\%). Thus, opioid receptor antagonism appears to be minimally involved in the expression of a preference for a fat nutrient source, yet intimately involved in the maintenance of fat intake per se.

In the acquisition study, the three training doses of NTX significantly decreased both $\mathrm{CS}+/ 3.5 \% \mathrm{CO}$ and $\mathrm{CS}-/ 0.9 \% \mathrm{CO}$ intakes relative to the VEH group. These opioidinduced reductions in the both corn oil concentrations are consistent with prior data (Cole et al., 2005; Dym et al., 2010; Glass et al., 2000; Higgs and Cooper, 1998; Islam and Bodnar, 1990; Jarosz et al., 2006; Marks-Kaufman et al., 1985; Naleid et al., 2007; Sahr et al., 2008; Zhang et al., 1998). Overall, CS+ intakes significantly exceeded CS- intakes in VEH and Limited VEH control groups as well as in all NTX groups. However, the magnitude of the CS+ preference was reduced in the NTX0.5 (70\%) and NTX1.0 (72\%) groups relative to the Limited VEH group (88\%) although not relative to the VEH group (77\%). Thus, while opioid receptor antagonism does not block the acquisition of a COCFP, it does attenuate the strength of the learned preference to some degree. This contrasts with the failure of NTX treatment to reduce the acquisition of sugarconditioned flavor preferences (Azzara et al., 2000; Baker et al., 2004; Yu et al., 1999), 
but it should noted that different training procedures were used in the fat- and sugarconditioning studies. In particular, whereas the rats in the present study were exposed to both the oral and post-oral actions of corn oil, the rats in the prior studies exposed to only the oral (sweet taste) or post-oral actions of sugars.

\section{NMDA Receptor Antagonism and Fat-CFP:}

Given the ability of MK-801 to block the acquisition, but not the expression of fructose-CFP (Golden and Houpt, 2007), we hypothesized that NMDA receptor antagonism would have similar effects on the acquisition and expression of CO-CFP. This hypothesis was confirmed. In the expression study, MK-801 significantly and dosedependently reduced CS+, but not CS- intakes, and significant preferences were observed following VEH (85\%) and 50 (72\%) and $100 \mathrm{ug} / \mathrm{kg}$ (70\%) MK-801 doses. The loss of preference (49\%) following the $200 \mathrm{ug} / \mathrm{kg}$ MK-801 dose was accompanied and presumably due to a dramatic decrease in total CS intake (to $2 \mathrm{ml} / 2 \mathrm{~h}$ ); note that a 200 $\mathrm{ug} / \mathrm{kg}$ dose was not used in the Golden and Houpt study (2007). Therefore, as previously observed for fructose-CFP (Golden and Houpt, 2007), NMDA receptor signaling appears to be minimally involved in the expression of a previously learned fat-based flavor preference.

In the acquisition study, treatment with $100 \mathrm{ug} / \mathrm{kg}$ MK-801 during training significantly decreased both CS+/3.5\% CO and CS-/0.9\% CO intakes compared to the vehicle treatment. Nevertheless, training intakes of the $\mathrm{CS}+/ 3.5 \% \mathrm{CO}$ exceeded that of the CS-/0.9\% CO in the MK801 group as well as in the VEH and Limited VEH groups. This demonstrates that the MK801 group discriminated between the two CS training solutions and found the $\mathrm{CS}+/ 3.5 \% \mathrm{CO}$ the more attractive solution. Yet, in the CS+ vs. CSchoice tests, the MK801 group, unlike the VEH and Limited VEH groups, failed to drink more CS+ than CS-. This was due to the significant and selective reduction in CS+ intake in the MK-801 group relative to vehicle groups, an effect that was identical to the abolition of the acquisition of fructose-CFP by MK-801 (Golden and Houpt, 2007). Consistent with this finding, the percent CS+ intake of MK801 group (63\%) was significantly lower than that of the VEH (84\%) and Limited VEH (88\%) groups. 
Importantly, the robust CS+ conditioning displayed by the Limited VEH group indicates that the inhibition of preference conditioning by MK-801 treatment was not secondary to the drug-induced suppression in CS training intakes. Thus, the present data along with those of Golden and Houpt (2007) indicate an important role of NMDA signaling in the acquisition of both fructose- (Golden and Houpt, 2007) and corn oil-CFP.

A role for glutamate and its receptors in learning has been wellcharacterized, and has been specifically linked to reward components of foodrelated learning. Thus, glutamate antagonism within the AMY and NAc impaired appetitive instrumental learning (Kelley et al., 1997; Hernandez et al., 2005). Glutamate antagonism within the AMY also impaired both the acquisition and expression of conditioned taste avoidance (Yasoshima et al., 2000). Within the VTA, glutamate antagonists impaired cue-sucrose learning and DA release in the NAc elicited by the sucrose-predictive cue (Stuber et al., 2008; Zellner et al., 2009; Zweifel et al., 2009). Finally, glutamate also interacted with DA within the NAc, AMY and $\mathrm{mPFC}$ to modulate reward-related appetitive learning (Smith-Roe \& Kelley, 2000; Baldwin et al., 2002; Andrzejewski et al., 2004). Future studies should investigate the role of NMDA receptor antagonism within the NAc, AMY and mPFC on the acquisition of fructose- and CO-CFP, and any interaction it may enjoy with DA signaling

\section{Acknowledgements}

This research was supported by National Institute of Diabetes and Digestive and Kidney Diseases Grant DK071761 and PSC/CUNY Grant 64216-42. We thank Huziefa Tayabali, Voula Galanoupolous, Gregory Fitzgerald, Ester Illayeva and Aliza Grossman for technical contributions to this project. 


\section{References}

Ackroff, K., \& Sclafani, A. (2009). Oral and post-oral determinants of dietary fat appetite. In Montmayeur,J.-P. \& le Coutre,J. (eds), Fat Detection: Taste, Texture, and Post Ingestive Effects. Taylor \& Francis, Boca Raton, pp. 295321.

Andrzejewski, M.E., Sadeghian, K., \& Kelley, A.E. (2004). Central amygdalar and dorsal striatal NMDA receptor involvement in instrumental learning and spontaneous behavior. Behavioral Neuroscience, 118, 715-729.

Azzara, A.V., Bodnar, R.J., Delamater, A.R., \& Sclafani, A. (2000). Naltrexone fails to block the acquisition or expression of a flavor preference conditioned by intragastric carbohydrate infusions. Pharmacology Biochemistry and Behavior, 67, 545-557.

Azzara, A.V., Bodnar, R.J., Delamater, A.R., \& Sclafani, A. (2001). D-1 but not D-2 dopamine receptor antagonism blocks the acquisition of a flavor preference conditioned by intragastric carbohydrate infusions. Pharmacology Biochemistry and Behavior, 68, 709-720.

Baker, R.W., Shah, M.J., Sclafani, A., \& Bodnar, R.J. (2003). Dopamine D1 and D2 antagonists reduce the acquisition and expression of flavor-preferences conditioned by fructose in rats. Pharmacology Biochemistry and Behavior, $75,55-65$.

Baker, R.W., Li, Y., Lee, M.G., Sclafani, A., \& Bodnar, R.J. (2004). Naltrexone does not prevent acquisition or expression of flavor preferences conditioned by fructose in rats. Pharmacology Biochemistry and Behavior, 78, 239-246.

Baldwin, A.E., Sadeghian, K. \& Kelley, A.E. (2002). Appetitive instrumental learning requires coincident activation of NMDA and dopamine D1 receptors within the medial prefrontal cortex. Journal of Neuroscience, 22, 1063-1071.

Bernal, S., Dostova, I., Kest, A., Abayev, Y., Kandova, E., Touzani, K., Sclafani, A., \& Bodnar, R.J. (2008). Role of dopamine D1 and D2 receptors in the nucleus accumbens shell on the acquisition and expression of fructose-conditioned flavor-flavor preferences in rats. Behavioural Brain Research, 190, 59-66. 
Bernal, S., Miner, P., Abayev, Y., Kandova, E., Gerges, M., Touzani, K., Sclafani, A., \& Bodnar, R.J. (2009). Role of amygdala dopamine D1 and D2 receptors in the acquisition and expression of fructose-conditioned flavor preferences in rats. Behavioural Brain Research, 205, 183-190.

Bernal, S., Touzani, K., Gerges, M., Abayev, Y., Sclafani, A., \& Bodnar, R.J. (2010). Opioid receptor antagonism in the nucleus accumberns fails to block the expression of sugar-conditioned flavor preferences in rats. Pharmacology Biochemistry and Behavior, 95, 56-62.

Cole, J.L., Leventhal, L., Pasternak, G.W., Bowen, W.D., \& Bodnar, R.J. (1995) Reductions in body weight following chronic central opioid receptor subtype antagonists during development of dietary obesity in rats. Brain Research, $678,168-176$.

Dela Cruz, J., Icaza-Cukali, D.P., Tayabali, H., Galanopoulos, V., Sampson, C., Bamshad, D., Touzani, K., Sclafani, A. \& Bodnar, R.J. (2012). Roles of dopamine D1 and D2 receptors in the acquisition and expression of fat-conditioned flavor preferences in rats. Neurobiology of Learning and Memory, 97, 332-337. Dym, C.T., Bae, V., Kraft, T., Yakubov, Y., Winn, A., Sclafani, A., \& Bodnar, R.J. (2010). Genetic variance contributes to dopamine and opioid receptor antagonistinduced inhibition of Intralipid (Fat) intake in inbred and outbred mouse strains. Brain Research, 1316, 51-61.

Glass, M.J., Billington, C.J., \& Levine, A.S. (2000). Naltrexone administered to central nucleus of amygdala or PVN: neural dissociation of diet and energy. American Journal of Physiology, Regulatory and Integrative Comparative Physiology, 279, R86-R92.

Golden, G.J., \& Houpt, T.A. (2007). NMDA receptor in conditioned flavor-taste preference learning: blockade by MK-801 and enhancement by Dcycloserine. Pharmacology Biochemistry and Behavior, 86, 587-596.

Hernandez, P.Jj, Andrzejewski, M.E., Sadeghian, K., Panksepp, J.B., \& Kelley, A.E. (2005). AMPA/kainate, NMDA, and dopamine D1 receptor function in the nucleus accumbens core: A context-limited role in the encoding and consolidation of instrumental memory. Learning and Memory, 12, 285-295. 
Higgs, S., \& Cooper, S.J. (1998). Evidence for early opioid modulation of licking responses to sucrose and Intralipid: a microstructural analysis in the rat. Psychopharmacology, 139, 342-355.

Hsiao, S, \& Smith, G.P. (1995). Raclopride reduces sucrose preference in rats. Pharmacology Biochemistry and Behavior, 50, 121-125.

Islam, A.K., \& Bodnar, R.J. (1990). Selective opioid receptor antagonist effects upon intake of a high-fat diet in rats. Brain Research, 508, 293-296.

Jarosz, P.A., Sekhon, P., \& Coscina, D.V. (2006). Effect of opioid antagonism on conditioned place preferences to snack foods. Pharmacology Biochemistry and Behavior, 83, 257-264.

Kelley, A.E., Smith-Roe, S.L., \& Holahan, M.R.. (1997). Response-reinforcement learning is dependent on N-methyl-D-aspartate receptor activation in the nucleus accumbens core. Proceedings National Academy of Sciences (U S A), 94, 12174-12179.

Malkusz, D.C., Banakos, T., Mohamed, A., Malkusz, G., Vongwattanakit, T., Martinez, S., Bohn, T., Saeed, S., Mahmud, F., Liss, C., Rozvi, A., Touzani, K., Sclafani, A. \& Bodnar, R.J. (2012). Dopamine signaling in the medial prefrontal cortex and amygdala is required for the acquisition of fructose-conditioned flavor preferences in rats. Behavioural Brain Research, 233, 500-507.

Marks-Kaufman, R., Plager, A., \& Kanarek, R.B. (1985). Central and peripheral contributions of endogenous opioid systems to nutrient selection in rats. Psychopharmacology, 85, 414-418.

Naleid, A.M., Grace, M.K., Chimukangara, M., Billington, C.J., \& Levine, A.S. (2007). Paraventricular opioids alter intake of high-fat but not high-sucrose diet depending on diet preference in a binge model of feeding. American Journal of Physiology, Regulatory and Integrative Comparative Physiology, 293, R99R105.

Sahr, A.E., Sindelar, D.K., Alexander-Chacko, J.T., Eastwood, B.J., Mitch, C.H., \& Statnick, M.A. (2008). Activation of mesolimbic dopamine neurons during novel and daily limited access to palatable food is blocked by the opioid 
antagonist LY255582. American Journal of Physiology, Regulatory and Integrative Comparative Physiology, 295, R463-R471.

Sclafani, A. (1999). Macronutrient-conditioned flavor preferences. In Berthoud, H.-R. \& Seeley,R. (eds), Neural and metabolic control of macronutrient intake. CRC Press, Boca Raton, FL, pp. 93-107.

Sclafani, A. \& Ackroff, K. (2012). The role of gut nutrient sensing in stimulating appetite and conditioning food preferences. American Journal of Physiology.Regulatory, Integrative and Comparative Physiology, 302, R1119R1133.

Shide, D.J. \& Blass, E.M. (1991). Opioid mediation of odor preferences induced by sugar and fat in 6-day-old rats. Physiology and Behavior, 50, 961-966.

Smith-Roe, S.L. \& Kelley, A.E. (2000). Coincident activation of NMDA and dopamine D1 receptors within the nucleus accumbens core is required for appetitive instrumental learning. Journal of Neuroscience, 20, 7737-7742.

Stuber, G.D., Klanker, M., de Ridder, B., Bowers, M.S., Joosten, R.N., Feenstra, M.G., \& Bonci, A. (2008). Reward-predictive cues enhance excitatory synaptic strength onto midbrain dopamine neurons. Science, 321, 1690-1692.

Touzani, K., Bodnar, R.J., \& Sclafani, A. (2008). Activation of dopamine D1 receptors in nucleus accumbens is critical for the acquisition, but not the expression, of glucose-conditioned flavor preference in rats. European Journal of Neuroscience, 27, 1525-1533.

Touzani, K., Bodnar, R.J., \& Sclafani, A. (2009). Dopamine D1-like receptor antagonism in amygdala impairs the acquisition of glucose-conditioned flavor preferences in rats. European Journal of Neuroscience, 30, 289-298.

Touzani, K., Bodnar, R.J., \& Sclafani, A. (2010). Acquisition of glucose-conditioned flavor preference requires the activation of dopamine D1-like receptors within the medial prefrontal cortex in rats. Neurobiology of Learning and Memory, 94, 214-219.

Yasoshima, Y., Morimoto, T., \& Yamamoto, T. (2000). Different disruptive effects on the acquisition and expression of conditioned taste aversion by blockades of 
amygdalar ionotropic and metabotropic glutamatergic receptor subtypes in rats. Brain Research, 869, 15-24.

Yu, W.-Z., Sclafani, A., Delamater, A.R., \& Bodnar, R.J. (1999). Pharmacology of flavor preference conditioning in sham-feeding rats: effects of naltrexone.

Pharmacology Biochemistry and Behavior, 64, 573-584.

Yu, W.-Z., Silva, R.M., Sclafani, A., Delamater, A.R., \& Bodnar, R.J. (2000a).

Pharmacology of flavor preference conditioning in sham-feeding rats: effects of dopamine receptor antagonists. Pharmacology Biochemistry and Behavior, $65,635-647$.

Yu, W.-Z., Silva, R.M., Sclafani, A., Delamater, A.R., \& Bodnar, R.J. (2000b). Role of D1 and D2 dopamine receptors in the acquisition and expression of flavor preference conditioning in sham-feeding rats. Pharmacology Biochemistry and Behavior, 67, 537-544.

Zellner, M.R., Kest, K., \& Ranaldi, R. (2009). NMDA receptor antagonism in the ventral tegmental area impairs acquisition of reward-related learning. Behavioural Brain Research, 197, 442-449.

Zhang, M., Gosnell, B.A., Kelley, A.E. (1998). Intake of high-fat food is selectively enhanced by mu opioid receptor stimulation within the nucleus accumbens. Journal of Pharmacology and Experimental Therapeutics, 285, 908-914.

Zheng, H., Kelly, L., Patterson, L.M., Berthoud, H.R. (1999). Effect of brainstem NMDA-receptor blockade by MK-801 on behavioral and fos responses to vagal satiety signals. American Journal of Physiology, Regulatory and Integrative Comparative Physiology, 277, R1104-R1111.

Zweifel, L.S., Parker, J.G., Lobb, C.J., Rainwater, A., Wall, V.Z., Fadok, J.P., Darvas, M., Kim, M.J., Mizumori, S.J., Paladini, C.A., Phillips, P.E., \& Palmiter, R.D. (2009). Disruption of NMDAR-dependent burst firing by dopamine neurons provides selective assessment of phasic dopamine-dependent behavior. Proceedings National Academy of Sciences (U S A), 106, 7281-7288. 


\section{Chapter 4}

\section{c-fos Induction in the Dorsal}

\section{Striatum and Mesotelencephalic}

\section{Dopamine Pathway Following Oral} Intake of Sugars and Fats in Rats

J.A.D. Dela Cruz',5, T. Coke ${ }^{3}$, T. Karagiorgis ${ }^{3}$, C. Sampson ${ }^{3}$, D. Icaza-Cukali3 ${ }^{3}$ K. Kest $^{1,3}$, K. Touzani ${ }^{4}$, A. Sclafani ${ }^{1,2,4}$ and R.J. Bodnar ${ }^{1,3}$

${ }^{1}$ Neuropsychology and ${ }^{2}$ Cognition, Brain and Behavior Psychology Doctoral Sub-Programs, The Graduate Center, and Departments of Psychology, ${ }^{3}$ Queens and ${ }^{4}$ Brooklyn Colleges, City University of New York, ${ }^{5}$ School of Mental Health and Neuroscience, Maastricht University 


\begin{abstract}
Although a number of studies have demonstrated that consumption of sugars and fats activate fos-like immunoreactivity (FLI) in the meso-corticolimbic and nigrostriatal systems, the present study had the advantage of examining an origin of DA (Ventral Tegmental Area: VTA) and five different projection zones of DA (Amygdala (AMY), dorsal striatum(CP), medial Prefrontal Cotrex (mPFC), Nucleus Accumbens (NAc) core and NAc shell) simultaneously for FLI following corn oil, fructose, glucose, and three controls (water, saccharin and xanthan gum). The major finding was that corn oil in solutions isocaloric to glucose and fructose, elicited significant increases in FLI in all of these sites except for the NAc shell. Glucose, which also conditions preferences through orosensory and post-ingestive actions, elicited significant increases in FLI in the AMY, dorsal striatum and NAc core, but not the mPFC, VTA or NAc shell. Correspondingly, fructose, which only conditions preferences through orosensory actions in short-term tests, elicited significant increases in FLI in the AMY and dorsal striatum, but not the MPFC, VTA or NAc core or shell. Saccharin which elicited considerable intake through purely orosensory mechanisms, failed to significantly alter FLI in any of the sampled sites. Interestingly, the NAc shell which has been implicated in reward-related food learning and which releases DA to sweet and fat stimuli, failed to display any significant changes in FLI under any of the conditions. In those situations in which significant FLI was observed, there were many instances of highly positive relationships across sites, supporting the idea of activation of a distributed brain network mediating sugar and fat intake.
\end{abstract}




\section{Introduction}

Obesity occurs particularly developed countries, where cheap, highly palatable, energy-dense food is readily available (Dragone, 2009), usually in the form of high-fat and or sugar-rich fare. Palatability is a factor that can exacerbate intake thereby playing an important role in driving caloric consumption in excess of metabolic demand and ultimately promoting obesity (Raynor and Epstein, 2001). In addition to innate factors governing intake of sugars and fats, learning also plays an important role in the development of preferences for high-fat and sugar-rich foods (Sclafani, 1999). Preferences can be based on learned associations between a stimulus (e.g., Kool Aid flavor) and the orosensory flavor characteristics of the nutrient (smell, sight, taste, texture) (flavor-flavor conditioning) or learned associations between a stimulus and the post-ingestive consequences of the nutrient (flavor-nutrient conditioning) (Azzara et al., 2001; Baker et al., 2003; Dela Cruz, et al., 2012a; Yu et al. 2000a, 2000b,). Most food preferences are learned through experiences of combinations of flavor-flavor and flavor-nutrient learning consequences in ingesting those foods. Sucrose (Azzara et al., 2001; Yu et al, 2000a, 2000b), one of its monosaccharides (glucose) (Sclafani and Ackroff, 1994; Touzani et al., 2009a, 2010a), and fat (in the form of corn-oil) (Elizade \& Sclafani, 1990; Dela Cruz, et al., 2012a, 2012b) are hypothesized to condition both flavor-flavor and flavor-nutrient preferences. In contrast, the other monosaccharide of sucrose, fructose, selectively conditions flavor-flavor preferences in short-term (e.g., 30-60 min/day) tests (Baker et al., 2003; Sclafani, et al., 1993, 1999), but both types in longer-term (20-24 h/day) tests (Ackroff \& Sclafani, 2004; Ackroff et al., 2001).

Many learned associations to flavor cues are thought to stem from the connection of the palatability of sweet food and the rewarding actions of dopamine (DA) released in the brain (Agmo et al., 1995; El-Ghundi, et al., 2003; Genn et al., 2004; Hajnal et al., 2004; Imaizumi et al., 2000; Liu, et al., 2010; Pecina, et al., 2003; Sawano, et al., 2000). This is supported by observations of decreased intake of sweet solutions under sham-feeding and real-feeding conditions following treatment with DA antagonists in rats (e.g., Geary \& Smith, 1985; Muscat \& Willner, 1989; 
Schneider, et al., 1986, 1990) and mice (Dym et al., 2009). Correspondingly, DA mediation of the rewarding effect of fat flavor is supported by observations that corn oil sham-feeding promotes nucleus accumbens (NAc) DA release (Liang, et al., 2006), and DA D1 and D2 antagonists suppress the sham-feeding response to corn oil and real-feeding of fats in rats (Baker, et al., 2001; Davis, et al., 2006; Rao, et al., 2008; Weatherford, et al., 1988; 1990) and mice (Dym et al., 2010). An alternative view postulated that DA systems are not acting by directly mediating hedonic reinforcers or predictive associations in hedonic reward learning ('liking'), but instead may be necessary for attributions of incentive salience as the neural representations of reward-related stimuli ('wanting') (e.g., Berridge, 2007, 2012; Berridge \& Robinson, 1998). DA appears critical for reward-related leaning preferences. Thus, systemic raclopride, a DA D2 antagonist, reduced preferences for a flavored $10 \%$ sucrose solution compared to a second sucrose flavored solution paired with vehicle treatment (Hsaio \& Smith, 1995). Systemic DA D1 (SCH23390) and D2 (raclopride) antagonists also reduced the expression and hastened the extinction of the acquisition of fat-conditioned flavor preferences (CFP) (Dela Cruz et al., 2012a). Systemic DA D1, but not D2 antagonism blocked flavor-nutrient conditioning of intragastric (IG) sucrose infusions (Azzara, et al., 2001). In flavorflavor conditioning paradigms, systemic DA D1 and D2 antagonists blocked acquisition and expression of sucrose-CFP in sham-feeding rats (Yu, et al., 2000a, 2000b) and fructose-CFP in real-feeding rats (Baker et al., 2003). The mesotelencephalic DA pathway originating in the ventral tegmental area (VTA), and projecting to the NAc core and shell, amygdala (AMY) and medial prefrontal cortex (mPFC) (e.g., Bjorklund and Dunnett, 2007; Lindvall et al., year; Swanson, 1982) appears to be critical in the DA mediation of flavor-nutrient and flavor-flavor CFP. Thus, the acquisition of flavor-nutrient conditioning induced by flavors paired with IG glucose infusions is blocked by microinjections of the DA D1 antagonist, SCH23390 into the NAc core and shell, the AMY or the mPFC (Touzani et al., 2008, 2009a, 2010a). Correspondingly, the acquisition and expression of fructose-CFP is differentially blocked by microinjections of DA D1 or D2 antagonists into the NAc shell, AMY and mPFC (Bernal et al., 2008, 2009; Malkusz et al., 2012). A second DA- 
rich projection zone in the dorsal striatum (caudate-putamen (CP)) has been associated with feeding in which DA depletion reduced intake (Dunnett \& Iversen, 1980; Jicha \& Salamone, 1991; Koob et al., 1978, Salamone et al., 1990; Ungerstedt, 1971), whereas virally-mediated restoration of DA production in the CP in DAdeficient mice reversed aphagia (Sotak et al., 2005; Szcypka, et al., 2001). Further, the magnitude of DA CP release correlated with the degree of pleasure sweet food induces in humans (Small, et al, 2003).

Another approach in understanding the neural substrates that mediate the intakes of sugars and fats is the c-fos technique, a protoonco-gene marker of neuronal activity (e.g., Day, et al., 2008; Dragunow \& Faull, 1989; VanElakker, et al., 2008). C-fos has been used in ingestive studies to identify sites involved in conditioned taste aversions (Houpt, et al., 1994; Koh \& Bernstein, 2005; Navarro, et al, 2000; Swank et al., 1995). Ingestion of sucrose or sucrose-rich foods increased fos-like immunoreactivity (FLI) in the central gustatory system including the nucleus tractus solitarius (NTS), parabrachial nucleus (PBN), area postrema and vagus nerve nuclei (Anseloni, et al., 2005; Chen, et al., 2011; Harrer, et al., 1996; Schwarz, et al., 2010; Streefland, et al., 1996; Yamamoto, et al., 1997, Yamamoto and Sawa, 2000a, 2000b; Washington, et al., 2010, Zhao, et al., 2011). Satiation of sweet solutions increased FLI in hypothalamic and supraoptic nuclei (Mitra, et al., 2010; Naimi, et al., 1997), whereas opioid antagonist administration paired with sugar consumption selectively increased FLI in the central nucleus of the AMY (Park \& Carr, 1998; Pomonis, et al., 2000). Oral voluntary sucrose intake involving orosensory and postingestive mechanisms significantly increased FLI in the central nucleus of the AMY and the NAc shell, but not the NAc core (Norgren, et al., 2006; Zhao, et al., 2011). Orosensory consequences of sucrose intake in sham-feeding rats elicited significantly increased FLI in the central nucleus of the AMY and NAc shell, but not the VTA (Mungarndee et al., 2008). Postingestive consequences of IG infusions of sucrose and glucose intake revealed significantly greater FLI in the NAc and central and basolateral nuclei of the AMY (Otsubo, et al., 2011; Yamamoto, et al., 1997). Mitra and co-workers (2011) found that repeatedly adding sucrose to scheduled chow access increased FLI in both the NAc shell and core as well as the 
mPFC). Using a sucrose concentration downshift paradigm, Pecoraro and Dallman (2005) observed that the greatest FLI increases in the basolateral AMY and NAc, but not the VTA. In sugar conditioning studies, Hamlin and co-workers (2006) found that extinction of sugar natural reward behaviors increased FLI in the basolateral AMY and the NAc. Kerfoot and co-workers (2007) conditioned sugar availability to a tone (CS+) with the CS+ alone increasing FLI levels in the basolateral AMY. Finally, presentation of palatable chow containing 30\% sucrose increased VTA FLI levels (Park and Carr, 1998).

The present study expanded on these aforementioned experiments by simultaneously examining FLI in the VTA, four mesotelecephalic DA projection zones (mPFC, NAc core, NAc shell and AMY), and the projection zone (CP) of the nigro-striatal system after novel and brief $(1 \mathrm{~h})$ exposure to oral voluntary ingestion of glucose, fructose, corn oil and saccharin solutions and comparing these changes with those elicited by water and xanthan gum (emulsifier of corn oil) solutions. The NAc core and shell were evaluated separately based on differences noted in the aforementioned studies and because of the differential involvement of the NAc shell in addiction and behavioral inhibition, and the NAc core in sensory-motor integration, reward, the regulation of goal-directed behavior, and emotional cues (Di Chiara, 2002). Increased DA levels are pronounced in the NAc shell than core following amphetamine and cocaine treatment (Pontieri et al., 1995). The VTA was exposed to double-labeling of c-fos and tyrosine hydroxylase (TH) immunohistochemistry. It was hypothesized that solutions effective in producing combined orosensory and post-ingestive effects (glucose and corn-oil) would elicit greatest c-fos activation in all areas, whereas short-term exposure to fructose that only activates orosensory (flavor-flavor) consequences would produce activation greater than the control (water) and saccharin, but less activation than either glucose or corn-oil. 


\section{Materials and Methods}

Subjects.

Male Sprague-Dawley rats (260-300 g, Charles River Laboratories, Wilmington, MA) were housed individually in wire mesh cages, and maintained on a 12:12 h light/dark cycle with chow (5001, PMI Nutrition International, Brentwood, MO) and water available ad libitum. The experimental protocols are approved by the Queens College Institutional Animal Care and Use Committee (Protocol 69) certifying that all subjects and procedures are in compliance with the National Institutes of Health Guide for Care and Use of Laboratory Animals.

\section{Testing Apparatus and Intake Procedures.}

Accurate measurement $(+0.1 \mathrm{ml})$ of the presented solutions were insured by using Nalgene centrifuge tubes with rubber stoppers and a 45 degree angle metal sipper tube (Lab Products, Seaford, DE) that were firmly secured to the hanging wire mesh home cages by a taut metal spring $(100 \mathrm{~mm})$ with clips at each end. The calibrated solutions were easily visible to the experimenter. Rats were food restricted to $85 \%$ of their original body weight and were given pre-training solutions (10 ml) of $0.2 \%$ saccharin (Sigma Chemical Co, St. Louis, MO) for 5 days over a $1 \mathrm{~h}$ session. On the sixth day, subgroups of animals, matched for their saccharin intake were offered one of the following six solutions $(10 \mathrm{ml}, 1 \mathrm{~h})$ : water, saccharin $(0.2 \%)$, fructose $(8 \%$, Sigma), glucose (8\%, Sigma), corn oil $(3.5 \%$, Mazzola suspended in $0.3 \%$ xanthan gum (Sigma)) or $0.3 \%$ xanthan gum. The 3.5\% corn-oil concentration was isocaloric to the $8 \%$ sugar solutions.

Tissue preparation and c-fos Procedures.

Ninety min after initial exposure to each test solution on the sixth day, each animal was anesthetized with euthosol (Virbac AH; Forth Worth, TX), and under deep anesthesia, was perfused transcardially with a phosphate buffer solution (PBS) followed by a phosphate-buffered fixative containing 4\% paraformaldehyde. Brains were quickly removed and fixed in $4 \%$ paraformaldehyde overnight at $4^{\circ} \mathrm{C}$. The 
brains were then placed in a 30\% sucrose/70\% PBS solution for several days until they sank to the bottom of their container. The brains were sectioned coronally (40 um sections) through the medial prefrontal cortex (mPFC), the Nucleus Accumbens (NAc) core and shell, the Dorsal Striatum (Caudate and Putamen: CP), the Amygdala (AMY), and the Ventral Tegmental Area (VTA) on a sliding microtome (Microm International). Free-floating sections were then collected into individual wells for the following immunohistochemistry procedures (Ranaldi, et al., 2010). Sections were washed with PBS and then treated with a 5\% Normal Goat Serum (NGS) and $0.2 \%$ Triton $\mathrm{x}-100$ for $1 \mathrm{~h}$. Sections were then incubated with primary antibodies (rabbit anti-c-fos, 1:5000, EMD Chemical) at room temperature for $36 \mathrm{~h}$ followed by incubation with secondary antibodies (biotinylated goat anti-rabbit; 1:200, Vector Labs, Burlingame, California) at room temperature for $2 \mathrm{~h}$. Sections were then rinsed several times in PBS and then incubated for $2 \mathrm{~h}$ in an avidin-horseradish peroxidase mixture (Vector Labs, Burlingame, California). Sections were then rerinsed in PBS and reacted with $0.05 \%$ diaminobenzidine in the presence of $0.0015 \%$ H2O2. VTA sections were also double-labeled by incubating them with a Tyrosine Hydroxlyase (TH) antibody (rabbit anti-rat TH, 1:2000, Millipore, Chandlers Ford, UK), and visualized using a secondary antibody-peroxidase complex for x time. All sections were then mounted onto gelatin-coated slides, dried overnight and coverslipped with a Tolune-Based Solution (TBS).

\section{Stereology}

Pairs of observers uninformed of the animal's testing conditions counted Fos-positive neurons in the MPFC, NAc (core and shell), AMY and VTA in at least three representative slices common to animals in all testing conditions using stereo investigator software (Micro Bright Field, Williston, VA) and an optical microscope. Thus, there were two uninformed raters per section to insure proper inter-rater reliability. Inter-rater reliability exceeded 0.8 for all sites, and the different rostrocaudal VTA levels were analyzed, and delineations were made for c-Fos immunoreactivity in TH+ and TH- VTA. The dorsal striatum (Caudate and Putamen: $\mathrm{CP}$ ) was analyzed subsequently with representative sections taken from levels that 
included the NAc (core and shell). Technical problems precluded the analysis of the substantia nigra, pars compacta on comparable VTA sections, and this brain area was not included in the present analysis.

\section{Statistics.}

Test intakes for five of the groups were analyzed by a 1-way analysis of variance followed by Tukey comparisons $(\mathrm{p}<0.05)$. The intake of the water group was not determined as all animals initially sampled the solution, but then did not return. The c-fos counts for the three representative slices for each site were averaged, and a 1-way analysis of variance evaluated c-fos activation induced by intake of the six solution for the MPFC, the NAc core and shell, AMY, VTA and CP. Tukey comparisons $(\mathrm{p}<0.05)$ were performed to reveal specific significant effects. Corn oil was compared to both water intake and intake of its suspension agent, xanthan gum. Fructose and glucose were compared to both water intake and intake of the non-nutritive sweetener, saccharin. Relationships between solution intakes and c-fos activation in each of the sites were established using Bonferroni $r$ correlations. Taking advantage of the fact that the same animals within a solution condition were evaluated across the six sites, relationships between c-fos activation across solutions and within each solution were also established using Bonferroni $r$ correlations.

\section{Results}

Solution Intakes.

Significant differences in intake were observed $(F(4,26)=38.90, p<0.0001)$ among the five measured solutions. Fructose intake $(9.6( \pm 0.4) \mathrm{ml})$ and glucose intake $(9.4( \pm 0.6) \mathrm{ml})$ were significantly higher than saccharin $(4.7( \pm 0.7) \mathrm{ml})$ or xanthan gum $(0.6( \pm 0.1) \mathrm{ml})$ intake. Further, corn oil intake $(7.4( \pm 0.6) \mathrm{ml})$ was significantly higher than xanthan gum intake. These results raised the possibility that solution intake per se might account for any observed c-fos activation in any of the sites. To examine this, Bonferroni $r$ correlations were performed in which intake 
of the five solutions was related to c-fos activation in each of the six sites. Significant correlations failed to be observed between solution intake and c-fos activation in the NAc core $(r(29)=0.186)$, the NAc shell $(r(29)=0.029)$, the mPFC $(r(29)=0.142)$, the VTA $(r(29)=0.100)$, the CP $(r(29)=0.139)$ and the AMY $(r(29)=0.409)$. Given the potential relationship between intake and amygdalar c-fos activation, further correlations were performed for each individual solution. Although there appeared to be no relationship between intake and c-fos activation for fructose ( $r=-0.133)$, glucose $(r=-0.133)$ or saccharin $(r=0.422)$, there was a strong positive correlation between corn oil intake and amydalar c-fos activation $(r=0.640)$ and a strong negative correlation between xanthan gum intake and amygdalar c-fos activation $(r=-0.939)$.

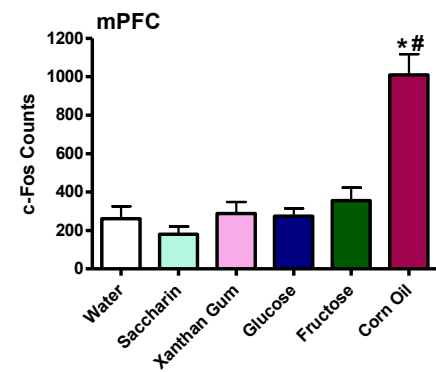

Condition

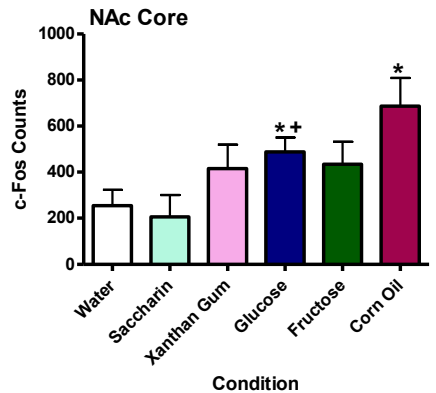

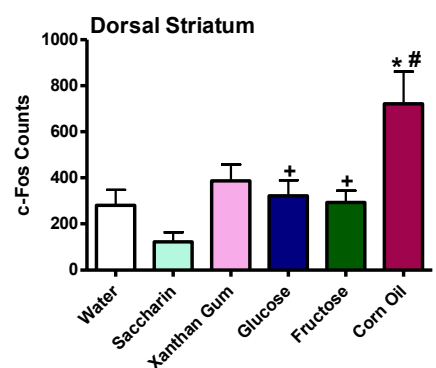

Condition

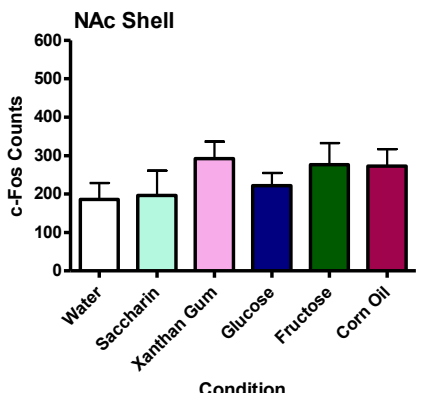

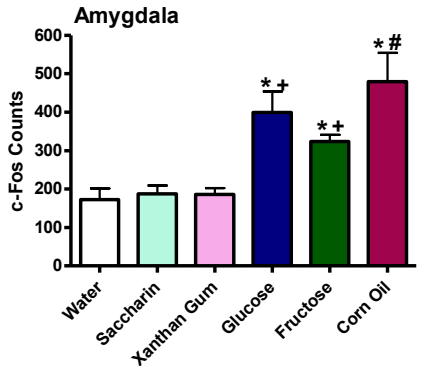

Condition

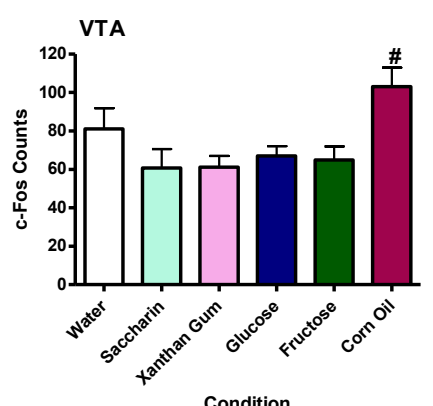

Figure 1. Alterations in c-fos activation (mean $+\mathrm{SEM})$ of the medial prefrontal cortex ( $\mathrm{mPFC}$, Panel A), dorsal striatum (C/P, Panel B), amygdala (AMY, Panel C), nucleus accumbens (NAc) core (Panel D) and shell (Panel E) and ventral tegmental area (VTA, Panel E) following consumption of water, saccharin (0.2\%), xanthan gum (control for corn oil), glucose (8\%), fructose $(8 \%)$ or corn oil $(3.5 \%)$.

mPFC c-Fos Activation. Significant differences in mPFC c-Fos activation were observed among solution conditions $(F(5,31)=20.60, p<0.0001)$. Exposure to the corn oil solution significantly increased c-Fos counts in the $\mathrm{MPFC}$ relative to 
exposure to water or the xanthan gum (Figure 1A). In contrast, exposure to glucose, fructose or saccharin failed to alter c-Fos counts in the mPFC relative to water exposure. Figure 2 displays respective 4 -fold and 10-fold magnifications of representative mPFC sections of animals exposed to corn oil (Panels A and C) and to water (Panels B and D).

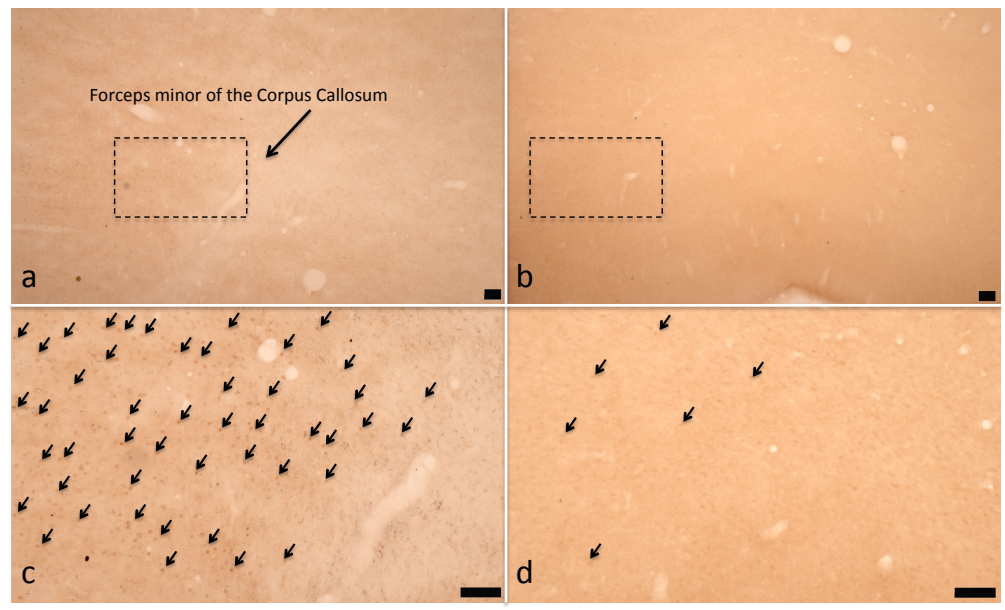

Figure 2. C-fos activation observed in representative $\mathrm{MPFC}$ sections of animals exposed to corn oil (Panels A (4-fold) and $C(10-$ fold $))$ and to water (Panels B (4fold) and $D(10$-fold)). Arrows are indications of representative c-fos positive cells. All scale bars are 100 microns.

Dorsal Striatal c-Fos Activation. Significant differences in dorsal striatal c-Fos activation were observed among solution conditions $(F(5,31)=6.82, p<0.003)$. Exposure to the corn oil solution significantly increased c-Fos counts in the dorsal striatum relative to exposure to water or the xanthan gum (Figure 1B). Moreover, exposure to either glucose or fructose significantly increased c-Fos counts in the dorsal striatum relative to saccharin exposure. In contrast, saccharin failed to differ from water in eliciting dorsal striatal c-Fos activation. Figure 3 displays 10-fold magnifications of representative dorsal striatal sections of animals exposed to corn oil (Panel A), glucose (Panel B), fructose (Panel C) and water (Panel D). 


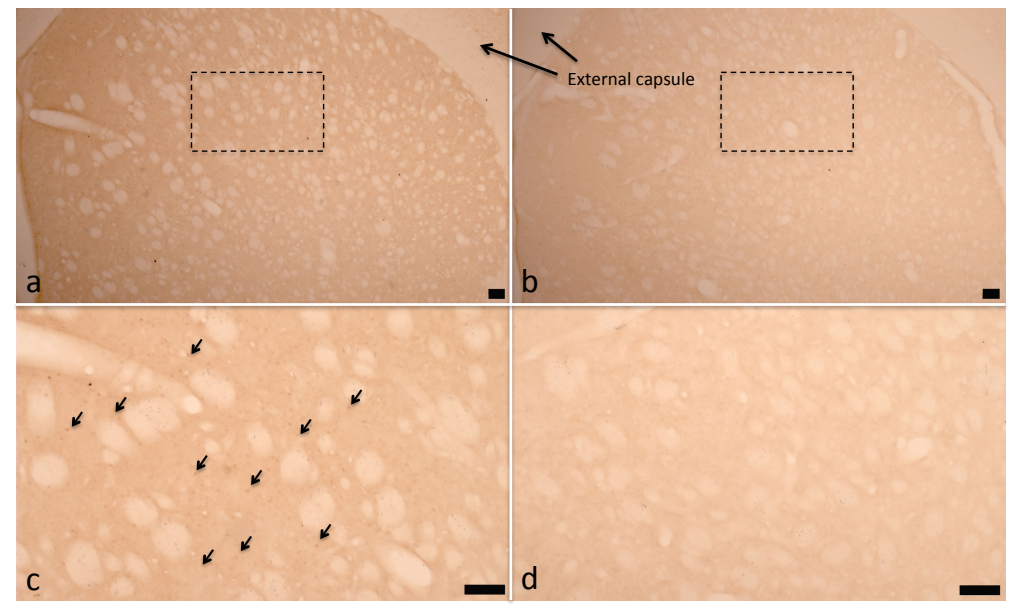

Figure 3. C-fos activation observed in representative $\mathrm{CP}$ sections of animals exposed to corn oil (Panels A (4-fold) and $C(10$-fold)) and to water (Panels B (4-fold) and D (10-fold)). Arrows are indications of representative c-fos positive cells. All scale bars are 100 microns.

Amygdalar c-Fos Activation.Significant differences in amygdalar c-Fos activation were observed among solution conditions $(F(5,31)=8.86, p<0.0001)$. Exposure to the corn oil solution significantly increased c-Fos counts in the amygdala relative to exposure to water or the xanthan gum (Figure 1C). Moreover, exposure to either glucose or fructose significantly increased c-Fos counts in the amygdala relative to saccharin or water exposure. In contrast, saccharin failed to differ from water in eliciting amygdalar c-Fos activation. Figure 4 displays 10-fold magnifications of representative amygdalar sections of animals exposed to corn oil (Panel A), glucose (Panel B), fructose (Panel C) and water (Panel D).

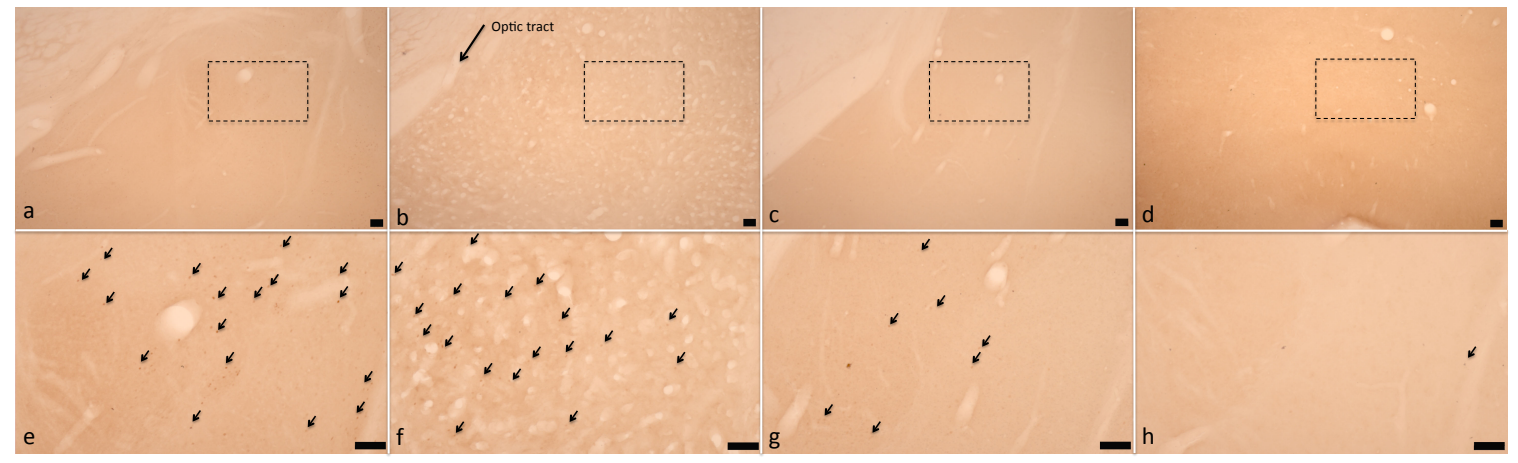

Figure 4. C-fos activation observed in representative (4-fold magnification) AMY sections of animals exposed to corn oil (Panel A), glucose (Panel B), fructose (Panel C) and water (Panel D), and in higher magnification (10-fold) for corn oil (Panel E), glucose (Panel G), fructose (Panel G) and water (Panel H). Arrows are indications of representative c-fos positive cells. All scale bars are 100 microns.

NAc Core c-Fos Activation. Significant differences in c-Fos activation in the NAc core were observed among solution conditions $(F(5,31)=3.33, p<0.017)$. Exposure to the corn oil solution significantly increased c-Fos counts in the NAc core relative 
to water exposure (Figure 1D). Moreover, exposure to glucose significantly increased c-Fos counts in the NAc core relative to saccharin or water exposure. In contrast, fructose and saccharin failed to differ from water in eliciting c-Fos activation in the NAc core. Figure 5 displays 4 -fold magnifications of representative sections in the NAc core of animals exposed to corn oil (Panel A), glucose (Panel B), fructose (Panel C) and water (Panel D).

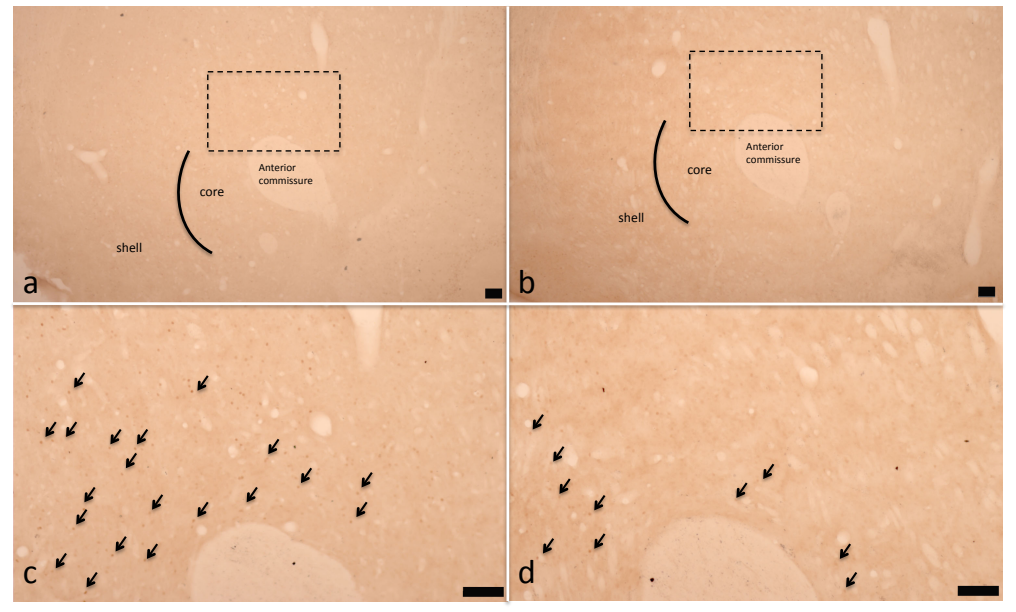

Figure 5. C-fos activation observed in representative NAc sections of animals exposed to corn oil (Panels A (4-fold) and C (10-fold)) and to water (Panels B (4-fold) and $D(10$-fold)). Arrows are indications of representative c-fos positive cells. All scale bars are 100 microns.

NAc Shell c-Fos Activation. In marked contrast, significant differences in c-Fos activation in the NAc shell failed to be observed among solution conditions $(F(5,31)=0.74, n s)$. Exposure to the corn oil, glucose and fructose solutions failed to significantly increase c-Fos counts in the NAc shell relative to any of the control conditions (Figure 1E). Figure 5 displays 4-fold magnifications of representative sections in the NAc shell of animals exposed to corn oil (Panel A), glucose (Panel B), fructose (Panel C) and water (Panel D).

VTA c-Fos Activation. Significant differences in the number of double-labeled VTA TH-positive and c-Fos-activated cells were observed among solution conditions $(F(5,31)=3.48, p<0.013)$. Exposure to the corn oil solution significantly increased cFos counts in TH+ VTA cells relative to exposure to xanthan gum (Figure 1F). In contrast, exposure to glucose, fructose or saccharin failed to alter c-Fos counts in the VTA relative to water exposure. Significant differences failed to be observed $(F(5,31)=1.18, n s)$ in the very few $\mathrm{TH}$-positive and c-Fos-negative cells observed in 
animals exposed to water (23), glucose (19), fructose (19), corn oil (18), saccharin (15) or xanthan gum (17). Figure 6 displays 4-fold and 10-fold magnifications of representative $\mathrm{TH}+$ and $\mathrm{TH}$ - and c-Fos-activated VTA cells of animals exposed to corn oil (Panels A and C) and to water (Panels B and D).

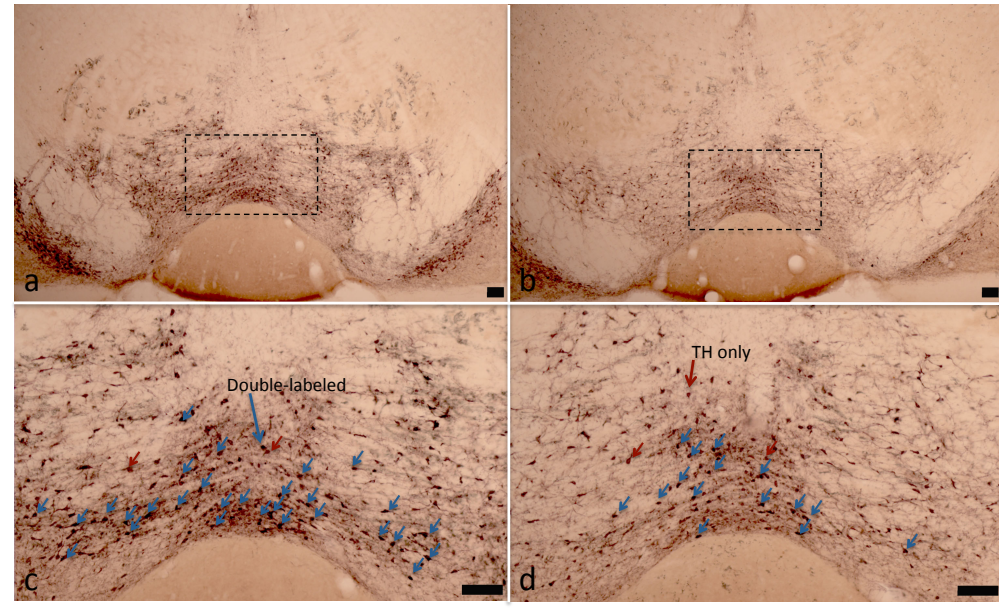

Figure 6. C-fos activation observed in representative TH-positive VTA sections of animals exposed to corn oil (Panels A (4-fold) and $C$ (10-fold)) and to water (Panels B (4-fold) and D (10-fold)). Blue arrows indicate representative doublelabeled TH/c-fos positive cells, while red arrows indicate c-fos only cells. All scale bars are 100 microns.

Relationships of c-Fos Activation among sites and solutions. The pattern of cFos counts in animals exposed to corn oil revealed positive correlations between the NAc core and its relationships with the NAc shell $(r=0.971), \operatorname{mPFC}(r=0.670)$ and VTA ( $\mathrm{r}=0.481)$, between the NAc shell and the mPFC ( $\mathrm{r}=0.528)$, and between the dorsal striatum and its relationships with the mPFC $(r=0.490)$ and VTA $(r=0.723)$. In contrast, the pattern of c-Fos counts in animals exposed to corn oil revealed inverse negative correlations between the amygdala and its relationship with the NAc core $(r=-0.711)$ and the NAc shell $(r=-0.709)$. The pattern of $c-F o s$ counts in animals exposed to glucose revealed positive correlations between the NAc core and its relationships with the NAc shell $(r=0.633)$, mPFC $(r=0.488)$ and dorsal striatum $(r=0.937)$, between the NAc shell and the mPFC ( $r=0.449)$, and between the dorsal striatum and its relationships with the mPFC $(r=0.542)$, VTA $(r=0.717)$ and amygdala $(\mathrm{r}=0.894)$. The pattern of $\mathrm{c}$-Fos counts in animals exposed to fructose revealed positive correlations between the NAc core and its relationships with the NAc shell $(r=0.969)$ and amygdala $(r=0.609)$, between the NAc shell and its relationships with the dorsal striatum $(\mathrm{r}=0.548)$ and amygdala $(\mathrm{r}=0.628)$, and between the dorsal striatum and amygdala ( $\mathrm{r}=0.501)$. In contrast, the pattern of $\mathrm{c}$ - 
Fos counts in animals exposed to fructose revealed inverse negative correlations between the dorsal striatum and mPFC $(r=-0.482)$. The pattern of c-Fos counts in animals exposed to saccharin revealed positive correlations between the NAc core and NAc shell ( $\mathrm{r}=0.792)$ and between the NAc shell and dorsal striatum ( $\mathrm{r}=0.715)$. In contrast, the pattern of c-Fos counts in animals exposed to saccharin revealed inverse negative correlations between the dorsal striatum and $\mathrm{mPFC} r=-0.544$ ) and between the NAc core and amygdala $(r=-0.630)$. The pattern of c-Fos counts in animals exposed to water revealed positive correlations between the NAc core and NAc shell $(\mathrm{r}=0 . .838)$ and between the VTA and mPFC $(\mathrm{r}=0.448)$. In contrast, the pattern of c-Fos counts in animals exposed to water revealed inverse negative correlations between the amygdala and its relationships with the NAc core $(\mathrm{r}=-$ 0.792) and NAc shell ( $\mathrm{r}=-0.514)$, and between the VTA and dorsal striatum ( $\mathrm{r}=-$ 0.485). Finally, the pattern of c-Fos counts in animals exposed to xanthan gum revealed positive correlations between the NAc core and its relationships with the NAc shell ( $\mathrm{r}=0 . .987)$, the dorsal striatum $(\mathrm{r}=0.778)$ and amygdala $(\mathrm{r}=0.447)$, between the dorsal striatum and its relationship with the NAc shell ( $r=0.667)$ and amygdala ( $\mathrm{r}=0.899)$, between the VTA and its relationship with the mPFC $(\mathrm{r}=$ $0.715)$ and amygdala $(r=0.638)$. In contrast, the pattern of $c$-Fos counts in animals exposed to xanthan gum revealed inverse negative correlations between the NAc core and its relationships with the mPFC $(r=-0.480)$ and VTA $(r=-.401)$, and between the NAc shell and its relationships with the mPFC $(r=-0.581)$ and VTA $(r=-$ $0.542)$.

\section{Discussion}

Acute, voluntary and short-term (1 h) exposure to corn oil, glucose, fructose and saccharin produced differential FLI activation of the VTA, four mesotelencephalic DA projection zones (mPFC, NAc core, NAc shell and AMY) and the main projection zone (CP) of the DA nigro-striatal system. The $8 \%$ glucose $(9.4 \mathrm{ml})$, $8 \%$ fructose $(9.6 \mathrm{ml})$ and $3.5 \%$ corn oil $(7.4 \mathrm{ml})$ solutions were isocaloric with respect to each other, and elicited comparable intakes following acute exposure. Exposure to corn oil elicited significant increases in FLI in the mPFC, dorsal striatum 
and AMY relative to water and a xanthan gum control, in the NAc core and VTA relative to water, but failed to alter FLI in the NAc shell. Water and xanthan gum failed to differ from each other in eliciting FLI from any of the six sites. Although a $0.2 \%$ saccharin solution elicited intake $(4.7 \mathrm{ml})$, it was significantly less than glucose or fructose consumption. Moreover, exposure to saccharin failed to elicit any changes in FLI in any site relative to water. Exposure to the two sugars, glucose and fructose, elicited differential patterns of FLI responses with respect to one another. Thus, exposure to glucose elicited significant increases in FLI in the AMY and NAc core relative to water and saccharin, in the dorsal striatum relative to saccharin, but failed to alter FLI in the mPFC, VTA or NAc shell. Correspondingly, exposure to fructose elicited significant increases in FLI in the AMY relative to water and saccharin, in the dorsal striatum relative to saccharin, but failed to alter FLI in the mPFC, VTA, NAc core or NAc shell. These data collectively support the hypothesis that short-term exposure to solutions effective in producing combined orosensory and post-ingestive effects, isocaloric concentrations of corn oil and glucose, would elicit the greatest c-fos activation in the most areas, whereas short-term exposure to fructose, capable of activating orosensory (flavor-flavor conditioning: Baker et al., 2003; Sclafani et al., 1993, 1999) consequences would produce less extensive activation than glucose and corn oil, but would elicit greater activation than water or saccharin.

Given the variation in voluntary intake across offered solutions, it is conceivable that FLI activation in these sites might be attributable to intake per se. This explanation could not account for the failure to observe significant and meaningful relationships between solution intake and FLI activation in the NAc core $(r=0.186)$, NAc shell $(r=0.029)$, mPFC $(r=0.142)$, VTA $(r=0.100)$ or CP $(r=0.139)$. The stronger relationship between solution intake and AMY FLI ( $\mathrm{r}=0.409)$ was influenced mostly between AMY c-fos and corn oil intake $(r=0.640)$ and xanthan gum intake ( $r=-0.939)$. Thus, it does not appear that solution intakes per se participate strongly in the observed differences in c-fos activation across solutions and sites. The following sections examine the specific differences in solutioninduced activation across each of the sites and then try to establish relationships 
across sites that might be consistent with suggestions of "distributed brain networks" influencing feeding (see reviews: Kelley, 2004; Kelley et al., 2005; Meredith et al., 2008; Will et al., 2003).

Nucleus accumbens: The NAc has long been implicated in the relationship between the rewarding aspects of food and brain DA function. Thus, DA turnover and extracellular DA in the NAc are increased similarly by food, saccharin, hypothalamic brain stimulation and cocaine (Hajnal and Norgren, 2001; Hernandez and Hoebel, 1988a, 1988b; Mark et al., 1991). DA in the NAc is stimulated by the oral properties of sucrose and corn oil (Hajnal et al., 2004; Liang et al., 2006; Savano et al., 2000). Indeed such DA-induced increases have been focused within the NAc shell following orosensory-specific sucrose bingeing schedules (Avena et al., 2006; Rada et al., 2005). These data show strong congruence with the ability of DA D1 and D2 receptor antagonists administered into the NAc shell to reduce the expression of the orosensory-mediated fructose-CFP (Bernal et al., 2008), and the ability of DA D1 receptor antagonists administered into either the NAc core or shell to eliminate the acquisition of postingestive-mediated IG glucose-CFP (Touzani et al., 2008). Such data would then predict that glucose and fructose should increase c-fos in both NAc subregions.

Norgren and coworkers (2006) interestingly found that rats trained to shamfeed sucrose over a 1-week paradigm displayed marked increases in c-fos relative to water in the NAc shell, but not the NAc core. Otsubo and co-workers (2011) found that glucose administration exclusively enhanced c-fos induction in the NAc core. In our paradigm, acutely exposing animals to glucose once after four days of saccharin training selectively increased c-fos activation in the NAc core, but not the shell. In contrast, acute exposure to fructose once after four days of saccharin training failed to alter c-fos activation in either site. Although glucose elicited strong FLI in the NAc core, but not the shell, a strong positive relationship between the two sites $(\mathrm{r}=$ 0.633) was observed in the animals exposed to glucose. Further, although corn oil elicited strong FLI in the NAc core, but not the shell, a strong positive relationship between the two sites ( $r=0.971)$ was observed in the animals exposed to corn oil. Finally, although fructose nonsignificantly increased FLI in both the NAc core and 
shell, another strong positive relationship between the two sites $(r=0.969)$ was observed in the animals exposed to fructose. Thus, given the differential patterns in c-fos activation across sugars and paradigms, these data suggest that DA modulation of NAc core and shell play different roles in the processes related to conditioning of sugar-related responses much like their respective differential involvement in other "reward-related" behaviors (e.g., Di Chiara, 2002; Pontieri et al., 1995) and Pavlovian approach behaviors (Day et al., 2006). Finally, ingestion of differently flavored beverages with (CS+) or without (CS-) maltose dextrin in healthy human volunteers demonstrated "liking" responses for the CS+ solution and activation of the NAc and lateral hypothalamus (de Araujo et al., 2013).

Amygdala: The AMY is another site long been implicated in motivation and learning related to food reward (Baxter and Murray, 2002; Cardinal et al., 2002; Gilbert et al., 2003) as well as a role for DA function in these responses (Andrzejewski et al., 2005; Hajnal \& Lenard, 1997; Harmer \& Phillips, 1999; Heffner et al., 1980). These data show strong congruence with the ability of DA D1 receptor antagonists administered into the AMY to reduce the expression of the orosensorymediated fructose-CFP (Bernal et al., 2009) and eliminate the acquisition of postingestive-mediated IG glucose-CFP (Touzani et al., 2009), and the ability of DA D2 receptor antagonists administered into the AMY to eliminate the acquisition of the orosensory-mediated fructose-CFP (Malkusz et al., 2012). Such data would then predict that glucose and fructose should increase AMY c-fos.

Sucrose and glucose intake consumed under real-feeding conditions, shamfeeding conditions and IG infusions significantly increased FLI in the central and basolateral nuclei of the AMY (Mungarndee et al., 2008; Norgren, et al., 2006; Otsubo, et al., 2011; Yamamoto, et al., 1997; Zhao, et al., 2011). Sugar-sensitive changes using other paradigms also elicited strong increases in AMY FLI (Hamlin et al., 2006; Kerfoot et al., 2007; Pecoraro and Dallman, 2005). The present findings confirmed and extended these findings by showing that both glucose and fructose consumption markedly increased FLI in the AMY relative to both consumption of water and saccharin. Further, corn oil consumption also markedly increased FLI in the AMY relative to both consumption of water and its xanthan gum suspension 
control. Indeed, of the six sites simultaneously examined, the AMY and dorsal striatum were the only sites sensitive to FLI-induced increases following all three palatable solutions. Indeed, a strong positive correlation was observed $(\mathrm{r}=0.894)$ between the AMY and dorsal striatum in animals exposed to glucose. A modest positive correlation was observed $(r=0.501)$ between the AMY and dorsal striatum in animals exposed to fructose. In contrast, a relatively weak positive correlation was observed $(r=0.358)$ was observed between the AMY and dorsal striatum in animals exposed to corn oil.

Medial prefrontal cortex: The MPFC is a third forebrain site implicated in motivation and learning related to food reward (Kelley, 2004; Ishikawa et al., 2008) as well as a role for DA function in these responses (Baldwin et al., 2002; Bassareo et al., 2002; Hernandez \& Hoebel, 1990; Izaki et al., 1999). Repeated addition of sucrose to scheduled chow access significantly increased mPFC FLI (Mitra et al., 2011). These data show strong congruence with the ability of DA D1 and D2 receptor antagonists administered into the $\mathrm{MPFC}$ to eliminate the acquisition of the orosensory-mediated fructose-CFP (Malkusz et al., 2012) and the ability of DA D1 receptor antagonists to eliminate the acquisition of postingestive-mediated IG glucose-CFP (Touzani et al., 2010). Such data would then predict that glucose and fructose should increase mPFC c-fos. Yet, our paradigm demonstrated that whereas corn oil consumption markedly increased mPFC FLI relative to both consumption of water and its xanthan gum suspension control, the increases in mPFC FLI following glucose or fructose failed to significantly differ from their controls. Positive correlations were observed between the MPFC and other corn-oil sensitive sites including the NAc core $(r=0.670)$ and the dorsal striatum $(r=0.490)$, but not other corn-oil sensitive sites including the AMY $(r=-0.346)$ or the VTA $(r=0.283)$.

Ventral tegmental area and Dorsal striatum: Unlike the NAc, AMY and mPFC, the VTA has not been studied as extensively for sugar- and fat-reward related processes and DA release. In the VTA, optogenetic induction of phasic, but not tonic VTA DA neurons in a subthreshold social defeat paradigm decreased sucrose preference (Chaudhury et al., 2013). Mice exposed to sucrose, and then made abstinent demonstrate increased c-Fos activation in the VTA upon relapse (Madsen 
et al., 2012). Mice preferred optogenetic stimulation of VTA DA neurons top sucralose, but not sucrose (Domingos et al., 2011). VTA insulin reduced sweetened high-fat food intake (Mebel et al., 2012). POMC overexpression in the VTA decreased weight gain in rats fed a high-fat diet (Andino et al., 2011), and ventricular agoutirelated peptide increased neuronal activation of VTA DA neurons (Davis et al., 2011). Offspring of dams fed a high-fat diet displayed reductions in VTA DA D2 receptor mRNA levels (Naef et al., 2011), whereas mice with overexpression of Delta-FosB and fed a high-fat diet show stabilization of VTA circuitry (Teegarden et al., 2008). Finally, human volunteers who consume saccharin-based soft drinks display greater activation to sweet taste in the VTA (Green \& Murphy, 2012). Despite the ability of sugars and fats to activate VTA DA neurons, the present study demonstrated that intake of corn oil selectively activated FLI in the VTA, and only did so in cells that were double-labeled with $\mathrm{TH}$, confirming that the activation occurred in DA-containing cells. Indeed, most (86\%) of the TH-positive cells in the sample were activated by the corn oil. Positive correlations in the ability of corn oil to increase FLI were observed between the VTA and the dorsal striatum $(r=0.723)$ and the NAc core $(r=0.481)$ respectively, but not the AMY or mPFC. In contrast, neither glucose nor fructose activated VTA FLI more than either water or saccharin, with activation noted in respectively $78 \%$ and $77 \%$ of the TH-positive cells. The respective ability of corn oil and inability of sugars to induce VTA FLI was not due to nutrient load as all of these solutions were isocaloric.

Only a couple of studies have examined food consumption and dorsal striatal responses. Thus, whereas mu-opioid receptor stimulation of the ventral striatum (NAc) markedly enhanced intake of a high-fat food, this response was far more muted following injections into the dorsal striatum (Zhang \& Kelley, 2000). In human volunteers, post-breakfast fullness was positively correlated with activation in the dorsal striatum (Mehta et al., 2012). This makes the present results all the more novel as both glucose and glucose each significantly activated FLI relative to saccharin consumption, and corn oil significantly activated FLI relative to water and the xanthan gum control. Positive relationships were observed for FLI between the dorsal striatum and NAc core $(r=0.937)$, AMY $(r=0.893)$, VTA $(r=0.717)$ and $\mathrm{mPFC}$ 
$(r=0.542)$ in animals consuming glucose. Interestingly, no meaningful relationships in FLI were observed between the dorsal striatum and the other sites in animals consuming fructose. However, positive relationships were observed for FLI between the dorsal striatum and VTA ( $\mathrm{r}=0.723)$ and $\mathrm{mPFC}(\mathrm{r}=0.490)$ in animals consuming corn oil. Therefore, one might suspect that the different origins and projections of the nigro-striatal (SN to dorsal striatum) and the meso-cortico-limbic (VTA to AMY, NAc and mPFC) DA systems might be tightly related. Unfortunately, due to technical difficulties, we could not ascertain complete SN counts of TH-positive cells in these conditions. Based on these very strong activations by both sugars and corn oil, it would be interesting to investigate whether dorsal striatal microinjections of DA D1 or D2 receptor antagonists would alter sugar and fat intake per se and/or the acquisition and expression of sugar- and fat-CFP. 


\section{References}

Ackroff, K., \& Sclafani, A. (2004). Fructose-conditioned flavor preferences in male and female rats: effects of sweet taste and sugar concentration. Appetite, 42(3), 287-297.

Ackroff, K., Touzani, K., Peets, T.K. \& Sclafani, A. (2001). Flavor preferences conditioned by intragastric fructose and glucose: differences in reinforcement potency. Physiology and Behavior, 72: 691-703.

Ågmo, A., Galvan, A., \& Talamantes, B. (1995). Reward and reinforcement produced by drinking sucrose: Two processes that may depend on different neurotransmitters. Pharmacology Biochemistry and Behavior, 52: 403-414.

Andino, L.M., Ryder, D.J., Shapiro, A., Matheny, M.K., Zhang, Y., Judge, M.K., Cheng, K.Y., Turner, N. \& Scarpace, P.J. (2011). POMC overexpression in the ventral tegmental area ameliorates dietary obesity. Journal of Endocrinology, 210: 199-207.

Andrzejewski, M.E., Spencer, R.C. \& Kelley, A.E. (2005) Instrumental learning, but not performance, requires dopamine D1-receptor activation in the amygdala. Neuroscience, 135: 335-345.

Anseloni, V. C. Z., Ren, K., Dubner, R. \& Ennis, M. (2005). A brainstem substrate for analgesia elicited by intraoral sucrose. Neuroscience, 133: 231-243.

Avena, N.M., Rada, P., Moise, N. \&Hoebel, B.G. (2006). Sucrose sham feeing on a binge schedule releases accumbens dopamine repeatedly and eliminates the acetylcholine stiety response. Neuroscience, 138: 813-820.

Azzara, A.V., Bodnar, R.J., Delamater, A.R. \& Sclafani, A. (2001). D 1 but not $\mathrm{D}_{2}$ dopamine receptor antagonism blocks the acquisition of a flavor preference conditioned by intragastric carbohydrate infusions. Pharmacology Biochemistry and Behavior 68: 709-720.

Baker, R.W., Osman, J., \& Bodnar, R.J. (2001). Differential actions of dopamine receptor antagonism in rats upon food intake elicited by mercaptoacetate or exposure to a palatable high-fat diet. Pharmacology Biochemistry and Behavior, 69: 201-208. 
Baker, R. M., Shah, M.J., Sclafani, A. \& Bodnar, R.J. (2003). Dopamine D1 and D2 antagonists reduce the acquisition and expression of flavor-preferences conditioned by fructose in rats. Pharmacology Biochemistry and Behavior, 75: 55-65.

Baldwin, A. E., Sadeghian, K., \& Kelley, A. E. (2002). Appetitive instrumental learning requires coincident activation of NMDA and dopamine D1 receptors within the medial prefrontal cortex. Journal of Neuroscience, 22, 1063-1071.

Bassareo, V., De Luca, M. A., \& Di Chiara, G. (2002). Differential expression of motivational stimulus properties by dopamine in nucleus accumbens shell versus core and prefrontal cortex. Journal of Neuroscience, 22, 4709-4719.

Baxter, M.G. \& Murray, E.A. (2002) The amygdala and reward. Nature Review Neuroscience, 3, 563-573.

Bernal, S.Y., Dostova, I., Kest, A., Abayev, Y., Kandova, E., Touzani, K., Sclafani, A. \& Bodnar, R. (2008). Role of dopamine D1 and D2 receptors in the nucleus accumbens shell on the acquisition and expression of fructose-conditioned flavor-flavor preferences in rats. Behavioural Brain Research, 190: 59-66.

Bernal, S., Miner, P., Abayev, Y., Kandova, E., Gerges, M., Touzani, K., Sclafani, A., \& Bodnar, R.J. (2009). Role of amygdala dopamine D1 and D2 receptors in the acquisition and expression of fructose-conditioned flavor preferences in rats. Behavioural Brain Research: 213: 183-190.

Berridge, K.C. (2007). The debate over dopamine's role in reward: the case forincentive salience. Psychopharmacology, 191: 391-431.

Berridge, K.C. (2012). From prediction error to incentive salience: mesolimbic computation of reward motivation. European Journal of Neuroscience 35, 1124-1143.

Berridge, K.C. \& Robinson, T.E. (1998). What is the role of dopamine in reward: hedonic impact, reward learning of incentive salience? Brain Research Reviews, 28: 309-369.

Bjorklund, A. \& Dunnett, S.B. (2007). Dopamine neuron systems in the brain: an update. Trends in Neurosciences, 30: 194-202. 
Cardinal, R.N., Parkinson, J.A., Hall, J. \& Everitt, B.J. (2002) Emotion and motivation: the role of the amygdala, ventral striatum, and prefrontal cortex. Neuroscience \& Biobehavioral Reviews, 26, 321-352.

Chaudhury, D., Walsh, J.J., Friedman, A.K., Juarez B., Ku, S.M., Ferguson, D., Tsai, H.C., Pomeranz, L., Christoffel, D.J., Nectow, A.R., Ekstrand, M., Domingos, A., MazeiRobison, M.S., Mouzon, E., Lobo, M.K., Neve, R.L., Friedman, J.M., Russo, S.J., Deisseroth, K., Nestler, E.J., Han, M.H. (2012). Rapid regulation of depressionrelated behaviours by control of midbrain dopamine neurons. Nature, 493, 532-536.

Chen, K., Yan, J., Li, J., Lv, B. \& Zhao, X. (2011). c-Fos expression in rat brainstem following intake of sucrose or saccharin. Frontiers in Medicine, 5, 294-301.

Davis, J.F., Choi, D.L., Shurdak, J.D., Krause, E.G., Fitzgerald, M.F., Lipton, J.W., Sakai, R.R. \& Benoit, S.C. (2011). Central melanocortins modulate mesocorticolimbic activity and food seeking behavior in the rat. Physiology \& Behavior, 102, 491495.

Davis, J.F., McQuade, J.A., Drazen, D.L., Woods, S.C., Seeley, R.J., \& Benoit, S.C. (2006). Role for dopamine-3 receptor in the hyperphagia of an unanticipated high-fat meal in rats. Pharmacology Biochemistry and Behavior, 85, 190-197.

Day, H.E., Kryskow, E.M., Nyhuis, T.J., Herlihy, L. \& Campeau, S. (2008). "Conditioned Fear Inhibits c-fos mRNA Expression in the Central Extended Amygdala". Brain Research, 1229: 137-146.

Day, J.J., Wheeler, R.A., Roitman, M.F. \& Carelli, R.M. (2006). Nucleus accumbens neurons encode Pavlovian apporach behaviors: evidence from an autoshaping paradigm. European Journal of Neuroscience, 23, 1341-1351.

De Araujo, I.E., Lin, T., Veldhuizen, M.G. \& Small, D.A. (2013). Metabolic regulation of brain responses to food cues. Current Biology, 23, 878-883.

Dela Cruz, J.A., Icaza-Cukali, D.P., Tayabali, H., Galanopoulos, V., Sampson, C., Bamshad, D., Touzani, K., Sclafani, A. \& Bodnar, R.J. (2012a) Roles of dopamine D1 and D2 receptors in the acquisition and expression of fatconditioned flavor preferences in rats. Neurobiology of Learning and Memory, 97: $332-337$. 
Dela Cruz, J. A. D., Bae, V. S., Icaza-Cukali, D., Sampson, C., Bamshad, D., Samra, A., ... \& Bodnar, R. J. (2012b). Critical role of NMDA but not opioid receptors in the acquisition of fat-conditioned flavor preferences in rats. Neurobiology of learning and memory.

di Chiara, G. (2002). Nucleus Accumbens Shell and Core Dopamine: Differential Role in Behavior and Addiction." Behavioural Brain Research. 137: 75-114.

Dragone, D. (2009). A rational eating model of binges, diets and obesity. The Journal of Health Economics, 28: 799-804.

Dragunow, M. \& Faull, R. (1989). The use of c-fos as a metabolic marker in neuronal pathway tracing. Journal of Neuroscience Methods 29: 261-265.

Dunnett, S. B., \& Iversen, S. D. (1980). Regulatory impairments following selective kainic acid lesions of the neostriatum.Behavioural Brain Research, 1: 497506.

Dym, C.T., Bae, V., Kraft, T.T., Yakubov, Y., Winn, A., Sclafani, A. \& Bodnar, R.J. (2010). Genetic variance contributes to dopamine and opioid receptor antagonistinduced inhibition of Intralipid (Fat) intake in inbred and outbred mouse strains. Brain Research, 1316: 51-61.

Dym, C.T., Pinhas, A., Robak, M., Sclafani, A. \& Bodnar, R.J. (2009). Genetic variance contributes to dopamine D1 and D2 antagonist-induced inhibition of sucrose intake in inbred and outbred mouse strains. Brain Research, 1257: 40-52.

El-Ghundi, M., O'Dowd, B.F., Erclik, M.\& George, S.R. (2003). Attenuation of sucrose reinforcement in dopamine D1 receptor deficient mice. European Journal of Neuroscience 17: 851-862.

Elizalde, G. \& Sclafani, A. (1990). Fat appetite in rats: Flavor preferences conditioned by nutritive and non-nutritive oil emulsions. Appetite, 15: 189-197

Geary, N. \& Smith, G.P. (1985). Pimozide decreases the positive reinforcing effect of sham fed sucrose in the rat. Pharmacology Biochemistry and Behavior, 22:787- 90.

Genn, R.F., Ahn, S. \& Phillips, A.G. (2004).Attenuated dopamine efflux in the rat nucleus accumbens during successive negative contrast.Behavioral Neuroscience, 118: 869-873. 
Gilbert, P.E., Campbell, A. \& Kesner, R.P. (2003) The role of the amygdala in conditioned flavor preference. Neurobiology of Learning and Memory, 79, 118-121.

Green, E. \& Murphy, C. (2012). Altered processing of sweet taste in the brain of diet soda drinkers. Physiology \& Behavior, 107, 560-567.

Hajnal, A. \& Lenard, L. (1997) Feeding-related dopamine in the amygdala of freely moving rats. Neuroreport, 8, 2817-2820.

Hajnal, A. \& Norgren, R. (2001). Accumbens dopamine mechanisms in sucrose intake. Brain Research, 904:76-84.

Hajnal, A., Smith, G.P. \& Norgren, R. (2004). Oral sucrose stimulation increases accumbens dopamine in the rat. American Journal of Physiology, 286(1): R31R37.

Hamlin, A. S., Blatchford, K. E. \& McNally, G. P. (2006). Renewal of an extinguished instrumental response: Neural correlates and the role of D1 dopamine receptors. Neuroscience, 143, 25-38.

Harmer, C.J. \& Phillips, G.D. (1999) Enhanced dopamine efflux in the amygdala by a predictive, but not a non-predictive, stimulus: facilitation by prior repeated D-amphetamine. Neuroscience, 90, 119-130.

Harrer, M. I. \& Travers, S. P. (1996).Topographic organization of Fos-like immunoreactivity in the rostral nucleus of the solitary tract evoked by gustatory stimulation with sucrose and quinine. Brain Research, 711:125137.

Heffner, T.G., Hartman, J.A. \& Seiden, L.S. (1980) Feeding increases dopamine metabolism in the rat brain. Science, 208, 1168-1170.

Hernandez, L. \& Hoebel, B.G. (1988a). Feeding and hypothalamic stimulation increase dopamine turnover in the accumbens. Physiology and Behavior, 44: 599-606.

Hernandez, L. \& Hoebel, B.G. (1988b), Food reward and cocaine increase extracellular dopamine in the nucleus accumbens as measured by microdialysis. Life Sciences, 42: 1705-1712. 
Hernandez, L., \& Hoebel, B. G. (1990). Feeding can enhance dopamine turnover in the prefrontal cortex. Brain Research Bulletin, 25, 975-979.

Houpt, T.A., Philopena, J.M., Wessel, T.C., Joh, T.H. \& Smith, G.P. (1994).Increased cFos expression in the rat nucleus of the solitary tract after conditioned taste aversion formation.Neuroscience Letters 172: 1-5.

Hsiao, S., Smith, G.P. (1995). Raclopride reduces sucrose preference in rats.. Pharmacology Biochemistry and Behavior, 50, 121-125.

Imaizumi M., Takeda, M. \& Fushiki, T. (2000). Effects of oil intake in the conditioned place preference test in mice. Brain Research, 870: 150-156.

Izaki, Y., Hori, K., \& Nomura, M. (1999). Dopamine and acetylcholine elevation onlever-press acquisition in rat prefrontal cortex. Neuroscience Letters, 258, 33-36.

Jicha, G. A., \& Salamone, J. D. (1991). Vacuous jaw movements and feeding deficits in rats with ventrolateral striatal dopamine depletion: possible relation to parkinsonian symptoms. Journal of Neuroscience, 11(12), 3822-3829.

Kelley, A.E. (2004). Ventral striatal control of appetitive motivation: role in ingestive behavior and reward-related learning. Neuroscience and Biobehavioral Reviews 27, 765-776.

Kelley, A.E., Baldo, B.A., Pratt, W.E., Will, M.J. (2005). Corticostriatal-hypothalamic circuitry and food motivation: integration of energy, action and reward. Physiology and Behavior, 86, 773-795.

Kerfoot, E. C., Agarwal, I., Lee, H. J. \& Holland, P. C. (2007). Control of appetitive and aversive taste-reactivity responses by an auditory conditioned stimulus in a devaluation task: A FOS and behavioral analysis. Learning \& Memory, 14, 581-589.

Koh, M.T. \& Bernstein, I.L. (2005).Mapping conditioned taste aversion associations using c-Fos reveals a dynamic role for insular cortex. Behavioral Neuroscience, 119: 388-98.

Koob, G. F., Riley, S. J., Smith, S. C., \& Robbins, T. W. (1978).Effects of 6hydroxydopamine lesions of the nucleus accumbens septi and olfactory 
tubercle on feeding, locomotor activity, and amphetamine anorexia in the rat.Journal of Comparative and Physiological Psychology, 92(5), 917-927.

Liang, N.C., Hajnal, A., \& Norgren, R. (2006). Sham feeding corn oil increases accumbens dopamine in the rat. American Journal of Physiology, 291, R1236R1239.

Lindvall, O., Björklund, A. \& Divac, I. (year).Organization of catecholamine neurons projecting to the frontal cortex in the rat.Brain Research.142:1-24.

Liu, Y., von Deneen, K.M., Kobeissy, F.H. \& Gold, M.S. (2010). Food addiction and obesity: evidnece from bench to bedside. Journal of Psychoactive Drugs, 42: 133-145.

Madsen, H.B., Brown, R.M., Short, J.L. \& Lawrence, A.J. (2012). Investigation of the neuroanatomical substrates of reward seeking following protracted abstinence in mice. Journal of Physiology, 590, 2427-2442.

Malkusz, D.C., Banakos, T., Mohammed, A., Malkusz, G., Vongwattanakit, T., Bohn, T., Mahmud, F., Saeed, S., Touzani, K., Sclafani, A. \& Bodnar, R.J. (2012). Activation of dopamine D1 and D2 receptors in the medial prefrontal cortex and of D2 receptors in the amygdala is required for acquisition of fructoseconditioned flavor preferences in rats. Behavioural Brain Research, 233(2), 500-507.

Mark, G.P., Blander, D.S. \& Hoebel, B.G. (1991). A conditioned stimulus decreases extracellular dopamine in the nucleus accumbens after the development of a conditioned taste aversion. Brain Research, 551: 308-310.

Mebel, D.M., Wong, J.C., Dong, Y.J., Borgland, S.L. (2012). Insulin in the ventral tegmental area reduces hedonic feeding and suppresses dopamine concentration via increased uptake. European Journal of Neuroscience, 36, 2336-2346.

Mehta, S., Melhorn, S.J., Smeraglio, A., Tyagi, V., Grabowski, T., Schwartz, M.W., Schur, E.A. (2012). Regional brain response to visual food cues is a marker of satiety that predicts food choice. American Journal of Clinical Nutrition 96, 989-999. 
Meredith, G.E., Baldo, B.A., Andrezjewski, M.E., Kelley, A.E. (2008). The structural basis foir mapping behavior onto the ventral striatum and its subdivisions. Brain Structure and Function 213, 17-27.

Mitra, A., Gosnell, B. A., Schiöth, H. B., Grace, M. K., Klockars, A., Olszewski, P. K. \& Levine, A. S. (2010). Chronic sugar intake dampens feeding-related activity of neurons synthesizing a satiety mediator, oxytocin. Peptides, 31, 1346-1352.

Mitra, A., Lenglos, C., Martin, J., Mbende, N, Gagne, A., Timofeeva, E. (2011). Sucrose modifies c-fos mRNA expression in the brain of rats maintained on feeding schedules. Neuroscience, 192: 459-474.

Mungarndee, S.S., Lundy, R.F. \& Norgren, R. (2008). Expression of fos during sham sucrose intake in rats with central gustatory lesions. American Journal of Physiology.Regulatory, Integrative and Comparative Physiology, 295: R751R763.

Muscat, R. \& Willner, P. (1989).Effects of selective dopamine receptor antagonists on sucrose consumption and preference.Psychopharmacology, 99:98-102.

Naef, L., Moquin, L., Dal Bo, G., Giros, B., Gratton, A., Walker, C.D. Maternal high-fat intake alters presynaptic regulation of dopamine in the nucleus accumbens and increases motivation for fat rewards in the offspring. Neuroscience, 176, 225-236.

Naimi, N., Rivest, S., Racotta, I. \& Richard, D. (1997). Neuronal activation of the hypothalamic magnocellular system in response to oropharyngeal stimuli in the rat. Journal of Neuroendocrinology, 9: 329-340.

Nanovar, M.R., Raminfard, S., Jahroni, V. \&Azari, H. (2012). Effects of a high-fat diet on the numerical density and the number of neuronal cells and the volume of the mouse hypothalamus: a stereological study. Anatomy and Cell Biology, 45: 178-184.

Navarro, M., Spray, K.J., Cubero, I.,Thiele, T.E. \&Bernstein I.L. (2000). cFos induction during conditioned taste aversion expression varies with aversion strength. Brain Research. 887: 450-453.

Norgen, R., Hajnal, A. \& Mungarndee, S.S. (2006).Gustatory reward and the nucleus accumbens.Physiology and Behavior, 89:531-535. 
Otsubo, H., Kondoh, T., Shibata, M., Torii, K. \& Ueta, Y. (2011). Induction of Fos expression in the rat forebrain after intragastric administration of monosodium L-glutamate, glucose and NAcl. Neuroscience, 196: 97-103.

Park, T.H. \& Carr, K.D. (1998)Neuroanatomical patterns of fos-like immunoreactivity induced by a palatable meal and meal-paired environment in saline- and naltrexone-treated rats. Brain Research 805: 169-180.

Peciña, S., Cagniard, B., Berridge, K.C., Aldridge, J.W. \& Zhuang, X. (2003). Hyperdopaminergic mutant mice have higher "wanting" but not "liking" for sweet rewards. Journal of Neuroscience 23: 9395-9402.

Pecoraro, N. \& Dallman, M. F. (2005).c-Fos after incentive shifts: expectancy, incredulity, and recovery. Behavioral Neuroscience, 119, 366-387.

Pomonis, J. D., Jewett, D. C., Kotz, C. M., Briggs, J. E., Billington, C. J. \& Levine, A. S. (2000). Sucrose consumption increases naloxone-induced c-Fos immunoreactivity in limbic forebrain. American Journal of Physiology.Regulatory, Integrative and Comparative Physiology, 278, R712R719.

Pontieri, F. E., Tanda, G. \& Di Chiara., G. (1995).Intravenous Cocaine, Morphine, and Amphetamine Preferentially Increase Extracellular Dopamine in the "shell" as Compared with the "core" of the Rat Nucleus Accumbens.Proceedings of the National Academy of Sciences USA, 92: 12304-12308.

Rada, P., Avena, N.M. \& Hoebel, B.G. (2005). Daily bingeing on sugar releases dopamine in the accumbens shell. Neuroscience, 134: 737-744.

Rao, R.E., Wojnicki, F.H., Coupland, J., Ghosh, S., \& Corwin, R.L. (2008). Baclofen, raclopride and naltrexone differentially reduce solid fat emulsion intake under limited access conditions. Pharmacology Biochemistry and Behavior, $89,581-590$.

Raynor, H.A. \& Epstein, L.H. (2001).Dietary variety, energy regulation, and obesity.Psychology Bulletin, 127, 325-341.

Salamone, J. D., Zigmond, M. J., \& Stricker, E. M. (1990).Characterization of the impaired feeding behavior in rats given haloperidol or dopamine-depleting brain lesions.Neuroscience, 39, 17-24. 
Sawano, S., Takeda, M., Imaizumi, M., Manabe, Y., Kuroda, K. \& Fushiki, T. (2000). Biochemical studies of dopaminergic activation by stimuli of corn oil in the oral cavity in mice. Methods Find Exp Clin Pharmacol 22: 223-227. American Journal of Physiology, 265: R320-R325.

Schneider, L.H., Davis, J.D., Watson, C.A. \& Smith, G.P. (1990). Similar effect of raclopride and reduced sucrose concentration on the microstructure of sucrose sham feeding. European Journal of Pharmacology, 186:61- 70.

Schneider, L.H., Gibbs, J. \& Smith, G.P. (1986). D-2 selective receptor antagonists suppress sucrose sham feeding in the rat. Brain Research Bulletin, 17:605-11.

Schwarz, J., Burguet, J., Rampin, O., Fromentin, G., Andrey, P., Tome, D., Maurin, Y. \& Darcel, N. (2010). Three-dimensional macronutrient-associated Fos expression patterns in the mouse brainstem. PLoS ONE, 5, e8974.

Sclafani, A. (1999). Macronutrient-conditioned flavor preferences. In: Berthoud H-R, Seeley R, editors. Neural and metabolic control of macronutrient intake. Boca Raton, FL: CRC; 93-107.

Sclafani, A., \& Ackroff, K. (1994). Glucose- and fructose-conditioned flavor preferences in rats: Taste versus postingestive conditioning. Physiology and Behavior, 56: 399-405.

Sclafani, A., Cardieri, C., Tucker, K., Blusk, D., \& Ackroff, K. (1993). Intragastric glucose but not fructose conditions robust flavor preferences in rats. American Journal of Physiology-Regulatory, Integrative and Comparative Physiology, 265(2), R320-R325.

Sclafani, A., Fanizza, L.J., \& Azzara, A.V. (1999). Conditioned flavor avoidance, preference and indifference produced by intragastric infusions of galactose, glucose and fructose in rats. Physiology and Behavior, 67: 227-234.

Small, D.M., Jones-Gotman, M. \& Dagher, A. (2003). Feeding-induced dopamine release in dorsal striatum correlates with mealpleasantness ratings in healthy human volunteers. Neuroimage, 19:1709-1715.

Sotak, B. N., Hnasko, T. S., Robinson, S., Kremer, E. J., \& Palmiter, R. D. (2005). Dysregulation of dopamine signaling in the dorsal striatum inhibits feeding. Brain Research, 1061(2), 88-96. 
Streefland, C., Farkas, E., Maes, F. W. \& Bohus, B. (1996).C-fos expression in the brainstem after voluntary ingestion of sucrose in the rat. Neurobiology, 4, 85102.

Swank, M. W., G. E. Schafe, \& Bernstein, I.L. (1995).c-Fos induction in response to taste stimuli previously paired with amphetamine or $\mathrm{LiCl}$ during taste aversion learning. Brain Research 673: 251-261.

Swanson, L.W. (1982). The projections of the ventral tegmental area and adjacent regions: A combined fluorescent retrograde tracer and immunofluorescence study in the rat. Brain Research Bulletin.9:321-353.

Szczypka, M. S., Kwok, K., Brot, M. D., Marck, B. T., Matsumoto, A. M., Donahue, B. A., \& Palmiter, R. D. (2001). Dopamine production in the caudate putamen restores feeding in dopamine-deficient mice. Neuron, 30, 819-828.

Teegarden, S.L., Nestler, E.J. \& Bale, T.L. (2008). Delta FosB-mediated alterations in dopamine signaling are normalized by a palatable high-fat diet. Biological Psychiatry, 64, 941-950.

Touzani, K., Bodnar, RJ, \& Sclafani, A. (2008). Activation of dopamine D1 receptors in the nucleus accumbens is critical for the acquisition, but not the expression, of flavor preference conditioned by instragastric glucose in rats. European Journal of Neuroscience, 27: 1525-1533.

Touzani, K., Bodnar, R.J., \& Sclafani, A. (2009). Dopamine D1-like receptor antagonism in amygdala impairs the acquisition of glucose-conditioned flavor preferences in rats. European Journal of Neuroscience, 30: 289-298.

Touzani, K., Bodnar, R.J., \& Sclafani, A. (2010a). Acquisition of glucose-conditioned flavor preference requires the activation of dopamine D1-like receptors within the medial prefrontal cortex in rats. Neurobiology of Learning and Memory, 94: 214-219.

Ungerstedt, U. (1971). Adipsia and aphagia after 6-hydroxydopamine induced degeneration of the nigro-striatal dopamine system.Acta Physiologica Scandinavica.Supplementum, 367, 95.

VanElzakker, M., Fevurly, R.D., Breindel, T. \& Spencer, R.L. (2008). Environmental novelty is associated with a selective increase in Fos expression in the output 
elements of the hippocampal formation and the perirhinal cortex. Learning and Memory,15: 899-908.

Washington, M. C., Raboin, S. J., Thompson, W., Larsen, C. J. \& Sayegh, A. I. (2010). Exenatide reduces food intake and activates the enteric nervous system of the gastrointestinal tract and the dorsal vagal complex of the hindbrain in the rat by a GLP-1 receptor. Brain Research, 1344:124-33.

Weatherford, S.C., Smith, G.P., \& Melville, L.D. (1988). D-1 and D-2 receptor antagonists decrease corn oil sham feeding in rats. Physiology and Behavior, 44, 569-572.

Weatherford, S.C., Greenberg, D., Gibbs, J., \& Smith, G.P. (1990). The potency of D-1 and D-2 receptor antagonists is inversely related to the reward value of sham-fed corn oil and sucrose in rats. Pharmacology Biochemistry and Behavior, 37: 317-323.

Will, M.J., Franzblau, E.B., Kelley, A.E. (2003). Nucleus accumbens mu-opioids reguate intake of a high-fat diet via activation of a distributed brain network. Journal of Neuroscience, 23, 2882-2888.

Yamamoto, T., Sako, N., Sakai, N. \& Iwafune, A. (1997). Gustatory and visceral inputs to the amygdala of the rat: Conditioned taste aversion and induction of c-foslike immunoreactivity. Neuroscience Letters, 226, 127-130.

Yamamoto, T. \& Sawa, K. (2000a)Comparison of c-fos-like immunoreactivity in the brainstem following intraoral and intragastric infusions of chemical solutions in rats.Brain Research, 866: 144-151.

Yamamoto, T. \& Sawa.K. (2000b).c-Fos-like immunoreactivity in the brainstem following gastric loads of various chemical solutions in rats. Brain Research, $866,135-143$.

Yu, W.Z., Silva, R.M., Sclafani, A., Delamater, A.R., \& Bodnar, R.J. (2000a).Pharmacology of flavor preference conditioning in sham-feeding rats: effects of dopamine receptor antagonists. Pharmacology Biochemistry and Behavior, 65, 635-647.

Yu, W.Z., Silva, R.M., Sclafani, A., Delamater, A.R., \& Bodnar, R.J. (2000b). Role of D1 and D2 dopamine receptors in the acquisition and expression of flavor 
preference conditioning in sham-feeding rats.Pharmacology Biochemistry and Behavior, 67, 537-544.

Zhang, M. \& Kelley, A.E. (2000). Enhanced intake of high-fat food following striatal mu-opioid stimulation: microinjection mapping and fos expression. Neuroscience, 99, 267-277.

Zhao, X. L., Yan, J. Q., Chen, K., Yang, X. J., Li, J. R. \& Zhang, Y. (2011). Glutaminergic neurons expressing c-Fos in the brainstem and amygdala participate in signal transmission and integration of sweet taste. Nan.Fang Yi.Ke.Da.Xue.Xue.Bao., 31, 1138-1142. 


\section{Chapter 5}

\section{Increased number of TH- immunoreactive cells in the Ventral Tegmental Area after Deep Brain Stimulation of the Anterior Nucleus of the Thalamus}

J.A.D. Dela Cruz ${ }^{1,3}$, S. Hescham1, B. Adriaanse1, H.W.M. Steinbusch¹, , B.P.F. Rutten $^{1}$, Y. Temel ${ }^{1,2}$, A. Jahanshahi1

Departments of Neuroscience ${ }^{1}$ and Neurosurgery ${ }^{2}$, Maastricht University Medical Center, Maastricht, Netherlands; Department of Psychology ${ }^{3}$, Neuropsychology subprogram, The CUNY Graduate Center, New York, NY, USA 


\begin{abstract}
Dopamine (DA) has been long implicated with the processes of memory. In longterm memory, the hippocampus and ventral tegmental area use DA to enhance longterm potentiation, while prefrontal DA D1 receptors are involved in working memory. Deep Brain Stimulation (DBS) of specific brain areas have been shown to reverse memory impairments in animal models. Here, we tested the hypothesis that the DAergic cells in the ventral tegmental area mediate memory impairments. Rats received DBS at the level of the mammillothalamic tract, the anterior nucleus of the thalamus, and entorhinal cortex before euthanasia. These regions are part of the socalled memory circuit. Brain sections were processed for $c$-Fos and tyrosine hydroxylase (TH) immunocytochemistry in the ventral tegmental area (VTA) and the substantia Nigra pars compacta (SNc). $C$-Fos, TH and $c$-Fos/TH immunoreactive cells were analyzed by means of stereology and confocal microscopy. Our results showed that DBS of the anterior nucleus of the thalamus induced substantial higher numbers of TH-immunoreactive cells in the ventral tegmental area, while there were no significant differences between the experimental groups in the number of $\mathrm{TH}$ immunoreactive cells in the substantia nigra pars compacta, $c$-Fos immunoreactive cells and $c$-Fos/TH double-labelled cells in both the substantia nigra pars compacta and ventral tegmental area. Our findings suggest a phenotypic switch, or neurotransmitter respecification, of DAergic cells specifically in the ventral tegmental area may be induced by DBS in the anterior nucleus of the thalamus.
\end{abstract}




\section{Introduction}

The neurotransmitter dopamine (DA) has been implicated in the process of learning and memory. DA has for example been linked to memory on different topics such as memory studies on sex and reinforcement (Becker, Rudick, \& Jenkins, 2001), on drug addiction (Carr, 2007; Volkow \& Wise, 2005), and feeding preferences (Dela Cruz et al., 2012). On a cellular level, DA has been shown to positively influence hippocampus dependent learning and memory by enhancing long-term potentiation (LTP) in the hippocampus through D1/D5 receptors (mainly the CA1 region) (Lisman \& Grace, 2005) by interacting with the ventral tegmental area (VTA). The hippocampus is also part of the Circuit of Papez, which has been linked to episodic and spatial memory (Markowitsch, 1997, Hescham, et al., 2013b).

Memory impairments are the core features of the different types of dementia and researchers have been exploring the application of non-pharmacological therapies in order to reduce or delay the progression of dementia. One treatment currently being tested is deep brain stimulation (DBS). Findings from recent preclinical studies (Hamani, et al., 2013; Hescham, et al., 2013a; Stone, et al., 2011) and clinical studies (Hamani, et al., 2008; Laxton, et al., 2010) have suggested that DBS can be used as a tool to enhance memory functions, including reversing memory impairments.

In addition to issues of memory, DBS is also used to treat other disorders, such as Parkinson's disease, Tourette's syndrome and several forms of epilepsy (Hescham, et al., 2013b, Andrade et al., 2006; Houeto et al., 2005; Savica et al., 2012; Temel \& Visser-Vandewalle, 2006; Wichmann \& DeLong, 2006). DBS has been proposed as an alternative to drug therapy. Stimulation also has the advantages of reversibility and adjustability in patients who would otherwise be thought of as candidates for surgery (Theodore \& Fisher, 2004). Changes in DA levels from DBS may have some impact in other types of disorders.

In the present study, DBS was implemented in different brain regions of rats with scopolamine-induced memory impairments. The current study focuses the quantifications of the number of tyrosine hydroxylase $(\mathrm{TH}$, a rate-limiting enzyme in 
the formation of DA) immunoreactive cells, the number of c-Fos (a proto-oncogene and marker for cell activation) immunoreactive cells and the co-localization of the two markers in the major sites of DA synthesis: the Ventral Tegmental Area (VTA) and the Substantia Nigra pars compacta $(\mathrm{SNc})$. It is hypothesized that DBS in various stimulation sites (Circuit of Papez sites: Entorhinal Cortex (EC), Mammillothalamic Tract (MTT) and the Anterior Nucleus of the Thalamus (ANT)) will have differential effects on the number of TH-immunoreactive cells or colocalized TH/c-Fos immunoreactive cells in the VTA and SNc after DBS and scopolamine-induced memory impairments. 


\section{Materials and Methods}

\section{Experimental groups}

Sprague Dawley rats were assigned at random to receive DBS in one of several brain sties: the mammillothalamic tract (MTT, $n=5)$, the entorhinal cortex $(E C, n=6)$, the anterior nucleus of the thalamus (ANT, $n=5)$ and a sham group $(n=3)$ was made for a negative control.

\section{Pre-perfusion experimental procedures}

Scopolamine-model of memory impairments was used as the experimental model of dementia during a previous behavioral study. During this study, the rats were stimulated in various parameters. For more information on this procedure please see (Hescham, et al., 2013a).

Deep brain stimulation

Three different experimental conditions were given: (a) DBS at an amplitude of 100 $\mu \mathrm{A}$ in the EC (b) DBS at an amplitude of $50 \mu \mathrm{A}$ in the ANT and (c) an amplitude of $200 \mu \mathrm{A}$ in the MTT. The used stimulation frequency was $100 \mathrm{~Hz}$ and the pulse width was set at $100 \mu \mathrm{s}$. These stimulation parameters were determined most optimal from the results of the object location task from a concurrent unpublished study. Before perfusion, the animals were stimulated for 1 hour. 


\section{Immunohistochemistry}

After perfusion, tissue was collected and cut into $30 \mu \mathrm{m}$ slices on a vibratome. A fluorescence protocol was conducted for the visualization of TH and c-Fos. First, primary antibodies of mouse anti-TH (1:100, Médimabs, Montreal, Canada) and rabbit anti c-Fos (1:500, Santa Cruz, Santa Cruz California, USA) were incubated overnight. The next day, the slices had incubation of the secondary antibodies: Alexa 594 donkey Anti-Mouse (1:100, Invitrogen, Grand Island, NY, USA) followed by Alexa 488 Donkey Anti-Rabbit (1:100, Invitrogen, Grand Island, NY) for 2 hours each.

\section{Histological analysis and quantification}

For analysis and cell counting of TH immunoreactive, c-Fos immunoreactive and cFos/TH double-labeled cells in the SNc and VTA of the brain sections, a spinning disk confocal microscope (Olympus DSU BX51WI, Pennsylvania, USA) was used. In all sections showing the SNc and VTA were delineated and the total numbers of TH containing cells were estimated with the optical fractionator. For more details about the stereologic counting procedure see (Temel et al., 2006). On the settings and data of our current quantifications, see the online resource.

\section{Statistical analysis}

One-way ANOVA's were performed using SPSS (version18 for Apple, SPSS, Chicago, IL, USA), and post-hoc multiple comparisons test were performed with a Tukey's Honest Significant Difference (HSD) test, due to the fact that it has the best allpossible pairwise comparisons when sample sizes are unequal. A p-value $<0.05$ was considered to be significant. 


\section{Results}

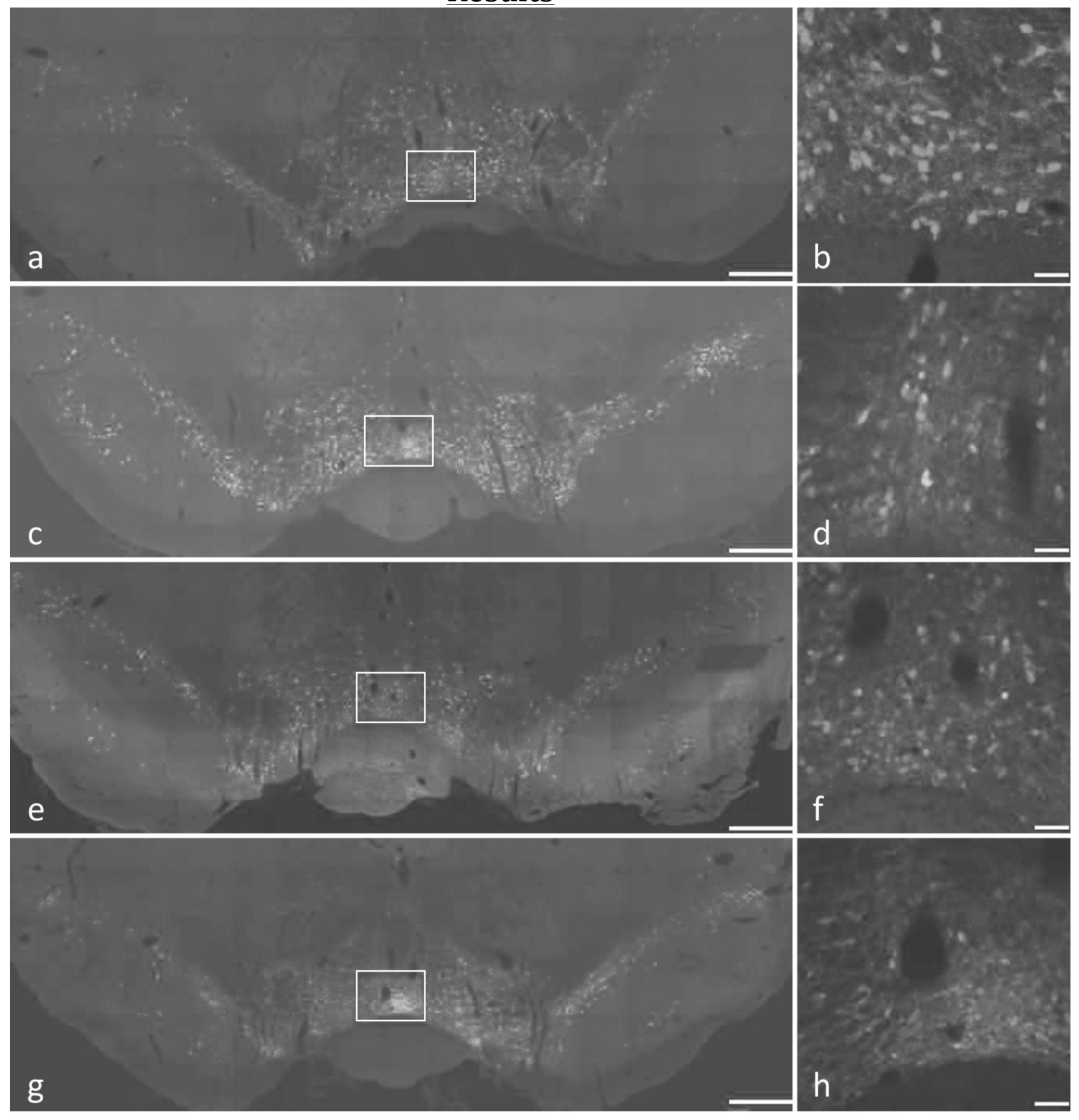

Figure 1. All pictures are around bregma level $-6.00 \mathrm{~mm}$. A) Overview of TH immunoreactive cells in the VTA and SNc for an MTT stimulated rat. B) The VTA in an MTT stimulated rat. C) Overview for an ANT stimulated rat. D) The VTA in an ANT stimulated rat. E) Overview for an EC stimulated rat. F) The VTA in an EC stimulated rat. G) Overview of for a sham rat. H) The VTA in a sham rat. Scale bars, A), C), E) and G) $500 \mu \mathrm{m}$; B), D), F), H) $50 \mu \mathrm{m}$. 
Number of TH-immunoreactive cells in the VTA and SNC

The one-way ANOVA indicated that DBS had a significant effects on the number of TH-immunoreactive cells in the VTA $(F(3,15)=5.902, p<0.05$; Figure 1). Post hoc comparisons using the Tukey's HSD indicated that the mean number of THimmunoreactive cells was significantly higher for the ANT-stimulated group $(M=24,773, S E M=942)$ as compared with the MTT-stimulated group $(M=18,884$, SEM=1,586), the EC-stimulated group ( $M=20,694$, SEM= 840), and the shamstimulated group $(M=16,648, S E M=2,474)$. In addition, $T H$ cell measurements in the VTA and VTA volume measurements were not significantly different throughout the four conditions. No significant difference was found between the MTT-stimulated group, the EC-stimulated group and the sham-stimulated group (Figure 2). No significant differences were found for the number of TH-immunoreactive cells in the SNc.

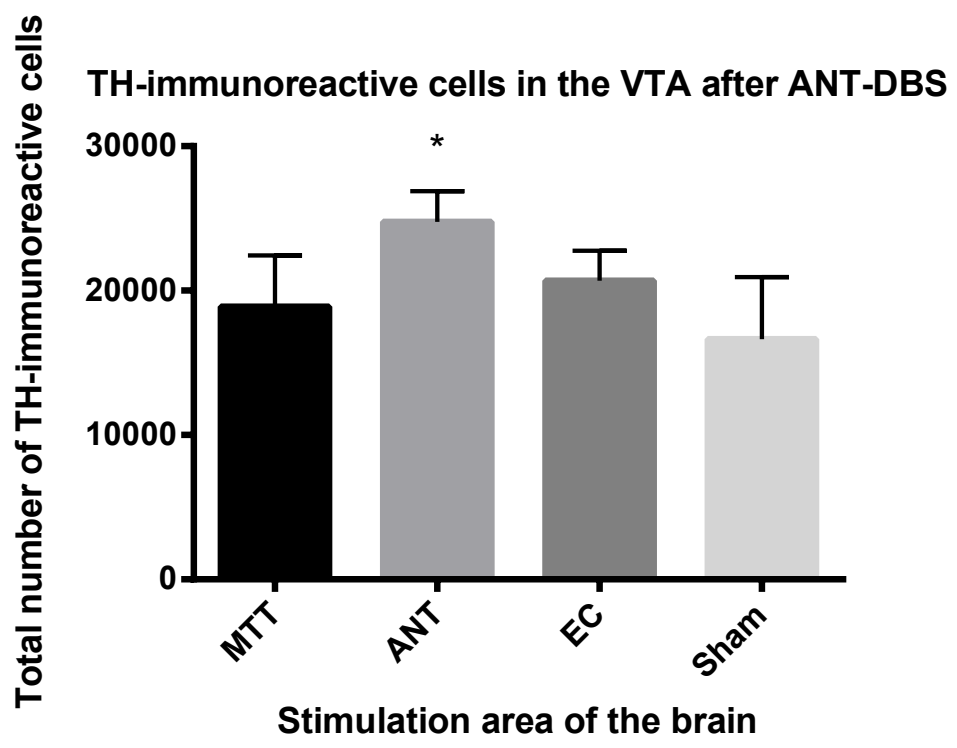

Figure 2. Number of TH-immunoreactive cells in the VTA after DBS. The group that was stimulated in the Anterior Nucleus of the Thalamus (ANT, $n=5$ ) was found to have significantly more TH-immunoreactive cells in the VTA than the groups stimulated in the Mammillothalamic Tract (MTT, $n=5$ ), in the Entorhinal Cortex (EC, $n=6$ ), and the sham stimulated group ( $n$ $=3) .{ }^{*} p<0.05$. 
c-Fos immunoreactive cells and double-labelled c-Fos/TH cells in the VTA and the SNC

One-way ANOVAs were conducted to compare the effect of different DBS sites on scopolamine-induced memory impairments of c-Fos immunoreactive cells in for both the VTA and the SNc. There were no significant differences found on c-Fos immunoreactive cells from DBS in the VTA, the SNc, or double-labeled c-Fos/TH cells at the $\mathrm{p}<0.05$ level.

\section{Discussion}

DBS-ANT increased the number of TH-immunoreactive cells in the VTA over the EC-stimulated, MTT-stimulated and sham group, while no difference was found in the SNc. The c-Fos immunoreactive cells and the double-labelled c-Fos/TH cells were not found to be significantly different between the conditions. From the c-Fos and double-labelled results, it can be concluded that DA, or any other active neurons in the VTA or SNc, were not involved in the activation of processes by DBS before being sacrificed.

One theory to explain the higher levels of $\mathrm{TH}$ is phenotypic switching, or neurotransmitter respecification. In a recent study, some populations of interneurons found in the adult rat hypothalamus switched between dopamine and somatostatin in response to exposure to short- and long-day photoperiods (Dulcis, et al., 2013). The changes did not depend on neurogenesis or apoptosis, but the neurotransmitter expression switch occurred as a response to environmental changes. Furthermore, a following study found changes in TH levels in the SNc and VTA when exposed to differing manipulations of environmental stimuli (Aumann, et al., 2011; Aumann, Tomas \& Horne, 2013). More TH neurons were found in mated males versus unmated rats, whereas less TH neurons were found in mated females. Also, more TH-immunoreactive cells were found in environmentally enriched males, while this increase was lost after an infusion of a gamma-Aminobutyric acid (GABA) receptor antagonist (Aumann, Tomas \& Horne, 2013). These studies show that neurons, in the brain are not fixed, but respond to environmental stimuli and behaviors. 
Dopaminergic neurons comprise $50-60 \%$ of all neurons in the VTA (Margolis, et al., 2006), while GABAergic neurons comprise of a sizable population (Oades \& Halliday, 1987), and glutamatergic neurons consist of a smaller population in the VTA (Oades \& Halliday, 1987). Presumably electrical stimulation in the ANT, and not the MTT or the EC, causes shifts in transcriptional level from one type of neurotransmitter cell to a DA cell in an attempt to have noninvasive restoration of the normal functioning nervous system. The GABAergic cells may have phenotypically switched to TH cells after stimulation in the ANT. One suggestion for a subsequent study would be to double-stain TH with GAD67, an antibody that tags GABA cell bodies to examine the neuronal compositions of the VTA between the four conditions of this study.

Interestingly, electrical stimulation of the ANT was found effective for treating refractory focal epilepsy in a clinical trial (Graber \& Fisher, 2012), while memory problems were reported as adverse effects (Fisher et al., 2010), which may be in part due to its central connectivity (Child \& Benarroch, 2013). In line with the finding from these studies, memory improvement was observed in rats stimulated in the EC during behavioral studies (Stone, et al., 2011), while memory impairments were retained in rats stimulated in the ANT (Hamani, et al., 2009). DBS effects in the MTT and memory are still unknown.

In conclusion, our findings suggest a phenotypic switch between GABA neurons and DA neurons in the VTA following ANT-DBS. The environmental stimuli of DBS in the ANT, but not DBS in the MTT or EC, may influence this increase in THimmunoreactive cells in the VTA. As dopaminergic projections from the VTA mediate reward-seeking behavior (among other functions), our current findings may imply that ANT-stimulation with DBS, such as used in the treatment of epilepsy, may induce alterations in reward-seeking and other behavioral phenotypes. 


\section{Acknowledgements}

The micrographs in this paper were taken with a confocal spinning disk microscope financed by The Netherlands Organisation for Scientific Research (NWO), grant number 911-06-003. 


\section{References}

Andrade, D.M., Zumsteg, D., Hamani, C., Hodaie, M., Sarkissian, S., Lozano, A.M., Wennberg, R.A. (2006). Long-term follow-up of patients with thalamic deep brain stimulation for epilepsy. Neurology 66, 1571-1573.

Aumann, T. D., Egan, K., Lim, J., Boon, W. C., Bye, C. R., Chua, H. K., ... \& Horne, M. K. (2011). Neuronal activity regulates expression of tyrosine hydroxylase in adult mouse substantia nigra pars compacta neurons. Journal of neurochemistry, 116(4), 646-658.

Aumann, T. D., Tomas, D., \& Horne, M. K. (2013). Environmental and behavioral modulation of the number of substantia nigra dopamine neurons in adult mice. Brain and Behavior.

Becker, J. B., Rudick, C. N., \& Jenkins, W. J. (2001). The role of dopamine in the nucleus accumbens and striatum during sexual behavior in the female rat. $J$ Neurosci, 21(9), 3236-3241.

Carr, D. B., \& Sesack, S. R. (2000). Projections from the rat prefrontal cortex to the ventral tegmental area: target specificity in the synaptic associations with mesoaccumbens and mesocortical neurons. The Journal of Neuroscience, 20(10), 3864-3873.

Carr, K. D. (2007). Chronic food restriction: enhancing effects on drug reward and striatal cell signaling. Physiol Behav, 91(5), 459-472. doi: 10.1016/j.physbeh.2006.09.021

Child, N. D., \& Benarroch, E. E. (2013). Anterior nucleus of the thalamus: Functional organization and clinical implications. Neurology. doi: 10.1212/01.wnl.0000436078.95856.56

Dela Cruz, J. A., Icaza-Cukali, D., Tayabali, H., Sampson, C., Galanopoulos, V., Bamshad, D., . . Bodnar, R. J. (2012). Roles of dopamine D1 and D2 receptors in the acquisition and expression of fat-conditioned flavor preferences in rats. Neurobiol Learn Mem, 97(3), 332-337. doi: 10.1016/j.nlm.2012.01.008 
Dulcis, D., Jamshidi, P., Leutgeb, S., \& Spitzer, N. C. (2013). Neurotransmitter switching in the adult brain regulates behavior. Science, 340(6131), 449-453. doi: $10.1126 /$ science.1234152

Fisher, R., Salanova, V., Witt, T., Worth, R., Henry, T., Gross, R., ... Group, Sante Study. (2010). Electrical stimulation of the anterior nucleus of thalamus for treatment of refractory epilepsy. Epilepsia, 51(5), 899-908. doi: 10.1111/j.1528-1167.2010.02536.x

Graber, K. D., \& Fisher, R. S. (2012). Deep Brain Stimulation for Epilepsy: Animal Models. In J. L. Noebels, M. Avoli, M. A. Rogawski, R. W. Olsen \& A. V. DelgadoEscueta (Eds.), Jasper's Basic Mechanisms of the Epilepsies (4th ed.). Bethesda (MD).

Hamani, C., McAndrews, M.P., Cohn, M., Oh, M., Zumsteg, D., Shapiro, C.M., Wennberg, R.A., Lozano, A.M. (2008). Memory enhancement induced by hypothalamic/fornix deep brain stimulation. Annals of Neurology 63, 119123.

Hamani, C., Dubiela, F. P., Soares, J. C., Shin, D., Bittencourt, S., Covolan, L., ... \& Oliveira, M. G. M. (2010). Anterior thalamus deep brain stimulation at high current impairs memory in rats. Experimental neurology, 225(1), 154-162.

Hamani, C., Stone, S. S., Garten, A., Lozano, A. M., \& Winocur, G. (2011). Memory rescue and enhanced neurogenesis following electrical stimulation of the anterior thalamus in rats treated with corticosterone. Exp Neurol, 232(1), 100-104. doi: 10.1016/j.expneurol.2011.08.023

Hescham, S., Lim, L. W., Jahanshahi, A., Steinbusch, H. W., Prickaerts, J., Blokland, A., \& Temel, Y. (2013a). Deep brain stimulation of the forniceal area enhances memory functions in experimental dementia: the role of stimulation parameters. Brain Stimul, 6(1), 72-77. doi: 10.1016/j.brs.2012.01.008

Hescham, S., Lim, L. W., Jahanshahi, A., Blokland, A., \& Temel, Y. (2013b). Deep brain stimulation in dementia-related disorders. Neurosci Biobehav Rev. doi: 10.1016/j.neubiorev.2013.09.002

Houeto, J.L., Karachi, C., Mallet, L., Pillon, B., Yelnik, J., Mesnage, V., Welter, M.L., Navarro, S., Pelissolo, A., Damier, P., Pidoux, B., Dormont, D., Cornu, P., Agid, 
Y., (2005). Tourette's syndrome and deep brain stimulation. Journal of Neurology, Neurosurgery \& Psychiatry 76, 992-995.

Laxton, A.W., Tang-Wai, D.F., McAndrews, M.P., Zumsteg, D., Wennberg, R., Keren, R., Wherrett, J., Naglie, G., Hamani, C., Smith, G.S., Lozano, A.M. (2010). A phase I trial of deep brain stimulation of memory circuits in Alzheimer's disease. Annals of Neurology 68, 521-534.

Lisman, J. E., \& Grace, A. A. (2005). The hippocampal-VTA loop: controlling the entry of information into long-term memory. Neuron, 46(5), 703-713. doi: 10.1016/j.neuron.2005.05.002

Margolis, E. B., Lock, H., Hjelmstad, G. O., \& Fields, H. L. (2006). The ventral tegmental area revisited: is there an electrophysiological marker for dopaminergic neurons?. The Journal of physiology, 577(3), 907-924

Markowitsch, H. J. (1997). Varieties of memory: Systems, structures, mechanisms of disturbance. Neurology, Psychiatry and Brain Research, 5(1), 37-56.

Mirski, M. A., Ziai, W. C., Chiang, J., Hinich, M., \& Sherman, D. (2009). Anticonvulsant serotonergic and deep brain stimulation in anterior thalamus. Seizure, 18(1), 64-70. doi: 10.1016/j.seizure.2008.06.011

Oades, R. D., \& Halliday, G. M. (1987). Ventral tegmental (A10) system: neurobiology. 1. Anatomy and connectivity. Brain Research Reviews, 12(2), 117-165.

Savica, R., Stead, M., Mack, K.J., Lee, K.H., Klassen, B.T., (2012). Deep Brain Stimulation in Tourette Syndrome: A Description of 3 Patients With Excellent Outcome. Mayo Clinic Proceedings 87, 59-62.

Stone, S. S., Teixeira, C. M., Devito, L. M., Zaslavsky, K., Josselyn, S. A., Lozano, A. M., \& Frankland, P. W. (2011). Stimulation of entorhinal cortex promotes adult neurogenesis and facilitates spatial memory. J Neurosci, 31(38), 1346913484. doi: 10.1523/JNEUROSCI.3100-11.2011

Temel, Y., Visser-Vandewalle, V., Kaplan, S., Kozan, R., Daemen, M., Blokland, A., . . . Steinbusch, H.W.M. (2006). Protection of nigral cell death by bilateral subthalamic nucleus stimulation. Brain Res, 1120(1), 100-105.

Theodore, W. H., \& Fisher, R. S. (2004). Brain stimulation for epilepsy. Lancet Neurol, $3(2), 111-118$. 
Volkow, N. D., \& Wise, R. A. (2005). How can drug addiction help us understand obesity? Nat Neurosci, 8(5), 555-560. doi: 10.1038/nn1452

Wichmann, T., DeLong, M.R., (2006). Deep Brain Stimulation for Neurologic and Neuropsychiatric Disorders. Neuron 52, 197-204.

Ziai, W. C., Sherman, D. L., Bhardwaj, A., Zhang, N., Keyl, P. M., \& Mirski, M. A. (2005). Target-specific catecholamine elevation induced by anticonvulsant thalamic deep brain stimulation. Epilepsia, 46(6), 878-888. doi: 10.1111/j.15281167.2005.49304.x 


\title{
Chapter 6
}

\section{Expression of hypoxia-inducible factor 1-beta (ARNT or ARNT2) in mouse substantia nigra and ventral tegmental area}

\author{
J.A.D. Dela Cruz',3, R. Schmidt-Kastner ${ }^{2}$, H.W.M. Steinbusch¹, B.P.F. Rutten' \\ School of Mental Health and Neuroscience ${ }^{1}$ Faculty of Health, Medicine and \\ Life Sciences, Maastricht University Medical Center, Maastricht, Netherlands \\ C.E. Schmidt College of Medicine ${ }^{2}$, Florida Atlantic University (FAU), Boca \\ Raton, Florida, USA \\ Neuropsychology Doctoral subprogram³ ${ }^{3}$, The Graduate Center, City University \\ of New York New York, USA
}




\begin{abstract}
Hypoxia has been proposed as a mechanism underlying gene-environment interactions in the neurodevelopmental model of schizophrenia, and hypoxiainducible factor 1 (HIF-1) could mediate the interactions. Here, we analyzed the constitutively expressed HIF-1 beta subunit, as formed by aryl-hydrocarbon receptor nuclear translocator (ARNT) or ARNT2, in the dopaminergic midbrain neurons of the mouse, i.e. Substantia Nigra (SN) and the Ventral Tegmental Area (VTA). We performed immunohistochemical studies on protein levels of ARNT and ARNT2 in the adult mouse brain, and colocalization analyses, with specific emphasis on tyrosine hydroxylase (TH) immunoreactive cells. In addition, we performed bioinformatic analyses to identify overlapping protein-protein interactions for ARNT and ARNT2. ARNT immunoreactivity showed widespread neuronal labeling without any regional differences with evident co-localization of ARNT and TH in the SN pars compacta and VTA. TH-immunoreactive cells showed weak immunoreactivity for ARNT2 whereas strongly ARNT2-immunoreactive cells were present in SN reticulata and other brain areas. The present findings thus indicate differential expression of ARNT and ARNT2 in neurons in the mouse midbrain, Preferential expression of ARNT in dopaminergic neurons may relate to functional vulnerability in neurological and psychiatric disorders.
\end{abstract}




\section{Introduction}

Molecular regulation of hypoxia by the hypoxia-inducible factor 1 (HIF-1) is primarily of interest for acute ischemia-hypoxia of the brain (Kietzmann, Knabe, \& Schmidt-Kastner, 2001; Prabhakar \& Semenza, 2012; Sharp \& Bernaudin, 2004). A role for hypoxia and HIF-1 has been suggested in the context of the etiology of neuropsychiatric disorders. As such, hypoxia has been proposed as common mechanisms underlying gene-environment interactions in the neurodevelopmental model of schizophrenia (SCZ) (Schmidt-Kastner, van Os, Esquivel, Steinbusch, \& Rutten, 2012). Analysis of genomic data (Richards et al., 2012) and exome sequencing (Gulsuner et al., 2013) has shown that HIF-1A is associated with SCZ, while pathway annotations in other genomic studies of SCZ also highlighted hypoxia genes (Gilman et al., 2012). Other recent genetic studies have shown variants in the HIF-1 system to be associated also with autism spectrum disorders (ASD) (Neale et al., 2012; O'Roak et al., 2012) as well as mood disorders (Shibata et al., 2013).

Most studies of HIF-1 in the brain have focused on the hypoxia-regulated HIF-1 alpha subunit (HIF-1a), which has been reported to show generalized neuronal expression (Acker \& Acker, 2004; Jain, Maltepe, Lu, Simon, \& Bradfield, 1998; Kietzmann et al., 2001). The HIF-1 beta subunit (HIF-1b) is the constitutively expressed heterodimerization partner, which is waiting for the activated HIF-1a to enter the nucleus, where they form the active transcription factor (HIF-1) with additional transcriptional regulators (Prabhakar \& Semenza, 2012; Wang, Jiang, Rue, \& Semenza, 1995). In most cells, the protein ARNT (aryl-hydrocarbon receptor nuclear translocator) serves as the HIF-1 beta subunit (Jiang, Rue, Wang, Roe, \& Semenza, 1996). A paralogue known as ARNT2 is expressed in the brain (Drutel, Kathmann, Heron, Schwartz, \& Arrang, 1996; Hirose et al., 1996) with a regional pattern (Petersen et al., 2000), which is suggestive of the possibility that many neurons may have two options for the HIF-1 beta subunit. Although ARNT and ARNT2 are encoded by different genes, high sequence similarity (Drutel et al., 1996; Hirose et al., 1996) has made their study challenging. Since the constitutive expression of different heterodimerization partners is used to diversify cellular 
responses, a regional difference in HIF-1 response of neurons is of considerable interest. Gene deletion studies in mice and functional studies in vitro have documented only partial overlap between ARNT and ARNT2 in hypoxia regulation (Keith et al., 2001), and a recent report of rare ARNT2 mutations in a complex syndrome proves that ARNT2 has specialized functions in the human brain (Webb et al., 2013).

Given that a wealth of findings in the literature has indicated that the dopaminergic neurotransmission system is centrally involved in psychosis (Howes et al., 2013; van Os, Kenis, \& Rutten, 2010) and other psychiatric disorders, it is worthwhile to explore the expression of hypoxia-regulated genes such as the HIF-1 in dopaminergic neurons. In this respect, earlier studies have already indicated that hypoxia increases the expression of tyrosine hydroxylase (TH) in peripheral dopaminergic neurons involving HIF-1 (Norris \& Millhorn, 1995). The expression of ARNT and ARNT2 in dopaminergic neurons has however not been investigated thus far. Here, we studied the constitutively expressed proteins, ARNT and ARNT2, in the $\mathrm{SNc}$, substantia nigra pars reticulata $(\mathrm{SNr})$ and ventral tegmental area (VTA) of mouse using immunohistochemistry, with a specific focus on the dopaminergic neurons. Antibodies to ARNT2 were selected by matching of the nuclear labeling pattern obtained by immunohistochemistry with the mRNA in situ hybridization pattern for mouse Arnt2. We also generated protein-interaction networks for ARNT and ARNT2 to determine shared partner proteins.

\section{Materials and Methods}

\section{Approval}

All parts of the experiment involving animals were performed with approval of the Animal Experiments and Ethics Committee of Maastricht University. 


\section{Tissue collection}

$\mathrm{N}=12$ wild type C57Bl6J mice (Central animal facility, Maastricht University, Netherlands) were given an overdose of pentobarbital and underwent perfusion fixation, first with tyrode solution and subsequently with Somogyi solution (4\% paraformaldehyde, $15 \%$ picric acid, $0.05 \%$ glutaraldehyde in $0.1 \mathrm{M}$ phosphate buffered saline (PBS)). Brains were fixed in fresh fixative (4\% paraformaldehyde, $15 \%$ picric acid, $0.1 \mathrm{M}$ PBS) at 40C for 2 hours and then stored in 1\% NaN3 at 40C. Brains were embedded in $10 \%$ gelatin (Sigma-Aldrich, Zwijndrecht, The Netherlands), and cut into $30 \mu \mathrm{m}$ slices in the frontal plane using a vibratome (Leica ${ }^{\circledR}$, Wetzlar, Germany). Slices were stored in $1 \mathrm{x}$ PBS $+1 \% \mathrm{NaN} 3$ in a cold room.

\section{Selection of ARNT2 antibodies}

Because of the sequence similarity of ARNT and ARNT2, a careful selection of antibodies from various commercial sources was carried out. The nuclear labeling pattern for ARNT2 obtained by immunohistochemistry was matched with the mRNA distribution for mouse Arnt2 in coronal sections of the Allen Brain Atlas.

\section{Immunohistochemistry for fluorescence double-labeling}

For double fluorescent visualization of TH and ARNT or ARNT2, a three-day fluorescence protocol was conducted. The slices were blocked in 3\% normal donkey serum (NDS) in Tris-buffered saline with 0.3\% Triton X-100 (TBS-T) for 30 minutes, and incubated in the first antibody, mouse anti-TH (Médimabs, Montreal, Canada; $1: 100$ ) overnight in $0.3 \%$ NDS in TBS-T. Slices were incubated with Alexa 594 donkey anti-mouse (Invitrogen, Grand Island, NY, USA; 1:100) in 0.3\% NDS in TBS-T for 2 hours. Next, the slices were placed in the second antibody, rabbit anti-ARNT ("HIF1ß": Novus Biologicals, Cambridge, UK; 1:600) or rabbit anti-ARNT2 (Santa Cruz Biotechnology, Inc, Santa Cruz, CA, USA; 1:200) in 0.3\% NDS in TBS-T for overnight incubation. The next day, the secondary antibody, Alexa 488 donkey antirabbit (Invitrogen, Grand Island, NY; 1:100) in 0.3\% NDS in TBS-T was applied for 2 hours. Lastly, staining with Hoechst dye (Sigma-Aldrich, Zwijndrecht, The 
Netherlands; 1:500) in TBS was carried out for 30 minutes. Slices were mounted on gelatin coated microscope slides, and coverslipped with glycerol. Similar protocols were conducted for double staining of ARNT2 antibody with glial fibrillary acidic protein (GFAP) antibody and ARNT2 antibody with Neuronal Nuclei (NeuN) antibody.

Immunohistochemistry for permanent labeling

Endogenous peroxidase activity were quenched by using a 3\% hydrogen peroxide solution for 30 minutes, slices were blocked for 30 minutes with 3\% NDS in TBS-T, followed by a rabbit anti-ARNT ("HIF1 $\beta$ ": Novus Biologicals, Cambridge, UK; 1:600) or rabbit anti- ARNT2 primary antibody (Santa Cruz Biotechnology, Inc; Santa Cruz, CA, USA; 1:1000) overnight in $0.3 \%$ NDS in TBS-T. Next, slices were incubated in donkey anti rabbit biotin (1:800) in 0.3\% NDS in TBS-T for $2 \mathrm{~h}$ and then placed in avidin-biotin complex for 2 hours (1:800, Vector laboratories, UK). To visualize the horseradish peroxide reaction product, the sections were incubated with 3,3'diaminobenzidine tetrahydrochloride (DAB) (Sigma, Uithoorn, The Netherlands) (with nickel chloride enhancement for ARNT2) for $10 \mathrm{~min}$. The cerebellar tissue stained with ARNT2 was further stained with haematoxylin for 2 minutes was washed with running tap water for 10 minutes. Lastly, all slides were coverslipped using Pertex (HistolabProducts ab, Göteborg, Sweden).

\section{Image analyses}

For analysis of fluorescence double labeling, a spinning disk confocal microscope (Olympus DSU BX51WI, Pennsylvania, USA) was used. An Olympus BX-50 microscope (Olympus Nederland BV, Zoeterwoude, Netherlands) was used for permanently stained sections. The virtual slice and z-stacks protocols were carried out with a stereological computer microscopy system (Microbrightfield BiosciECe®, Williston, VT) on both microscopes. Virtual slices were later stitched on Image J (Preibisch, Saalfeld, \& Tomancak, 2009). 


\section{Results}

\section{ARNT:}
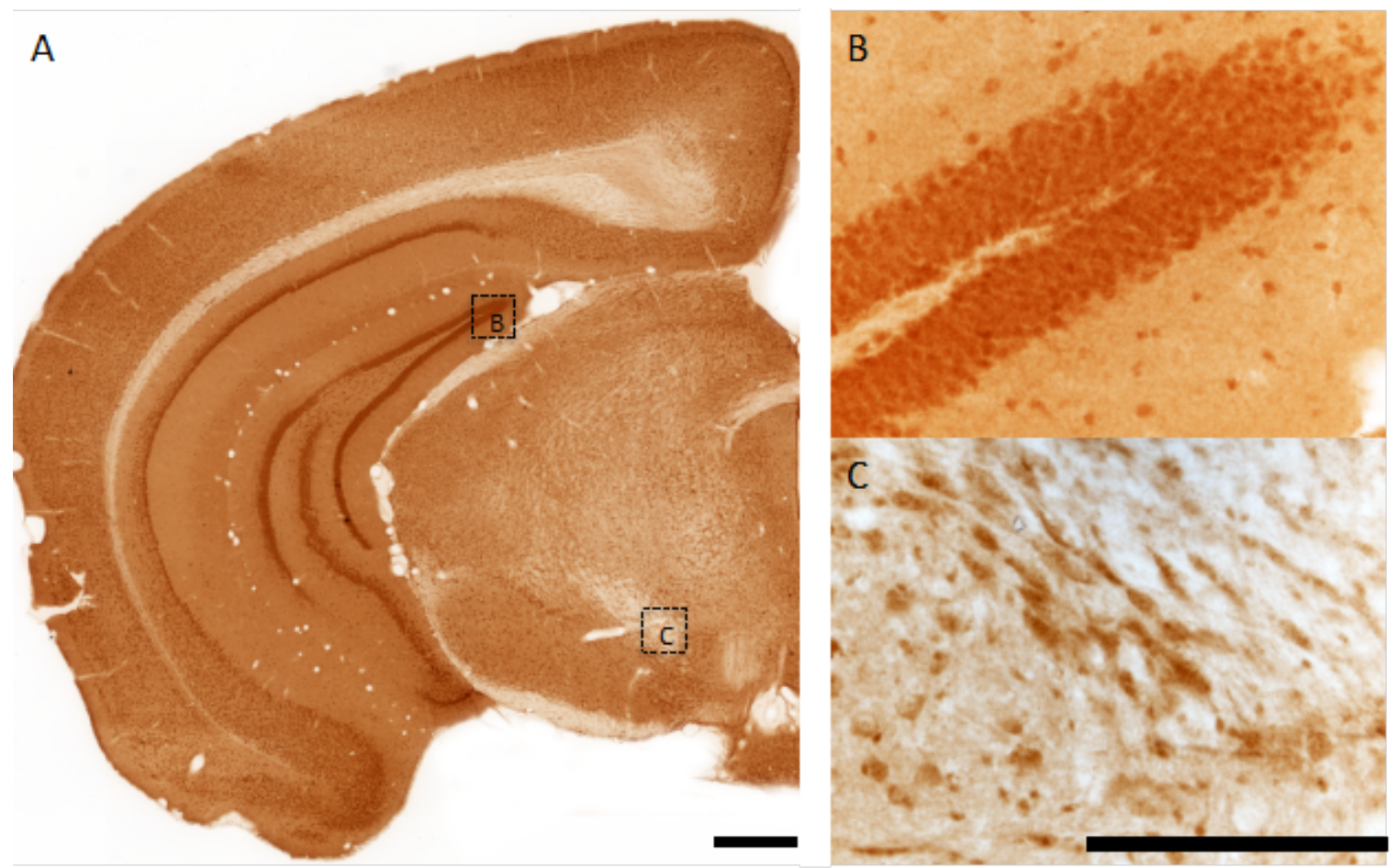

Figure 1. A) A low powered view of the mouse midbrain at bregma level $-0.47 \mathrm{~mm}$, permanently immunolabeled for ARNT. B) A higher powered view of the hippocampus. C) A higher powered view of the substantia nigra. Scale bar $=500 \mu \mathrm{m}$ in A and 100 $\mu \mathrm{m}$ in B-C.

General distribution: ARNT antibodies showed strong and widespread neuronal labeling without evident regional differences on inspection. The hippocampus and neocortex revealed dense neuronal labeling (Fig.1). Nuclear labeling was granular, with sparing of the nucleolus, and cytoplasmic staining was present. The generalized labeling pattern with antibodies to ARNT is in line with the description of global expression of ARNT protein in the literature (Aitola \& Pelto-Huikko, 2003; Kainu, Gustafsson, \& Pelto-Huikko, 1995; Petersen et al., 2000; Sekine, Mimura, Yamamoto, \& Fujii-Kuriyama, 2006) 
Midbrain: ARNT antibodies showed widespread labeling in the mouse midbrain

(Figure 1A, 1B, 1C). Specifically, SNr and SNc had a similar density of labeling as the rest of the midbrain (Figure 1C).
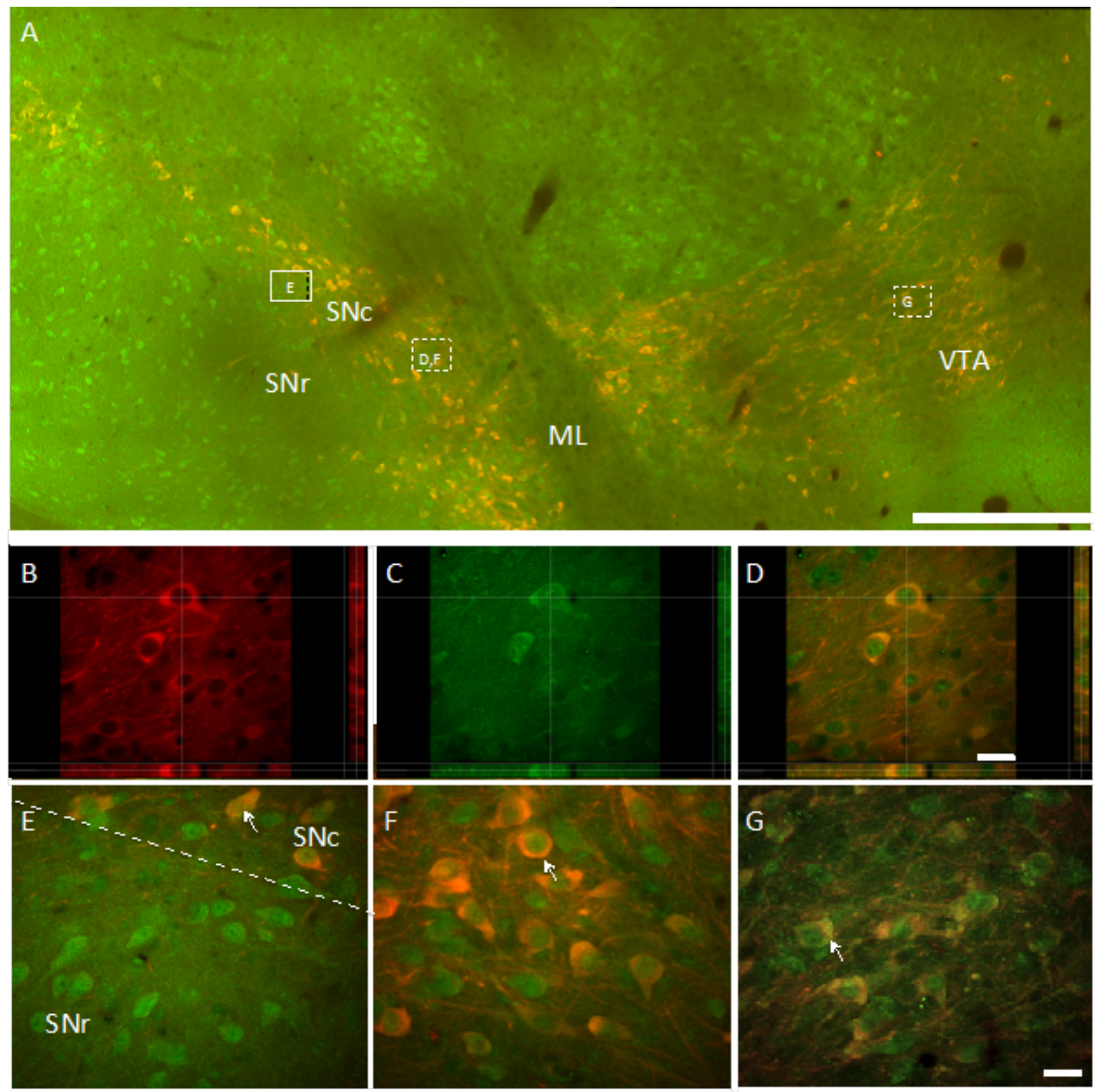

Figure 2. A) A low powered overview of the midbrain at bregma level $-3.15 \mathrm{~mm}$. showing immunolabeling for ARNT in green and TH signals in orange-red in the substantia nigra pars compacta (SNc) and the ventral tegmental area (VTA). The medial lemniscus (ML) separates the two DA regions. B-D) Images show three-dimensional reconstructions of representative image stacks. The crossing lines indicate the position within the $\mathrm{X}-\mathrm{Y}$ view at which the $\mathrm{Y}-\mathrm{Z}$ and $\mathrm{X}-\mathrm{Z}$ views were generated. E-F) A high powered views of the E) SNr, F) SNc, and G) VTA. White arrows show a representative colocalization between ARNT (green) and TH (red). The orange displayed in the cytoplasm of the TH is caused by dual signals from the ARNT and the TH antibodies. Scale bar $=100 \mu \mathrm{m}$ in A and $20 \mu \mathrm{m}$ in B-G. 
ARNT/TH double-staining: We focused on the dopaminergic neurons of the midbrain, i.e. SNc and VTA (Figure 2A). Labeling for ARNT was seen in the nucleus of virtually all TH-positive neurons in the SNc and VTA. Co-localization of ARNT and TH staining extended into the cytoplasm (Figure 2B, 2C, 2D). 


\section{ARNT2:}
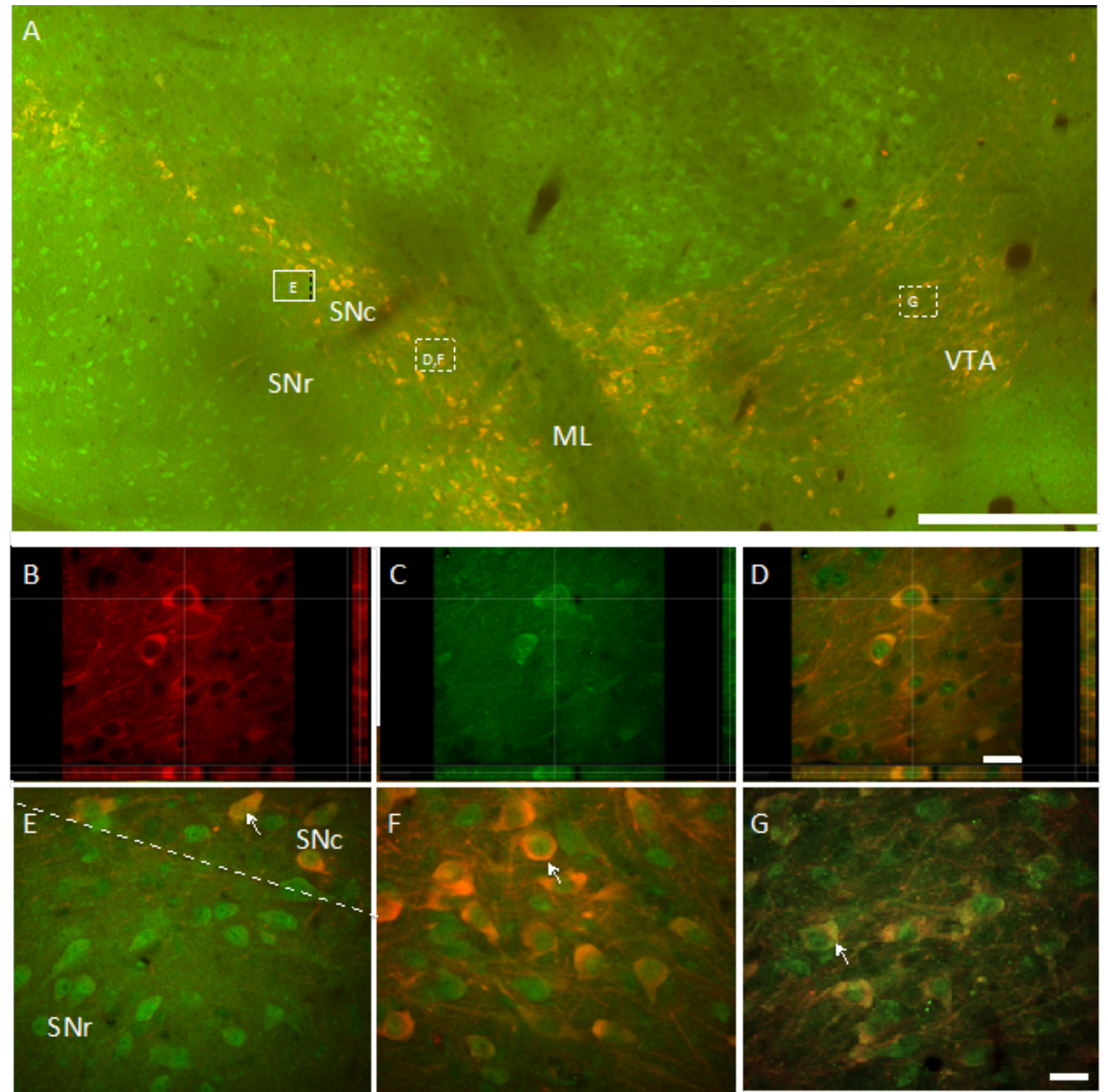

Figure 3. Low powered overviews of sections permanently immunolabeled for ARNT2 at bregma levels of A) -0.47 mm, B) $1.79 \mathrm{~mm}, \mathrm{C})-3.15 \mathrm{~mm}$, and D) $-5.19 \mathrm{~mm}$. The section at $-5.19 \mathrm{~mm}$ was further stained with haematoxylin. Scale bar= $500 \mu \mathrm{m}$. 


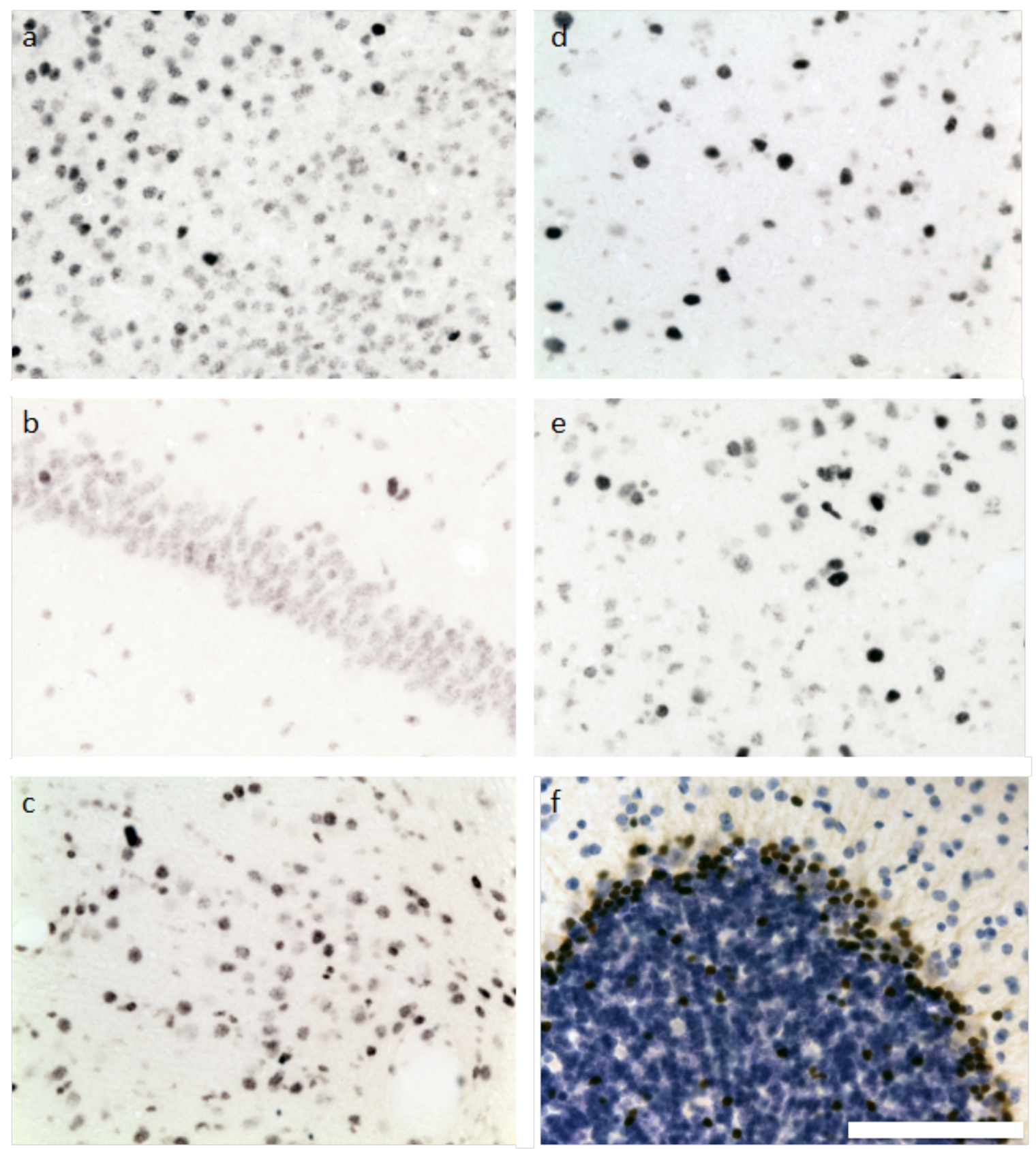

Figure 4. Higher powered views of permanent immunolabeling for ARNT2. Pictures were taken from the same animal with the same intensities for comparison. A) Cortex at bregma level $-0.47 \mathrm{~mm}$. B) CA1 of the hippocampus at bregma level $-1.79 \mathrm{~mm} \mathrm{C}$ Reticular thalamic nucleus at bregma level $-1.79 \mathrm{~mm}$. D) Ventral Tegmental area at bregma level $-3.15 \mathrm{~mm}$ E) Substantia nigra pars compacta at bregma level $-3.15 \mathrm{~mm}$. F) Cerebellum at bregma level -5.19, which was further stained with haematoxylin. Scale bar $=100 \mu \mathrm{m}$.

General Distribution: Antibodies to ARNT2 showed two distinct patterns of labeling: (i) very strongly labeled nuclei with a distinct regional pattern and (ii) diffuse, weak labeling of nuclei with a generalized pattern (Figure 3). Strong nuclear 
immunolabeling was seen in CA1 (Figure 4b), in cells scattered in the dendritic layers of the hippocampus (Figure 3D), the cortex (Figure 4a), the reticular thalamic nucleus (Figure 4c) and the globus pallidus. Faint ARNT2 labeling was seen in the striatum, CA3 (Figure 3D), and in most of thalamus. In the cerebellum (Figure 3F), specific and strong labeling was found (Figure 4f) in cells in the granular layer and cerebellar white matter. Analyses of morphology and localization of these cells indicated that they were not Purkinje cells, but rather a subpopulation of cerebellar cells that seemed to surround Purkinje cells. A further haematoxylin staining on the cerebellar tissue indicated that the ARNT2 cells around the purkinje cells were not in the granular cell layer of the cerebellum, although there were a few ARNT2 cells in the granular cell layer. It is suggested that these cells could be basket cells.

Midbrain: Strongly ARNT2-positive nuclei were found in the SNr whereas weak mainly signals were seen in SNc and VTA (Figure 3C). The SNc (Figure 4e) and VTA (Figure4d) also have a few intense ARNT2 nuclei. 

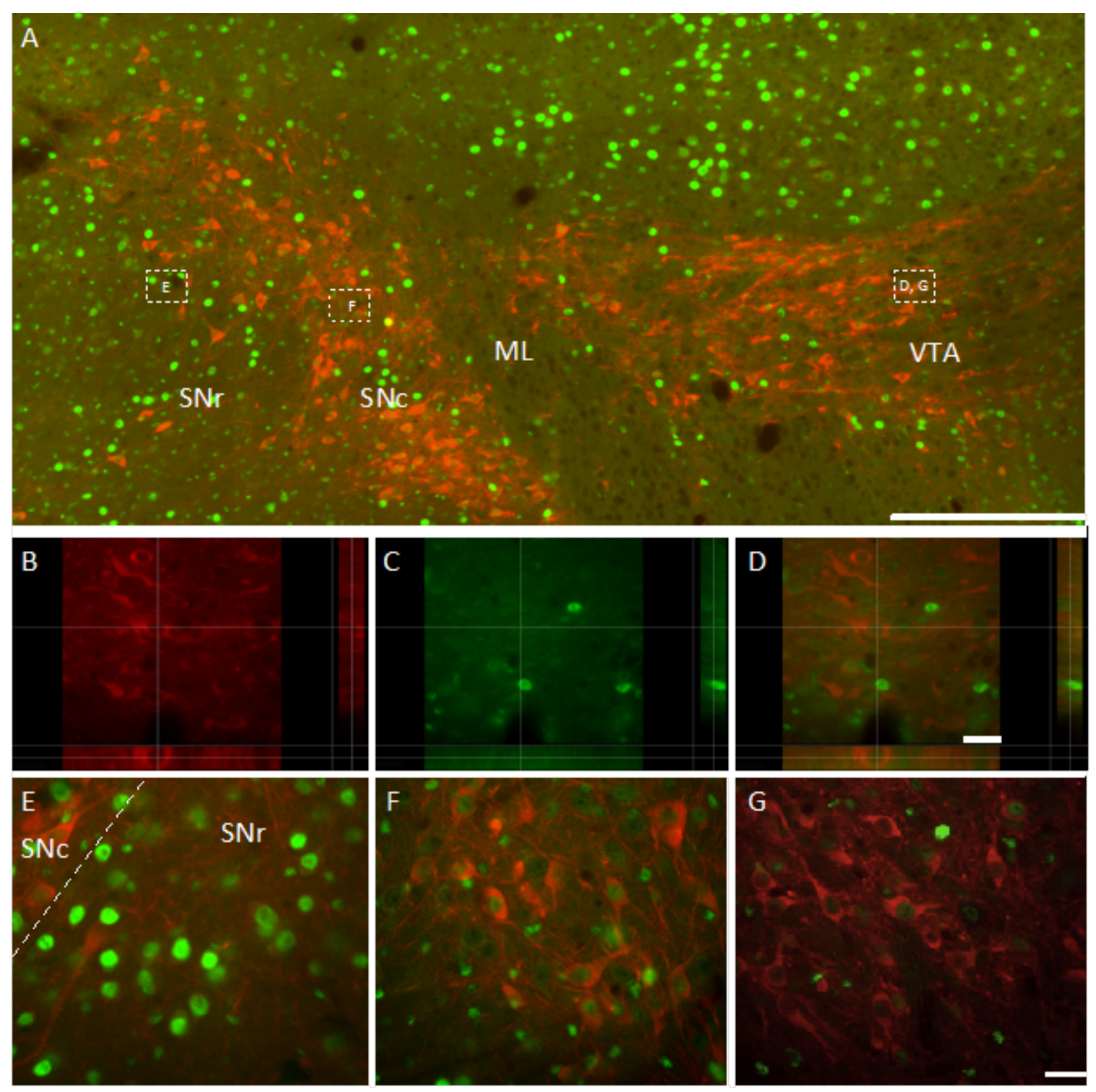

Figure 5. A) A low powered overview of the midbrain at bregma level $-3.15 \mathrm{~mm}$ showing the ARNT2 signals in green and TH signals in orange-red of the SN and the VTA. The medial lemniscus (ML) separates the two DA regions. B-D) Images show a three-dimensional reconstruction of a representative image stack. The crossing lines indicate the position within the X-Y view at which the Y-Z and X-Z views were generated. E-F) A high powered view of the E) SNr, F) SNc, and G) VTA. Scale bar $=100$ $\mu \mathrm{m}$ in $\mathrm{A}$ and $20 \mu \mathrm{m}$ in B-G.

ARNT2/TH double-staining: Double-labeling with anti-TH antibodies showed very low levels of ARNT2 in nuclei of TH-positive cells of SNc. Weak intensity of nuclear ARNT2 labeling within TH-positive neurons was found in VTA. Some scattered THimmunoreactive neurons with weak ARNT2 labeling were also found in the SNr. Strongly ARNT2 positive nuclei in the SNr and VTA were not surrounded by TH labeling (Figure 5B, 5C, 5D). 

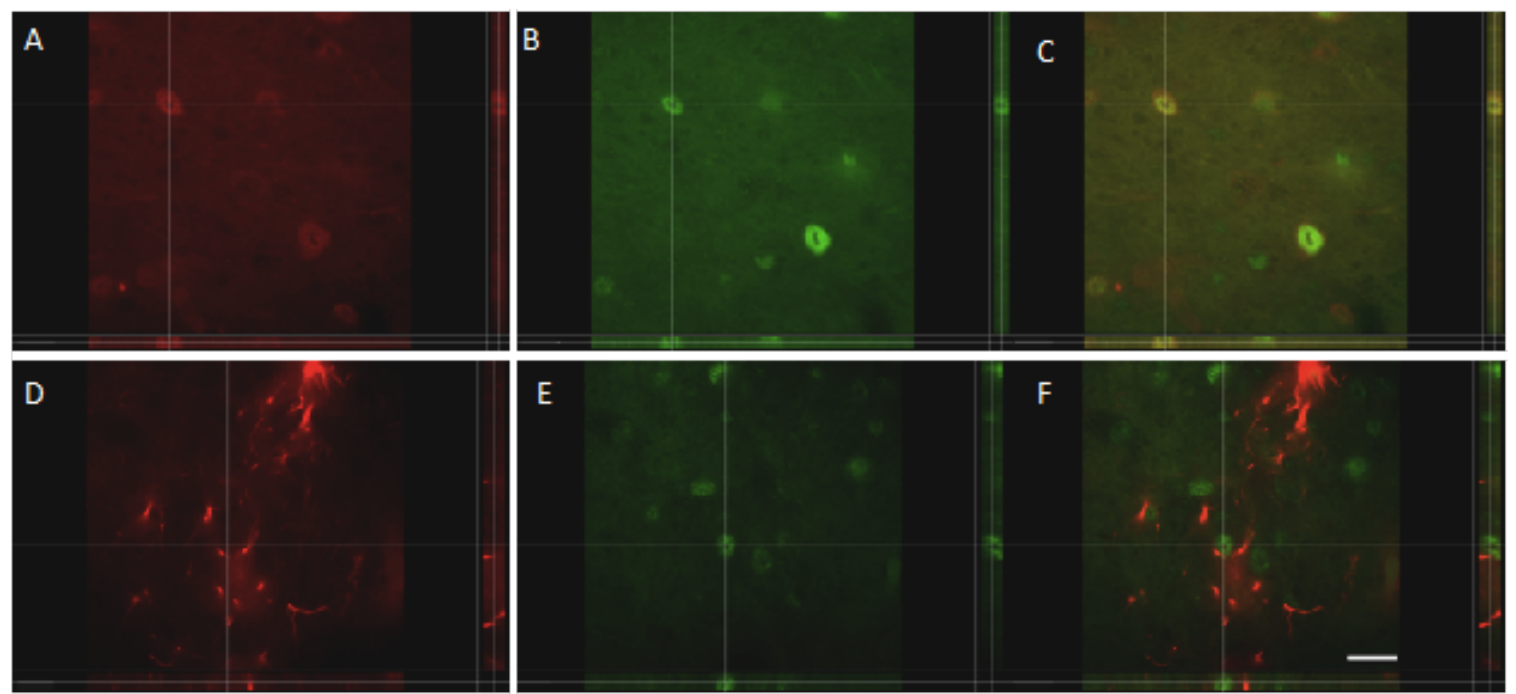

Figure 6. : Images show 3D reconstructions. A-C) Immunohistochemical stainings of neurons using Neuronal Nuclei (NeuN) antibody show colocalization of neurons with cells stained with ARNT2 antibody, as seen in the crossed lines of the 3D construction. D-F) Immunohistochemical stainings of astrocytes using glial fibrillary acidic protein (GFAP) antibody show a lack of colocalization with cells stained with ARNT2 antibody. GFAP was found not to be colocalized with ARNT2. Scale bar= 20 $\mu \mathrm{m}$.

ARNT2/GFAP and ARNT2/NeuN double-staining: Double-labeling with NeuN antibodies as a neuronal marker indicated that most strongly ARNT2-labeled nuclei in SNr belonged to neurons (Figure 6D, 6E, 6F). The strongly ARNT2-labeled nuclei were not found to colocalize with GFAP as an astrocytic marker (Figure 6A, 6B, 6C).

\section{Discussion}

In order to address expression of genes regulating the response to hypoxia in dopaminergic neurons in the substantia nigra and VTA, we performed detailed neuroanatomical studies on regional and cell-type-specific expression of ARNT and ARNT2 in the mouse midbrain. TH-positive neurons in SNc and VTA strongly expressed ARNT in their nucleus (which was similar to other neurons at the same section level). We found regional patterns of nuclei with strong immunohistochemical labeling for ARNT2 in the forebrain, which is congruent with earlier observations on the Arnt2 mRNA distribution (Peterson et al., 2000). Our double-labeling studies indicated that strongly-ARNT2 positive nuclei belonged to neurons. Immunoreactivity for ARNT2 was very low in TH-positive neurons in SNc and low in most of VTA. By contrast, neurons in SNr had strongly ARNT2-positive 
nuclei, while neurons in SNr also expressed ARNT. Thus, we observed distinct colocalization patterns of TH with ARNT and ARNT2 in the mouse midbrain. Specifically, dopaminergic neurons in SNc may be limited to ARNT as partner for HIF-1 alpha during hypoxia responses; this observation may be related to the hypothesis that the large axonal arbor puts SNc neurons on a tight energy budget (Bolam \& Pissadaki, 2012).

This is the first anatomical study of the HIF-1b subunits ARNT and ARNT2 in relation to dopaminergic systems in the mouse midbrain. Previous studies have focused almost entirely on the oxygen regulated HIF-1 alpha, which is ubiquitously expressed by neurons (Kietzmann et al., 2001; Acker and Acker, 2004). The constitutively expressed HIF-1 beta subunit has been less well analyzed. Most cells use ARNT as HIF-1 beta subunit, and our immunohistochemical studies with antibodies to ARNT indicate a generalized neuronal expression in the mouse brain. In the brain, ARNT2 is expressed with a distinct regional and cell-type specific distribution, which is in concert with earlier work on Arnt2 mRNA (Peterson et al., 2000).

Our observations of region-, and cell-type-specific colocalization patterns may be of functional importance, because ARNT and ARNT2 are known to have only partially overlapping functions in hypoxia signaling (Keith, Adelman, \& Simon, 2001) and that therefore distinct brain regions and cell types may respond differently on hypoxic challenges, based on differences in ARNT and ARNT2 expression, for example (Maltepe, Keith, Arsham, Brorson, \& Simon, 2000; Stolze et al., 2002). Distinctly different patterns of expression for ARNT and ARNT2 are also found during brain development (Aitola \& Pelto-Huikko, 2003), where gene deletion of Arnt2 in the mouse for example lead to hypothalamic abnormalities and premature postnatal death that were specifically related to SIM1, and not HIF-1 functions (Michaud, DeRossi, May, Holdener, \& Fan, 2000), and a severely impaired hypoxia response (Keith et al., 2001). Because ARNT/HIF-1 alpha complexes were still formed in Arnt2 -/- neurons, these may be sufficient to maintain normal steadystate levels of target gene expression in vivo. Accordingly, vascularization in the Arnt2 -/- brains was normal during development whereas deletion of Arnt had 
dramatic consequences for vascular development (Keith et al., 2001). Thus, Keith et al. (2001) suggested that ARNT2/HIF-1 alpha can regulate HIF-1 target genes, but ARNT/HIF-1 alpha complexes may be sufficient to regulate normal hypoxic responses during development in vivo. Other studies postulated differences in the role of ARNT and ARNT2 in neurons (Drutel et al., 1999; Drutel et al., 2000). Recently, Hao et al. (2013) showed high Arnt/low Arnt2 expression in undifferentiated cells and a strong increase in Arnt2 upon neuronal differentiation, while the switch for high Arnt2 was regulated by epigenetic modifications in neuronal differentiation (Hao, Bhakti, Peet, \& Whitelaw, 2013). It has been proposed that expression of ARNT or ARNT2 allows for the formation of differential transcriptional complexes in neurons (Hao et al. 2013).

It is possible that the expression of ARNT2 in dopaminergic midbrain neurons is limited by design to dampen hypoxia responses. TH has been described as hypoxia regulated by involving HIF-1 in peripheral dopaminergic neurons (Mannello, Medda, \& Tonti, 2011; Norris \& Millhorn, 1995; Panchision, 2009). Midbrain neurons may want to avoid fluctuations of TH expression due to local hypoxic events because it would impact the dopamine levels in the remote striatum.

The present findings are of relevance for genetic studies in psychiatric and neurological disorders. A recent report of ARNT2 mutations leading to loss function indicates important roles in postnatal brain development (Webb et al., 2013). ARNT2 has been also reported to interact with key proteins in neurodevelopmental disorders, i.e. necdin in Prader-Willi syndrome (Friedman \& Fan, 2007) and FMRP in Fragile X-Syndrome (Darnell et al., 2011). A genomic study of high altitude populations reported a significant polymorphism of ARNT2, suggesting an important physiological role in the hypoxia response in humans (Scheinfeldt et al., 2012). Given the low ARNT2 expression, genetic variation in ARNT could be an important factor in the hypoxia response of dopaminergic midbrain neurons. Limited options for HIF-1 responses in SNc neurons have also implications for degeneration in Parkinson's disease.

To conclude, our observations of distinct colocalization patterns of TH with ARNT and ARNT2 in the mouse midbrain may serve as a starting point for further 
studies testing distinct effects of hypoxia on dopaminergic transmitters systems, and the biological underpinnings of the impact of hypoxia in the etiology of a range of psychiatric and neurological disorders.

\section{Acknowledgements}

Many thanks to Hellen Steinbusch, Lieke van Gastel, Roy Lardenoije and Jo Stevens for their technical support on this project. The micrographs in this paper were taken with a confocal spinning disk microscope financed by The Netherlands Organisation for Scientific Research (NWO), grant number 911-06-003. 


\section{References}

Acker, T., \& Acker, H. (2004). Cellular oxygen sensing need in CNS function: physiological and pathological implications. J Exp Biol, 207(Pt 18), 31713188. doi: 10.1242/jeb.01075

Aitola, M. H., \& Pelto-Huikko, M. T. (2003). Expression of Arnt and Arnt2 mRNA in developing murine tissues. J Histochem Cytochem, 51(1), 41-54.

Bolam, J. P., \& Pissadaki, E. K. (2012). Living on the edge with too many mouths to feed: why dopamine neurons die. Mov Disord, 27(12), 1478-1483. doi: $10.1002 /$ mds. 25135

Darnell, J. C., Van Driesche, S. J., Zhang, C., Hung, K. Y., Mele, A., Fraser, C. E., . . . Darnell, R. B. (2011). FMRP stalls ribosomal translocation on mRNAs linked to synaptic function and autism. Cell, 146(2), 247-261. doi: 10.1016/j.cell.2011.06.013

Drutel, G., Heron, A., Kathmann, M., Gros, C., Mace, S., Plotkine, M., . . Arrang, J. M. (1999). ARNT2, a transcription factor for brain neuron survival? Eur J Neurosci, 11(5), 1545-1553.

Drutel, G., Kathmann, M., Heron, A., Gros, C., Mace, S., Schwartz, J. C., \& Arrang, J. M. (2000). Two splice variants of the hypoxia-inducible factor HIF-1alpha as potential dimerization partners of ARNT2 in neurons. Eur J Neurosci, 12(10), 3701-3708.

Drutel, G., Kathmann, M., Heron, A., Schwartz, J. C., \& Arrang, J. M. (1996). Cloning and selective expression in brain and kidney of ARNT2 homologous to the Ah receptor nuclear translocator (ARNT). Biochem Biophys Res Commun, 225(2), 333-339. doi: 10.1006/bbrc.1996.1176

Friedman, E. R., \& Fan, C. M. (2007). Separate necdin domains bind ARNT2 and HIF1alpha and repress transcription. Biochem Biophys Res Commun, 363(1), 113-118. doi: 10.1016/j.bbrc.2007.08.108

Gilman, S. R., Chang, J., Xu, B., Bawa, T. S., Gogos, J. A., Karayiorgou, M., \& Vitkup, D. (2012). Diverse types of genetic variation converge on functional gene 
networks involved in schizophrenia. Nat Neurosci, 15(12), 1723-1728. doi: 10.1038/nn.3261

Hao, N., Bhakti, V. L., Peet, D. J., \& Whitelaw, M. L. (2013). Reciprocal regulation of the basic helix-loop-helix/Per-Arnt-Sim partner proteins, Arnt and Arnt2, during neuronal differentiation. Nucleic Acids Res, 41(11), 5626-5638. doi: 10.1093/nar/gkt206

Hirose, K., Morita, M., Ema, M., Mimura, J., Hamada, H., Fujii, H., . . Fujii-Kuriyama, Y. (1996). cDNA cloning and tissue-specific expression of a novel basic helixloop-helix/PAS factor (Arnt2) with close sequence similarity to the aryl hydrocarbon receptor nuclear translocator (Arnt). Mol Cell Biol, 16(4), 17061713.

Howes, O. D., Williams, M., Ibrahim, K., Leung, G., Egerton, A., McGuire, P. K., \& Turkheimer, F. (2013). Midbrain dopamine function in schizophrenia and depression: a post-mortem and positron emission tomographic imaging study. Brain, 136(Pt 11), 3242-3251. doi: 10.1093/brain/awt264

Jain, S., Maltepe, E., Lu, M. M., Simon, C., \& Bradfield, C. A. (1998). Expression of ARNT, ARNT2, HIF1 alpha, HIF2 alpha and Ah receptor mRNAs in the developing mouse. Mech Dev, 73(1), 117-123.

Jiang, B. H., Rue, E., Wang, G. L., Roe, R., \& Semenza, G. L. (1996). Dimerization, DNA binding, and transactivation properties of hypoxia-inducible factor 1.J Biol Chem, 271(30), 17771-17778.

Kainu, T., Gustafsson, J. A., \& Pelto-Huikko, M. (1995). The dioxin receptor and its nuclear translocator (Arnt) in the rat brain. Neuroreport, 6(18), 2557-2560.

Keith, B., Adelman, D. M., \& Simon, M. C. (2001). Targeted mutation of the murine arylhydrocarbon receptor nuclear translocator 2 (Arnt2) gene reveals partial redundancy with Arnt. Proc Natl Acad Sci U S A, 98(12), 6692-6697. doi: 10.1073/pnas.121494298

Kietzmann, T., Knabe, W., \& Schmidt-Kastner, R. (2001). Hypoxia and hypoxiainducible factor modulated gene expression in brain: involvement in neuroprotection and cell death. Eur Arch Psychiatry Clin Neurosci, 251(4), 170-178. 
Maltepe, E., Keith, B., Arsham, A. M., Brorson, J. R., \& Simon, M. C. (2000). The role of ARNT2 in tumor angiogenesis and the neural response to hypoxia. Biochem Biophys Res Commun, 273(1), 231-238. doi: 10.1006/bbrc.2000.2928

Mannello, F., Medda, V., \& Tonti, G. A. (2011). Hypoxia and neural stem cells: from invertebrates to brain cancer stem cells. Int J Dev Biol, 55(6), 569-581. doi: 10.1387/ijdb.103186fm

Michaud, J. L., DeRossi, C., May, N. R., Holdener, B. C., \& Fan, C. M. (2000). ARNT2 acts as the dimerization partner of SIM1 for the development of the hypothalamus. Mech Dev, 90(2), 253-261.

Neale, B. M., Kou, Y., Liu, L., Ma'ayan, A., Samocha, K. E., Sabo, A., .. Daly, M. J. (2012). Patterns and rates of exonic de novo mutations in autism spectrum disorders. Nature, 485(7397), 242-245. doi: 10.1038/nature11011

Norris, M. L., \& Millhorn, D. E. (1995). Hypoxia-induced protein binding to 02responsive sequences on the tyrosine hydroxylase gene. J Biol Chem, 270(40), 23774-23779.

O'Roak, B. J., Vives, L., Girirajan, S., Karakoc, E., Krumm, N., Coe, B. P., . . Eichler, E. E. (2012). Sporadic autism exomes reveal a highly interconnected protein network of de novo mutations. Nature, 485(7397), 246-250. doi: 10.1038/nature10989

Panchision, D. M. (2009). The role of oxygen in regulating neural stem cells in development and disease. J Cell Physiol, 220(3), 562-568. doi: $10.1002 /$ jcp. 21812

Petersen, S. L., Curran, M. A., Marconi, S. A., Carpenter, C. D., Lubbers, L. S., \& McAbee, M. D. (2000). Distribution of mRNAs encoding the arylhydrocarbon receptor, arylhydrocarbon receptor nuclear translocator, and arylhydrocarbon receptor nuclear translocator-2 in the rat brain and brainstem.J Comp Neurol, 427(3), 428-439.

Prabhakar, N. R., \& Semenza, G. L. (2012). Adaptive and maladaptive cardiorespiratory responses to continuous and intermittent hypoxia mediated by hypoxia-inducible factors 1 and 2. Physiol Rev, 92(3), 967-1003. doi: 10.1152 /physrev.00030.2011 
Preibisch, S., Saalfeld, S., \& Tomancak, P. (2009). Globally optimal stitching of tiled 3D microscopic image acquisitions. Bioinformatics, 25(11), 1463-1465. doi: 10.1093/bioinformatics/btp184

Richards, A. L., Jones, L., Moskvina, V., Kirov, G., Gejman, P. V., Levinson, D. F., ... O'Donovan, M. C. (2012). Schizophrenia susceptibility alleles are enriched for alleles that affect gene expression in adult human brain. Mol Psychiatry, 17(2), 193-201. doi: 10.1038/mp.2011.11

Scheinfeldt, L. B., Soi, S., Thompson, S., Ranciaro, A., Woldemeskel, D., Beggs, W., . . Tishkoff, S. A. (2012). Genetic adaptation to high altitude in the Ethiopian highlands. Genome Biol, 13(1), R1. doi: 10.1186/gb-2012-13-1-r1

Schmidt-Kastner, R., van Os, J., Esquivel, G., Steinbusch, H. W., \& Rutten, B. P. (2012). An environmental analysis of genes associated with schizophrenia: hypoxia and vascular factors as interacting elements in the neurodevelopmental model. Mol Psychiatry, 17(12), 1194-1205. doi: 10.1038/mp.2011.183

Sekine, H., Mimura, J., Yamamoto, M., \& Fujii-Kuriyama, Y. (2006). Unique and overlapping transcriptional roles of arylhydrocarbon receptor nuclear translocator (Arnt) and Arnt2 in xenobiotic and hypoxic responses. J Biol Chem, 281(49), 37507-37516. doi: 10.1074/jbc.M606910200

Sharp, F. R., \& Bernaudin, M. (2004). HIF1 and oxygen sensing in the brain. Nat Rev Neurosci, 5(6), 437-448. doi: 10.1038/nrn1408

Shibata, T., Yamagata, H., Uchida, S., Otsuki, K., Hobara, T., Higuchi, F., ... Watanabe, Y. (2013). The alteration of hypoxia inducible factor-1 (HIF-1) and its target genes in mood disorder patients. Prog Neuropsychopharmacol Biol Psychiatry, 43, 222-229. doi: 10.1016/j.pnpbp.2013.01.003

Stolze, I., Berchner-Pfannschmidt, U., Freitag, P., Wotzlaw, C., Rossler, J., Frede, S., . . . Fandrey, J. (2002). Hypoxia-inducible erythropoietin gene expression in human neuroblastoma cells. Blood, 100(7), 2623-2628. doi: 10.1182/blood2001-12-0169

van Os, J., Kenis, G., \& Rutten, B. P. (2010). The environment and schizophrenia. Nature, 468(7321), 203-212. doi: 10.1038/nature09563 
Wang, G. L., Jiang, B. H., Rue, E. A., \& Semenza, G. L. (1995). Hypoxia-inducible factor 1 is a basic-helix-loop-helix-PAS heterodimer regulated by cellular 02 tension. Proc Natl Acad Sci U S A, 92(12), 5510-5514.

Webb, E. A., AlMutair, A., Kelberman, D., Bacchelli, C., Chanudet, E., Lescai, F., ... Dattani, M. T. (2013). ARNT2 mutation causes hypopituitarism, post-natal microcephaly, visual and renal anomalies. Brain, 136(Pt 10), 3096-3105. doi: 10.1093/brain/awt218 


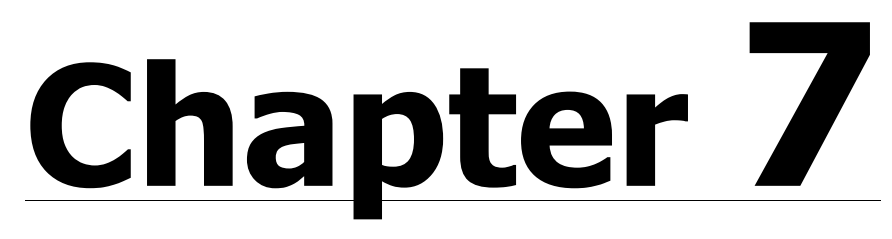

\section{Summary and Conclusion}




\section{Part I: Roles of dopamine D1 and D2, opioid and glutamate NMDA receptor signaling in the acquisition-expression of fat-conditioned flavor preferences in rats; \\ c-Fos analysis of the mesotelencephalic dopamine reward- nigrostriatal pathways following intake of sugars and fats in rats.}

\section{The effects of different neurotransmitters on fat-conditioned flavor preference}

Overconsumption of food is partly based on learned preferences for specific types of food, especially those that contain sugars and fats. Fat-rich and sugar-rich foods are highly attractive and are capable of eliciting Conditioned Flavor Preferences (CFP) in animal models. Fats and sugars are highly palatable and lead to positive effects in the gut, leading to overeating and consumption. Sugars have been extensively studied in both flavor-flavor $(\mathrm{F} / \mathrm{F})$ and flavor-nutrient $(\mathrm{F} / \mathrm{N})$ conditioning (Azzara, Bodnar, Delamater, \& Sclafani, 2001; Sclafani \& Ackroff, 1994; Touzani, Bodnar, \& Sclafani, 2009; Yu, Silva, Sclafani, Delamater, \& Bodnar, 2000a, $2000 \mathrm{~b}$ ), while the roles of fat-CFP in both F/F and F/N conditioning have not been fully explored. Because both fats and sugars contribute to overeating, it may be assumed that fats cause have similar reactions to specific neurotransmitters as sugars do.

Chapter 2 explores two types of dopamine (DA) receptors, D1 and D2, in their role in fat-CFP through ingestion of differing corn-oil solutions and pairing them with differing flavors. Previously, it was found that systemic injections of the DA D1 antagonist (SCH23390) and to a lesser degree, the DA D2 (Raclopride) antagonist, blocked acquisition of fructose-flavor conditioning, whereas both DA D1 and D2 antagonists significantly reduced expression of fructose-CFP (Baker, Shah, Sclafani, \& Bodnar, 2003) for F/F conditioning, while the DA D1, but not DA D2, blocked F/N conditioning of intragastric (IG) infusions of sucrose (Azzara et al., 2001). The current study found that the DA D1 antagonists produced a dose-limited reduction in expression of corn oil-CFP (both $\mathrm{F} / \mathrm{F}$ and $\mathrm{F} / \mathrm{N}$ ) in contrast to 
SCH23390-induced eliminations of the fructose-CFP (F/F CFP) in rats (Baker et al., 2003), while the DA D2 antagonist was only blocked CS+ preference at the 200 $\mathrm{nmol} / \mathrm{kg}$ dose in expression of corn oil-CFP. The DA D1 antagonist failed to block acquisition of a CS+ preference, while the DA D2 antagonist only had one significant drug acquisition effect at the $50 \mathrm{nmol} / \mathrm{kg}$ dose which resulted in a hastening of extinction of the CS+ preference. DA D1 and D2 antagonism is much less effective at attenuating the acquisition of fat-conditioned flavor preferences. Overall, the data from the current study indicate a limited DA D1 and D2 receptor signaling involvement in acquisition and expression of a fat-CFP relative to previous robust effects for sugar-CFP.

While DA did not seem to have strong effect in fat-CFP, other neurotransmitters were also suspected to be involved. Opioids have been linked to affect the general rewarding characteristics of sugars (Arbisi, Billington, \& Levine, 1999; Fantino, Hosotte, \& Apfelbaum, 1986), but the opioid receptor antagonist, Naltrexone (NTX), failed to alter the expression or acquisition of sugar-CFP. NTX dose-dependently reduced fructose (CS+) and saccharin (CS-) intakes when injected during training, yet NTX was unable to reduce conditioning in either acquisition CFP or expression CFP (Baker, Li, Lee, Sclafani, \& Bodnar, 2004), NTX also failed to alter either the acquisition and expression of CFP elicited by IG sucrose solutions (F/N conditioning) (Azzara, Bodnar, Delamater, \& Sclafani, 2000). In the current study of chapter 3, NTX failed to block acquisition of corn oil-CFP and was moderately attenuated by NTX in the expression of corn-oil CFP. It can be concluded that while opioids may have a role in the ingestion of sugars and sweet palatable foods, it does not have much involvement in the learning and memory of either a sugar or a fat.

Lastly, the $N$-methyl-D-aspartate (NMDA) glutamate receptor has been shown to play a role in food-incentive learning (Kelley, 2004; Ranaldi et al., 2011). The non-competitive NMDA antagonist, MK-801, significantly increased sucrose intake in moderately food-deprived animals (Covasa, Ritter, \& Burns, 2004; Qiang et al., 2000). Glutamate signaling has shown to be involved in sugar conditioned flavor preference as well. MK-801 was found to block acquisition, but not expression of fructose-CFP. The other study in chapter 3 subsequently examined glutamate 
NMDA signaling in fat-CFP. Lower doses of MK-801 slightly reduced CS+ intake in expression, while high doses blocked CS+ intake. In contrast, MK-801 treatment during training blocked acquisition of corn oil-CFP. The data from both sugar and fat studies suggest that there is a critical role for NMDA signaling in the acquisition of fructose $(\mathrm{F} / \mathrm{F})$ and fat $(\mathrm{F} / \mathrm{F}$ and $\mathrm{F} / \mathrm{N}) \mathrm{CFP}$, and at best limited involvement of NMDA receptors in the expression of a previously learned preference.

\section{The DA reward pathways through ingestion of sugars and fats}

Many of the learned associations to flavor cues are thought to stem from the connection of the hedonic taste, the palatability of the nutrients, and the "reward" associated with dopamine (DA) release in the brain particularly from the Ventral Tegmental Area (VTA) to its major mesotelencephalic projection sites including the nucleus accumbens (NAc), amygdala (AMY) and medial prefrontal cortex (mPFC), as well as from the Substantia Nigra Pars Compacta (SNc) to the striatum (Caudate and Putamen: CP). The systemic and central pharmacological analyses of mediators of sugar and fat intake as well as preferences conditioned by these nutrients can provide important information about underlying substrates. Further, the increased release of endogenous neurochemical mediators (particularly DA) in similar brain sites (e.g., NAc, AMY, mPFC) following sugar and fat intake can provide further insight into these processes. One remaining area of inquiry concerns the spatial resolution of activation within these sites in response to fat and sugar nutrients. cFos is an indirect marker of neuronal activity because this protoonco-gene is often expressed when neurons fire action potentials (Dragunow \& Faull, 1989; VanElzakker, Fevurly, Breindel, \& Spencer, 2008). Chapter 4 explored the differing projection sites as well as the VTA to see if ingestion of a fat or sugar produces greater activation than the controls. Ingestion of corn-oil (which conditions F/F and $\mathrm{F} / \mathrm{N}$ processes) activated DA-labeled cells in the VTA as well as DA-projection fields in the AMY, NAc core, dorsal CP, and mPFC. The NAc shell failed to display activation. Glucose (which conditions $\mathrm{F} / \mathrm{F}$ and $\mathrm{F} / \mathrm{N}$ processes), significantly increased c-fos activation in the AMY, NAc core, and dorsal CP. However, ingestion of glucose failed to increase c-fos activation in the VTA, NAc shell or mPFC. Ingestion 
of fructose (which conditions only F/F processes), significantly activated cells in the AMY and dorsal striatum, and to a lesser degree, the NAc core, while failing to display activation in the VTA, MPFC and NAc shell. Lastly, ingestion of saccharin and xanthan gum suspension failed to activate in any site relative to water intake. From this study, it can be concluded different solutions activate different areas of the brain in varying ways. In those situations in which significant activation was observed, there were many instances of highly positive relationships across sites, supporting the idea of activation of a distributed brain network mediating sugar and fat intake. Interestingly, both corn-oil and glucose was found to have F/F and F/N processes, but affected the mesotelencephalic and nigrostriatal pathways in various manners. There may be more to CFP feeding studies than just F/F and F/N conditioning, but further research needs to be conducted to pinpoint what this difference may be.

\section{Future perspectives}

A logical next step after the CFP studies presented in this thesis would be to study microinjections of DA D1, DA D2 and NMDA antagonists into specific sites of the brain, specifically the mesotelencephalic and nigrostriatal pathways, with cornoil CFP. These microinjection CFP studies have already been conducted with sugarCFP (Bernal et al., 2008; Bernal et al., 2009; Malkusz et al., 2012). Since previous studies (Bernal et al., 2010) and current studies examining opioid antagonists failed to produce sugar- and fat-CFP, further investigations are not necessary. It may be intriguing to compare the DA specific site data to what was found in chapter 4 , to see if the different brain sites correlate the same way, especially since corn-oil strongly activated many brain sites.

For the c-fos studies, it would be interesting to see activation in the brain from sham studies and intragastric infusion studies. The sham studies would examine activation only orosensory processes (F/F studies), as it was previously conducted in CFP studies (Yu et al., 2000a, 2000b), while the intragastric infusions would examine only post-ingestive processes (F/N studies), as it was previously conducted in CFP studies (Azzara et al., 2000, 2001). This would be especially 
intriguing with corn-oil ingestion. Since corn-oil activated the brain so strongly in so many areas, it would be interesting to see if there is a different in activation between the $\mathrm{F} / \mathrm{F}$ processes and the $\mathrm{F} / \mathrm{N}$ processes.

\section{Part II. Dopamine, memory, Deep Brain Stimulation and hypoxia}

\section{Dopamine and deep brain stimulation treatment for diseases with memory impairment}

Research has shown that DA is involved in various parts of the brain to help perform various memory tasks. Reward, and reinforcement (the "stamping-in" of memory) have been linked to the brain areas talked about in the previous chapters. DA D1 and D5 receptors in the dorsal hippocampus have been found to be involved in episodic memory (Bethus, Tse, \& Morris, 2010). Anterior Nucleus of the Thalamus (ANT), Mammillothalamic Tract (MTT) and Entorhinal Cortex (EC) were chosen as deep brain stimulation (DBS) sites because of the they are all part of the Circuit of Papez. Another brain area belonging to the Circuit of Papez is the hippocampus and both are known to be connected to memory. Interestingly, our study became less about how DA is involved in memory and memory impairments and more of how differing DBS sites affect DA levels in the SNc and VTA.

Chapter 5 explored the DA synthesis sites when these memory processes are disrupted, by emitting DBS in several sites of the Circuit of Papez to reverse the memory loss caused by injection of scopolamine, a muscarinic acetylcholine antagonist. Levels of tyrosine hydroxylase $(\mathrm{TH}$, a rate-limiting enzyme in the formation of DA) and c-fos (a proto-oncogene and a marker for cell activation) were explored in the two major sites of DA synthesis: the VTA and the SNc. There were no significant differences found with the c-fos marker in the VTA and the SNc, or in the TH levels of the SNc. However, DBS stimulation into the ANT induced an increase in TH cells in the VTA, while DBS stimulation into the EC and the MTT did not, relative 
to the controls. This seems to be in line with behavioral findings of our unpublished data and previous studies. DBS into the EC (Stone et al., 2011) reversed the effects of memory loss caused by scopolamine, while DBS into the ANT had memory loss retention (Hamani et al., 2009). It is suspected that the neurons in the VTA had a phenotypic switching from GABA cells to TH cells caused by the environmental factor of DBS into the ANT, but not by DBS in the EC or MTT. Environmental changes have previously been seen with mating rats changes GABA cells to TH cells in both the VTA and SNc (Aumann, Tomas, \& Horne, 2013). ANT-DBS had been found to be effective in treating refractory focal epilepsy (Graber \& Fisher, 2012), but some side effects include depression and memory loss. As dopaminergic projections from the VTA mediate reward-seeking behavior (among other functions), our current findings may imply that ANT-stimulation with DBS, such as used in the treatment of epilepsy, may induce alterations in reward-seeking and other behavioral phenotypes.

\section{Dopamine and hypoxia}

Besides reward-motivated behavior and memory, DA has many other roles as one of the neurotransmitters released in the brain, several of which include motor control, cognition, and release of several important hormones. DA is also known to play a key role in psychiatric disorders (van Os, Kenis, \& Rutten, 2010), and is suspected to play a role in the survival functions of hypoxia (Grunblatt, 2004; Norris \& Millhorn, 1995). Our studies in chapter 6 found a colocalization of DA with both two types of hypoxia inducible factor- $1 \beta$ (HIF-1 $1 \beta$ ) subunits: aryl-hydrocarbon receptor nuclear translocator (ARNT) and ARNT2 in the SNc as well as in the VTA. In the midbrain DA system, neurons in the SNc and VTA expressed ARNT in the same intensity within TH neurons and beyond, while immunoreactivitity for ARNT2 in TH neurons was low. The SNr contained diffuse amounts of ARNT, while it contained intense ARNT2 immunoreactive cells as compared to the TH neurons. Dopaminergic (TH) neurons may primarily express HIF-1 by using ARNT, whereas other non-TH neurons have both ARNT and ARNT2 available. This is an interesting finding 
because ARNT and ARNT2 are known to have only partially overlapping functions in hypoxia signaling (Keith, Adelman, \& Simon, 2001). The differences between the two cellular compositions may induce differential responses to hypoxia. Previous data suggest that ARNT2/HIF-1 alpha can regulate HIF-1 target genes, but ARNT/HIF-1 alpha complexes may be sufficient to regulate normal hypoxic responses during development in vivo. In addition, TH has been described as hypoxia regulated by involving HIF-1 peripheral dopaminergic neurons (Mannello, Medda, \& Tonti, 2011). It is hypothesized that midbrain neurons may want to avoid fluctuations of TH expression due to local hypoxic events because it would impact the remote striatum. The findings from Chapter 6 indicate both shared and nonshared expression patterns of ARNT and ARNT2 in dopaminergic neurons in the mouse midbrain. Thereby possibly directing distinct vulnerability to hypoxia for different types of dopaminergic neurons.

\section{Future perspectives}

The next step for the DBS study is to look at the same brain tissue from the same DBS-treated, scopolamine-injected animals, and run additional studies on them. Because it was suggested that the DA cells were previously GABA cells, it is proposed to double-stain the SNc and VTA with TH and GAD67 (an antibody that labels GABA cell bodies) to see if the populations of TH and GABA are similar to those found in the controls. To strengthen the credibility that GABA is involved: a study similar to Aumann and colleagues (2013) can be conducted. I would suggest injections of a GABA antagonist through cannula injections into the VTA and SNc followed by DBS into the ANT, EC and MTT. We will examine TH levels in the VTA and the SNc to observe the possible changes made from the GABA antagonist. Lastly, it would be interesting to see if the DA projections from the VTA and SNc are also affected. Immunohistochemical staining of DA fibers in the NAc and striatum could be performed to visualize if the fibers are affected by the use of DBS in the ANT.

For the DA and hypoxia study, the next step could be to induce hypoxia in mice and study the colocalization levels of ARNT/TH and ARNT2/TH in the VTA and SNc. From here, quantitate studies through stereology can compare the levels of 
colocalization of the wild type mice and hypoxia-treated mice. Increased DA levels were already observed in hypoxia studies involving stem cells (Mannello et al., 2011; Panchision, 2009). HIF-1 $\alpha$ was found -in addition to other functions- to regulate the differentiation and production of dopaminergic neurons (Panchision, 2009). It is tempting to speculate that hypoxia may increase DA levels and that dopaminergic cells expressing either ARNT or ARNT2 may differentially respond to hypoxia conditions. If this hypothesis proves true, animal models of mental disorders, such as Parkinson's disease or schizophrenia, could be included as an additional independent variable in the hypoxia studies. This would strengthen the link of the gene $\mathrm{x}$ environment interaction hypothesis that hypoxia may be a factor in increasing the risk of mental disorders (Schmidt-Kastner, van Os, Esquivel, Steinbusch, \& Rutten, 2012). 


\section{References}

Aitola, M. H., \& Pelto-Huikko, M. T. (2003). Expression of Arnt and Arnt2 mRNA in developing murine tissues. J Histochem Cytochem, 51(1), 41-54.

Arbisi, P. A., Billington, C. J., \& Levine, A. S. (1999). The effect of naltrexone on taste detection and recognition threshold. Appetite, 32(2), 241-249. doi: 10.1006/appe.1998.0217

Aumann, T. D., Tomas, D., \& Horne, M. K. . (2013). Environmental and behavioral modulation of the number of substantia nigra dopamine neurons in adult mice. Brain and Behavior.

Azzara, A. V., Bodnar, R. J., Delamater, A. R., \& Sclafani, A. (2000). Naltrexone fails to block the acquisition or expression of a flavor preference conditioned by intragastric carbohydrate infusions. Pharmacol Biochem Behav, 67(3), 545557.

Azzara, A. V., Bodnar, R. J., Delamater, A. R., \& Sclafani, A. (2001). D1 but not D2 dopamine receptor antagonism blocks the acquisition of a flavor preference conditioned by intragastric carbohydrate infusions. Pharmacol Biochem Behav, 68(4), 709-720.

Baker, R. M., Li, Y., Lee, M. G., Sclafani, A., \& Bodnar, R. J. (2004). Naltrexone does not prevent acquisition or expression of flavor preferences conditioned by fructose in rats. Pharmacol Biochem Behav, 78(2), 239-246. doi: 10.1016/j.pbb.2004.03.013

Baker, R. M., Shah, M. J., Sclafani, A., \& Bodnar, R. J. (2003). Dopamine D1 and D2 antagonists reduce the acquisition and expression of flavor-preferences conditioned by fructose in rats. Pharmacol Biochem Behav, 75(1), 55-65.

Bernal, S. Y., Dostova, I., Kest, A., Abayev, Y., Kandova, E., Touzani, K., . . B Bodnar, R. J. (2008). Role of dopamine D1 and D2 receptors in the nucleus accumbens shell on the acquisition and expression of fructose-conditioned flavor-flavor preferences in rats. Behav Brain Res, 190(1), 59-66. doi: 10.1016/j.bbr.2008.02.003 
Bernal, S. Y., Miner, P., Abayev, Y., Kandova, E., Gerges, M., Touzani, K., ... Bodnar, R. J. (2009). Role of amygdala dopamine D1 and D2 receptors in the acquisition and expression of fructose-conditioned flavor preferences in rats. Behav Brain Res, 205(1), 183-190. doi: 10.1016/j.bbr.2009.06.032

Bernal, S. Y., Touzani, K., Gerges, M., Abayev, Y., Sclafani, A., \& Bodnar, R. J. (2010). Opioid receptor antagonism in the nucleus accumbens fails to block the expression of sugar-conditioned flavor preferences in rats. Pharmacol Biochem Behav, 95(1), 56-62. doi: 10.1016/j.pbb.2009.12.006

Bethus, I., Tse, D., \& Morris, R. G. (2010). Dopamine and memory: modulation of the persistence of memory for novel hippocampal NMDA receptor-dependent paired associates. J Neurosci, 30(5), 1610-1618. doi: 10.1523/JNEUROSCI.2721-09.2010

Covasa, M., Ritter, R. C., \& Burns, G. A. (2004). NMDA receptor blockade attenuates CCK-induced reduction of real feeding but not sham feeding. Am J Physiol Regul Integr Comp Physiol, 286(5), R826-831. doi: 10.1152/ajpregu.00570.2003

Dragunow, M., \& Faull, R. (1989). The use of c-fos as a metabolic marker in neuronal pathway tracing. J Neurosci Methods, 29(3), 261-265.

Fantino, M., Hosotte, J., \& Apfelbaum, M. (1986). An opioid antagonist, naltrexone, reduces preference for sucrose in humans. Am J Physiol, 251(1 Pt 2), R91-96.

Graber, K. D., \& Fisher, R. S. (2012). Deep Brain Stimulation for Epilepsy: Animal Models. In J. L. Noebels, M. Avoli, M. A. Rogawski, R. W. Olsen \& A. V. DelgadoEscueta (Eds.), Jasper's Basic Mechanisms of the Epilepsies (4th ed.). Bethesda (MD).

Grunblatt, E. (2004). The benefits of microarrays as tools for studying neuropsychiatric disorders. Drugs Today (Barc), 40(2), 147-156.

Hamani, C., Ewerton, F. I., Marcolin de Almeida, F., Bonilha, S. M., Covolan, L., Fantin Cavarsan, C., . . L Lozano, A. M. (2009). Bilateral anterior thalamic nucleus lesions are not protective against seizures in chronic pilocarpine epileptic rats. Stereotact Funct Neurosurg, 87(3), 143-147. doi: 10.1159/000209294 
Keith, B., Adelman, D. M., \& Simon, M. C. (2001). Targeted mutation of the murine arylhydrocarbon receptor nuclear translocator 2 (Arnt2) gene reveals partial redundancy with Arnt. Proc Natl Acad Sci U S A, 98(12), 6692-6697. doi: 10.1073/pnas.121494298

Kelley, A. E. (2004). Ventral striatal control of appetitive motivation: role in ingestive behavior and reward-related learning. Neurosci Biobehav Rev, 27(8), 765-776. doi: 10.1016/j.neubiorev.2003.11.015

Malkusz, D. C., Banakos, T., Mohamed, A., Vongwattanakit, T., Malkusz, G., Saeed, S., . . . Bodnar, R. J. (2012). Dopamine signaling in the medial prefrontal cortex and amygdala is required for the acquisition of fructose-conditioned flavor preferences in rats. Behav Brain Res, 233(2), 500-507. doi: 10.1016/j.bbr.2012.05.004

Maltepe, E., Keith, B., Arsham, A. M., Brorson, J. R., \& Simon, M. C. (2000). The role of ARNT2 in tumor angiogenesis and the neural response to hypoxia. Biochem Biophys Res Commun, 273(1), 231-238. doi: 10.1006/bbrc.2000.2928

Mannello, F., Medda, V., \& Tonti, G. A. (2011). Hypoxia and neural stem cells: from invertebrates to brain cancer stem cells. Int J Dev Biol, 55(6), 569-581. doi: $10.1387 / \mathrm{ijdb} .103186 \mathrm{fm}$

Norris, M. L., \& Millhorn, D. E. (1995). Hypoxia-induced protein binding to 02responsive sequences on the tyrosine hydroxylase gene. J Biol Chem, 270(40), 23774-23779.

Panchision, D. M. (2009). The role of oxygen in regulating neural stem cells in development and disease. J Cell Physiol, 220(3), 562-568. doi: $10.1002 /$ jcp. 21812

Qiang, W., Sun, L., Hu, W., Zuo, P., Ren, M., \& Liu, J. (2000). [Effects of high dose of dynorphin on NMDA receptor and NOS activities in spinal cord of rats]. Zhongguo Yi Xue Ke Xue Yuan Xue Bao, 22(2), 134-138.

Ranaldi, R., Kest, K., Zellner, M. R., Lubelski, D., Muller, J., Cruz, Y., \& Saliba, M. (2011). The effects of VTA NMDA receptor antagonism on reward-related learning and associated c-fos expression in forebrain. Behav Brain Res, 216(1), 424432. doi: 10.1016/j.bbr.2010.08.026 
Schmidt-Kastner, R., van Os, J., Esquivel, G., Steinbusch, H. W., \& Rutten, B. P. (2012). An environmental analysis of genes associated with schizophrenia: hypoxia and vascular factors as interacting elements in the neurodevelopmental model. Mol Psychiatry, 17(12), 1194-1205. doi: 10.1038/mp.2011.183

Sclafani, A., \& Ackroff, K. (1994). Glucose- and fructose-conditioned flavor preferences in rats: taste versus postingestive conditioning. Physiol Behav, 56(2), 399-405.

Stone, S. S., Teixeira, C. M., Devito, L. M., Zaslavsky, K., Josselyn, S. A., Lozano, A. M., \& Frankland, P. W. (2011). Stimulation of entorhinal cortex promotes adult neurogenesis and facilitates spatial memory. J Neurosci, 31(38), 1346913484. doi: 10.1523/JNEUROSCI.3100-11.2011

Touzani, K., Bodnar, R. J., \& Sclafani, A. (2009). Dopamine D1-like receptor antagonism in amygdala impairs the acquisition of glucose-conditioned flavor preference in rats. Eur J Neurosci, 30(2), 289-298. doi: 10.1111/j.14609568.2009.06829.x

van Os, J., Kenis, G., \& Rutten, B. P. (2010). The environment and schizophrenia. Nature, 468(7321), 203-212. doi: 10.1038/nature09563

VanElzakker, M., Fevurly, R. D., Breindel, T., \& Spencer, R. L. (2008). Environmental novelty is associated with a selective increase in Fos expression in the output elements of the hippocampal formation and the perirhinal cortex. Learn Mem, 15(12), 899-908. doi: 10.1101/lm.1196508

Yu, W. Z., Silva, R. M., Sclafani, A., Delamater, A. R., \& Bodnar, R. J. (2000a). Pharmacology of flavor preference conditioning in sham-feeding rats: effects of dopamine receptor antagonists. Pharmacol Biochem Behav, 65(4), 635647.

Yu, W. Z., Silva, R. M., Sclafani, A., Delamater, A. R., \& Bodnar, R. J. (2000b). Role of $D(1)$ and $D(2)$ dopamine receptors in the acquisition and expression of flavor-preference conditioning in sham-feeding rats. Pharmacol Biochem Behav, 67(3), 537-544. 